DOE/ER-0058

$61^{16 / 38}$
DR. 1217

\title{
MASTER
}

\section{Summaries of FY 1979 Research in the Chemical Sciences}

May 1980

U.S. Department of Energy Office of Energy Research Division of Chemical Sciences 


\section{DISCLAIMER}

This report was prepared as an account of work sponsored by an agency of the United States Government. Neither the United States Government nor any agency Thereof, nor any of their employees, makes any warranty, express or implied, or assumes any legal liability or responsibility for the accuracy, completeness, or usefulness of any information, apparatus, product, or process disclosed, or represents that its use would not infringe privately owned rights. Reference herein to any specific commercial product, process, or service by trade name, trademark, manufacturer, or otherwise does not necessarily constitute or imply its endorsement, recommendation, or favoring by the United States Government or any agency thereof. The views and opinions of authors expressed herein do not necessarily state or reflect those of the United States Government or any agency thereof. 


\section{DISCLAIMER}

Portions of this document may be illegible in electronic image products. Images are produced from the best available original document. 

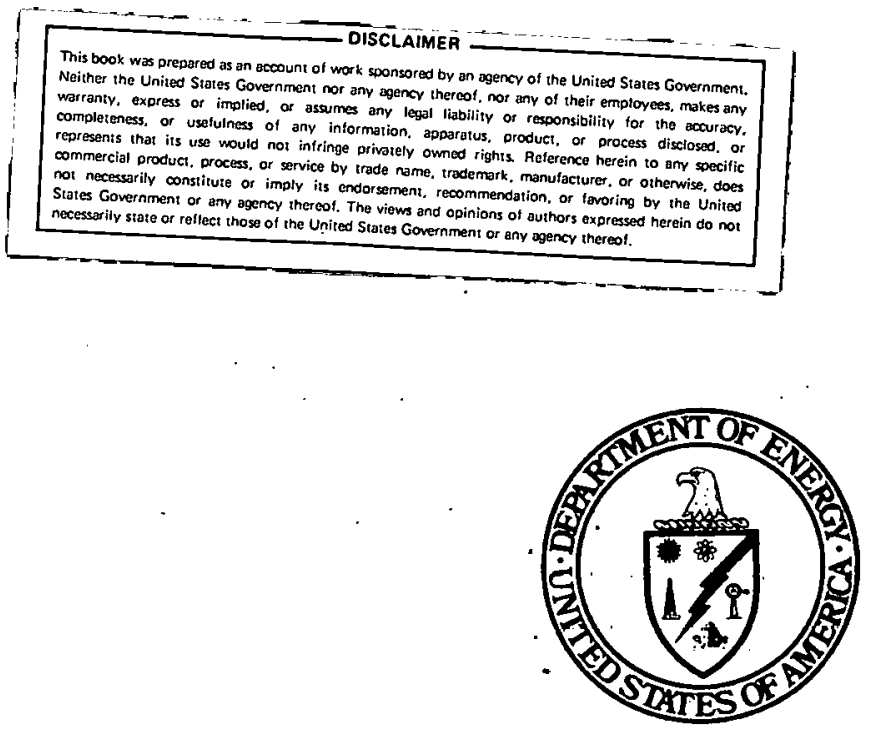

\section{Summaries of FY $19^{-9}$ Research in the Chemical Sciences}

May 1980

\section{U.S. Department of Energy Office of Energy Research Division of Chemical Sciences Washington, D.C. 20646}


Avallable from:

National Technical Information Service (NTIS)

U.5. Department uI Cüüler ce

5285 Port Royal Road

Springfleld, VIrginia . 22161

Price:

Printed Copy: $\quad \$ 11.00$

Microf Iche: $\$ 3.00$ 


\section{PREF ACE}

The purpose of this booklet is to help those interested in research supported by the Department of Energy's Division of. Chemical Sciences, which is one of six Divisions of the office of Basic Energy Sciences in the office of Energy Research.

Chemists, physicists, chemical engineers and others who are considering the possibility of proposing research for support by this Division w11l find the booklet useful for gauging the scope of the program in basic research, and the relationship of their interests to the overall program. These summaries are intended to provide a rapid means for becoming acquainted with the Chemical Sciences program for members of the scientific and technological public, and interested persons in the Legislative and Executive Branches of the Government, in order to indicate the areas of research supported by the Division and energy technologies which may be advanced by use of basic knowledge discovered in this program.

The research program summarized here is intended to add significantly to the knowledge base on which successful energy technologies can grow. For this purpose, scientific excellence is a major criterion applied in the selection of research supported by Chemical Sciences. Another important consideration is the identifying of chemical, physical and chemical engineering subdisciplines which are advancing in ways which produce new information related to energy, needed energy data, or new ideas. Another consideration concerns the varyling meeds fur knowledge among the developing energy technologies. For example, the potential benefits of unraveling the complexities of coal or sunlight induced chemistry seem more applicable to this tax-supported program than adding fine points about the make-up of petroleum. Thus, the energy relevance of individual programs comes under a spectrum of interpretation.

The program is distributed among several different kinds of performing organizations. About half the projects take place at DOE 1 aboratories, and half take place at universitles and industrial laboratories. In DOE laboratories, most of the researchers are fully engaged in this work, while most university and industrial researchers necessarily divide their time among duties involving this research, other research, or teaching responsibilities. Therefore, about $70 \%$ of the funding goes to Federal laboratorles, $25 \%$ goes to the academic sector, and the remainder is at industrial and not-for-profit laboratories. 
Questions about the details of an individual project may be directed to the investigators involved or the persons in charge at DOE Laboratories (see below). Other questions about the program may be directed to the undersigned.<smiles>CCCCCCCCCCCCC(C)CCCC</smiles>

Elliot S. Pierce, Director Division of Chemical Sciences

Office of Basic Energy Sciences 


\section{Office of the Division Director}

Division Director
Secretary

Special Assistant
Dr. Elliot S. Plerce

Mr 8. Peggy Winpigler

Mr: Thomas W. Buttery
(301) 353-5804

(301) 353-5804

(301) $353-5802$

Fundamental Interactions Branch

Branch Chief Secretary
Dr. Richard J. Kandel

Mrs. Julie Mason
(301) 353-5820

(301) $353-5820$

Photochemical \& Radiation Sciences

Technical Manager

Dr. RIchard J. Kandel

(301) $353-5820$

Chemical Physics

Technical Manager

Asst. Technical Manager

Atomic Physics

Technical Manager

Processes \& Techniques Branch

Branch Chief

Secretary

Separations

Technical Manager

Analygio

Technical Manager

Chemical Energy

Technical Manager

Asst. Technical Manager

Chemical Engineering Science

Technical Manager
Dr. 0. Will1am Adams

Dr. Mary E. Gress

Dr. Joseph V. Martinez

(301) $353-5820$
(301) 353-5820

(301) 353-5820
Dr. F. Dee Stevension Miss Cathy Masser

Dr. Walter J. Haubach

(301) 353-5802
(301) 353-5802

(301) 353-5802

Dr. Walter J. Haubach

(301) 353-5802

Dr. F. Dee Stevenson

(301) 353-5802

Dr. Robert S. Marianell1 ' (301) 353-5802

Dr. F. Dee Stevenson

(301) 353-5802 
Each Branch of the Division of Chemical Sciences is divided into programs which cover various disciplines. The following is a description of each of those programs. The staff members responsible for each program are indicated on page iii.

FUNDAMENTAL INTERACTIONS BRANCH (01- )

Photochemical and Radiation Sciences (01-1)

This program consists of research into the interactions of radiation with matter in all forms, but particularly with gases and liquids. A large part deals with the effects of ionizing radiation and fast electrons. The photochemical research is largely devoted to studies with visible radiation aimed at the capture and conversion of solar energy. This encompasses such fields as artificial photosynthesis, photoinduced electron transfer reactions in homo- and heterogeneous media, photoelectrochemistry, photocatalysio, and the molecular storage of energy. A small part is devoted to research in hot atom chemistry, the otudy of the effects of nuclear decay and the consequent release of energy on chemira1, reactiono.

Chemical Physics (01-2)

Disciplines covered by this program include chemical dynamics, energy transfer, molecular structure and spectroscopy, theoretical quantum chemistry, and statistical mechanics.

Special emphasis is placed on basic research related to combustion; advanced diagnostic methods, spectroscopy, theory and the kinetics of elementary combustion reactions are of special interest. A major user-oriented facility, the Combustion Research Facility (CRF) at Sandia Laboratories/ Livermore will be supported by this program when it opens in 1980. This laboratory will be a user facility in support of researchers from universit les, industry and national laboratories and will offer use of advanced instrumentation to interested combustion scientists.

The National Resource for Computation in Chemigtry (NRCC) at Lawrence Berkeley Laboratory (LBL), jointly funded by DOE and NSF, is supported by this program. NRCC supports a broad program based upon research, service and educational activities, including the support of research grants, primarily for computer time on machines at LBL.

Atomic Physics $(01-3)$

The Atomic Physics Program supports basic research on phenomena dominated by the presence of atoms and their ions as distinct entities. Support is provided for experimental and thenretical studics of atom and lon structures, energy levels and energy state lifetimes, and of transport and exchange processes characterized by the rate of magnitude at which energy, momentum and matter transfer occur. These studies require having available the best and most complete knowledge of the properties and interactions of photons, electrons, atoms, ions and simple molecules. 
Recent emphasis of this research has involved the understanding of relatively high energy atomic physics that involves (1) ions stripped of all or most of their electrons, and (2) atoms and ions whose electrons are promoted in energy up to and including the energy continuum.

\section{PROCESSES AND TECHNIQUES BRANCH (02- )}

\section{Chemical Energy (02-1)}

This program addresses energy related chemistry which includes such areas as heterogeneous and homogeneous catalysis, coal and related fossil chemistry, chemical dissociation of water for hydrogen production, hydrogen storage and the chemistry of converting biomass to fuels. The emphasis is on understanding the chemical principles underlying the new and developing technologies and on innovative research with long-term potential for new energy concepts. The disciplines of organic, inorganic, physical, thermoand electrochemistry are central to this program.

\section{Separations (02-2)}

The research supported in.this area can be catalogued in several different ways; however, the following description is useful to understand its composition. Research is supported which is directed at improving our basic understanding of separation methods. These methods include lon-exchange, field flow fractionation, solvent extraction, chromatography, adsorption processes and the use of membranes. Another priority area is isotope separation. This heavily emphasizes isotope theory and its use to predict isotopic properties which are requisites for investigating new isotopic separation techniques. The program involves primarily the light elements where isotopic properties are sufficiently different so that theory and experiment can be compared. Separation methods being investigated include laser photochemistry, thermal diffusion, and chemical exchange. Methods of separation of fluid-solid and solid-solid mixtures are also being investigated. A substantial part of the program consists of the investigation of new solvent extraction reagents. This part of the program is trying to discover the relationship between the structure of organic extractant molecules and the selectivity of these molecules for cations, anions, and their complexes, to better enable us to fabricate molecules for specific extraction purposes. 
The analytical program is aimed at supporting research on analytical techniques where a better understanding of basics would enable other investigators to improve the sensitivity, reliability, ease of operation and/or lower the costs of analytical determinations. Entirely new analytical techniques are also investigated but this program is not an inst rument development program. New techniques are quickly reported in the 1iterature so that those interested in instrument development can build on work supported by this program. The program covers optical spectroscopy, mass spectroscopy, photoacoustic spectroscopy, particle spectroscopy, 1aser spectroscopy, activation analysis, and many other areas of analytical chemistry. In other words, this program is not geared to using existing techniques to unravel the composition of materials nor to develop techniques to analyze particular species, but is aimed at obtaining a thorough understanding of all of the various aspects of chemical analysis so that others may use this understanding to improve the uses of analysis.

Chemtcal Engineering Sciences (02-4)

The chemical engineering sclences program addresses such topics ao turbulence modeling needed for combustion codes, development of thermodynamic models for establishing the properties of complex chemical substances including multicomponent solutions, the development of advanced models for catalytic reactors using such new catalytic concepts as interfacial and fluid phase transfer catalysis, and gas-solid reaction modeling with the related mass and momentum transport. Also included is research on models for gas phase reactions in fludized beds and entrained suspensions. Emphasis is on improving and/or developing the scientific basis for engineering generalizations and their unifying theories. Such efforts are expected to include work in fluid mechanics, particle dynamics, mass and energy transport (steady and unsteady state), engineering thermodynamics, and physical and chemical rate processes. 
The following is a list of "persons in charge" of chemical sciences projects at DOE laboratories. These individuals are department/division, or laboratory administrators who can provide information about specific programs or refer inquiries to appropriate individuals.

AMES LABORATORY

Iowa State University

Ames, Iowa 50011

Chemical Sciences - Fundamental Interactions

H. J. Svec - Phone: (FTS) 865-6486 or (515) 294-6486

V. A. Fassel - Phone: (FTS) 865-2112 or (515) 294-2112

Chemical Sciences - Processes and Techniques

J. H. Espenson - Phone: (FTS) 865-5730 or (515) 294-5730

V. A. Fassel - Phone: (FTS) 865-2112 or (515) 294-2112

ARGONNE NATIONAL LABORATORY

9700 South Cass Avenue

Argonne, Illinots 60439

Chemistry Division

P. R. Fields - Phone: (FTS) $972-3570$ or (312) $972-3570$

J. Unik - Phone: (FTS) 972-3571 or (312) 972-3571

Chemical Engineering Division

F. A. Cafasso - Phone: (FTS) 972-4542 or (312) 972-4542

Physics Division

J. P. Schiffer - Phone: (FTS) 972-4004 or (312) 972-4004

M. Peshkin - Phone: (FTS) 972-4101 or (312) 972-4101

BARTLESVILLE ENERGY TECHNOLOGY CENTER

P. O. BOX 1398

Bartlesville, Oklahoma 74003

W. D. Good - Phone: (FTS) 735-4210 or (918) 336-2400, Ext. 210

BROOKHAVEN NATIONAL LABORATORY

Upton, Long Island, New York 11973

Chemistry Department

J. Hud1s - Phone: (FTS) 666-4301 or (516) 345-4301

Department of Energy and Environment

B. Manowitz - Phone: (FTS) 666-3037 or (516) 345-3037

D. H. Gurinsky - Phone: (FTS) $666-3504$ or (516) $345-3504$

D. J. Metz - Phone: (FTS) 666-3054 or (516) 345-3054

Physics Department

N. P. Samios - Phone: (FTS) 666-3866 or (516) 345-3866

A. Schwarzschlld - Phone: (FTS) 666-4015 or (516) 345-4015 
LAWRENCE BERKELEY LABORATORY

University of California

Berkeley, California 94720

Chemical Biodynamics Division

M. Calvin - Phone: (FTS) 451-4321 or (415) 486-4321

Energy and Environment Division

E. J. Cairns - Phone: (FTS) 451-5001 or (415) 486-5001

Materials and Molecular Research Division

A. W. Searcy - Phone: (FTS) 451-5619 or (415) 486-5619

The National Resource for Computation in Chemistry

W. A. Lester, Jr. - Phone: (FTS) 451-6722 or (415) 486-6722

LAWRENCE LIVERMORE LABORATORY

P. O. Box 808

Livermore, Californta 94550

G. D. Dorough - Phone: (FTS) 532-4892 or (415) 422-4892

LOS ALAMOS SCIENTIFIC LABORATORY

University of California

P. 0. Box 1663

Los Alamos, New Mexico 87545

CMB DIVISION

M. G. Bowman - Phone: (FTS) 843-6014 or (505) 667-6014

CNC Division

R. R. Ryan - Phone: (FTS) 843-6045 or (505) 667-6045

P Division

G. A. Keyworth - Phone: (FTS) 843-6162 or (505) 667-6162

Q Division

W. E. Keller - Phone: (FTS) 843-4838 or (505) 667-4838

MORGANTOWN ENERGY TECHNOLOGY CENTER

P. O. Box 880

Morgantown, West Virginia 26505

Energy Conversion and Utilization Division

D. C. Strimbeck - Phone: (FTS) 923-7232 or (304) 599-7232

Analytical and Supporting Research Division

W. E. Wallace, Jr. - Phone: (FTS) 923-7294 or (304) 599-7294

MOUND FACILITY

P. 0. Box 32

Mi.nmisburg, Ohio 45342

Nuclear Operations Department

B. R. Kokenge - Phone: (FTS) 774-3268 or (513) 865-3268

R. E. Vallee -Phone: (FTS) $774-3318$ or (513) 865-3318 
NOTRE DAME RADIATION LABORATORY

University of Notre Dame

Notre Dame, Indiana 46556

R. H. Schuler - Phone: (FTS) 332-7308 or (219) 283-7502

OAK RIDGE NATIONAL LABORATORY

P. 0. Box X

Oak Ridge, Tennessee 37830

Analytical Chemistry Division

W. D. Shults - Phone: (FTS) 624-4881 or (615) 574-4881

Chemical Technology Division

D. E. Ferguson - Phone: (FTS) $624-6148$ or (615) $574-6148$

Chemistry Division

0. L. Keller - Phone: (FTS) $624-4987$ or (615) $574-4987$

Physics Division

P. H. Stelson - Phone: (FTS) $624-4773$ or (615) $574-4773$

PACIFIC NORTHWEST LABORATORY

P. O. Box 999

Richl and, Washington 99352

Chemical Technology Department

R. E. Nightingale - Phone: (FTS) 444-7511 Ext. 946-2597 or (509) 946-2597

P. C. Walkup - Phone: (FTS) 444-7511 Ext. 946-2432 or (509) 946-2432

T. E. Divine - Phone: (FTS) 444-7511 Ext. 946-2567 or (509) 946-2567

Physical. Sciences Department

J. M. Nielsen - Phone: (FTS) 444-3530 or (509) 942-3530

N. E. Ballou - Phone: (FTS) 444-3061 or (509) 942-3061

PITTTSBURGH ENERGY TEC̣HNULUGY CEENTEK

4800 Forbes Avenue

Pittsburgh, Pennsylvania 15213

Chemical and Instrumental Analysis Division

A. G. Sharkey, Jr. - Phone: (FTS) 726-2310 or (412) 892-2400 Ext. 2310

SANDIA LABORATORIES/ ALBUQUERQUE

P. O. Box 5800

Albuqerque, New Mexico 87115

John K. Galt, Vice President - Phone: (FTS) 475-4669 or (505) 264-4669

SANDIA LABORATORIES/LIVERMORE

Livermore, California 94550

Combustion Sciences Department

D. L. Hartley - Phone: (FTS) 532-2747 or (4.15) 422-2747

SOLAR ENERGY RESEARCH INSTITUTE

1456 Cole Boulevard

Golden, Colorado 80401

A. J. Nozik - Phone: (FTS) 327-1953 or (303) 231-1953 


\section{THIS PAGE}

\section{WAS INTENTIONALLY \\ LEFT BLANK}




\section{DOE Laboratories}

Photochemical and Radiation Sciences

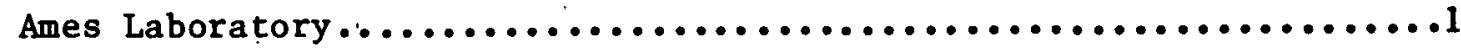

Argonne National Laboratory

Chemistry Division................................ 2

Brookhaven National Laboratory

Chemistry Department.............................. 9

Department of Energy and Environment...................13

Lawrence Berkeley Laboratory

Chemical Biodynamics Division........................15

Energy and Environment Division..................... 16

Materials and Molecular Research Division................ 17

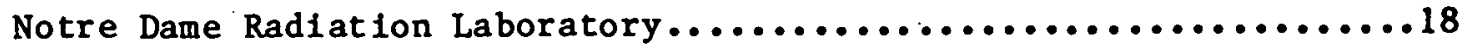

Oak Ridge National Laboratory

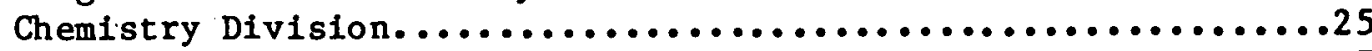

Solar Energy Research Institute........................ 27

Chemical Physics

Ames Laboratory .......................................28

Argonne National Laboratory

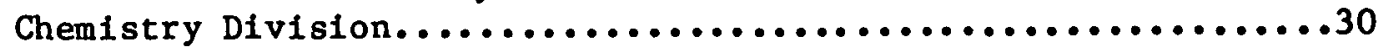

Brookhaven National Laboratory

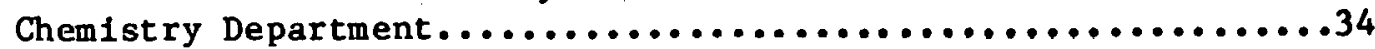

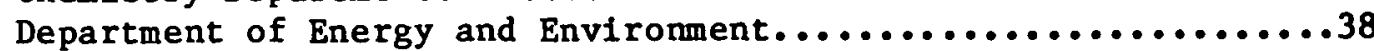

Lawrence Berkeley Laboratory

Energy and Environment Division.......................40

Materials and Molecular Research Division.................41

National Resource for Computation In Chemistry.............46

Oak Ridge National Laboratory

Chemistry Division...............................4 47

Sandia Laboratories/Livermore......................... 49

Chemical Energy

Ames Laboratory...................................... 64

Argonne National Laboratory

Chemistry Division................................67

Chemical Engineering Division....................... 70

Bartlesville Energy Technology Center......................71

Brookhaven National Laboratory

Chemistry Department................................72

Department of Energy and Environment..................... 74

Lawrence Berkeley Laboratory

Energy and Environment Division.......................

Materials and Molecular Research Division.................78

Lawrence Livermore Laboratory

Chemical Engineering Division........................82

Metals and Ceramics Division........................ 83 
Los Alamos Scientific Laboratory

B Division.......................................84

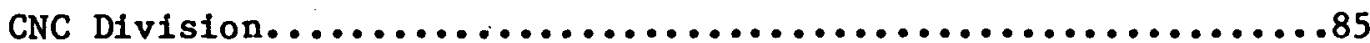

Morgantown Energy Technology Center.......................86

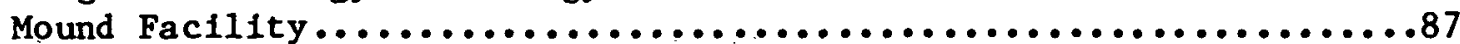

Oak Ridge National Laboratory

Chemistry Division...................................88

Chemical Technology Division.........................92

Pacific Northwest Laboratory

Chemical Technology Department.........................93

Physical Sciences Department..........................94

Pittsburgh Energy Technology Center...................... 95

\section{Separations}

Ames Laboratory.....................................96

Argonne National Laboratory

Chemiatry Division................................ 98

Brookhaven National Laboratory

Chemistry Department...................................99

Departüent of Energy and Environment:.................... 100

Los Alamos Sclentific Laboratory

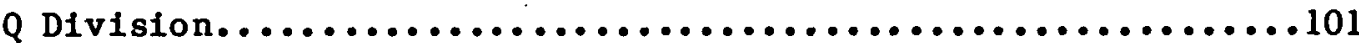

Morgantown Energy Technology Center......................102

Mound Facility.....................................103

Oak Ridge National Laboratory

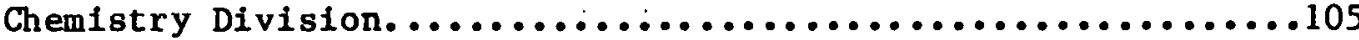

Chemical Technology Division........................107

Analysis

Ames Laboratory....................................110

Argonne National Laboratory

Chemistry Division...................................113

Brookhaven National Laboratory

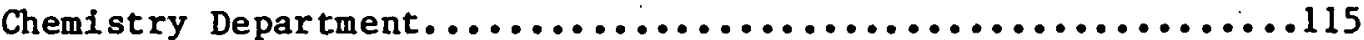

Department of Energy and Environment....................116

Physics Department..................................118

Lawrence Berkeley Laboratory

Energy and Enviroment Division.......................119

Oak Ridge National Laboratory

Analytical Chemical Division.........................120

Pacific Northwest Laboratory

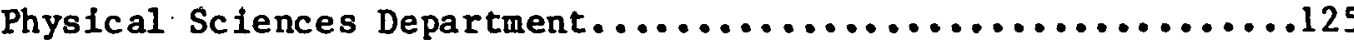

Chemical Enginering Sciences

Brookhaven National Laboratory

Department of Energy and Environment......................129

Lawrence Berkeley Laboratory

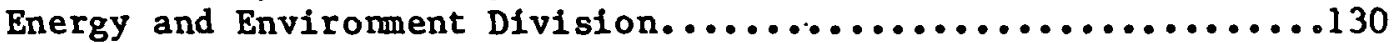

Materials and Molecular Research Division..................131

Pacific Northwest Laboratory

Chemical Technology Department........................132 
Offisite Contracts

Photochemical and Radiation Sciences.....................133

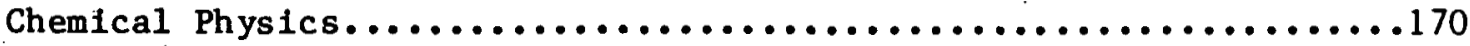

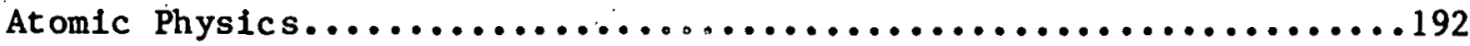

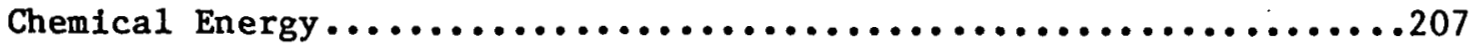

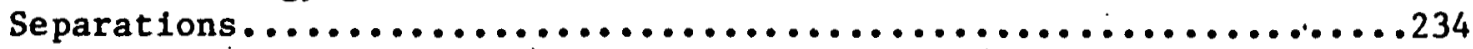

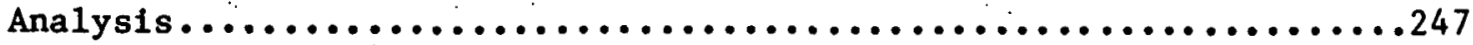

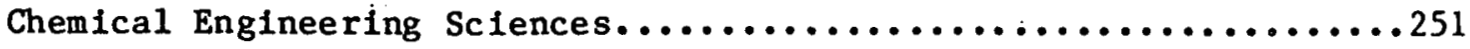

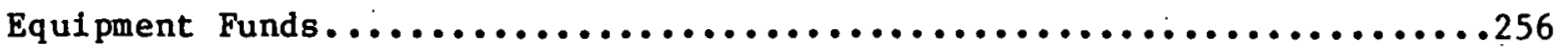

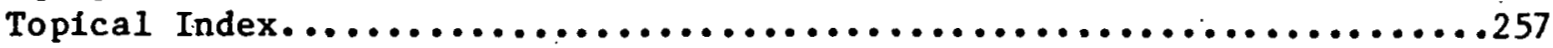

Institutional Index for of fsite Contracts.......................259

Investigator Index........................................ 264 
All the summaries of projects funded by a particular Chemical Sciences program (e.g., chemical physics) in a particular Laboratory's division or department are in a contiguous sequence in this book. Total dollars are given at the beginning of each such sequence.

There are two numbers above each summary, other than its ordinal number. The number immediately to the right of the name(s) of the investigator(s) indicates the scientific person years devoted to the project. The other number is the three digit code which identifies the DOE program which funds the project, as defined previously. 
Photochemical and Radiation Sciences

Ames Laboratory

Iowa State University

Ames, Iowa 50011

1. PHOTOPHYSICS, PHOTOCHEMISTRY AND SPECTROSCOPY

G. J. Small
Total $\$ 188,000$

$2.0 \quad 01-1$

This program is concerned with understanding the mechanisms by which light quanta (photons) create excited electronic-vibrational states of organic molecules and solids, and the fate of the excitation following the fundamental light absorption process. The latter encompasses both photophysical and photochemical relaxation phenomena. Specific projects include: electronic. energy (exciton) transport in ordered and disordered solids with emphasis on the scattering processes which determine whether the transport is coherent (unidirectional) or incoherent (hopping); two-photon absorption spectroscopy as a probe of the electronic and vibrational properties of molecules and molecular solids; ultra-fast photochemical rearrangement reactions as studied by hole burning spectroscopy; the formation of mixed exciton-photon states and their modification of the usual laws of light absorption; and the development of new 1 aser based methodologies (e.g. nonphotochemical hole burning spectroscopy) for probing the structure and 1 ight induced isomerization processes in amorphous solids (glasses).
2. PICOSECOND SPECTROSCOPY AND
2.5
$01-1$
REACTION DYNAMICS

W. S. St ruve

This program exploits picosecond laser spectroscopy to study dynamics of photochemical reactions. The emphasis of the program is to correlate ultrafast photoreactivity with excited state structure of molecules in which the latter is already comparatively well understood, and to evaluate the detailed effects of inert condensed media on photoreaction mechanisms. The chemical systems currently under study include 9-iodoanthracene, $\operatorname{Re}_{2}{ }^{C 1}{ }_{8}$, $\left[\mathrm{W}(\mathrm{CP})(\mathrm{CO})_{3}\right]_{2}$, and transazobenzene. The experimental techniques currently used are time-resolved fluorescence, resonance Raman emission, and transient absorption spectroscopy, with $\mathrm{Nd}^{3+}: \mathrm{glass,} \mathrm{high-}$ repetition rate flashlamp-pumped tunable dye, and $c w$ modelocked dye lasers as excitation sources. A prime motivation of this research is to supply insights into molecular excited state processes pertinent to solar energy photocatalyst design. 
Photochemical and Radiation Sciences

Chemistry Division

Argonne National Laboratory

9700 South Cass Avenue

Argonne, Illino is 60439
Total $\$ 2,895,000$

$3.6 \quad 01-1$
3. RADIATION CHEMISTRY OF SOLUTIONS

G. Closs, C. D. Jonah, J. R.

Miller, S. Gordon, M. C. Sauer, A. D. Trifunac, K. H. Schmidt

The radiation chemistry of solutions is concerned with two basic objectives: (1) understanding the fundamental mechanisms of energy deposition associated with the passage of high energy ionizing radiation through solutions, and (2) the use of the reactive intermediate species produced by these processes as probes to study electron transfer processes, redox reactions, diffusion kinetics, and free radical reactions with a wide variety of solutes. Objective (1) _entails the study of events which $s$ pan the time range of $10^{-13}$ to $10^{-5}$ seconds and includes such basic studies as electron solvation mechanisms in polar and non-polar liquids, reactions of the "dry electron" and "dry hole" $\left(\mathrm{H}_{2} \mathrm{O}\right)^{+}$, reactions of $\mathrm{e}-$ and $\mathrm{OH}$ in both homogeneous and inhomogeneous domains of energy deposition, and reactions of ions and excited states in hydrocarbons. Objective (2) involves the primary reactive species enumerated above, as we 11 as secondary reactions of these species producing other reactive entities such as (CNS) ${ }^{-} \mathrm{Br}^{-}, \mathrm{Cl}^{-}, \mathrm{I}^{-}$and $\mathrm{CO}^{-}$which vary in redox potential. With such probes, the program explores the redox behavior of the actinides and lanthanides with metal 1 ig and compounds, which are related to conversion and storage of solar energy and to biochemical studies. These studies are being extended to nonaqueous systems where the fundamental processes listed under (1) are much less well understood. The ANL electron 1 inac with its unique capacity to deliver high-current pulses of electrons varying from 25 picoseconds to 6 microseconds is ideally suited for these investigations. 
Chemistry Division, ANL, continued

4. FUNDAME NTAL CHEMICAL PROCESSES

$4.9 \quad 01-1$

STUDIED WITH RADIATION CHEMICAL PROBES

G. Closs, J. R. Miller,

A. D. Trifunac

Two areas of research are being pursued: (1) the development and application of magnetic resonance probes to radiation and photochemistry, and (2) the study of electron transfer in rigid media. The use of magnetic resonance techniques in radiation and photochemistry is motivated by the need to acquire a more complete picture of radical interaction and radical reaction mechanisms. This program has successfully realized several new experimental tools to that end. Time-resolved electron spin resonance and most recently kinetic electron spin echo are new techniques for the study of transient radicals with the best time resolution available. The flow nuclear magnetic resonance experiment is another tool that is being used to study radical reaction products. Thus, for the first time, one can probe and study transient radical behavior nanoseconds after radical creation and study reaction mechanisms of many radiolytic and photolytic reactions. Basic questions regarding the structure and the chemistry of transient radicals, and the chemical consequences of non-uniform radical distribution in solution found in early time periods of radiolysis are being answered. Electron transfer (ET) plays fundamental roles in photosynthesis, solar energy storage, radiation and photochemistry, and photoconduction in solids. ET rates are controlled by an "electronic interaction" and a "nuclear interaction." Pulse radiolysis in rigid media measures both. This new method is becoming the world's most powerful tool for understanding ET. Energy-selective mechanisms have been observed, which are not found in fluid solutions, and long-range (10-40 $)$ electron tunneling has been observed which transfers either negative or positive charge. Studies of the temperature dependence of ET down to $4 \mathrm{~K}$ are providing crucial tests for the many quantum-mechanical theories of ET rates. 
Chemistry Division, ANL, continued

5. PHOTOCHEMISTRY AND CHEMICAL

$2.4 \quad 01 \div 1$

STORAGE OF SOLAR ENERGY

G. Closs, D. Meise l,

C. D. Jonah, W. Mulac

The prospects for utilization of solar energy in photoelectrochemical devices or as a use ful alternative energy source is severely hindered by the inefficiency of the various stages following the absorption of $a$ photon and leading to the charge transfer products. The possibilities of harvesting light energy by using it to drive electron transfer reactions are being explored in semiorganized molecular assemblies (micelles, polyelectrolytes, etc.) of inorganic complexes and organic molecules. To inhibit-the wasting of energy through back electron transfer reactions, reactions in systems utilizing various combinations of coulombic interactions among the donor, acceptor, and the micro-environment are being systematically investigated. The possibility of intercepting the back reaction of other processes, notably proton transfer, before geminate recombination and annihilation occur is the basis of a detailed study. Further processes which will carry the stage of single electron transfer products to the more useful and stable state of two electron transfer products are being investigated using colloidally dispersed metal catalysts. 
Chemistry Division, ANL, continued

6. COMBUSTION AND ATMOSPHERIC

S. Gordon, G. Closs, K. H.

Schmidt, M. C. Sauer, J. R.

Miller, C. D. Jonah

Recent emphasis on the importance of efficient utilization of fossil

fuels makes a detailed understanding of combustion mechanisms of organic compounds an important area of investigation. Combustion is complex, involving competing, sequential and branching ractions. The diverse conditions involved in recently proposed combustion techniques such as fluidized bed reactors and magnetohydrodynamics, as well as the use of fuel sources of varying compostion, make it even more important to understand the basic mechanisms in these processes. Associated with these reactions is the production of effluents which affect air quality and the environment. The objective of this program is to study in detail chemical reaction mechanisms of importance in combustion and in atmospheric processes over a wide range of experimental parameters to allow extrapolation of results from one set of conditions to another with greater confidence. To accomplish this objective, the program utilizes free radicals involved in the combustion process, generated by an electron linac and a Febetron, in order to study reactions of the radicals with organic compounds over a wide temperature range to evaluate their non-Arrhenius behavior. Parallel with these studies are photochemical studies to evaluate the role of excited states of the reactive species in the reactions. Free radical reactions of sulfur-containing compounds are being examined to explore the possible application of radiation to the study of potential methods for desulfurizing coal. 


\section{$-6-$}

Chemistry Division, ANL, continued

7. CHLOROPHYLL AND PHOTOSYNTHESIS

$4.7 \quad 01-1$

RESEARCH

J. J. Katz, J. C. Hindman

$\checkmark$

This research program consists of physical and chemical studies on chlorophyl1, designed to reveal essential features of chlorophyll structure and function relevant to its in vivo behavior. This information will contribute to the development of biomimetic artificial photosynthesis systems for solar energy conversion. The objectives of this program are: the development of chlorophyl1lipid and chlorophyll-protein systems of defined isotopic composition suitable for spectroscopic and structural investigation by nmr and small angle neutron scattering; determination of the relative strengths of the donor functions in chlorophyll $\underline{b}$, bacteriochlorophylls a and $\underline{b}$ and chlorobium. chlorophyll by nmr and ir; measurement of hyperfine coupling constants in paramagnetic chlorophyll cations by nmr; exploration of the properties of chlorophyll dications as possible models for photosystems II; investigation of the structure and properties of chemically 1 inked and of self-assembled chlorophyll special pairs ( $\mathrm{Chl}$ ) as models of green plant and bacterial. photo-reaction centers; laser photochemical studies on the excited states of chlorophyll and synthetic $\mathrm{Chl}$ by absorption and fluorescence spectroscopy; and optical studies on energy trâhsfer relevant to the structure and function of antenna chlorophyll. 
Chemistry Division, ANL, continued

8. REACTION CENTER STRUCTURES FUNCTIONS AND MECHANISMS

J. R. Norris, G. Closs, M. C. Thurnauer, L. L. Shipman, M. K. Bowman
$4.6 \quad 01-1$

The goal of this program is to understand fully the light conversion processes in photosynthesis. Currently a serious impediment to a complete comprehension of photosynthesis is the total absence of precise structural data on reaction centers. The program is specifically directed toward acquiring the needed structural information and consists of the following experimental goals: (1) identification of unknown photoactive intermediates, e.g., is pheophytin an acceptor in green plants?; (2) measurement of the temporal properties of natural and artifical electron transfer systems, emphasizing green plants; (3) determination of distances between electron transfer agents involved in the initial phases of photosynthesis; and (4) establishment of relative orientations and conformations of molecules, such as the chlorophyll special pair and its models. The sparsity of the structural data on items (3) and (4) signals an urgent need for application of new techniques, specifically designed for the study of photosynthesis. Particularly promising tools are electron spin echo (ESE) and nuclear magnetic resonance (NMR). Pioneering applications of ESE to photosynthesis in this program are providing essential data in all four of the above categories. Recent advances in the NMR of the solid state are also being applied to structural investigations of photosynthesis. Data from these new techniques provide an experimental basis for an extensive theoretical program on the molecular aspects of photosynthesis and solar energy conversion. 
Chemistry Division, ANL, continued

9. ARTIFICIAL PHOTOSYNTHESIS

M. R. Wasielewski, J. J. Katz
2.5

01-1

The goal of this research is to develop solar energy conversion systems based on photosynthesis. Four interdependent aspects of this problem are being investigated: (1) the preparation of synthetic photoreaction centers that mimic the natural electron transfer photochemistry, yet remain free from the many instabilities of the biological systems; (2) photochemical and electrochemical studies of the mechanism of light-induced electron transfer reactions, especially as manifested by the synthetic photoreaction centers; ( 3 ) biomimetic devices for solar energy conversion using synchetic photoreaction centers; (4) a molecular electronic approach to the conduction of charge away from artificial reaction centers using successive electron transfers. Recently a reaction center model has been produced, which, for the first time duplicates the asymmetric charge transfer kinetics of the primary event of bacterial photosynthesis. In this model, a dimeric chlorophyll derivative transfers an electron to an adjacent pheophytin molecule in less than 6 psec following illumination with visible light. The back electron transfer rate is 10,000 times slower than the forward rate, which permits coupling the initial charge separation to secondary electron transfer steps.

10. PREPARATION OF ORGANISMS AND
BIOLOGICAL MATERIALS OF UNUSUAL
ISOTOPIC COMPOSITION
H. L. Crespi, J. J. Katz,
J. R. Norris, M. R. Wasielewski

The purpose of this program is the large-scale production by biosynthesis of isotopically altered organisms and biological materials associated with photosynthesis. Algae, photosynthetic bacteria, and other microorganisms highly enriched in, or completely substituted with deuterium, carbon-13, nitrogen-15 and magnesium- 25 are being produced in mass culture. The isotopically altered chlorophylls, carotenoids, chlorophyll-protein complexes, electron transfer proteins, chloroplasts, chromatophores, and bacteriorhodopsin isolated from these organisms are of decisive value in ongoing research as an adjunct to nuclear magnetic resonance, electron spin resonance, smallangle neutron scattering, and resonance Raman analysis of photosynthetic systems. Associated with the biosynthetic effort is a chemical program directed toward the large-scale preparation of chlorophyll and some of its derivatives for use in biomimetic studies of artificial photosynthesis. Chemical modification of chlorophyil and high-pressure chromatographic separation methods are being used to provide multigram amounts of starting materials for the preparation of these biomimetic systems. 
Photochemical and Radiation Sciences

Chemistry Department

Brookhaven National Laboratory

Upton, New York 11973
Total $\$ 1,985,000$

$$
6.4 \quad 01-1
$$

B. H. J. Bielski, R. W. Dodson

R. A. Holroyd, H. A. Schwarz

This program uses radiolysis and photolysis, emphasizing pulse methods, to study the behavior and reactions of transient chemical species (ions, electrons, free radicals, and excited states of molecules). The properties and reactions of electrons in dielectric fluids are being investigated as is the effect of density on electron mobility in high pressure gases and 1iquids. The electron photodetachment spectra and threshold energies for anions of oxygen, aromatic compounds, and other solutes are being studied by a combined pulse radiolysis and laser technique. In aqueous solution work, the fate of 1 igands is being followed when the coordination number of ions such as $\mathrm{Cr}$ (III) and $\mathrm{Rh}$ (III) changes upon oxidation or reduction. Reactions of superoxide radicals $\left(\mathrm{O}_{2}\right)$ and singlet molecular oxygen in biological systems as well as the mechanism by which certain enzymes fix nitrogen are also under investigation. Infrared spectra are being determined for protonated molecular clusters and other ions in the gas phase.
12. SELECTIVE LASER-INDUCED
3.3
$01-1$
CHEMISTRY
D. M. Brenner

This laser-induced chemistry program has two directions: (1) the identification of new chemical processes initiated by the unique properties of laser light and (2) the use of lasers to study phenomena occurring in times $\left\langle 10^{-6} \mathrm{~s}\right.$, which, heretofore, were inaccessible by conventional methods. The possibility of exerting non-kinetic or non-thermodynamic control over reactions by fast infrared laser excitation is being explored. Evidence indicates changes in photon flux influence branching ratios of competitive unimolecular reactions by affecting the rate of optical pumping. The latter has been observed directly in real time by IR-visible double resonance under molecular beam conditions. Propynal is first vibrationally excited with an infrared laser, then a visible laser is used to probe spectroscopically the distribution of vibrational energy and its time evolution. The effects of collisions on the energy distribution are being investigated. Similarly, ultraviolet lasers are being employed to study photodissociation of isolated molecules. Product fragments possessing excess energy are analyzed spectroscopically to determine internal energy distribution. The amount of excess energy stored as internal energy is also analyzed.mass spectrometrically by measuring appearance potentials. 
Chemistry Department, BNL, continued

\author{
13. PHOTOCHEMICAL ENERGY CONVERSION \\ AND SOLUTION KINETICS \\ C. Creutz, N. Sutin
}

$$
6.4 \quad 01-1
$$

Transition metal complexes show considerable promise as mediators in solar energy conversion and storage. This program involves photochemical investigations of such complexes and, in particular, the electron-transfer properties of excited states exemplified by their reactions with inorganic oxidants and reductants in solution. Particular attention is being paid to homogeneous and heterogeneous. systems capable of effecting the decomposition of water into hydrogen or other useful chemicals and oxygen. Efficient light conversion and storage requires the diversion of a significant fraction of the electronically excited molecules into "useful reactions" which must be driven in competition with rapid physical deactivation processes (luminescence and radiationless decay) and chemical "back-reactions". A major objective of this program is the quantitative study of these physical and chemical deactivation processes; the lifetimes and other physical properties of excited states are being measured and the rates of electron-transfer reactions of transition metal complexes are being determined. An important aspect of this work is the study of the chemistry of low oxidation states of transition metal complexes.
14. PICOSECOND SPECTROSCOPY
2.2
01-1
T. Netzel

The focus of this research program is on understanding light-driven electron transfer processes. The major experimental technique is picosecond ( $p s$ ) absorption spectroscopy. However, ps emission and Raman measurements are being made where necessary and when possible. Two types of molecular systems are being investigated. Mixed valence compounds where the goal is to measure directly the rates of electron transfer through bridging ligands from one metal site to another are being studied. These experiments are exploring the roles of inner- and outer-sphere barriers in thermal electron transfer as well as the effects of different driving forces. The second type of molecular system under investigation involves covalently linked diporphyrin molecules. To date porphyrins, chlorophylls, and pheophytins have been shown to transfer electrons from their triplet states readily. However, yields of only a few percent of charge transfer products have been found from singlet states. Current work is examining the effects of distance, orientation and solvent on singlet charge transfer reactions: The goal is to link thermodynamic and spectroscopic information to predict probabilities and rates of light-induced electron transfer. 
Chemistry Department, BNL, continued

15. PHOTOCHEMICAL AND RADIATION SCIENCES M. D. Newton

$1.3 \quad 01-1$

The goal of this program is the exploitation of the National Synchrotron Light Source (NSLS) in many areas of chemical research. The NSLS now under construction at Brookhaven will provide high intensity, monochromatic photon beams ranging in energy from the ultraviolet to the $x$-ray region. The usefulness of these photon beams to the chemical community depends, in large part, on the facilities which will be made available for chemical experimentation. An appreciable effort is now underway by members of the Chemistry Department to design, build, and eventually use such facilities. The projected scientific programs in Chemistry at the NSLS are, in many cases, outgrowths of ongoing Departmental work and include gas phase photoionization and chemical kinetics studies, fluorescence lifetime and photoconductivity measurements, photoelectron spectroscopy, and $x-r$ ay diffraction. Experiments are also being $p l a n n e d$ on the EXAFS and $x$-ray fluorescence facilities which will also be available at the NSLS, and a new Departmental program in chemical catalysis will benefit greatly from the various NSLS resources. Most of the present efforts are being carried out in collaboration with university-based chemists who will form the nucleus of the outside user community at the synchrotron.

16. ENERGY TRANSFER IN

$2.4 \quad 01-1$

S.HFMTSAT. KTNFTTS.S

R. E. Weston

Chemical reaction rates depend strongly on the distribution of reactant energy among translational, rotational, vibrational, and electronic degrees of freedom. Conversely, the energy distribution in reaction products can be used as a sensitive probe of the reaction mechanism. In this program the transfer of both electronic and vibrational energy are being studied. Although the experimental methods differ in detail, in both cases atoms or molecules are produced in specific excited states by a pulse of ultraviolet, visible, or infrared radiation. The excited species can transfer energy to another molecule by collision, or can spontaneously lose energy by emission of fluorescence radiation at a rate determined by the natural lifetime of the excited species. The competition between energy transfer and emission leads to a decrease in observed fluorescence lifetime, which can be related to a bimolecular rate constant (and a cross section) for energy transfer. Specific investigations now under yay include: (i) the rate of vibrational energy transfer between ${ }^{13} \mathrm{CO}$ and ${ }^{12} \mathrm{CO}$; (ii) ratess of vibrational relaxation of CO by alkali metals; (iii) lifetimes of $S_{,}\left(B^{3} \Sigma^{-}\right.$) excited to various. viprational levels, and quenching rates; (ivf the branching ratio for $I\left({ }^{2} P_{1 / 2}\right)$ and $I\left({ }^{2} P_{3 / 2}\right)$ production in the reaction $F+D I$. 
Chemistry Department, BNL, continued .

17. CHEMISTRY OF ENERGETIC ATOMS:

BAS IC RESEARCH AND APPLICATIONS

A. P. Wolf, R. M. Lambrecht

This program is devoted to a study of the chemistry of energy-rich atomic and molecular species. These may be neutral or charged reactants in ground or electronically excited states, or reactants with high kinetic energies. Included are reactive intermediates produced by nuclear processes, reactions of $\mathrm{C}, \mathrm{N}, \mathrm{O}$, and halogen atoms, and studies of atom-atom and atom-molecule reactions in an energy range inaccessible by conventional methods. Atomic species are also produced in known electronic states and with a known temperature using a microwave discharge. Spectroscopic techniques are used to identify reactants and products and to determine rates of gas phase reactions. Applications include: Chemical reactivity and spin states of carbon, oxygen, and halogen atoms; facile.reaction rate determination of atomic carbon, oxygen and halogens with organic and inorganic substrates; very high temperature oxidation kinetics; techniques for 1 abeling compounds of medical, biological, and environmental interest; charged particle activation analysis of coal for oxygen and sulfur; catalytic and surface structure reactivity with oxygen, utilizing oxygen 15; functional group and structure analysis utilizing tritium and labeled halogens; and analyses of transient radicals on coal surfaces, using short-lived nuclides. 
Photochemical and Radiation Sciences

Department of Energy and Enviromment Brookhaven National Laboratory

Upton, New York 11973

\section{PORPHYRIN CHEMISTRY}

J. Fajer
Total $\$ 757,000$

$6.8 \quad 01-1$

Porphyrins are organometallic compounds which play indispensable catalytic roles in biochemical energy conversion. This work represents a multidisciplinary program which involves synthetic, structural, theoretical and physical chemistry, and it encompasses (1) the electron structure and chemical properties of porphyrins and their radicals; (2) the biological role of porphyrins and their ions in photosynthetic metabolic reactions; and (3) applications of these catalytic reactions to solar energy production of electricity by photo-excitation of porphyrins deposited on solid interfaces or isolated in micelles, the production of hydrogen and oxygen in solution using porphyrins to mimic the photosynthetic cell and photo-decompose water, and also to fix nitrogen photochemically via porphyrin derivatives. In addition, polymeric and heteroporphyrins are under investigation in photoassisted and electrochemical catalysis for oxygen reduction (for fuel cell applications) and custom chemical synthesis. The methods used to study these reactions, which involve oxidation-reduction mechanisms, include techniques such as optical and picosecond spectroscopy, electron spin resonance (esr), nuclear magnetic resonance ( $\mathrm{nmr}$ ), and electron nuclear double resonance (endor): The redox reactions are induced chemically, photochemically, and electrochemically, and the chemistry. is guided by theorétcal calculations used lu piedict the chemical propertico of tho model systems. These, in turn, are used to establish the role of the porphyrins in biochemical catalysis and use them in biomimetic energy transduction. 
Department of Energy and Environment, BNL, continued

19. INVESTIGATION OF THE CHEMISTRY
OF ENERGETIC COMPOUNDS
M. Hillman

The aim of this project is to prepare special organometallic compounds whose properties will give them potential use in conductivity, e.g., a free metal atom trapped in a hydrocarbon cage, a metal atom whose electron distribution is deformed by pressure from neighboring atoms, intensely colored mixed valence compounds, a three dimensional aromatic system involving a metal core, etc. The present concern is with the preparation of examples of the first two of these compounds, and the measurement of their properties. Bridged ferrocene derivatives containing four- or five-carbon bridges are being prepared. Transformation of these derivatives to free and to trap the iron atoms is under investigation and looks promising. Mössbauer spectra of various bridged derivatives have measured the extent of deformation of electron distribution, the largest being in a tristrimethylene bridged ferrocene. The preparation of the tetrakistrimethylene bridged ferrocene is underway. Other pertinent physical properties that have been measured include electrode potentials.

20. KINETICS AND MECHANISMS OF $3.0 \quad 01-1$ CHEMICAL PROCESSES RELATED TO THE DEVELOPMENT AND USE OF ENERGY

J. W. Sutherland

The objective of this program is to develop basic kinetic and mechanistic information about selected chemical systems which are associated with the development and use of energy sources and for which present data are inadequate or unavailable. Short-lived transient chemical species are characterized by flash photolytic and pulse radiolytic techniques, while steady-state photolytic, steady-state radiolytic and standard kinetic methods are used to identify and measure yields of final products of a particular overall reaction. Principal topics being investigated are the photochemistry of selected molecules adsorbed on high surface area solids and the chemistry of transient nitrogen compounds. Some aspects of the reactivity of sulfur dioxide are also being studied. Information developed in this program is relevant to investigations into systems being considered for the photochemical conversion and storage of solar energy, into methods for nitrogen fixation, and to problems in sulfur chemistry associated with the development and use of geothermal energy sources and of fossil fuels. The results of this investigation, in addition to their intrinsic value to the general field of chemical kinetics, are available as quantitative input data for models designed to assess the impacts of using various energy sources. 
Photochemical and Radiation Sciences

Chemical Biodynamics Division

Lawrence Berkeley Laboratory

University of California

Berkeley, California 94720
Total $\$ 375,000$

$6.0 \quad 01-1$

\section{PHOTOSYNTHETIC SOLAR ENERGY UTILIZATION \\ M. Calvin, J. N. Otvos}

This project is a basic science effort, directed towards developing methods and systems for the utilization of solar energy that are based on knowledge of green plant photosynthesis. Photosensitized electron transfer reactions across phase boundaries have been achieved and are being studied with the aim of stabilizing the primary oxidation and reduction photoproducts and preventing their back reaction. Subsequently, the stored energy in these products will be channeled into the production of hydrogen and oxygen from water. The phase boundaries studied so far across which electrons have been moved with concomitant energy storage are the lipid bilayer walls of phospholipid vesicles and the interfacial region of microemulsions. The reduced photoproduct can readily be converted to hydrogen, but the complementary reaction on the other side of the interface, the production of molecular oxygen, has not yet been successful. However, novel chemical systems for trapping active oxygen atoms have been prepared and are receiving intensive study. Dye-sensitized semiconductor devices with both liquid (electrolyte) and metal junctions are another means for producing the initial charge separation step. Choice of suitable dyes produces sensitivity over a large part of the solar spectrum, and use of sintered pellets as the dye substrate greatly enhances efficiency and ease of fabrication. Development of a novel dry, dye-sensitized Schottky barrier solar cell is being pursued. Efficiency of the basic semiconductor-dye-metal system has been improved in several ways, including doping of the dye and introduction of hole carriers between the dye and metal. 
Photochemical and Radiation Sciences

Energy and Environment Division Lawrence Berkeley Laboratory

University of California

Berkeley, California 94720
Total $\$ 135,000$

$1.9 \quad 01-1$

\section{BIOCONVERSION OF SOLAR ENE RGY}

L. Packer

The "photochemical conversion of solar energy" by bacteriorhodopsin, a protein pigment derived from purple membranes of halobacteria is being characterized. Photoconversion of solar energy by bacteriorhodopsin operates essentially via a photocycle of $7 \mathrm{msec}$ duration that is directly coupled to a proton pump. Bacteriorhodopsin is the simplest and most stable naturally occuring light energy converter presently known. Chemical modification of specific amino acid residues has demonstrated that the conformation of the dark and light adapted forms of the protein differ and that the aromatic amino acids tryptophan and tyrosine are important for activity. Charge modification of certain residues having net negative or positive charge is also being used to clarify the energy conversion process. New ESR methods demonstrate that surface electrical charges are generated by 1 ight absorption and that these may be essential for the proton pumping capacity of bacteriorhodopsin. Future studies emphasize the molecular as pects of the energy conversion and how surface charge effects may be useful for enhancing the photovoltaic effects of bacteriorhodopsin on stable planar membrane systems. Attempts are being made to develop model systems that will efficiently carry out the salt pumping activity of halo-bacteria which is coupled to the proton pump of bacteriorhodopsin with the intention of building practical desalination devices. 
Photochemical and Radiation Sciences

Materials and Molecular Research Division

Lawrence Berkeley Laboratory

University of Cali fornia

Berkeley, California 94720

23. PHOTOCHEMISTRY OF MATERIALS

$3.1 \quad \cdot 01-1$

IN THE STRATOSPHERE

Total $\$ 289,000$

H. S. Johnston

This project is concerned with the photochemical processes that contribute to the production and destruction of stratospheric ozone. Laboratory studies are carried out to obtain optical cross sections, quantum yields, and rate constants for species that occur in the stratosphere. Recently, temperature dependent cross sections have been determined for nitrous oxide and for nitrogen pentoxide. The quant um yields as a function of wavelength have been obtained for two product channels of the nitrate free radical. As others measure the concentrations of trace species in the atmosphere, this project interprets these results in terms of its "method of instantaneous rates". In favorable cases, these interpretations exend to the full three-dimensional atmosphere, for example, the photolysis of nitrous oxide and its reactions with singlet atomic oxygen. Conventional one-dimensional models of atmospheric dynamics and photochemistry are used to support the interpretation of atmospheric observations and in the planning and interpretation of 1 abor atory experiments.
24. PHOTON-ASSISTED SURFACE REACTIONS,
$1.2 \quad 01-1$
MATERIALS AND MECHANISMS
G. A. Somor jai

This project explores photo-chemical reactions that take place at the solid-vapor interface. These reactions include the photo-dissociation of water to produce hydrogen and oxygen and the photon-assisted reactions of carbon dioxide and water to produce simple hydrocarbons (photosynthesis). The purpose of these studies is to explore the mechanisms of photon-assisted surface reactions and then establish the optimum conditions (of surface structure, composition, temperature and reactant mixture) to maximize the rate of production of the desired chemicals (hydrogen and/or hydrocarbons). Light of band gap energy ( $3.1 \mathrm{eV}$ ) was used to irradiate strontium tit anate crystal surfaces. The catalytic evolution of hydrogen was detected in the presence of sodium hydroxide at the surface. The rate of the photocatalytic reaction could be increased ten-fold when platinum was deposited on the oxide. At least two reaction mechanisms 3 were uncovered, both involving surface hydroxyl groups and the lower $\mathrm{T} \cdot \mathrm{i}^{3+}$ oxidation state ions of the oxide. 
Photochemical and Radiation Sciences

Notre Dame Radiation Laboratory

Total $\$ 1,890,000$

University of Notre Dame

Notre Dame, Indiana 46556

25. INORGANIC PHOTOCHEMICAL STUDIES

2.5

$01-1$

G. J. Ferraudi

The photochemical properties of the transition metal ion complexes with macrocyclic 1 ig ands are being investigated. The effect of 1 ig and structure, including the size $n f$ the marrocyclic ring, the extenoion of the $\pi$ oyotem and its overlap with the electronic density of the metal ion, are being examined using different members of a given family of macrocyclics. In addition, studies are being carried out on complexes of different metal centers with the same electronic structure. For example the photolysis of macrocyclic complexes of cobalt(II) and nickel(III), both having $d$ electronic configuration, are being examined in order to introduce variations in the photo-chemical responses of the complexes. Reference pulse radiolytic experiments are also being carried out to provide spectroscopic and reaction rate information on intermediates which are generated in redox reactions between radicals and inorganic systems. Many macrocyclic complexes of metal ions undergo photochemically produced electron transfer with light in the visible region of the spectrum and have potential applications for initiating processes with solar radiation. 
Notre Dame Radiation Laboratory, Notre Dame, continued

26. ESR STUDIES ON RADIATION-CHEMICALLY AND PHOTOCHEMICALLY PRODUCED INTERMEDIATES

R. W. Fessenden

Electron spin resonance spectroscopy (ESR) is being used to study the electronic and geometric structure, mechanism of formation, reaction kinetics and electron spin population dynamics of short lived radical intermediates produced in solution by photochemical processes and by electron beam irradiation. In both cases these studies use continuous and pulsed irradiation methods, with the latter permitting direct examination of the time response ESR signals on the micro-second time scale. These time resolved studies are being directed toward obtaining an understanding of the phenomenon known as chemically induced dynamic electron spin polarization (CIDEP), toward direct measurement of the rates for reactions of specific radicals and toward direct observations on the relaxation of the" electron-nuclear spin system toward the Boltzmann equilibrium. The more conventional steady state studies are being used to identify radical intermediates in photolysis and radiolysis, to study electron distribution within specific radicals and to examine electron exchange and protonation equilibria. Information from these ESR experiments is integrated with that obtained from related optical studies and chemical approaches to give a more complete picture of the mechanisms of radiation chemical and photochemical reactions.

27. THEORETICAL ASPECTS OF

4.0

01-1

RADIATION CHEMISTRY

K. Funabashi

A. Mozumder

Theoretical studies of the effects of the absorption of ionizing radiation in condensed systems are being carried out to provide a basic underlying structure for understanding radiation chemical experiments. Currently, attention is being focused on cross sections for capture of thermal electrons, problems associated with electron thermalization, dielectric relaxation in polar liquids and on influence of field dependent transport coefficients on escape probabilities. The random-walk model for electron scavenging is being examined in some detail and is applied to the nature and properties of reactions at early times particularly as they apply to track effects. Studies are being carried out on the mechanisms for localization of energy in irradiated polyatomic systems with particular application to the selectivity experiments observed in the radiation induced capture of the central bonds in aliphatic hydrocarbons. Conclusions from these studies are important in areas outside radiation chemistry, particularly those where ions are important such as reactions of ions in the atmosphere or on the electrical properties of insulators. 
Notre Dame Radiation Laboratory, Notre Dame, continued

28. ELECTRICAL AND CHEMICAL

$1.0 \quad 01-1$

PROPERTIES OF DIELECTRICS

AND THIN FILMS

W. H. Hamill

W. B. Berry

The phenomena associated with the injection, transport and trapping of very low energy excess electrons and holes in insulating 1 iquids and disordered solids are being investigated. Topics being considered include electron and hole injection, bond transport in crystals and certain liquids, hopping transport in most 1 iquids, impurity and defect trapping and ion recombination. Consequences of the experimental observation that the rate of electron transport is proportional to the logarithm of time after injection are being explored in some detail. These studies, while motivated primarily by interests in the radiation physics and chemistry of low dielectric media, are of concern to electron transport in areas such as photosynthesis and ultimately to applied areas such as xerography and transmission line technology.

\section{CHEMICAL PHYSICS OF REACTING} SYSTEMS

$5.0 \quad 01-1$

J. J. Kozak, M. Schwartz

Theoretical methods are being exploited to interpret phenomena in radiation chemistry and photochemistry; especially those involved in chemical dynamic processes related to energy storage and transfer. The dynamical aspects of the interaction of radiation with matter, and the temporal decay of excited states of two- and three-level atomic and molecular systems, are being studied using new analytical techniques developed for solving the time-dependent Schrodinger equation. Newly developed quantum mechanical methods are being applied to electronic structure calculations. Together with existing methods, these calculations are being used to study problems involving molecular structure, potential energy surfaces, reaction mechanisms, electron-solvent interactions, electron scattering, photoionization and the distribution of spin densities within radicals. Also in progress are theoretical studies of the interaction of metal atoms with one another and with substrates in chemical reactions; these are expected to be of particular importance to the understanding of mechanisms of catalysis. An overall theory of photo- and radiation-induced redox reactions in organized molecular assemblies is being developed which takes into account the dimensionality and finite spatial extent of these organizates. This latter theory should be of considerable importance in any attempt to use these organizates for storage of solar energy. 
Notre Dame Radiation Laboratory, Notre Dame, continued

30. PULSE RADIOLYSIS STUDIES OF
RADIATION CHEMICAL REACTIONS
P. Neta, L. K. Patterson

Pulse radiolysis techniques are being used to characterize the kinetic properties and absorption spectra of short lived transient species produced by ionizing radiation. Emphasis in these studies is on processes which involve electron transfer or redox mechanisms. The approaches being developed provide methods for examining electron transfer equilibria and allow the determination of one-electron oxidation or reduction potentials for various types of organic radicals. Kinetic spectrophotometric studies are being carried out to examine details of the oxidation and reduction of organic molecules by both organic and inorganic radicals. Additionally, time resolved studies are used to determine the reactivities of the intermed$i$ ates following radiation initiated cleavage of both organic compounds and inorganic ions. The ultimate aim of these various studies is to expand the understanding of reaction intermediates so as to be able to predict their role in both radiation and conventional chemical environments.
31. RADIATION CHEMISTRY DATA
1.0
01-1 CENTER
A. B, Ross

The Radiation Chemistry Data Center (RCDC) carries out a continuous survey of the literature of radiation chemistry and photochemistry, assembles appropriate bibliographic information on computer readable keyworded files, critically examines and compiles experimental data on intermediates produced by light and ionizing radiation and provides to Department of Energy contractors and the scientific community in general a variety of information services from its data bank. These information services include keyword and author searches of its bibliographic files, searches of article titles for specific terms, preparation of current-awareness aids and bibliographies, and compilation of specific data such as rate and spectroscopic information on reaction intermediates. The Biweekly List of Papers on Radiation and Photochemistry is issued regularly to interested subscribers. Critically reviewed and evaluated data on reaction intermediates are prepared by the Center which are of general importance to proper considerations of both the basic scientific and technological application of chemical processes, particularly those involved in radiation chemical and photochemical (solar energy) programs. 
Notre Dame Radiation Laboratory, Notre Dame, cont inued
32. ORGANIC PHOTOCHEMICAL PROCESSES
5.0
$01-1$
J. C. Scaiano

Photochemical processes in organic systems are being examined to provide information on the role of intermediates including radicals, biradicals and triplet states, on energy transfer mechanisms and on the resultant overall photochemistry. Currently, emphasis is on the use of laser f1ash photolysis techniques to study both intermolecular and intramolernlar energy migration. Studies include examination of intermolecular energy transfer between quasi-isoenergetic triplets, intramolecular transfer in molecules containing two chromophores, energy hopping along a polymeric chain, and energy trapping in co-polymers containing several types of chromophores. These studies on energy migration in polymers are particularly relevant to photosynthesis and to possibilities for enhancing the properties of polymers toward photodegradation or photostabilization. Other studies in progress are directed toward understanding photochemical processes involving biradicals, particularly those produced from aromatic ketones, and toward the reactions of photolytically produced oxygen centered radicals. Flash photolysis is used to examine both the spectral and kinetic properties of these radicals.

\section{SPECTROSCOPY OF REACTION INTERMEDIATES \\ s. I. Sheng}

$4.0 \quad 01-1$

Spectroscopic studies of intermediates produced photochemically and by ionizing radiation are being carried out to identify such intermediates and to provide detailed information on their molecular and electronic configuration, on intermolecular interactions and on the modes by which electronic and vibrational energy are dissipated. Raman scattering and IR absorption are being used to study the vibrational structure of chemical intermediates including radicals and radical ions and to probe the intermolecular interactions in oriented crystal films. Polarized vibrational spectroscopy of their polyene films is aimed at resolving the Davydov splitting and at providing an understanding of the important vibrational modes involved in interactions of electronically excited states. Gas phase photoacoustic experiments are used to establish the extent to which the potential energy surface for dissociation can be characterized by the vibrational energy content of the fragments. Collisioninduced IR absorption experiments designed to test an electron density deformation model of repulsive molecular collisions are being carried put. 
Notre Dame Radiation Laboratory, Notre Dame, continued

34. CHEMICAL STUDIES OF RADIATION
INDUCED REACTIONS
R. H. Schuler

A wide variety of chemical reactions induced by the absorption of ionizing radiation are being examined using a broad base of highly developed chemical and instrumental methods for examining both intermediates in time resolved studies and for analysis of ultimate products. It is the purpose of these studies to obtain detailed information on the nature of radiation induced reactions. Studies are largely directed toward examining the formation and subsequent reaction of free radicals in aqueous solution over the time scale of $10^{-8}$ to 10 seconds. Reactions at shorter times that occur 1 argely within the radiation tracks are examined using chemical approaches. Studies in non-aqueous media include the application of scavenging methods to examine radical formation and reaction, particularly in hydrocarbons. Studies are also being carried out at the Notre Dame Heavy Ion Facility to examine track effects in radiation chemical reactions induced by 1 ow $Z$ ions having an energy of $\sim 5 \mathrm{MeV} / \mathrm{nucleon}$. These studies provide important information on the molecular and radical yields for high linear energy transfer radiations and are being developed to give information on the time evolution of heavy particle tracks.

35. RADIATION CHEMISAT. AND PHOTO-

3.0

$01-1$

CHEMICAL STUDIES OF REACTIONS AT CHEMICAL INTERFACES

R. H. Schuler (acting)

Studies of radiation chemical and photochemical effects in micellar systems which emphasize the unique catalytic effects of micellar isolation and the transport of reaction intermediates across interfacial barriers are in progress. These studies are of basic interest to both $r$ adiation chemistry and radiation biology and offer promise to provide methods for controlling the deposition of energy in photochemical and solar energy applications. The effect of micellar structures on reaction rates is being examined to provide information applicable to the control of reactions by proper choice of micellar material. Qualitative changes in chemical reactions which result from profound changes in the lifetime and ionization potential of the reaction intermediates in micellar media are being examined. These studies are aimed at determining the way in which the reaction is controlled by the aqueous-1ipid interface and at developing micellar methods to examine kinetic details of chemical reactions. 
Notre Dame Radiation Laboratory, Notre Dame, continued

36. PHOTOISOMERIZATION

A. M. Trozzolo
$3.0 \quad 01-1$

Photochemical studies are being carried out on the valence isomerism of heterocyclic compounds, the chemistry of ground state triplet molecules (produced photochemically), electron transfer reactions of singlet oxygen, and the excited-state reactions of laser dyes. In addition, a number of adiabatic photochemical reactions are being studied which are quite novel since they produce excited-state products. Studies on heterocyclic compounds involve a number of photochromic systems in which a relatively strained ring has opened photochemically to produce a high energy intermediate whose stability can be controlled, The electron $t r$ anster reactions of singlet oxygen are being studied in view of the important role that this species plays in photooxidation and degradation of polymers, photobiology, chemiluminescence and enzymatic actions.
37. ENERGY TRANSFER IN ATOMIC
3.0
01-1
AND MOLECULAR SYSTEMS
D. H. Winicur

Molecular beam methods are being used to examine the mechanisms, cross sections and intermediate species involved in energy transfer in elementary processes. Interactions between metastable excited rare-gas atoms and various small molecules such as $\mathrm{CO}_{2}, \mathrm{H}_{2} \mathrm{O}, \mathrm{H}_{2}$, and $\mathrm{F}_{2}$ are determined from measurements of differential scattering cross sections using crossed molecular beams. The results from these experiments provide detailed information on the nature of the interactions during the molecular collision, indicate the states present immediately after the initial energy transfer and allow a determination of the potential-energy curves for the interacting species. Currently emphasis is on processes involving translationto-rotation and translation-to-vibration energy conversion, on electronic energy exchange between excited argon atoms and water and on determination of the cross sections for formation of rare gas/halogen exciplexes. Understanding of energy transfer mechanisms is of particular importance to the development of chemical 1 asers and it is planned to extend these studies to a wide variety of energy transformations of interest to radiation, photo-, 1 aser and atmospheric chemistry. 
Photochemical and Radiation Sciences

Chemistry Division

Total $\$ 270,000$

Oak Ridge National Laboratory

P. 0. Box X

Oak Ridge, Tennessee 37830

\section{SURFACE EFFECTS-HYDROGEN RECYCLE CHEMISTRY}

1.5

01-1

S. Datz, S. H. Overbury

An understanding of the processes attending the interaction of energetic (100-3000 eV) hydrogen atoms with some low $\mathrm{Z}$ solid surfaces which would be encountered in the first wall or limiters of MFE reactors is being sought. Low $Z$ elements are desirable because of lower radiative 1088 from impurities, but with low $Z$ elements, such as carbon, there is the possibility of reaction with the implanted hydrogen and isotopic effects which can create differential holdup causing a change in plasma composition. The following processes have been studied: single surface atom collisions, electronic and nuclear stopping, charge changing processes in the solid and at the surface, angular and energy distributions of re-emitted nonthermalized particles, straggling in energy and angle, and range. The fifst experiments investigated the energy $108 \mathrm{~s}$ ( $100<\mathrm{E}<3000 \mathrm{eV}$ ) of $\mathrm{H}_{2}{ }^{+}, \mathrm{H}^{+}$, and $\mathrm{D}^{+}$transmitted through thin carbon foils. The stopping powers were found to. give good agreement with the theoretical relation $S(E)=k_{1} E^{1 / 2}$. In another series of experiments, the energy distributions of reflected $\mathrm{H}^{+}$and $\mathrm{H}^{-}$. were measured from smooth pyrolytic graphite, thick amorphous carbon foils, and from rough polycrystalline graphite. The total reflection coefficients $(230 \%)$ and angular distributions obtained are in reasonable agreement with Monte Carlo calculations-made for this system. The angular distribution appears to be describable by a simple theoretical model which makes use of single binary scattering and the stopping powers obtained from the thin foil experiments. Neutralization behavior for these particles was found to be describable in terms of collisional neutralization and capture in the electron selvage at the surface. This new result should be quite general for any surface. 
Chemistry Division, ORNL, continued

39. RADIATION CHEMISTRY AND PHOTOCHEMISTRY

C.J. Hochanadel, T. J. Sworski

This is a program of basic research in photochenistry and chemical kinetics. The immediate goal is to obtain kinetic information that will allow meaningful modeling of the chemistry in systems of interest for the development and use of energy. These systems include combustion, coal conversion, atmospheric chemistry, and solar energy. The reactions studied generally involve small free radicals such as $\mathrm{H}, \mathrm{OH}, \mathrm{O}, \mathrm{HO}, \mathrm{CH}_{3}, \mathrm{CH}_{3} \mathrm{O}, \mathrm{HCO}, \mathrm{CN}, \mathrm{NCO}, \mathrm{NH}$, and $\mathrm{NH}_{2}$ that are produced in model systems by ${ }^{2}$ lash photolysis. The research involves identifying the reactive intermediates, establishing the reaction mechanisms, and evaluating absolute rate constants for elementary reactions. The photolytic flash is either a 3 microsecond Xe flash or a 30 nanosecond flash from an excimer laser. The reactions are observed by time resolved kinetic spectrophotometry. Theoretical curves for comparison with experimental data are obtained by numerical modeling; kinetic parameters are adjusted by the method of least squares to fit the data to the se curves with error 1 imits established by sensitivity analysis. In recent studies of the $\mathrm{CH}_{3}$ and $\mathrm{HCO}$ radicals produced by the photodissociation of $\mathrm{H}_{2}$ in the presence of $\mathrm{CH}_{4}$ or $\mathrm{CO}$, the absorption spectrum of $\mathrm{HCO}$ was measured and the following rate constants were evaluated: $k(\mathrm{H}+\mathrm{HCO})$, $k(\mathrm{HCO}+\mathrm{HCO}), k\left(\mathrm{H}+\mathrm{CH}_{3}\right), k\left(\mathrm{OH}+\mathrm{CH}_{3}\right), \mathrm{k}\left(\mathrm{OH}+\mathrm{CH}_{4}\right), \mathrm{k}\left(\mathrm{OH}+\mathrm{H}_{2}\right)$, and $\mathrm{k}(\mathrm{H}+\mathrm{CO}+\mathrm{M})$ for $=\mathrm{CO}, \mathrm{H}_{2}$, and $\mathrm{CH}_{4}$. 
Photochemical and Radiation Sciences

Research Division

Total $\$ 225,000$

Solar Energy Research Institute

1536 Cole. Boul evard

Golden, Colorado 80401

40. PHOTOCATALYSIS RESEARCH LEADING

TO $\mathrm{N}_{2}$-FIXATION AND $\mathrm{CO}_{2}$-REDUCTION

J. ${ }^{2}$ S. Connolly, J. C. Smart,

A. J. Frank

This program involves a three-fold approach to photocatalysis with the long-term goal of reducing $\mathrm{N}_{2}$ and $\mathrm{CO}_{2}$ to useful energy forms with solar energy. The key elements are photosensitization, redox catalysis and coupled systems. Initial efforts are focused on the photophysical and photochemical properties of bacteriochlorophyll a (BChla) which fits many of the criteria for a "model" photosensitizer for solar applications. Specifically, the quantum yields of fluorescence and intersystem crossing and excited-state behavior of $\mathrm{BCh}$ la and related bacteriochlorins are being examined by pulsed and steady-state techniques. In a similar context, synthesis and reaction studies are being conducted of bis (fulvalene) dimetal complexes whose absorption spectra, redox behavior and catalytic properties appear to fulfill many of the requirements for stable intermediates in sequential, multiphoton electron-transfer processes. Finally, sensitizers and redox catalysts are being coupled into molecular assemblies (e.g., polymer membranes) via specific matching of spectroscopic, photochemical, electrochemical, catalytic and structural properties. 
Chemical Physics

Ames Laboratory

Iowa State University

Ames, Iowa 50011
Total $\$ 500,000$
$2.5 \quad 01-2$
41. STATISTICAL MECHANICS OF GASEOUS SYSTEMS
D. K. Hoffman

This work has three basic aspects. The first deals with the nonequilibrium features of adsorption-desorption mechanisms and related problems in surface chemistry and catalysis. The aim 18 to understand how the energetic and geometrical features of a solid surface serve to influence the surface distribution of adsorbed opecies which in, turn is an important determinant of catalytic behavior. The general approach is to derive kinetic equations, based on an assumed adsorption (desorption) mechanism, and to obtain solutions on a time scale for which equilibration does not occur. A second aspect of this work is to understand transport and relaxation processes in polyatomic gases. An important feature of this program is to develop reliable collision models from which transport and relaxation cross sections which sensitively depend on inelastic collision mechanisms can be calculated quantitatively. The computational schemes under investigation attempt to exploit recent advances made in developing accurate approximation techniques for inelastic scattering problems. Finally, an effort is underway to develop a formal kinetic theory of reacting fluids with particular emphasis on reactive gases. It is anticipated that this theory will be useful for studying kinetic processes in flames and other reactive systems not at equilibrium.

42. ATOMIC, MOLECULAR AND FREE 1.9 01-2 RADICAL CROSSED BEAM KINETICS C. $-\mathrm{Y}$. Ng

Utilizing fundamental principles of chemical dynamics together with molecular beam and photoionization metluds, the emphasis in this program is on obtaining reliable experimental kinetic data and precise thermochemical data directly or indirectly related to combustion systems. Currently, two specially designed molecular beam photoionization apparatuses are in operation. Research efforts are concentrated on high resolution photoionization studies of molecules, transient radicals, dimers and clusters; very low pressure pyrolysis of hydrocarbons; rate constant measurements of fast flow reactor techniques. and photoionization mass spectrometry; direct identification of product channels and energy contents, and quantitative identification of the intermediate radicals and stable products in flames using photoionization mass spectrometry. 
Ames Laboratory, cont inued

43. MOLECULAR BONDING THEORY

$2.7 \quad 01-2$

K. Ruedenberg, S. Elbert

This work predicts changes in molecular properties such as geometry, electromagnetic behavior, spectral distributions and, in particular, energy content, occurring during chemical reactions by means of theoretical calculations. It is hoped to contribute information which is needed in energy-related research, but which is difficult or impossible to obtain. experimentally. Of special interest are reaction energies of elusive intermediates and activation energies of transition states for reactions involving oxidation-reduction and combustion-related hydrogen exchange reactions involving carbon, nitrogen, oxygen, hydrogen, and silicon. In order to improve the accuracy of practical computational methods, fundamental developments are being made in beyond-Hartree-Fock many-electron quantum mechanics. Also, through reliable analyses of electronic rearrangements along reaction paths, concepts are being developed to permit non-specialists to anticipate experimental results.
44.
MASS SPECTROMETRY-ION SOURCE CHEMISTRY
0.9
$01-2$
H. J. Svec, G. D. Flesch

Studies of the dissociation of gaseous ions from the hexacarbonyls and pentacarbony1-thiocarbonyls of $C_{r}$, Mu, and $W$ rcveal that the detached neutral CO and CS are vibrationally excited in their $\nu_{1}$ "state, viz. 0.27 and $0: 16 \mathrm{eV}$ respectively. The same result is suspected to be true when the decarbonyls of the Group VIIB elements and ketones dissociate to form $C O$ as a neutral product. This is the first direct evidence that such an exciced stale way be formed when co is a product in the dissociative ionization of a large molecule and may account for the reactivity of certain large molecules. When the tetramethyl derivatives of silane, germane and stannane dissociate as a result of jnteracting with energetic electrons, methyl radicals and $\mathrm{Si}, \mathrm{Ge}$, and $\mathrm{Sn}$ may be produced, the latter form in the ground electronic state and an autoionizing state. Although similar evidence for the formation of an autoionizing state of carbon from neopentane is ambiguous because of mass interferences in the neutral fragment mass spectrometer, such a state of carbon is expected to exist. Such atoms are very reactive and are suspected to be involved in the formation of soot when hydrocarbons burn in a fuel rich flame. The design and fabrication of a double-ended neutral fragment mass spectrometer is underway. The design includes coincidence counting circuitry whereby neutral fragments and their complementary ions can be identified directly. A study of the dissociative ionjzation of tetramethylplumbane is expected to prove the assumption that $\mathrm{Pb}$ is formed in an autoionizing state. By analogy, the breakdown of tetraethyl lead to form $\mathrm{Pb}$ * may play an important role in the poisoning of catalysts in automotive exhaust systems. 
Chemical Physics

Chemistry Division

Argonne National Laboratory

Tota1 $\$ 1,030,000$

9700 South Cass Avenue

Argonne, Illinois 60439

45. HIGH-RESOLUTION SPECTROSCOPY

$2.7 \quad 01-2$

H. M. Crosswhite, F. S. Tomkins,

- K. T. Lu

Electronic states with high principal quant um numbers inceract strongly with continuum states, doubly-excited series (channels) and with other Rydberg series members of the same parity. Conventional shell theory breaks down in this region and orbital quant un numbers become submerged. Multichannel quant um defect theory shows the close phenomenological connection between autoionizing and bound states. Recent magnetic and electric field experiments show new phenomena which suggest theoretical and experimental studies of spectral phenomena that reflect the critical onset of two or more competing effects. The $9.1 \mathrm{~m}$ spectrograph is being equipped for automatic photoelectric scanning in preparation for experiments at higher fields, and with crossed electric and magnetic fields for more detailed magnetic studies of motional Stark interactions and of quasi-Landau and Fano-resonance profiles: The vacuum-ultraviolet region will be covered by the new five-meter spectrograph. Selective excitation by polarized lasers will be used to simplify spectra of the more complex atoms. Spectroscopic properties of autoionizing resonances are being used to generate tunable vacuum-ultraviolet coherent radiation by fourwave mixing processes. Two systems are currently being studied: magnesium vapor for the 1400-1659 $\AA$ region and heryllium vapor for shorter wavelengths. comprehensive studies of the fundamental nonlinear processes are included. 
Chemistry Division, ANL, continued

46. THEORETICAL CHEMISTRY

T. H. Dunning, Jr., G. Das,

A. F. Wagner, L. L. Shipman
4.3

$01-2$

Theoretical chemistry at ANL is a diverse, basic research program with applications to the chemical, biological and physical sciences. Specific activities include studies of (1) gas phase species and reactions involved in combustion, atmospheric chemistry, molecular beam studies, etc.; (2) the physical and chemical properties of metal atom compounds and clusters relevant to fundamental research in chemistry and in catalysis; and (3) the primary photophysical and photochemical events in photosynthesis. In addition, a substantial effort is devoted to the development of the ACCESS system, a modern theoretical chemistry "machine" for electronic structure calculations. The basic thrust of the program is the ab initio calculation of molecular electronic structure and spectra, of interatomic and intermolecular potential energy curves and surfaces, and the study of the molecular dynamics of the ab initio or other realistic potential surfaces. Capabilities range from rigorous, accurate techniques applicable to small and medium size systems to approximate, inexpensive techniques applicable to large systems or to large clusters of small systems.

\section{MOLECULAR SPECTROSCOPY}

$1.2 \quad 01-2$

J. R. Ferraro, L. J. Basile

This research is aimed at discovery of new electrical conductors by chemical synthesis as will as syntheses utilizing a combination of high external pressures and temperatures. One-dimensional conductors, superand semi-ronductors, and fast ionic conductors are being examined. Some new fast ionic conductors have recently been syntheslzed. These are of the silver iodide type, which contain substituted pyridinium cations, and which demonstrate promising ionic conductivities. Presently, investigations are underway of these compounds for thermal stability, the existence of new conductive phases at high temperature and/or pressure, and the effect of various 1 igands. The program emphasizes the chemical properties of these new conductors in an effort to develop a better understanding of how chemical composition can influence solid state performance (e.g., electrical conductivity, stability) and to provide theoretical implications on the nature of the mechanism of the electrical conduction. The program is of practical interest in the area of energy conservation and electrical energy storage. 
Chemistry Division, ANL, continued

48. CHEMISTRY OF THE MHD PROCESS

J. C. Hindman

The goal of this program is to characterize the equilibrium and nonequilibrium components in high-temperature coal-fired plasmas in order that methods may be devised for the control of plasma conductivity. These studies are concerned with those chemical species directly and indirectly involved in the production of electron density in the plasma, in the recovery of seed material, and in the formation of atmospheric pollutants. Particular attention is directed to the fact that the plasma is a dynamic system, and that both kinetic and thermodynamic data are needed to improve the predictions of modeling codes. Laser spectroscopic methods are under development for the study of time resolved species concentration profiles and plasma temperatures. Studies on the coherent anti-Stokes spectroscopy (CARS) of combustion related molecules such as $\mathrm{H}_{2}$ and $\mathrm{H}_{2} \mathrm{O}$ indicate that this technique will be useful for concentratfon and temperature profile measurements of major plasma species. Resonance CARS, where the excitation is in an absorption band of the molecule, is expected to increase the sensitivity of the method and perhaps make it possible to monitor a variety of diatomic and polyatomic molecules present in low concentrations in an MHD plasma. A study of the pollutant molecule, $\mathrm{NO}_{2}$, has shown that resonance enhancement is obtained, but that the Raman process is complex, so that measurements of this molecule can only be made at low pressures. Whether this is the case for other molecules of interest remains to be determined. 
Chemistry Division, ANL, continued

49. MOLECULAR BEAM STUDIES OF ACCELERATED SPECIES AND OF

NAKED METAL ATOM CLUSTERS

S. Wexler, E. K. Parks,

C. E. Young

Collisional ionization and collisional ion-pair formation ("chemi-ionization") reactions of hyperthermal atoms and molecules are being studied by the crossed-molecular beam method. A unique experimental facility consisting of three sophisticated "chemical accelerators" is used to produce hyperthermal beams of atoms and molecules of controlled translational energy by a variety of methods, which are then collided with crossed target beams of thermal species. The cross sections, energetics and dynamics of a large number of reactions, including collision-induced dissociation, electron transfer, associative rearrangement and "simple" ionization are being determined. These reactions are important elementary steps in the sequential chemical processes occurring in combustion, plasmas, gas lasers, magnetohydrodynamic (MHD) generation of electric power, advanced isotope separation methods, and the chemistry of upper atmosphere. Current research in this program involves the completion of a long-term investigation of the collisioninduced disociation of the cesium halides by fast rare gas atoms and $\mathrm{SF}_{6}$ molecules and the comprehensive investigation of electron transfer between $\mathrm{K}$ atoms and $0_{2}$ molecules: Future investigations will be on collision-induced dissociation by chemically reactive projectiles. The program is presently being expanded to include studies of the catalysis of chemical reactions on naked metal atom clusters, generated by a variation of the seeded supersonic jet method. A variety of diagnostic methods are being planned to. characterize the size, composition and catalytic activity of the metal atom clusters. 
Chemical Physics

Chemistry Department

Brookhaven National Laboratory

Upton, New York 11973
Total $\$ 2,566,000$
50. NEUTRON SCATTERING AND MOLECULAR STRUCTURE AND DYNAMICS BY NEUTRON AND $X$-RAY DIFFRACTION

H. J. Bernstein, L. M. Corliss,

J. M. Hastings, T. F. Roetzle,

R. K. McMullan, R. Thomas
$7.9 \quad 01-2$

Neutron and $x$-ray scattering methods are being used to solve significant problems in molecular structure, magnetism, phase transformations, and dynamic properties of solids: The present emphasis of the structural program is on transition metal hydrides and hydride coordination compounds; ionic conductors, and organic crystals. In the case of metal hydrides such as FeTiH, which is of interest 28 a hydrogen storage system, neutron diffraction allows the precise description of the distribution of hydrogen or deuterium over interstitial sites in the host metal lattice, which in turn may be related to physical properties. Studies of metal hydride coordination compounds, such as the octahedral cluster system $\left[\mathrm{HCo}_{6}(\mathrm{CO})_{15}\right.$ ] with an interstitial hydrogen atom, are important since these compounds provide molecular models for the interaction of hydrogen with metals and metal surfaces. Empirical charge density studies employing a combination of $x$-ray and neutron diffraction measurements are providing detailed descriptions of chemical bonding in crystalline solids with special emphasis given to hydrogen bonds and transition metal atom-organic moiety bonds. Inelastic neutron scattering is being used to study atomic motion in solids, and, in magnetic systems, to obtain information ahout the spatial distribution and spontaneous fluctuations of magnetization. The latter properties are essential to the understanding of critical phenomena in the region of second-order phase transformations. Solids which have been examined include dysprosium aluminum garnet, dysprosium gallium garnet, $\mathrm{Fe}_{2} \mathrm{As}$, and $\mathrm{NdSn}_{3} \cdot$ 
Chemistry Department, BNL, continued

51. HIGH FLUX BEAM REACTOR OPERATION

0.0

$01-2$

L. M. Corliss, J. M. Hastings,

T. F. Koetzle

The High Flux Beam Reactor provides an intense, steady-state source of thermal neutrons used in a variety of experiments by members of the Chemistry, Physics, and Biology Departments at Brookhaven and by outside groups as well. The nine beam ports are currently outfitted with twelve experimental facilities. Chemistry and Solid-State Physics have a program for the joint use of these facilities. These include both elastic and inelastic neutron scattering spectrometers. The Chemistry effort is concentrated in areas of structural studies, magnetic phase transitions, and critical phenomena.

52. THEORETICAL CHEMISTRY

5.4

$01-2$

S. Ehrenson, J. Muckerman, M. Newt on

The goals of this program are to apply theoretical methods to the study of energy flow in chemical reactions and molecular interactions involved in the storage and interconversion of energy in the gas phase and in condensed phases, including phenomena associated with charged species (i.e., solvation and charge-transfer processes). The methods principally used are ab initio and semiempirical calculations of the energies and structures of molecules in specific electronic states, and classical and semiclassical treatments of the nuclear motion in kinetic processes involving these systems. Specific chemical problems of interest are: ab initio models for. aqueous electron exchange processes, hydrogen bonding in hydroxylic systems; the electronic structure of transition metal clusters and their chemisorptive interaction with organic molecules; dielectric effects of solvents surrounding cavities of various shapes; application of statistics for linear and nonlinear free energy correlation methods to chemical and physical properties of large molecules; dynamics and energetics of elementary combustion reactions; and the dynamics of reactions involving excited states of atoms and molecules. 
Chemistry Department, BNL, continued

53. ION-MOLECULE REACTIONS WITH

APPLICATIONS TO FUSION ENERGY STUDIES

L. Friedman, R. J. Beuhler
$5.8 \quad 01-2$

Mass spectrometric techniques are being used to study energy transfer processes in sublimation or desorption of complex, fragile, molecules from surfaces, and to investigate production of secondary electrons by ion bombardment of surfaces. Both objectives focus on development of analytical techniques for detection of macro-molecular weight species. Studies of very rapid desorption of complex molecules from surfaces also contribute to an understanding of mechanisms of heterogeneous catalysis. Rapid heating desorption experimento on $\mathrm{Pb}\left(\mathrm{NO}_{3}\right)_{2}$ and polystyrene, selected as model inorganic and organic molecular systems, respectively, show evidence of heterogeneous ion-molecule reactions which facilitate desorption of complex, fragile, molecular species. Water cluster molecule ions, containing as many as 3000 water molecules, and accelerated with energy as much as $250 \mathrm{keV}$, are being used to study secondary electron emission phenomena. Lower incident-ion velocity thresholds have been observed with these macro-ion projectiles. These lower thresholds reflect energy transfer between displaced energetic lattice atoms and electrons in the localized, high temperature regions produced by ion bombardment. The incident-ion velocity thresholds are important in analytical studies because they determine the minimum accelerating voltage required for detection of specific macro-molecular weight ions. 
Chemistry Department, BNL, continued

54. MOLECULAR BEAM STUDIES OF CHEMICAL

A windowless experimental facility for gas phase studies on the $700-\mathrm{MeV}$ ring at the National Synchrotron Light Source has been designed and is being built. The apparatus will be used by both outside users and on-site investigators. The planned BNL use of this facility features the measurement of photoionization excitation functions of beams of molecules and radicals in predetermined quant um states, utilizing the unique tunable vacuum ultraviolet radiation and mass spectrometric detection. The target beams will be prepared by laser excitation of molecules and radicals that have been strongly cooled in a helium nozzle expansion. The main thrust of the work is to develop procedures for the analysis of gas mixtures at very low pressures and under highly nonequilibrium conditions, with emphasis on the determination of distributions of excitation energy. Applications of these procedures to the study of reacting flow systems, flames, and reactive scattering in crossed beams are envisioned. Investigations of the hydrogenhalogen-halogen hypersurface are being carried out, using astatine as one of the halogens. The principle methods being used are reactive scattering in crossed molecular beams, e.g., a study of the reaction $\mathrm{Br}+\mathrm{HAt} \rightarrow \mathrm{HBr}$ + At, and reactions in diffusion tubes, e.g., a study of the reaction HAt + $\mathrm{O}_{2} \rightarrow \mathrm{HO}_{2}+$ At. Both of these methods exploit the remarkable advantages of the use of short-lived radioactivity already discovered and developed at BNL. In particular, use is made of the isotope ${ }^{21}$ At, the half life of which is 0.032 seconds. 
Chemical Physics

Department of Energy and Environment

Total $\$ 450,000$

Brookhaven National Laboratory

Upton, New York 11973

55. MOLECULAR STRUCTURE OF PORP.HYRINS AND

$0.9 \quad 01-2$

PHOTOENERGY TRANSDUCING SYSTEMS

J. Fajer

The objectives of this program are to provide the structure-function and structure-reactivity correlations for compounds considered as potential energy transducers in photochemical or catalytic redox reactions. These include porphyrins, especially those containing multivalent transition metals, models of photosynthetic systems such as oxidized, reduced; and neutral chlorins and bacteriochlorins, and dimeric and polymeric species in crystalline or monolayer arrays. They offer the stability and resolution necessary for detailed interpretation that are unavailable from the naturally occurring systems. Much more structural information is needed on currently studied model systems, as well as on new systems in preparation, to fully interpret electron spin resonance (ESR), nuclear magnetic resonance (NMR), resonance Raman spectroscopy, and theoretical calculations of these systems. The techniques used include $x$-ray and neutron diffraction, EXAFS, photo-acoustic, and single crystal micro-spectroscopy.

\author{
56. B IOELECTROCHEMI STRY AND ELECTROCHEMISTRY \\ S. W. Feldberg \\ $3.1 \quad 01-2$
}

The purpose of this research is to study the role of synthetic bilayer lipid membranes (blm) in electron transfer processes. These ultrathin membranes (less than 100 Angstroms thick) can orient and organize reactants. Of particular interest now are studies of blm's containing magnesium etiochlorin or magnesium didodecyl amide ( $R$ ). These membranes facilitate electron transport between aqueous phaşes containjing ferricyanide and ferrocyanide. The system, $\mathrm{Pt} / / \mathrm{Fe}(\mathrm{CN})^{-3}{ }_{24} \mathrm{Fe}(\mathrm{CN})_{6}{ }^{-4} / /$ glycerol monooleate blm, $\mathrm{R}^{+}, \mathrm{R} / / \mathrm{Fe}(\mathrm{CN})_{6}{ }^{-3}, \mathrm{Fe}(\mathrm{CN})_{6}^{24} / / \mathrm{Pt}$, is symmetrical and passes current with the application of a small voltage across the platinum electrodes. Most notable is that the current for a given set of conditions is proportional to the square of the concentration of $R$ in the blm. This observation is consistent with a theory proposed for the electron jump mechanism. The currents observed with the magnesium mesochlorin are comparable to those observed with the magnesium etiochlorin. If the dodecyl tails minimize translocation of the chlorin itself this may be construed as evidence for the electron jump mechanism. 
Department of Energy and Environment, BNL, continued
57. COMBUSTION STUDIES ON ALTERNATIVE FUELS
3.9
$01-2$
R. B. Klemm

Primary emphasis in this program is on the study of chemical kinetic and mechanistic factors involved in the combustion and pollutant formation processes that occur with the use of alternative fuels. The fuels of interest comprise a wide range of fuel types and include: alcohols, synthetic hydrocarbons, and hydrogen; most of which are derived from coal or biomass. Two isolated methods are utilized in this project to determine specific rates for combustion related, elementary reactions, viz., the flash photolysis-resonance fluorescence technique (FP-RF, 200-520 K), and the discharge flow-resonance fluorescence technique (DF-RF, 295-1200* K). Combined, these experimental methods provide an unusually wide temperature span, 200-1200 K, over which to study the kinetics of combustion initiation reactions, and oxidation reactions of combustion intermediates. These two techniques, being substantially different, complement one another and reinforce the validity of the experimental results. Also, the data from these experiments are of significant utility in indirect high temperature studies like ignition lifetimes, flame-probe, and shock-tube experiments. In addition to the elementary reaction kinetic studies, a photoionization mass spectrometer experiment is being developed jointly between the Department of Energy and Environment and the Chemistry Department that will utilize the National Synchrotron Light Source. This apparatus will be employed in this program to examine molecular beams sampled from a low pressure, premixed flame. Concentration profiles for radical and stable flame species will be modeled to provide mechanistic information on high temperature systems. 
Chemical Physics

Energy and Environment Division

Total $\$ 40,000$

Lawrence Berkeley Laboratory

University of California

Berkeley, California 94720

58. UNIMOLECULAR RINETICS

$1.0 \quad 01-2$

N. Brown

This research is concerned with formally extending unimolecular rate theory and applying the theory to important combustion reactions. Three types of reactions successfully treated with unimnlerillar rate theory are diasooiation, recombination, and fsomerization reactions. One or more of these reaction types play a crucial role in combustion initiation, fuel pyrolysis, radical quenching, and pollutant formation or destruction mechanisms. Unimolecular reactions are governed by a complex competition between collisional energy transfer and intramolecular energy redistribution. The kinetics are of the second order type at. low pressure where collisional intermolecular energy transfer is rate controlling, and first order in the high pressure regime which is rate limited by intramolecular energy transfer. Intermolecular and intramolecular processes are coupled in the intermediate "fall-off" regime between the high and low pressure 1 imits. The research has three major objectives. The first of these is to improve the theoretical description of so-called weak collisional effects. This is being achieved using a master equation approach and properly evaluating rotational factors. Second, an improved description of bond fission reactions occurring at or near the high pressure rate coefficients is being obtained. Third, the use of double reduced fall-off curves is being characterized for specified reactions. 
Chemical Physics

Materials and Molecular Research Division

Lawrence Berkeley Laboratory

University of California

Berkeley, California 94.720

59. ENERGY TRANSFER AND STRUCTURAL STUDIES OF MOLECULES ON SURFACES

C. B. Harris
Total $\$ 1,648,000$

2.4

$01-2$

The purpose of this research program is twofold. First, it is to develop new spectroscopic techniques for investigating the electronic and molecular structure of molecules adsorbed on catalytic metal surfaces. Using these techniques, in conjunction with other surface science techniques such as LEED, Auger analysis and others, a variety of problems are being investigated. These include: (a) investigating the changes induced in the molecular and electronic structure of aromatic hydrocarbons upon physiand chemisorption to catalytic metal surfaces, (b) the study of ring cracking reactions of aromatic hydrocarbons on nickel surfaces and the resulting product distributions and finally, (c) the study of the vibrational structure of molecules adsorbed on metal surfaces via laser Raman scattering. The second purpose of the research program is to study how electronic and vibrational energy, once initially deposited into an adsorbed molecule, is redistributed into the metal surface and bulk states as a function of both the character of the molecules and their interaction with the metal surface as well as. the distance away from the surface. The research is essentially experimental in character, aimed at investigating several questions important in surface science on a fundamental level. 
Materials and Molecular Research Division, LBL, continued

60. CROSSED MOLECULAR BEAMS

$3.7 \quad 01-2$

Y. T. Lee

Investigations are underway of the dynamics of elementary atomic and molecular processes and the energetics and the structure of exotic radicals, ions and ion clusters using the crossed molecular beam method. Information on mechanism and dynamics of chemical reactions is obtained from the direct identification and measurements of velocity and angular distributions of product molecules from "single collisions." Significant advancement has been made recently in combustion related elementary reactions. In the reaction of oxygen atomo with bengene; the importance of a substilution channel was elucidafed for the first time. Successful crossed molecular beam studies on $O(D)+H_{2}, D_{2}$ as well as $O(D)+\mathrm{CH}_{4}$ have also been carried nut. The significant and exciting resonance phenomenon in chemical reactions which was predicted in quantum mechanical calculations was observed in the angular distribution of $H F(v=2)$ formed in the $F+H_{2}$ reaction. Using the autoionization process for the preparation of vibrational state selęcted $\mathrm{H}_{2}{ }^{+}$the effect of translational and vibrational energy in $\mathrm{H}_{2}+\mathrm{D}_{2} \rightarrow \mathrm{HD}_{2}+\mathrm{H}$ has been studied in great detail. By using the vibrational predissociation process. the infrared spectrum of isolated water molecule clusters has been obtained in a molecular beam.
61. CHEMICAL DYNAMICS STUDIES
2.2
$01-2$
B. H. Mahan

Derivation of fundamental and practical information about chemical dynamics from the study of collision processes which involve ions, molecules, and photons in the gas phase is underway. Methods of predicting the rates of chemical reactions, energy transfer processes, collisional dissociations, collisional ionizations and charge transfer processes, using as primary information the electronic energy states of the reactants, products and intermediates are being studied. The most recent activities are focused on the investigation of the reagent electronic state dependence iq $\mathrm{N}^{+}+\mathrm{H}_{2} \rightarrow \mathrm{NH}^{+}+\mathrm{H}$. Snme studies have begun on the investigation of $\mathrm{S}^{+}$reactions. To calculate the equilibrium properties of high temperature ionized gases, the electronic states, vibrational frequencies, and geometries of small molecular ions must be known. To acquire this information, a unique apparatus designed to obtain the spectra of mass identified gaseous ions by laser induced fluorescence has been constructed and is bęing operaţed successfully. Spectra obtained most recently include $\mathrm{BrCN}^{+}$and $\mathrm{ClCN}^{+}$Intensive efforts on the investigation of electronic spectra of $\mathrm{H}_{2} \mathrm{O}^{+}$are underway. 
Materials and Molecular Research Division, LBL, continued
62. THEORY OF ATOMIC AND MOLECULAR COLLISION PROCESSES
W. H. Miller

$1.3 \div 01-2$

This research is primarily involved with the development of theoretical methods and models for describing atomic and molecular collision processes. The overall goal is to understand the dynamics of chemical phenomena at a molecular level and may thus be described as "molecular level chemical kinetics". Specific topics of interest include the theory of inelastic and reactive scattering, collision processes involving electronically excited atoms and molecules, collisional ionization phenomena, statistical theories of chemical reactions, scattering of atoms and molecules from surfaces, and the interactions of molecular systems with high power laser radiation. The ability to understand--and thus to model and to predict-chemical kinetic phenomena in the gas phase has widespread practical importance in a number of different areas. Among these are atmospheric chemistry and physics (the upper and the lower atmosphere), the interactions of molecules with strong laser fields, energy transfer and chemical reactions in flames and combustion, similar processes in gas phase chemical lasers, and collision processes important in magnetohydrodynamics.

63. SELECTIVE PHOTOCHEMISTRY
C. B. Moore

The fundamental goals of this program are to understand the photophysics of selective excitation of molecules, the dynamics of energy transfer and specificity 1088 , and the chemical reactions of specifically excited states. For diatomic molecules, it is well known that specific vibrational levels may be laser-excited and that this may enhance the chemical reactivity of the molecule. For large polyatomic molecules, there are many vibrational modes. It has been found that energy flows rapidly among the modes before the molecule undergoes unimolecular reaction and the lowest energy reaction path generally dominates. Mode selectivity is completely lost. Where is the boundary at which loss starts to occur? For how long can selectivity be preserved? Is there a critical molecular size and excitation energy for mode selectivity to disappear? How is this energy flow affected by the environment: gas phase, liquid phase, inert matrices, and on surfaces? Answers to these questions may lead to a whole new class of chemical reactions. CW and pulsed lasers are used for exciting molecules to specific states. The techniques of intracavity dye laser spectroscopy, Fourier transform infrared spectroscopy, gas chromatography and mass spectrometry are used for product analysis. 
Materials and Molecular Research Division, LBL, continued

\author{
64. PHYS ICAL CHEMISTRY WITH EMPHASIS $01-2$ \\ ON THERMODYNAMIC PROPERTIES \\ K. S. Pitzer
}

This program is directed toward the discovery and development of methods for calculation of thermodynamic and related properties of important chemical systems by use of quantum and statistical mechanics together with experimental measurements for key systems. Current efforts include relativistic quantum mechanical methods for the calculation of energies, bond distances, and other properties of the ground and excited states of molecules containing very heavy atoms where the conventional nonrelativistic methods are inadequate. Such results are important in evaluation of possible laser systems and for models of catalytic entities including heavy atoms such as platinum. Another general area is that of the statistical calculation of properties of systems including ions. Earlier theoretical advances on such systems are now being applied in practical thermodynamic work for a wide range of aqueous electrolytes. Current theoretical work is emphasizing exact treatment of dissociation equilibria in a plasma at very high temperature.
65. POTENTIAL ENERGY SURFACES FOR
1.4
$01-2$
CHEMICAL REACTIONS
H. F. Schaefer, III

This research program has two goals, related yet distinct. The first goal is the development of new theoretical and/or computational methods for the description of electrons' behavior in molecules. Specifically, the single outstanding.problem in the field is the correlation problem, that of formulating models for going beyond the single-particle or Hartree-Fock approximation. The second goal of this research is to apply these theoretical methods to significant problems of broad chemical interest. Currently, two areas are of dominant interest: (a) model theoretical studies of organometallic compounds, chemisorption, metal clusters and catalysis, and (b) the potential. energy surfaces which govern gas-phase chemical reactions. Research in the former area is aimed at a truly molecular understanding nf ratalysis, a subject critical to future energy requirements, but sometimes approached by brute force trial and error methods. In the latter area, the present research sometimes tends toward molecules potentially important in the development of high powered laser systems. 
Materials and Molecular Research Division, LBL, continued
66. PHOTOELECTRON SPECTROSCOPY
6.3
$01-2$ D. A. Shirley

Electron spectroscopy is the study of electronic structure of matter. The electronic structure of gas-phase species, including high-temperature species, is determined by the use of pulsed synchrotron radiation, including absorption, fluorescence, and time-of-flight photoelectron spectroscopy. Present experiments are of photoelectron angular distributions and correlationstate studies, and also measurements of radical lifetimes, quantum beats, and energy transfer in excimer systems using pulsed synchrotron radiation. In condensed phases, measurements are made of electronic structure of solids and atomic and electronic structure of surface-absorbate systems, from angle-resolved photoemission. Finally, photoelectron spectroscopy of van der Waals' molecules and other exotic species is planned. Exploration and development of new experimental methods, such as photoelectron diffraction and surface EXAFS, are being pursued based on synchrotron radiation in the energy range 10-1,000 eV.
67. MOLECULAR BEAM SPECTROSCOPY
0.6
$01-2$

$$
\text { J. S. Winn }
$$

This project derives fundamental information on the microscopic physical and chemical properties of metal atoms and small metal clusters. Spectroscopic and kinetic probes of energy states, reaction pathways and fragment geometries are made using a variety of experimental techniques. Reaction chemiluminescence and electronically excited reagent chemistry are studied using optical analysis of flowing afterglow chemiluminescent flames. Total product identification in these flow reactions is effected by mass spectroscopy. These studies are characterized by electric discharge energization of reagents. Thermal initiation at a variety of pressures is studied by molecular beam methods. Adiabatic expansion is being explored as a means of producing increasing concentrations of metal clusters and of monitoring the effect of clustering on product distributions. Product identification and intermediate species characterizations are aided by a combination of electric deflection and electric resonance spectroscopy. Emphasis is placed on the chemistry of transition metal atoms and clusters introduced as metal carbonyls into the gas phase. Reactions of these species at elevated temperatures and in dc electric discharges with saturated and unsaturated hydrocarbons, various oxidants, gaseous hydrogen, and other organometallic compounds are being pursued and compared to solution chemistry and surface chemistry results. 
Chemical Physics

National Resource for Computation in Chemistry

Lawrence Berkeley Laboratory

University of California

Berkeley, California 94720
Total $\$ 813,000$

\section{NATIONAL RESOURCE FOR COMPUTATION}

IN CHEMISTRY
W. A. Lester
8.0
01-2

l'he various functions of the National Resource for Computation in Chemistry (NRCC) may be broadly categorized as education, service, and research. The education function: The NRCC has estahlished a Bulletin to provide current information on all aspects of the NRCC's program, including plans and progress on computer code development. Because the NRCC scientific staff will be dominantly computational chemists, they will often be able to assess readily the value of new algorithm developments for chemistry and communicate their findings to the community in the Bulletin. Workshops will be organized to educate chemists on both the NRCC capabilities and on new developments in computation which have chemical application. The workshops will also serve to identify new applications, areas and extensions of existing program efforts. The service function: As one facet of this function, the NRCC will make documented state-of-the-art versions of general purpose computer programs operational on the NRCC's computers. The majority of chemists will be able to access these programs and run them remotely at the NRCC from their home location or obtain copies of the codes for use at their home installations. NRCC staff members responsible for maintaining this library of programs will serve as consultants in their use. Providing chemists with access to state-of-the-art computational facilities is another important function benefiting from the many useful programs operational on its computers. The research function: Research and development of new computational methods for chemical problems will be accomplished by visiting scientists, postdoctoral fellows, the resident NRCC staff, and non-resident scientists under awards from the NRCC. The goal here is to develop new, more powerful computational algorithms and to make the software based on them available to the larger chemistry community. The staff of the NRCC, in addition to their service functions indicated above, will be active in the forefront of research problems in most subdisciplines of chemistry including chemical kinetics, cryotallography, macromolecular science, non-numerical methods, physical organic chemistry, quantum chemistry, and statistical mechanics. The NRCC is jointly supported by DOE and the NSF. 
Chemical Physics

Chemistry Division

Oak Ridge National Laboratory

Total $\$ 533,000$

P. 0. Box X

Oak Ridge, Tennessee 37830

69. THEORETICAL CHEMISTRY

O. H. Crawford, D. W. Noid

$1.0 \quad 01-2$

This research focuses and stimulates those Laboratory experimental programs which are probing frontier areas of theoretical understanding. Areas currently under investigation include the interactions of accelerated heavy ions channeled through single crystals, complicated vibrations of molecules (termed "ergodic") described by statistical concepts, variational procedures for solving the time-dependent Schrodinger equation to handle chemically reactive collisions, semiclassical atomic and molecular physics, chemical reaction dyanmics, and energy flow within molecules. Recent results have been obtained in a new field of spectroscopy called "resonant coherent excitation of channeled ions." For example, oxygen ions from an accelerator can be channeled through a thin single crystal of silver, causing transitions to be induced in the ions by the periodic field of the crystal rather than a radiation field. To understand the measured energy transitions, a time-dependent effective Hamiltonian theory of channeled ions has been formulated to describe how resonant transitions are induced by coherent interaction with the crystal and how this coherence decays with time. The method formulated may have much more general applicability to problems involving reactions and energy transfer in large molecules. In molecular theory, the significance of ergodic motion in excited molecules is being investigated. These molecules can be intermediates in chenical teactions as well as of spectroscopic interest. Semiclassical and quantum approaches to this frontier problem are under investigation. Particular interest centers on the transition from the quasi-periodic to the ergodic state in the molecular motion and on the energy transfer processes involved. 
Chemistry Division, ORNL, continued
70. ATOMIC AND MOLECULAR
3.5
$01-2$ COLLISION DYNAMICS
S. Datz, H. F. Krause, B. K. Annis

The goal of this program is a fundamental understanding of atomic and molecular collision processes. These include chemical reactivity and intermolecular energy transfer at thermal and epithermal energies; electron transfer at energies of $1-100 \mathrm{eV}$; and electron and penetration phenomena at very high energies. The approach is to study single collision phenomena in atomic and ionic beams using model systems and to apply the information to more general systems and to other problems. Current examples of this approach to thermal processes include the study of reactione of carbon atoms and molecules using molecular beam methods. In the "hot atom" energy region, studies of collisional detachment of $\mathrm{Cl}^{-}$to negative molecular ion resonances are being studied, and collision studies with negative molecular ions found in MHD plasmas will be initiated. Ion channeling is used to study crystal fields, and spectroscopy of fast ions in solids and radiation from lepton channeling is being studied as a possible source of $\mathrm{x}$-radiation.

71. PHOTOCHEMICAL, PYROLYTIC AND

$2.0, \quad 01-2$

REACTIVE INTERMEDIATES BY

ELECTRON SPIN RESONANCE

R. Livingston, H. Zeldes

Chemical free radicals in fluids are being studied by electron spin resonance. Formation by pyrolysis is achieved by heating the pressurized fluid as it slowly flows through the active region of the spectrometer. Temperatures to $560^{\circ} \mathrm{C}$ and pressures to $2000 \mathrm{psi}$ are used. The radicals are highly reactive with lifetimes typically of the orier of 100 microseconds and are observed at steady state concentration. Radicals produced photolytically in liquids are also being studied. Well resolved hyperfine structure is observed which leads to positive identification. Chemical and physical properties of the radicals are measured including concentration, rates of dynamic processes, oquilibria and $i$ he case of pyrolysis, the final chemical products. Benzylic radicals which are relevant to the chemistry of coal conversion and the combustion of aromatic fuels are now under most intensive study. Radicals are formed with the aid of initiators and by thermal decomposition of suitable aromatic hydrocarbons. 
Chemical Physics

Combustion Sciences Department

Total $\$ 1,237,000$

Sandia Laboratories-Livermore

Livermore, California 94550

72. COMBUSTION ANALYSIS BY ADVANCED

6.5

$01-2$ METHODS

M. A: Gusinow, D. R. Hardesty

The primary goal of the present research is the utilization of laser spectroscopic techniques for studying the chemistry of combustion-related reacting systems with special emphasis on soot formation mechanisms, nitrogen chemistry and turbulent combustion. Measurements of minor species by laser induced fluorescence/absorption are being conducted with an eye to elucidating pertinent radical chemistry (e.g., OH and $\left.\mathrm{NH}_{2}\right)$. Raman spectroscopy of $\mathrm{CO}_{2}$ and $\mathrm{H}_{2} \mathrm{O}$ with comparisons to theory is underway, and this technique is being applied to a detailed study of a co $+\mathrm{H}_{2}$ flame. Detailed modeling of the $\mathrm{NH}_{3} / \mathrm{O}_{2} / \mathrm{NO}$ system is ongoing and ${ }^{2}$ is being compared to experiment. A considerable emphasis is being given to turbulent diffusion flame studies and the measurement of mean and fluctuating values of velocity, temperature, and-major species concentrations. The techniques being used are Rayleigh and Raman scattering along. with two-component laser velocimetry

73. CRF PLANNING, DEVELOPMENT

$3.5 \quad 01-2$

AND OPERATION

J. Marion, E. Jones

This activity includes the planning, developing and operation of the Combuotion Rcocarch Facility at Sandia in Livermore. The pregent effort is focused on management of the construction project, planning for occupancy, development of the necessary diagnostic and support equipment and describing the procedures for user access. The facility will open in late FY 80 and will provide state-of-the-art combustion research laboratories to outside users. Combustion diagnostics will be emphasized and a wide range of laser capabilities will be available. In addition, CRF will contain advanced burner facilities and other combustion devices plus a powerful computer capability that will allow for a strong interaction between experiment and modeling. As indicated below, CRF will also house in-house combustion research that will complement and interact with user activities. 
Combustion Sciences Department, Sandia-Livermore, continued

74. COMBUSTION DIAGNOSTICS RESEARCH

$5.5 \quad 01-2$

M. A. Gusinow, P. Mattern

This work emphasizes the development of new techniques and the application of more classical approaches, such as spontaneous Raman scattering and analytical spectroscopy, for the study of combustion. The present studies are concerned with evaluating the utility of optical spectroscopy such as polarization CARS and stimulated Raman spectroscopy to the measurement of primary and trace species in reacting systems. Basic studies (both experimental and theoretical) are being conducted on the effect of rotation-vibration interaction on line intensities for Raman and fluorescence spectroscopy. Because of the importance of radical chemistry, experiments are being built up utilizing field-gradient ESR and time-resolved mass spectrometry coupled with laser pumping of specific reactants. 
Atomic Physics

Physics Division

Argonne National Laboratory

Total $\$ 1,350,000$

9700 South Cass Avenue

Argonne, Illinois 60439

75. PHOTOIONIZATION-PHOTOELECTRON
RESEARCH
J. Berkowitz, J. H. D. Eland

Studies of photoionization processes in this program involve fixed-wavelength photoelectron spectroscopy, photoion-photoelectron coincidence spectroscopy and variable-wavelength photoionization mass spectrometry. The measurement of photoelectron spectra of involatile materials.includes a study of rather complex systems, including the phthalocyanines, trinuclear metal complexes and sulfur nitrides. The results already obtained on the phthalocyanines, molecules related to the biologically important chlorophyll and heme groups, reveal that the metal d-orbitals lie deeper than the outermost ligand orbitals, contrary to earlier views. A new apparatus, which increases the accessible temperature range, incorporates a double oven and enables measurement of the angular distribution of photoelectrons. Initial results on the photoelectron spectra of lithium-halide monomers and dimers, silver halide monomers and trimers, and atomic iodine are highly encouraging. Coincidence experiments use a new technique to substantially improve energy and mass resolution, compared with earlier. work. They reveal angular effects in molecular ion decompositions which can be related to photoelectron angular distributions from oriented molecules. In recent studies with variable-wavelength photoionization mass spectrometry, measurements have been made of the ionization potential of $U F_{6}$ and the appearance potentials of its fragment ions and the ionization thresholds for lithium halide monomers, dimers, and trimers. 
Physics Division, ANL, continued
76. BEAM-FOIL RESEARCH AND COLLISION
2.1
01-3
DYNAMICS OF HEAVY IONS
H. G. Berry

Precision wavelength measurements are being made on radiation emitted by highly stripped ions of two and three electrons in order to test basic atomic calculations of relativistic and quantum-electrodynamic effects. Using fast ion beams excited by thin carbon foils, wavelength accuracies of $15 \mathrm{ppm}$ are achieved. Further tests of many-electron relativistic calculations are made through decay-time measurements of both three electron systems, and in one-electron-like systems of heavy ions (e.g., Kr VIII). In atomic collision studies, systematic meassurement $̧$ have been made of the alignment and orientation produced in $n,{ }_{P}$ and ${ }^{2}{ }_{D}$ states of HeI $(n=3-8)$ as functions of beam energy and exciter-foil tilt angle, with initial interpretations in terms of the secondary electron flux, and the dipole interaction beţween the solid and the projectile. Charge-changing cross sections for $\mathrm{Xe}^{+}(25-100 \mathrm{keV})$ on neutral xenon gas have also been measured.

77. HIGH-RESOLUTION SPECTROSCOPY WITH

$3.5 \quad 01-3$

TUNABLE LASERS AND ATOMIC BEAMS

W. J. Childs, L. S. Goodman, S. A. Lee

A new atomic-beam apparatus is used for laser fluorescence studies of atoms. In addition to very high-resolution Doppler-free spectroscopy, it is designed for ultrahigh precision laser-rf double resonance studies of hyperfine structure ( $h f s$ ) and represents a significant advance, particularly in linewidth, for studies of excited metastable atomic levels. The apparatus is used to study $h f s$ and isotope shifts for a variety of elements including $\mathrm{Sm}, \mathrm{La}, \mathrm{Tb}, \mathrm{V}$, and $\mathrm{U}$ and the tremendous potential of the new method for yielding information of importance for atomi 3 tructure theory has been conclusively demonstrated. The results for ${ }^{23} \mathrm{U}$ are 10,000 times more precise than the best previous work, and in addition to their value for the understanding of the atomic structure of uranium, may well be of great importance for laser isotope separation of atomic liranium. New experiments on the absorption of very highly excited atoms in intense ( $50 \mathrm{kG}$ ) crossed magnetic and electric fields, measurement of the Lamb shift in the $n=2$ levels of singly-ionized lithium, and studies of hfs and isotope shifts in highly excited, non-Rydberg atomic levels are being carried out. 
Physics Division, ANL, continued

78. DISSOCIATION AND OTHER INTERACTIONS

$5.1 \quad 01-3$

OF ENERGETIC MOLECULAR IONS IN SOLID

AND GASEOUS TARGETS

D. S. Gemme11

Argonne's 4-MV Dynamitron accelerator is used to study the interactions of fast (MeV) molecular ions with matter. A unique feature of the apparatus is the exceptionally high resolution $\left(\sim 0.005^{\circ}\right.$ and $\left.\sim 300 \mathrm{eV}\right)$ in angle and energy obtained in measuring dissociation fragments. The apparatus has recently been modified to permit the detection of fragments in coincidence. The work has two main objectives: (a) a general study of the interactions of fast charged particles with matter, but with the emphasis on those aspects that take advantage of the unique features inherent in employing molecular-ion beams (e.g., the feature that each molecular ion incident. upon a solid target forms a tight cluster of atomic ions that remain correlated in space and time as they progress through the target) and (b) a study of the structures of the molecular ions that constitute the incident beams. Precise measurements on the energies and angles of the breakup fragments produced when fast molecular ions dissociate in foils and gases offer exciting possibilities as a new method for determining molecular-ion structures.

79. INTERACTION OF ENERGETIC PARTICLES
WITH SOLIDS
M. S. Kaminsky

Studies are being conducted to determine how certain fundamental atomic processes occurring at solid interfaces (e.g., ion/atom scattering, atom/ molecule release by sputtering, blistering, secondary ion emission, and the energy loss and charge states of particles penetrating through lattices) are influenced by the degree of lattice damage, the gas concentration, buifdup in lattices due to trapping of the incident ions (e.g., H $\mathrm{H}^{+} \mathrm{D}^{+}$, ${ }^{4} \mathrm{He}^{+}$), and to chemical changes (e.g., formation of metal hydrides). with a transverse sectioning technique of irradiated samples which has been developed, the development of gas bubbles over the entire implant region of nickel irradiated with energetic helium ions is observed with transmission electron microscopy with a high depth resolution of $250 \AA$. With depth profile measurements of implanted helium (Rutherford backscattering technique, elastic recoil technique) it has been established that in the region of maximum gas implant, gas bubble density is so high that development and propagation of recoil lattice atom collision cascades is severely hindered. The influence of these effects on several of the atomic processes mentioned above is currently being studied. Information of this type for light-ion bombardment of solids is of oignificant importance for a better understanding of atomic collision processes and for practical applications such as fusion plasma impurity control and accelerator technology. 
Physics Division, ANL, continued

80. MÖSSBAUER EFFECT RESEARCH G. J. Perlow, J. E. Monahan

$1.0 \quad 01-3$

The major effort is devoted to experiments and theory concerning quantum beats of recoil-free $\gamma$ rays. They are an interference phenomenon among the energy components of the radiation-field amplitude produced by frequency modulation of a Mössbauer source. The interference exactly vanishes except when radiation passes through a resonant absorber which alters the phase and amplitude of one or more of the components. It is manifested in a time spectrum of the counting rate of the transmitted radiation. A harmonic analysis of the time spectrum shows the harmonic amplitudes to be very sensitive to small energy shifts between source and absorber. In measurements of the relativistic second-order Doppler shift in a resonant absorber whose temperature is varied, shifts corresponding to changes of about $2 \mathrm{~K}$ in temperature are observed. A theory of the process using the optical theory of the resonant media describes both the beats and an interesting dispersion phenomenon seen when Mössbauer velocity spectra are taken with counts received during some restricted phase interval of the modulation cycle.
81. MONOCHROMATIC X-RAY BEAM PROJECT
0.8
$01-3$
S. L. Ruby

The purpose of this program is to verify experimentally some of the newly predicted phenomena associated with nuclear-resonant Bragg acattering of $x$-rays, and then to use them to produce highly directional and monochromatic $x$-ray beams by selective reflection of synchrotron radiation. The frequency spread is expected to be six orders of magnitude sharper than ${ }_{7}$ any existing beam. Such beams would have angular divergence less than $10^{-7}$ steradian and a coherence length of some 10 meters, making it possible to extend into the $x$-ray region the techniques which the laser has brought to visible light-namely, long-path-length interferometry, and eventually holography. Initial experiments with the best available ${ }^{3} \mathrm{Fe}$-containing crystal reflectors (14-keV resonance) gave negative results due to unexpectedly large concentration gradients of the silicon with which the iron had to be prepared. New approaches to the achievement of monochromatic $x$-ray beams are being otudied. 
Atomic Physics

Physics Department

Brookhaven National Laboratory

Upton, New York 11973
Total $\$ 98,000$

\section{ATOMIC PHYSICS RESEARCH}

K. W. Jones
$2.3 \quad 01-3$

A variety of heavy ion beams, with energies in the range 20-250 MeV, from the Brookhaven Tandem Van de Graaff facility are used for experiments in beam-foil spectroscopy, $x$-ray production in heavy ion-atom collisions, and electron-heavy ion excitation and ionization cross sections. Beam-foil experiments concentrate on measurements of the charge state dependence of spectra in the region from 5 to $50 \mathrm{~nm}$ for $\mathrm{Ti}, \mathrm{Fe}$, and Mo and on lifetimes of resonance transitions in the $\mathrm{Be}-, \mathrm{Na}-, \mathrm{Cu}$ - and $\mathrm{Zn}-1$ ike sequences. Mechanisms for producing $x$-rays in heavy ion-atom collisions are inferred from measurements of total x-ray production cross sections and the impact parameter dependence of the cross sections. Apparatus for measurement of excitation and ionization cross sections in a crossed electron-heavy ion beam experiment is under construction. Results obtained should be useful for the design of Tokamak fusion devices and in the interpretation of the radiation observed from them, as well as for the development of atomic theory. Experiments to extend this work to include the excitation and ionization of highly-ionized heavy atoms from an electron-beam ion source, by photons from the National Synchrotron Light Source (NSLS), are now being designed. High intensity photon beams from the NSLS will make possible a wide array of experiments in atomic physics. 
Atomic Physics

Materials and Molecular Research Division Lawrence Berkeley Laboratory

University of California

Berkeley, California 94720
Total $\$ 372,000$

4.0

$01-3$

83. ATOMIC PHYSICS

R. Marrus

This research is concerned with the experimental study of collisions and spectroscopy in simple atomic systems. Three major investigations are being pursued: (1) using highly-strlpped heavy-ion beams produced by the LBL Super-HILAC, charge-changing cross-sections of ions to $8.5 \mathrm{MeV} / \mathrm{amu}$ and $\mathrm{Z}=92$, and electron capture to the continuum are currently under study. Spectroscopic studies of strong UV transitions from low-1ying states of heavy ions in the heliumlike, lithiumlike, and berylliumlike sequences are also in progress. Particular emphasis is placed upon elements important to the development of fusion energy. 
Atomic Physics

Materials and Molecular Research Division, LBL, continued

84. LOW ENERGY ATOMIC PHYSICS

3.3

01-3

H. A. Shugart

The basic purpose of this research is to study: (1) atoms, molecules and ions using lasers, ion traps and beam techniques; (2) ultraviolet laser development in conjunction with a spectroscopic search for an important possible influence of a weak neutral electron-nucleus interaction in atomic physics; (3) development of simple universal optical methods for detecting trace atoms or molecules using coherent forward scattering; and (4) invention of a purely electrostatic ion trap with possible use for residual gas analysis, vacuum leak detection, precision spectroscopy, cross-section and ion-molecule reaction studies. 
Atomic Physics

P Division

Total $\$ 72000$

Los Alamos Scientific Laboratory

University of California

P. O. Box 1663

Los Alamos, New Mexico 87545

85. THE HIGH DENSITY Z PINCH: DIAGNOSTICS

$1.0 \quad 01-3$

AND ATOMIC PHYSICS

L. A. Jones, D. B. Thomson

The High Density Z-Pinch experiment represents an attempt to create a hot, dense plasma in a geometry suffictently simple that it facllitates a comparison between the observed plasma parameters and those predicted by sophisticated MHD multi-dimensional codes being developed. With this research tool, studies are planned on the energy levels, radiation rates, and Stark broadening effects in partially lonized atoms in a medium similar to that encountered in MFE reactors. Two new diagnostics are being deployed: a time and spatially resolved interferometric holographic apparatus to measure electron density, and a visible light line spectrum apparatus to obtain time resolved electron temperature and density. These diagnostics are essential to the study of the physics of partially ionized atoms. The Z-pinch device has been built and placed into operation. A Nd:glass laser is being used to initiate discharges in 1 atm of hydrogen at $270 \mathrm{kV}$ which result in plasma columns about $1 / 4 \mathrm{~mm}$ in diameter and which carry about $350 \mathrm{kA}$. The discharge channel diameter grows at an expansion velocity of about $4 \mathrm{~cm} / \mathrm{sec}$; the discharge is stable against sausage and gross kink instabilities but becomes unstable via the internal kink mode. These results are presently being compared with the predictions of MHD calculation. 
Atomic Physics

Physics Division

Total $\$ 866,000$

Oak Ridge National Laboratory

P. 0. Box X

Oak Ridge, Tennessee 37830

86. THEORETICAL ATOMIC PHYS ICS

1.3

01-3

R. L. Becker, C. Bottcher

Theoretical models and detailed calculations are being made for atomic collision and radiation processes, primarily those under experimental investigation at ORNL in the fusion energy and heavy-ion accelerator programs. Ionization and electron capture in atomic hydrogen by energetic highly stripped ions, important sources of energy $108 s$ in plasmas containing impurity ions, are calculated by classical trajectory Monte Carlo and by quantum mechanical coupled-channel methods. Inner-shell vacancy production in atoms such $a \$_{6} \mathrm{C}$, $\mathrm{Ne}, \mathrm{Ar}$, and $\mathrm{Cu}$ induced by light fully stripped ions (e.g., $\mathrm{p}, \alpha, \mathrm{C}^{+6}, \mathrm{O}^{78}$ ) are calculated in a coupledchannels formulation which includes multi-electron processes and provides differential cross sections. The characterization of autoionizing states of ions as a function of atomic number and ionic charge is underway and is being applied to electron impact ionization, dielectronic recombination and charge transfer to the continuum (forward-ejected-electron spectroscopy). The effect of magnetic and electric fields on recombination rates is being calculated. Generalization of the coupled Bloch equations to cover "doubleresonance" is being made to provide a realistic quantum-optical description of coherent pumping of continum and autoionizing states by. multi-photon processes. Successive transitions within a vibrational ladder and relaxation processes are being investigated. 
Physics Division, ORNL, continued

87. MOLECULAR RESEARCH WITH

2.0

01-3 ELECTRON SPECTROSCOPY

T. A. Carlson, M. O. Krause

Use is being made of angle resolved photoelectron spectroscopy to study the nature of photoionization processes for atoms and molecules. Data are being taken on atoms, free gas molecules and molecules oriented on surfaces. Theoretical calculations, parallel to the experimental program are being performed to test concepts of molecular photoionization. It is planned to extend expcrimentation to the use of synchrotron radiation.

Out of these studies should emerge a basis for understanding the dynamics of the photoionization process and lhe nature of the electronic structure of atoms and molecules, including the following: (1) the characterization of molecular wave functions by a more critical method than using energies alone; (2) a test for the electron correlation contribution to the dynamics of the photoelectron effect; and (3) an important advance in the determination of the nature of surface adsorption of molecules related to heterogeneous catalysis.

88. COLLISION OF LOW-ENERGY
MULTICHARGED IONS
D. H. Crandall, C. F. Barnett

The ORNL source of low velocity, multicharged ions is being used to study two types of atomic collisions in regimes not previously accessible. Electron capture by multicharged ions from atomic hydrogen and electron impact excitation and ionization of multicharged ions are being studied. Electron capture is least understood and has the largest cross secfions for multicharged ions and neutral atoms at velocities below $2 \times 10^{8}$ $\mathrm{cm} / \mathrm{s}$, accessible with the ORNL source. A number of cross sections have been megsured and some trends established. Studies at very low velocities $\left(v<10^{7} \mathrm{~cm} / \mathrm{s}\right)$ appear most interesting, and experiments using merged beams to attain the lower relative velocities are planned. The electron impact excitation and ionization measurements have, to date, ohown better agreement with theory than was anticipated. However, only a few electronic configurations have been tested. An important effect has been identified in that inner-shell excitation followed by autoionization was found to contribute significantly to total ionization cross sections in some cases. The relative intensity of this contribution is sensitive to electronic configuration. Further testing of this effect and its importance in high temperature plasmas is planned. 
Physics Division, ORNL, continued

89. MERGED ELECTRON HEAVY ION BEAMS

$2.0 \quad 01-3$

W. B. Dress, P. F. Dittner

This project provides a means for study of recombination and ionization processes involving electrons and ions. The detalls of dielectronic recombination are the first goals of the investigation. An apparatus based on a focused electron beam concentric with an ion beam from the ORNL EN-tandem is nearing completion. All components are completed, and sections have been aligned and vacuum tested. The final assembly is to be completed with a test of the electron gun at ultra-high vacuum. Calibration of the overall device is to take place with both hellum and nitrogen beams where the relevant charge-exchange cross sections are we11-known. Ionic species of immediate interest include both the lighter lons (down to lithium) where the quantum-mechanical details of recombination should be resolvable, as well as heavier species such as iron and chromium which are of practical interest to the mechanisms of plasma energy loss.

90. ACCELERATOR ATOMIC PHYS ICS

$3.3 \quad 01-3$

P. D. Miller, C. D. Moak,

P. M. Griffin

This research effort is concerned with achieving a detailed understanding of the interactions of hlyh energy heavy ions with gas, solid, and electron targets. Many activities are collaborative efforts with members of the Chemistry Solid State, and Health and Safety Research Divisions of ORNL as well as visiting faculty from several universities. Examples of activities which are currently being pursued are: 1) Resonant coherent excitation of one- and Lwu-electron ione in the range horon to fluorine in axial and planar channels in gold single crystals is being investigated. The velocity dependence of the excitation is being used to probe static and dynamic fields operating on the ions as they pass through various crystal channels. 2) Electron capture and loss to projectile continuum states are being investigated. In particular, the forward electron peak, including both continum and discrete resonant contributions, is being observed in coincidence with each of the projectiles' final charge states. These spectra contain a great deal of information on strengths of the various multiple electron excitation channels which operate when, for example carbon and oxygen ions interact with. gas atoms. Other areas of investigation include: 3) Multiple electron loss cross sections; 4) Radiative electron capture, and stopping powers in channels; 5) The effect of chemical environment on $x$-ray satellite spectra; 6) The effect of multiple ionization on Coster-Kronig transitions which affect L-x-ray relative intensities; and 7) Profiling depth distributions of hydrogen in coal, glass, minerals, and stainless steels. 
Physics Division, ORNL, continued

91. EN TANDEM OPERATIONS

This facility is operated for atomic physics research investigating channeling, solid state material damage, electron ejection and capture from ion-atom collisions, and collisional phenomena with merged beams. Ion source development to increase the variety of heavy ions available also continues. 
Atomic Physics

Department 4210

Sandia Laboratories--Albuquerque

Total $\$ 118,000$

P. 0. Box 5800

Albuquerque, New Mexico 87115

92. MHD ATOMIC PROCESSES

$1.7 \quad 01-3$

A. W. Johnson

Relative transition probabilities are being measured for the ns-4p ( $n=$ 6-15), nd-4p $(n=5-13)$ and $n f-3 d(n=7-14)$ lines of neutral potassium. The measurements are made in an argon plasmajet containing about 3 mole percent potassium atoms. The prevaifing $f-\gamma e e-s y s t e m$ plasma conditions are $\mathrm{P} \sim 11$ Torr, $\mathrm{T} \sim 3300 \mathrm{~K}$, and $\mathrm{n} \sim 2 \times 10^{14} \mathrm{~cm}^{-3}$. The relative A-value accuracy is estimated to be ${ }^{e_{5}-10 \%}$. These relative transition strengths provide a means for improving the accuracy of optical measurements of electron temperatures in MHD channels. In an associated study, nonlinear laser spectroscopy is being used to measure pressure and Stark broadening and shift coefficients for several of the same potassium lines. A knowledge of these coefficients will allow accurate spatially resolved optical measurements of the electron density in MHD channels. The measured electron temperatures and densities will validate discharge models of the plasma. 
Chemical Energy

Ames Laboratory

Iowa State UnIversity

Ames, Iowa 50011
Total $\$ 445,000$

1.79

$02-1$

93. ORGANOMETALLIC COMPLEXES IN HOMOGENEOUS CATALYS IS

R. J. Angelici

The purpose of this research is to prepare and study organometallic complexes which contain highly reactive 11 gands which are belleved to be involved in catalytic reactions, including the Fischer-Tropsch reaction. The commonly postulated carbene ligand is one which can be incorporated into stable iron complexes in the following forms: $\mathrm{Fe}=\mathrm{C}\left(\mathrm{OCH}_{3}\right)_{2}$, $\mathrm{Fe}=\mathrm{C}\left(\mathrm{SCH}_{3}\right)_{2}$, and $\mathrm{Fe}=\mathrm{C}\left(\mathrm{OCH}_{3}\right)\left(\mathrm{SCH}_{3}\right)$. These carbenes are_hlghly 2 reactive toward nucleophilic groups such 28 amines, $\mathrm{OH}^{-}$and $\mathrm{H}^{-}$. Such reactions have led to the formation of still other types of carbene complexes. It 18 hoped that the reactions of these derivatives with $\mathrm{H}_{2}$ and $\mathrm{CO}$ will reveal information concerning the mechanism of the Fischer-Tropsch reaction and lead to a more desirable distribution of products in that reaction.

94. CHEMICAL KINETICS AND REACTIVITY OF TRANSITION METAL COMPLEXES

J. H. Espenson

This program involves the study of organometallic complexes of transition metals, especially monoalkyl derivatives such as $\left(\mathrm{H}_{2} \mathrm{O}\right)_{5} \mathrm{Cr}-\mathrm{R}^{2 t}$, $\mathrm{R}-\mathrm{Co}(\mathrm{dm} g \mathrm{H}){ }_{2} \mathrm{~B}$, and $\mathrm{R}-\mathrm{Rh}(\mathrm{dmgH}){ }_{2} \mathrm{~B}$. The chemical efforts consist of studies of the chemical kinetics and reaction mechanisms of selected reactions. Effort is focused on reactions in which a metal-carbon bond 18 formed or broken, or In which transformations or rearrangements of the organic group, $R$, occur. Included in this work are studies of nrgannmetallics which may represent classes of compounds thought to be important in Fischer-Tropsch reactions. Considerable effort has been devoted to the study of $\alpha$-hydroxymethyl, $M-\mathrm{CH}_{2} \mathrm{OH}$, and $\alpha$-hyd roxyalkyl, $M-C\left(R, R^{\prime}\right) . \mathrm{OH}$, compounds. The casu of further reaction as a function of the nature of $M$ and of external reagents 18 of particular concern. 
Ames Laboratory, cont inued

95. NUCLEAR MAGNETIC RESONANCE (NMR)

Solid state techniques in NMR are being used to infer chemical structures in coals, and to characterize surfaces and surface adsorbed molecules involved in hydrogen transfer reactions. Work on coals includes inferring pyerage sizes of polynuclear aromatic rings via high resolution ${ }^{H}$ and IC NMR of solid coals. Evaluation of the results and conclusions is done in part via F.T.I.R. spectra obtained on coals shared with other laboratories. Of particular interest are determinations of diffusion constants of molecules such as $\mathrm{NH}_{3}$, tetralin, and decal in in selected coals. Work on surfaces includes? (1) measurement of diffusion of hydrogen in the hydrogenation catalyst $\mathrm{H}_{1} 65^{\mathrm{MoO}} 3$ in order to identify the rate spillover, (2) investigation of the environment of protons in $\mathrm{H} \mathrm{MoO}_{3}$ and the Ziegler catalysts $\mathrm{ZrXH}(\mathrm{X}=\mathrm{C} 1, \mathrm{Br} \text {, and } \mathrm{y}=1 \text {, and } 0.5)^{\mathrm{x}}$ by high resolution solid state NMR, 3) ${ }^{y}$ characterization of methanation catalysts formed by selective polymerizafion of $\mathrm{Pt}$ Rh cluster complexes via high resolution solid state NMR of ${ }^{3} \mathrm{C}$ in these compounds and (4) characterization of CO chemisorbed in zeolites in which catalytically active centers such as $\mathrm{Ag}$ have been deposited.

96. PROPERTIES OF RARE EARTH

0.5

$02-1$

ELECTROT.YTES

F. H. Spedding

Work is being carried out on aqueous solutions of rare earth salts, with the goal of understanding the structure of the solutions and the degree of hydration of the metal ion. Toward these ends, several aspects are bcing investigated: (1) isopiestic data to determine activity coefficients for aqueous rare earth nitrates; (2) 1 iquid $X$-ray diffraction studies of dilute rare earth chloride solutions; (3) Raman spectra of rare earth chloride solutions; and (4) Raman spectra of solids, especially low-frequency excitations in solids such as $\mathrm{HoF}_{3}{ }^{\circ}$ 
Ames Laboratory, continued

97. THERMOCHEMICAL CYCLES FOR THE PRODUCTION OF HYDROGEN FROM WATER

D. L. Ul richson

The reaction characteristics of the reverse Deacon reaction $\left(\mathrm{Cl}_{2}+\mathrm{H}_{2} \mathrm{O} \rightarrow\right.$ $2 \mathrm{HCl}+1 / 2 \mathrm{O}_{2}$ ) are being studied to determine optimum design palameters for commercial operation. This reaction has been proposed for use in several thermochemical hydrogen production cycles but the rate of reaction, the reaction mechanism and the need for catalysts have not been assessed. A plug flow reactor is being used to measure the reaction rate and determine the kinetic order. Preliminary analysis of the data suggests that the reaction is first order with respect to chlorine concentration and independent of water concentration for temperatures between $500^{\circ} \mathrm{C}$ and $700^{\circ} \mathrm{C}$. Residence times between 3 and 8 seconds give conversions of chlorine between 5 and 50 percent depending on the water to chlorine ratio. Rare earth chlorides are being tested as catalysts. 
Chemical Energy

Chemistry Division

Argonne National Laboratory

9700 South Cass Avenue

Argonne, Illinois 60439
Total $\$ 744,000$

\section{INORGANIC CHEMISTRY}

E. H. Appelman, J. G. Malm, L. Stein

This program concentrates on the chemistry of fluorine, reactive fluorides, and compounds derived from them. This effort involves searching for and characterizing new and unusual inorganic oxidants and fluorinating agents in order to explore their chemical behavior, and to identify promising applications of these new substances to other areas of science and technology. Major current areas of investigation are: (1) reaction of fluorine and reactive fluorine compounds with aqueous solutions; (2) reaction of powerful oxidants and fluorinating agents with organic compounds; (3) new aspects of noble gas chemistry and applications to the development of chemical methods of collection of noble gases; and (4) studies of unusual chemistry in anhydrous HF, particularly involving uranium fluorides. Of particular current interest are studies of the chemistry of two newly discovered species, the fluoroxysulfate ion, $\mathrm{SO}_{4} \mathrm{~F}^{-}$, and the dixenon cation, $\mathrm{Xe}_{2}^{+}$. 
Chemistry Division, ANL, continued

99. THERMOCHEMICAL GENERATION OF HYDROGEN

E. H. Appelman, F. Schreiner

This program is directed to the development of a set of chemical reactions that can use reactor heat to dissociate water into hydrogen and oxygen. Such a system offers an alternative to the present technology by which heat is used to generate electricity, which can then produce hydrogen by electrolysis. The work is aimed at establishing the feasibility of a particular baseline cycle ("ANL-4"), which consists of the sequence of reactions :

$$
\begin{aligned}
2 \mathrm{NH}_{3}+2 \mathrm{CO}_{2}+2 \mathrm{H}_{2} \mathrm{O}+2 \mathrm{KI} & \frac{\text { ambient temp }}{\text { in solution }} 2 \mathrm{KHCO}_{3}+2 \mathrm{NH}_{4} \mathrm{I} \\
& 2 \mathrm{KHCO}_{3} \stackrel{425 \mathrm{~K}}{\longrightarrow} \cdot \mathrm{K}_{2} \mathrm{CO}_{3}+\mathrm{H}_{2} \mathrm{O}+\mathrm{CO}_{2} ; \\
\mathrm{Hg} & +2 \mathrm{NH}_{4} \mathrm{I} \stackrel{700 \mathrm{~K}}{\longrightarrow} \mathrm{HgI}_{2}+2 \mathrm{NH}_{3}+\mathrm{H}_{2} ; \\
\mathrm{HgI}_{2} & +\mathrm{K}_{2} \mathrm{CO}_{3} \stackrel{100 \mathrm{~K}}{\longrightarrow} \mathrm{Hg}+2 \mathrm{KI}+\mathrm{CO}_{2}+1 / 2 \mathrm{O}_{2} .
\end{aligned}
$$

The sum of these four reactions is readily seen to be the splitting of a mole of water. All of these reactions proceed as written under practical conditions and without significant side reactions, and an overall flow scheme has been prepared for the cycle as a prartical process. Modifications of the cycle are being investigated to improve its efficiency. 
Chemistry Division, ANL, continued

100. THE CHEMICAL NATURE OF COALS

$3.6 \quad 02-1$

M. H. Stud Ier, R. Hayatsu, R. E. Wịnans

Coals are exceedingly complex systems consisting chiefly of organic macromolecular materials with lesser amounts of simpler organic compounds trapped within the coal lattice admixed with inorganic mineral matter. Hundreds of trapped compounds are separated from the macromolecular material by vacuum distillation and solvent extraction and identified by mass spectrometry (MS) combined with gas chromatography (GC). The macromolecular material is cleaved by a variety of reagents and catalysts Into smaller units more readily identified by GCMS. In this manner a large number of aromatic and heteroaromatic units indigenous to coals are being identified. Information is being obtained about cross-1inks between aromatic units, occurrence of functional groups, and structural changes which take place during coalification. To correlate the abundance of data obtalned, a chemical sequence is being developed for the conversion of biological materials to peat $\rightarrow$ humus $\rightarrow$ ignite $\rightarrow$ bituminous coal $\rightarrow$ anthracite during the coalification process. Information is being obtained on the role played by 11 gnin during the coalification process. This information bears on the chemical structures of petroleum, shale o1ls and Fischer-Tropsch products. Such a framework will be useful for systematizing fundamental Information on fossil energy sources and for designing conversion processes for gasification, liquefaction or production of chemical feedstocks. For example, investigation of the solubilization of coals with KOH in glycols at low temperatures shows that reduction of aromaticity during the process is due to saturation of the polycyclic aromatic rings and not sulvenl addllión unly. 
Chemical Energy

Chemical Engineering Division

Total $\$ 220,000$

Argonne National Laboratory

9700 South Cass Avenue

Argonne, Illinois 60439

101. FLUID CATALYSIS

3.1

$02-1$

H. M. Feder, J. Rathke

This research attempts to illuminate the paths whereby dissolved organotransition metal catalysts under high-temperature and high-pressure conditions activate various small molecules and direct their subsequent reactions toward specific products. Intimate details connecting the molecular and electronic structures of the catalysts, the nature of intermediate species, and the thermochemical parameters of each reaction step are sought by a combination of chemical kinetics, spectroscopic, and isotopic studies. Because the reactions, either novel or well-known, often have important actual or potential significance for industrial processes for synthetic fuel conversion, energy storage, or chemical feedstock manufacture, a second part of this research is devoted to investigation of new modalities for the employment of homogeneous catalysts. These modalities include partition between immiscible liquid phases, incorporation into surface-active molecules, and immobilization on solids. 
Chemical Energy

Bartlesville Energy Technology Center

P. 0. Box 1398

Bartlesville, Ok1 ahoma 74003

Total $\$ 152,000$

102. THERMODYNAMIC CHARACTERIZATION OF CONDE NSED-RING COMPOUNDS

N. K. Smith, B. E. Gammon,

D. W. Scott

Research is in progress on the thermodynamic properties of the polynuclear aromatic hydrocarbons and their hydrogenation and cracking products. Present attention is focused on the properties of two families of compounds, the phenanthrenes and anthracenes and their derivatives, compounds that occur in very significant quantities in the products of coal liquefaction. The synthesis and purification of four-ring compounds that must necessarily precede thermodynamic study are also in progress at Oklahoma State University. Receiving lesser attention at present are synthesis and purification of condensed-ring compounds containing the hetero-atoms nitrogen and sulfur, compounds also important in coal and shale processing. 
Chemical Energy

Chem1stry Department

Total $\$ 460,000$

Brookhaven National Laboratory

Upton, New York 11973

103. CHEMISTRY OF ORGANOMETALLIC

.25

$02-1$

COMPLEXES RELATED TO

HOMOGENEOUS CATALYS IS

M. Andrews

A number of transition metal carbonyl complexca can serve as homogeneous catalysts for the water gas shift reaction under basic conditions, presumably via an intermediate metal carboxy complex. This new program, started late in FY 1979, includes the synthesis, chemistry, and structure of $\left(\mathrm{C}_{5} \mathrm{H}_{5}\right) \operatorname{Re}(\mathrm{CO})(\mathrm{NO})\left(\mathrm{CO}_{2} \mathrm{H}\right)$, one of the few known isolable metal

carboxy complexes. This work is providing insights into the probable mechanism of the metal carbonyl-catalyzed water gas shift reaction and should therefore facilitate the design of an optimal catalyst. In addition, new lines of research are being started in the areas of selective oxidations via transteion metal nitro complexes, and indirect hydrogenation of carbon monoxide derivatized species.

104. STRUCTURE AND BONDING IN METAL-

$4.5 \quad 02-1$

HYDROGEN SYSTEMS: ESCA, EXAFS,

DIFFRACTION STUDIES

J. Hud 1s, M. L. Perlman,

T. F. Koetzle

The object of this work is to obtain detailed information about the electronic interactions among atoms in metals, alloys, metal hydrides, and in other metal-containing groupings. Several experimental techniques are being employed: photoelectron spectroscopy; neutron and x-ray diffraction; Mössbauer spectroscopy; and, recently, extended x-ray ahsorption finc otructure (EXAIS) spectroscopy, an application of synchrotron radiation to determination of distances between an atom of a specifiable element and its neighbors. Data from these measurements are analyzed in terms of valence and conduction-band electronic configuratluns of the materials. Further development of theoretical analysis methods is itself an objective of this research. Metal hydrides constitute an interesting class of alloys and one of the alms of these investigations is to search for relations between their thermodynamic and structural-electronic properties. Studies of metal hydrides and their parent metals and alloys are of interest not only from a fundamental view but for potentlally practical application in the storage of hydrogen. 
Chemistry Department, BNL, continued

105. MECHANISMS OF PHOTO-, ENZYME, AND CHEMICALLY CATALYZED CIS$2.8 \quad 02-1$ TRANS. ISOMERIZATION. ENERGY STORAGE

\section{S. Seltzer}

The goal of this research is to elucidate the mechanisms of cis-trans isomerization around carbon-carbon double bonds brought about by light, enzymes, and other chemical species. At present, research is concentrated on two systems: (a) maleylacetone cis-trans isomerase, and (b) the lightdriven proton pump derived from the purple membrane of halobacteria. Current research on maleylacetone cis-trans isomerase, a required enzyme for aromatic amino acid metabolism, centers on elucidating the importance of the very active thiol group of the enzyme and the role it plays in the isomerization mechanism. Bifunctional reagents, designed to react with both the thiol group and the site of coenyzme binding, are being used to determine the distance of the thiol from another part of the active site. The chemistry of the interaction of the thiol with substrate is being investigated by nuclear magnetic resonance. The mechanism by which the purple membrane converts the energy of absorbed light to chemical energy and then stores it in the form of a proton gradient is being studied. The membrane's pigment, bacteriorhodopsin, utilizes retinal as the chromophore, as does the retina of the eye, although different cis-trans isomers are present in each. Besides the interest in the photoinduced and dark cistrans isomerization, the chemistry of the interaction of the chromophore with the amino acid side chains of the protein is being studied. ๑ 
Chemical Energy

Department of Energy and Environment

Total $\$ 685,000$

Brookhaven National Laboratory

Upton, New York 11973

106. HIGH TEMPERATURE CHEMISTRY

5.0

$02-1$

J. J. Egan

This project studies the thermodynamic and transport properties of compound. semiconductors potentially useful for photovoltaic cells. Electrochemical techniques are being used to investigate the effect of composition on the cunceulratiun, mubility, and diffusion of electrons and electron holes in these substances. Cells employing solid electrolytes at high temperatures, as well as molten salt electrolytes, are proving especially useful for characterizing these systems. High temperature calorimetry is also being used. Molten salts are being studied since they are important for the development of high energy density batteries and fuel cells. The electronic conductivity of these melts in particular is being examined by special techniques, since this property determines the self-discharge of batteries and fuel cells as well as the efficiency of electrolysis in the production of metals. 
Department of Energy and Environment, BNL, continued

107. CHEMISTRY AND PHYSICS OF

COAL UTILIZATION

T. E. Gangwer

The objective of this program is the development of basic kinetic data and fundamental reaction mechanisms for hydrogenation reactions applicable to a broad range of chemical reduction systems. The current effort is concentrating on the hydrogen donation chemistry undergone by molecules which have labile hydrogens. The program is investigating the kinetics of tetral in, 1,2-d ihydronaph thalene; 9,10-dihydroanthracene and related hydroaromatic molecules that have labile hydrogens with which to carry out chemical reductions. This hydrogenation chemistry is being probed in both the gas. and liquid phases. Since the mechanisms for these systems have been found to be heterogeneous, the hydrogenation chemistry at gas, solid and liquid interfaces is being investigated. Thus the hydrogen transfer activities of the hydroaromatic systems are being studied in the presence of catalysts such as iron oxides, iron sulfides and aluminum oxides. The hydrogenation, by the hydroaromatic systems, of structurally related compounds such as anthracene, nathphalene, phenanthrene and other polycyclic aromatics is being pursued to determine the role of aromaticity in the mechanisms. In addition, the influence of electron donating and withdrawing ring substituent systems of the hydroaromatics are being probed to gain mechanistic insights. The kinetic and mechanistic understanding of hydrogenation chemistry gained from this program will contribute to the understanding of industrial processes, such as coal conversion, which are based on chemical reduction processes.

108. CATALYSIS
R. Sapienza

This research project is designed to investigate and demonstrate the validity of a unified mechanism for carbon oxide reduction reactions. This mechanism assumes that these reactions proceed via an oxygen coordinated intermediate and provides a basic perception into the role of catalysts in this chemistry. This work is currently directed to explore the important carbon-carbon coupling step of the Fischer-Tropsch and related reactions. The cxperimental approach is two-fold. Support for postulated intermediates is being investigated by decomposing and forming appropriate organic complexes with metals, a type of organic synthesis. The intramolecular reductive coupling of aldehydes and ketones to give olefins and/or diols, the reductive elimination of diols and the products of the decomposition of metal alkoxide systems are the major focus of this area. An alternate approach is emphasizing the catalyzed reactions of coupling precursors such as formaldehyde using typical Fischer-Tropsch metal systems. 
Department of Energy and Environment, BNL, continued

109. METAL HYDR IDES

R. H. W1 swall, J. J. Re111y

$4.9 \quad 02-1$

This program explores the properties of a group of metal-hydrogen systems that range from very dilute solutions to hydrogen-rich compounds. The chief goals are to relate the hydriding properties of alloys to their constitution, to determine and systemize the crystal structures of representative metal hydrides, to account for isotope effects. in metal-hydrogen systems in terms of their other properties, and to elucidate the role of surface processes and structures in such systems. Topics of particular current interest are the $\mathrm{H}-\mathrm{H}$ interactions in different aliny types, as determlined from pressure-temperatire-composition measurements; the analysis of the partial molar entropy of hydrogen in a metal into its several components; comparisons of the behavior toward hydrogen of diffcrent crystal forms or allotropes of a given alloy such as $\mathrm{TaV}_{2}$ and $\mathrm{TiCr}_{1.8}$; the surface chemisorption of hydrogen films by metals; and the study, by 8 neutron and $x$-ray diffraction, of single crystals of the hydrides of $v, N b$ and Ta. From the last-named, new insights on the interactions between hydrogen and metal atoms in metal lattices are being obtained. Besides the experimental tools mentioned, use is made of magnetic susceptibility measurements and low temperature ( $2 \mathrm{~K}-30 \mathrm{~K})$ calorimetry. The results are expected to be relevant to (1) the development of hydrogen reservoirs and machines which use hydrogen as a working fluid, (2) the separation of hydrogen isotopes, (3) the embrittlement of metals by hydrogen, (4) the catalysis of hydrogenation reactions, and (5) the recovery of pure hydrogen from mixed gases. 
Chemical Energy

Energy and Environment Division

Total $\$ 300,000$

Lawrence Berkeley Laboratory

University of Callfornia

Berkeley, California 94720

110. SELECTIVE HYDROGENATION OF COAL

2.1

$02-1$

E. A. Grens, T. Vermeulen

This project is concerned with the decomposition of coal to liquid and soluble products in the presence of homogeneous catalysts at temperatures below the pyrolysis temperature of the coal $\left(2325^{\circ} \mathrm{C}\right)$. Coal conversion at these low temperatures, in contrast to most 1iquefaction approaches, which first pyrolize the coal and then hydrogenate coal pyrolysis products, provides valuable insight into the decomposition reactions of the coal Itself; it also can serve as a basis for liquefaction processes operating under mild conditions and making little or no char or light gas (e.g. $\mathrm{CH}_{4}$ ) products. Products have been characterized by elemental analysis, molecular weight distribution by GPC, and aromatic/aliphatic character by proton NMR. The effects of the se catalyst systems on oxygen in the coal is being given major attention. Analysis 1 s for carbonyl and hydroxyl, as well as total oxygen; these forms are affected differently by the catalytic treatment. More active homogeneous catalysts are being sought, particularly those which will selectively attack ring nitrogen.

11. BIOCONVERSION ÜF CELLULÜSE

C. R. Wilke, H. W. Bl anch
$3.1 \quad 02-1$

This research program is directed toward the conversion of the carbohydrate content of cellulosic materials (such as whole tree biomass and agricultural waste) to ethanol and other energy bearing products. These carbohydrates may be viewed as a form of stored solar energy, and large quantities of such blomass are available. Additional supplies could be grown specifically for bloconversion. In the development of an optimum processing scheme, certain fundamental problems need to be studied to provide the theoretical background for cellulose and hemicellulose hydrolysis to sugars, and subsequent fermentation to ethanol and other related chemical feedstocks. These studies relate to the enzymatic attack of insoluble materials (1ignocellulosics) and to the development of new organisms for lignocellulosic material converstion. Thus these studies have general applicablifty to a wide variety of substrates and areas in which polymeric insoluble materials are involved. 
Chemical Energy

Materials and Molecular Research Division

Lawrence Berkeley Laboratory

Unfversity of California

Berkeley, Californ 1a 94720
Total $\$ 645,000$

$2.5 \quad 02-1$

. $52-1$

.

.
112. HIGH ENERGY OXIDIZERS AND DELOCALIZED-ELECTRON SOLIDS

N. Bartlett

The oxidative intercalation of graphite or boron nitride can generate durable and conductive (better than aluminum) salts. The chemical, stolchiometric and structural requirements for the best conductors need to be determined. Some have potential application as anodes in the electrochemical generation of strong oxidizers. The close chemical and structural §̧̣lationship of some graphite salts to their protonated relatives, such as $\mathrm{C}_{24} \cdot\left(\mathrm{SO}_{3} \mathrm{~F}^{-}\right)_{3}$ and $\mathrm{C}_{24} \mathrm{SO}_{3} \mathrm{~F}-2 \mathrm{HSO}_{3} \mathrm{~F}$, raised the possibility of their factle interconversion by redox and proton transfer and their possible exploitation in cyclic energy storage. The oxidation of farge, electron-delocalized, molecules ( such_as coronene) to make salts $A^{+} X^{-}$, $\mathrm{A}^{2+}\left(\mathrm{X}^{-}\right)_{2}$ etc., in which the anion $\left(\mathrm{X}^{-}\right)$is relatively small, provides for the possibility of overlap of the partially filled orbitals of one cationic A species with those of its neighbors. The electron delocalization may, thereby, become extended throughout the three dimensional crystal lattice. The effectiveness of the A species-A species interaction will determine the electrical conducting capability of the salts.
113. CONVERSION OF COAL TO CLEAN
3.9
$02-1$ LIQUID AND GASEOUS FUELS
A. T. Be11, G. A. Somorjai

The purpose of this program is to develop an understanding of the fundamental processes involved in the conversion of coal to liquid and gaseous fuels. A major part of the work is devoted to the catalytic synthesis of hydrocarbons and alcohols from carbon monoxide and hydrogen. The primary objectives of this effort are to determine the factors which IImit catalyst activity, selectivity, and resistance to poisoning, and the relationship between catalyst composition/structure and performance. A variety of surface diagnostic probes are utilized on both single crystal and supported catalysts to obtain detailed chemical information. In a second effort, a study is being performed to establish the reaction pathways involved in the liquefaction of coal catalyzed by strong Lewis Aclds. Investigations are conducted both with coal and with model compounds containing representative organic structures present in coal. 
Materials and Molecular Research Division; LBL, continued
114. TRANSITION METAL CATALYZED CONVERS ION OF $\mathrm{CO}$, NO, $\mathrm{H}_{2}$ AND ORGANIC MOLECULES TO
0.8
$02-1$ FUELS AND PETROCHEMICALS

R. G. Bergman

Small gaseous molecules (e.g., $\mathrm{CO}, \mathrm{NO}, \mathrm{H}_{2}$ ) and volatile organic compounds (e.g., ethylene) are important chemical bullding blocks for a wide range of fuels and petrochemicals. Industry is making increasing use of these raw materials in homogeneous processes catalyzed by organotransition metal complexes, because homogeneous processes are capable of affording selectivities which often cannot be obtained in heterogeneous reactions. The goal of this project is to study the reactions of organotransition metal complexes with small molecules such as $\mathrm{CO}, \mathrm{H}_{2}$, NO and ethylene, in order to develop new homogeneous processes and understand in detail how these processes operate. The work focuses on overall reactions which form new carbon-hydrogen, carbon-nitrogen and carbon-carbon bonds. It concentrates on understanding the basic mechanistic steps which can be comblned to carry out these overall reactions; the most critical of these involve formation and cleavage of metal-carbon, -hydrogen and -nitrogen bonds. In addition to providing direct information about homogeneous reactions catalyzed by complexes containing one metal, the research may provide concepts and results applicable to related reactions involving catalysis by binuclear complexes, cluster complexes, and metal surfaces.
115. FORMATION OF OXYACIDS OF
1.0
$02-1$ SULFUR FROM $\mathrm{SO}_{2}$
R. E. Connick

The basic chemistry of sulfur dioxide and species formed from it are being investigated. The results are pertinent to the removal of sulfur dioxide from stack gases of power plants and to the behavior of sulfur dioxide in atmospheric pollution, Attention is being focused on the reactions of $\mathrm{SO}_{2}, \mathrm{HSO}_{3}^{-}$and $\mathrm{SO}_{3}$ with varlous oxldizing and reducing agents and the disproportion reactions of these sulfur spectes. One particular reaction--the oxidation by oxygen--is being studied in detail because of 1 ts overriding importance in the practical chemistry of $\mathrm{SO}_{2}$. The reaction is known to be a chain reaction in aqueous solution, both thermally and photochemically, but the chain carriers and mechanism are unknown. An important aspect is the pronounced effect of a wide variety of substances in either inftiating or terminating the chain reaction and thus altering the rate drastically. Attempts are being made to detect the chain carriers directly, using flash photolysis to initiate the reaction and rapld scan spectrophotometry or other rapid detection techinlques to detect them. 
Materials and Molecular Research Division, LBL, continued

\author{
116. SYNTHETIC AND PHYS ICAL CHEMISTRY 1.5 \\ W. L. Jo11y
}

The main aim of this research is to elucidate the chemical bonding in compounds related to catalyst systems by means of $X$-ray photoelectron spectroscopy. Atomic core electron binding energies obtal ned by this technique are interpreted in terms of atomic charges which indicate the nature of the vilence electron distribution and bonding in the molecules. The extent of d electron "back-bonding" and the modes of 11gand-metal interactions in various transition metal complexes are evaluated. Core electron binding energles also yleld thermodynamic data; they are used to calculate the heats of formation of gaseous ionic species. The study of the synthesis and characterization of the new molecule diaminoborane, $\mathrm{HB}\left(\mathrm{NH}_{2}\right)_{2}$, 18 being completed.
117. METAL-CLUSTER - METAL SURFACE ANALOGY
1.6
$02-1$
E. L. Muetterties

\begin{abstract}
A definition of the coordination chemistry of transition metal surfaces on a comparative basis with that of molecular metal complexes and molecular metal clusters is the objective of this research. Displacement reactions supplemented with diffraction and spectroscoplc data are beling utilized in the elucidation of structural, bonding, and chemical features of nickel and platinum single crystal surfaces with benzene, ethylene and carbon monoxide. Benzene chemisorption on the Pt(111) surface 18 largely thermally reversible. Thermal desorption of $\mathrm{C}_{6} \mathrm{H}_{6}$ and $\mathrm{C}_{6} \mathrm{D}_{6}$ from this platinum surface ylelds only $\mathrm{C}_{6} \mathrm{D}_{6}$ and $\mathrm{C}_{6} \mathrm{H}_{6}$; there ${ }^{6}$ is no evidence for hydrogen-deuterium exchange for the molecules reversibly desorbed from this surface. Chemisorption of ethylene is only partially reversible. Nevertheless, a substantial quantity of molecular ethylene can be thoroughly desorbed from this surface. Similar results are being obtained with the $N i(111)$ surface but the degree of reversibility is substantially lower for this more reactive metal. The catalytic chemistry for ethylene and for benzene in the presence of hydrogen and deuterium are being examined for the low Index: -kel and platinum surfaces in order to make a precise comparison of surface chemistry with molecular metal cluster chemistry.
\end{abstract}


Materials and Molecular Research Division, LBL, continued

118. ELECTROCHEMICAL SYSTEMS

1.2

$02-1$

J. Newman

Th1s work comprises a theoretical and experimental study of transport phenomena in electrochemical systems. This study includes measurements of transport properties in concentrated electrolytic solutions and analyses of mass transfer rates and current distributions in several systems of practical importance. In particular, these principles are applied to liquid junction cells with polycrystalline semiconductor electrodes in order to provide design criteria for advanced solar energy conversion systems. Furthermore, kinetic and mass-transfer data are being obtained. which are applicable to corrosion in laminar and turbulent flow regimes. These data allow one to determine average and maximum corrosion rates of iron in acid solutions." 
Chemical Energy

Chemical Engineering Division

Lawrence Livermore Laboratory

University of California

P. 0. Box 808

Livermore, California 94550

119. EFFECTS OF METAL SURFACES ON THE KINETICS OF HYDR IDE FORMATION

R. Alire, S. Steward
Total $\$ 95,000$

1.2

02-1

The objective of this study is to elucidate the surface chemistry of metals, alloys and intermetallic compounds that react extensively with hydrogen. Previous indirect evidence has shown that the condition of metal surfaces significantly affects the reaction rate between the bulk metal and hydrogen. Several metal systems, e.g., FeT1, LaNi ${ }_{5} \mathrm{LaCo}_{5}$, and $\mathrm{ZrAl}$, all very reactive toward hydrogen, are belng examined with Auger electron spectroscopy (AES), x-ray photoelectron spectroscopy (XPS), secondary ion mass spectrometry (SIMS), and 1on scattering spectrometry (ISS). Depth profiles using these techniques indicate that the more reactive metal, $1 . e ., \mathrm{La}, \mathrm{TI}$, and $\mathrm{Zr}$, segregates to the surface. Compounds of these metals, e.g., oxldes, are very stable and their formation at the surface would lower the surface free energy of these intermetallic compounds; the experimental results, therefore, agree with predictions made from thermodynamic considerations. Surface segregation and subsequent compound formation at the surface are strongly related to the reactivity of these metal systems to hydrogen and other chemical species. 
Chemical Energy

Metals and Ceramics Division

Total $\$ 205,000$

Lawrence Livermore Laboratory

University of California

P. 0. Box 808

Livermore, California 94550

120. THERMOCHEMICAL PRODUCTION OF

2.4

$02-1$ HYDROGEN FROM WATER

o. Krikorian

A basic chemical research program is being conducted on thermochemical cycles for producing hydrogen from water using nonhydrocarbon energy sources (High Temperature Gas Reactor, Solar and Magnetic Fusion Energy). Special emphasis is on the search for new and better cycles, exploring innovations to improve existing cycles, and studying the thermodynamics, kinetics, and mechanisms of key reactions in cycles. Reactions presently under experimental study are: $2 \mathrm{ZnO}(8)+\mathrm{Se}(l)+\mathrm{SO}_{2}(g) \rightarrow \mathrm{ZnSe}(s)+$ $\mathrm{ZnSO}_{4}(\mathrm{~s})$, and $\mathrm{ZnSO}_{4}(\mathrm{~s})+\mathrm{ZnO}_{(\mathrm{s})}+\mathrm{SO}_{2}(\mathrm{~g})+1 / 2 \mathrm{O}_{2}(\mathrm{~g})$. The mechanism of the first reaction ${ }^{4}$ is under investigation and reaction conditions that will accelerate the reaction are being sought. The rate depends strongly on the degree of surface contact between $\mathrm{Se}(1)$ and $\mathrm{ZnO}(\mathrm{s})$, and on $\mathrm{SO}_{2}$ pressure. For the second reaction, high temperature enthalpy measurements are being completed for $\mathrm{ZnSO}_{4}$ and $\mathrm{ZnO}_{2} \mathrm{ZnSO}_{4}$ (a decomposition intermediate), and the transition energy for the $\alpha-\beta$ transition in $\mathrm{ZnSO}_{4}$ at $1015 \mathrm{~K}$ has been measured. Studies of the kinetics of decomposition of $\mathrm{ZnSO}_{4}$ have begun. Other work is planned to study a cycle based on $\mathrm{LHH}$, and paper studies are underway on new cycles at temperatures of 1200-2200K. 
Chemical Energy

B Division

Los Alamos Sclentific Laboratory University of California

P. 0. Box 1663

Los Alamos, New Mexico 87545
Total $\$ 340,000$
121. SYNTHESIS OF THERMOCHEMICAL CYCLES
4.35
02-1
M. G. Bowman, C. Hollabaugh,
C. Mason, E. I. Onstott

This research project consists of the identification, initial evaluation and preliminary development of thermochemical cycies for the production of hydrogen from water. An important activity is the definition of criteria for the selection of cycles adapted to the characteristics of different heat sources such as high temperature nuclear fission reactors, fusion reactors and solar concentrators. Potential cycles are identified from thermochemical considerations and then tested by determinations of reaction rates, reaction yields and accurate thermochemical properties. Current studies concern: (1) mixed metal lodate-metal iodide cycles; (2) hybrid thermochemical-electrochemical cycles based on solid sulfate decomposition reactions; (3) methods for reducing overvol tages during electrochemical reactions; (4) cycles based on cadmium carbonate and oxide decompositions; (5) Initial considerations of $\mathrm{CO}_{2}$ decomposition in solar furnaces; (6) potential hybrid thermochemical-photochemical cycles. 
Chem1cal Energy

CNC Division

Los Alamos Sclentific Laboratory

University of Californta

P. 0. Box 1663

Los Alamos, New Mextco 87545

122. LABILE SO COMPLEXES

G. J: Kübas
Total $\$ 180,000$

1.4

02-1

The synthesis, reactivity, structure, and bonding of transition metal$\mathrm{SO}_{2}$ complexes are being Investigated in order to advance the basic chémlstry of small molecule pollutants and to develop new scaveng ing methods. Reactions of coordinated $\mathrm{SO}_{2}$ are being explored in the hope of promoting its conversion to useful ${ }^{2}$ or innocuous products. Discoveries In this program of complexes containing side-on bonded $\left(\eta^{2}-\right) \mathrm{SO}_{2}$ and others with 1 igand-11gand interactions are closely aligned with ${ }^{2}$ this goal. Binding of both the sulfur and one oxygen to a metal can be expected to activate $\mathrm{SO}_{2}$ towards novel reactions; this is demonstrated by the interaction of ${ }^{2} \mathrm{Ru}(\mathrm{CO}){ }_{2}\left(\mathrm{PPh}_{3}\right)_{2}\left(\mathrm{n}^{2}-\mathrm{SO}_{2}\right)$ with a second $\mathrm{SO}_{2}$ to give a sulfate $\mathrm{Ru}(\mathrm{CO})_{2}\left(\mathrm{PPh}_{3}\right)_{2}^{2}\left(\mathrm{SO}_{4}\right)$ and $\mathrm{Ph}_{3} \mathrm{PS}$ (oxidation and reduction of $\mathrm{SO}_{2}$ ). Other current investigations show that the hydrogen reduction of $\mathrm{SO}_{2}{ }^{2}$ to sulfur and water occurs at lower temperature $\left(\sim 150^{\circ} \mathrm{C}\right)$ by use of ruthentum on alumina catalyst compared to alumina alone. Also, new molybdenum( 0 ) complexes are being ${ }_{2}$ studied in which the $\mathrm{SO}_{2}$ coordination can readily be converted between $\eta^{2}$ - and $\mathrm{s}$-bonded. In the absence of $\mathrm{SO}_{2}$, coordinative unsaturation and reversible binding of other small molecules $\left(\mathrm{C}_{2} \mathrm{H}_{4}, \mathrm{H}_{2}\right.$, $\mathrm{N}_{2}$ ) can occur. 
Chemical Energy

Morgantown Energy Technology Center

Total $\$ 70,000$

P. 0. Box 880

Morgantown, West Virginia 26505

123. CHEMICAL KINETICS AND

1.5

$02-1$ SURFACE CHEM ISTRY

G. L. Ka rapinka

The objective of this project is the elucidation of the mechanism of the heteroatom removal from organosulfur and organonitrogen compounds catalyzed by supported cobalt-molybdenum type catalysts. This study so far, showed: (1) saturation of the heteroatom part of the molecule before $C-N$ or $C-S$ bond scission takes places, (2) influence of the acidity of the catalyst on catalytic performance, (3) extstence in the catalyst of two separate sites for hydrogenation and for cracking, (4) polsoning effect by organonitrogen compounds of the cracking sites. The oxidation state of the active catalytic species or the change of oxidation states during the catalytic process are being determined. ESCA and other techniques are being used for that purpose. The nature of the active catalytic species - heteroatom complex is also being investigated. Based on the understanding of the catalytic mechanism, superior hydrotreating catalysts for the treatment of liquefied coal are being prepared. 
Chemical Energy

Mound Facility

Total $\$ 220 ; 000$

P. 0. Box 32

Miamisburg, Ohio 45342

124. FUNDAMENTAL INVESTIGATIONS OF

2.7

02-1 METAL HYDR IDES

G. C. Abell, R. C. Bowman, Jr.,

M. P. Guse

The objectives of this program are to Identify and evaluate atomistic properties which may lead to the development of improved metal hydrides for energy storage applications. NMR techniques are being used to determine relationships among crystal structure, electronfc structure, and hydrogen diffusion behavior in $\mathrm{TiFeH}_{4}, \mathrm{Ti} \mathrm{CuH}$, and $\mathrm{TiCr}_{3} \mathrm{H}$; isotope effects in phase transition and diffusion mechanisms in $\mathrm{VH}^{1}, 8 \mathrm{VD}$, and $\mathrm{VT}$; and the

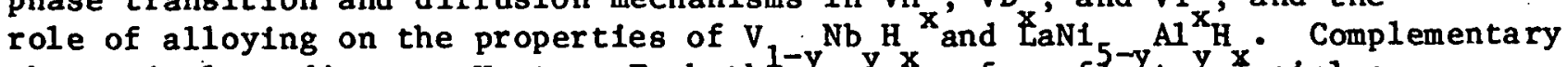
theoretical studies use Hartree-Fock theoty toxperform firgt principles quantum-mechanical calculations of the electronic properties of metal atom clusters with and without hydrogen atoms as well as the development of Hartree-Fock band theory techniques for transition metal hydrides. A new Anderson-type model for disordered systems, which describes electrontc states assoclated with dilute hydrogen in transition metals, is being developed and tested against observed properties of the bcc metals $\mathrm{V}, \mathrm{Nb}$ and $\mathrm{Ta}$. 
Chemical Energy

Chemistry Division

Oak Ridge National Laboratory

Total $\$ 1,865,000$

P. 0. Box X

Oak Ridge, Tennessee 37830

125. HETEROGE NEOUS CATALYS IS

$3.5 \quad 02-1$

RELATED TO ENERGY SYSTEMS

P. A. Agron, S. H. Overbury,

W. C. Waggener

In order to Improve the understanding of catalytlc aurface structures and of their interactions with reactive molecules, three techniques are being employed and developed. (1) Recently, a technique that will allow studies of molecule-surface interactions in catalytic processes at their characteristic temperatures and pressures has been invented. The arrangement consists of a ribbon of a catalytically active metal, such as nickel, which has been thinly coated on one side with an inert metal, such as gold. Tangential forces developed by molecules adsorbed on the nickel side bend the ribbon, allowing their measurement and correlation with directions in the surface. (2) Low-energy ion scattering allows characterization of typical catalytic surfaces by revealing atom-atom distances and orlentations in the solid surface, the ldentity and location of adsorbed species, the grosser structural detalls, such as steps. (3) Angle-resolved uv and $x$-ray photoelectron spectroscopy is being used to characterize the bonding of larger, sulfurcontaining organic molecules to oriented single crystal surfaces of copper and nicke1.
126. INORGANIC CHIMISTRY
2.0
$02-1$
OF HYDROGEN CYCLES
C. E. Bamberger, P. R. Robinson

Inorganic chemistry involved in the production of hydrogen from water by means of thermochemical cycles is being developed. The discovery and characterization of new chemical reactions and compounds, determination of related thermodynamic and kfinetic data, and the expcrimental development and Improvement of thermochemical cycles is included. Emphasis is placed on cycles whose reactions occur at temperatures achlevable by solar furnaces or nuclear reactors. The goal of the project 18 to develop an understanding of the chemistry which might be involved In large-scale, economical production of hydrogen via thermochemical cycles. Recent work led to the discovery of a family of cycles based on cerium and manganese compounds. These unique cycles are the first experimentally demonstrated thermochemical processes which split $\mathrm{CO}_{2}$ into $\mathrm{CO}$ and $1 / 2 \mathrm{O}_{2}$, In addition to splitting water into $\mathrm{H}_{2}$ and $1 / 2 \quad \mathrm{O}_{2} \cdot$ 
Chemistry Division, ORNL, continued

127. AQUEOUS CHEMISTRY AND

$5.0 \quad 02-1$

THERMODYNAMICS TO ELEVATED

TEMPERATURES AND PRESSURES

R. H. Busey, H. F. Holmes,

W. L. Marshall, F. H. Sweeton

Physical chemical techniques are applied to the study of the thermodynamics of processes in aqueous media at the high temperatures and pressures found in geothermal and reactor systems. The specific approaches now being applied are: phase studies, potentiometric, isopiestic, and calorimetric measurements. For the first time, isopiestic measurements have been made on the mixed electrolyte systems $\mathrm{NaCl}-\mathrm{KCl}$ and $\mathrm{NaCl}-\mathrm{CaCl}_{2}$ up to $200^{\circ} \mathrm{C}$. These data have been analyzed in terms of Pitze $r^{\prime} s$ model. Other pure electrolyte and mixed electrolyte systems are under investigation, including phase studies on oxide and hydroxides of particular interest. Equilibrium measurements are being made as a function of $\mathrm{pH}$, temperature and salt medium to define aluminum ion hydrolysis behavior in dilute solutions. A heat flow-solution flow microcalorimeter has been developed and is being. calibrated.for measurements in solution to $500^{\circ} \mathrm{C}$ and 500 bars. This will extend present capabilities to previously unattainable conditions and provide new enthalpy data on aqueous systems. Critical reviews, correlations, and development of equations of state are an important part of this program.

128. ORGANIC CHEMISTRY AND THE

$02-1$

CHEMISTRY OF FOSS IL FUELS

C. J. Collins, B. M. Benjamin,

E. W. Hagaman, L. L. Brown

Studies are directed toward the fundamental chemistry underlying the conversion of coals to liquid fuels. Emphasts is placed on the eluctdation of the organic structures of coals and their chemical functionalities. The role of internal hydrogen shuttling whthin the coal itself is under study. Also of great interest are the identity and nature of easily cleavable bonds in the coal macromolecular structure. New methods for low temperature cleavage of such bonds in the coal macromolecules are being investigated for the purpose of determining structures and reactivity. Several approaches are also being evaluated for the determination of molecular weights and sizes of the organic moleties in coal-derived liquids and in coals themselves. Several techniques are under consideration, lncluding a combination of small angle-x-ray and neutron diffraction. 
Chemistry Division, ORNL, continued

129. COMPARATIVE INORGANIC CHEMISTRY

$2.5 \quad 02-1$

J. S. Johnson, R. Triolo

Broad, systematic studies are belng made of a group of relative aqueous/organic systems in order to develop generalizations derived from intensively studied single systems. Areas of investigation include experimental and theoretical aspects of solution structure, aqueous/organic miscibilities and interfacial tensions, and micellar formulations that are important in enhanced oil recovery and solvent extraction. For each system studied, at least two components are included from water/1norganic salt/hydrocarbon/alcohol/ surfactant (or protosurfactant) systems that would represent in its cotality a practical system in enhanced ofl recovery. (The term "protosurfactant" denotes compounds simflar to surfactants, except they are not expected to form micelles.) Currently, the structure of t-butyl alcohol/water solutions is being studied by large-angle and small-angle $x$-ray scattering to be followed by the equivalent neutron experiments. Small-angle $x$-ray scattering results have recently been obtained on micellar and microemulsion systems. In systematic survey work, results are being obtained on the miscibilities of water/hydrocarbon/alcohol/alkyl benzene carboxylate systems and on the interfacial tensions and phase behavior of aqueous/hydrocarbon systems containing carboxylate surfactants. Particular attention is being given to the effects of bulkiness of substituents near the lonizable group of the surfactant.

130. STEAM GENERATOR CHEMISTRY R. E. Me Amier

$0.4 \quad 02-1$

This program focuses on the transport and deposition of materials, especially oxides, which occur in the corrosion and contamination of steam generators in nuclear plants. The hydrolysis of transition metal ions and the behavior of ferrites are two principal concerns. The initial work in this program is to evaluate from known thermodynamic data on hydrolysis reactions the expected hydrolysis behavior of metal ions. An experimental program using precision potentlometric techniques will be applied to the study of the hydrolysis of cobalt(II); later, studies will be conducted with continuous measurement of $\mathrm{pH}$ and solubility in packed columns. The initial solid to be studied is well-crystallized cobaltous hydroxide. with later emphasts on cobalt ferrites. Details on the solution chemistry of cobalt will be studied to establish equilibrium and kinetic models for the bulldup or control of radiation fields that affect occupational exposure levels. 
Chemistry Division, ORNL, continued

0

131. MOLTEN SALT CATALYSTS FOR CLEAN 4 02-1

FUEL SYNTHESIS

G. P. Smith, A. S. Dworkin,

A. C. Buchanan, III, L. 0. Gilpatrick

This project is a fundamental investigation of molten salt catalysts and molten salt catalyzed reactions relevant to the synthesis of clean fuels from fossil sources. Its goal is the determination of the origins of catalytic activity and selectivity in order to help improve applications of known catalysts and to ald in the search for better catalysts. Hydrogenation, dehyd rogenation, condensation, protonation and one-electron oxfdation of polycyclic aromatic compounds are catalyzed by molten salts with a posttransition metal halide, like antimony trichloride or zinc chloride, as the dominant constituent. The effects of added transition metal halides, other Lewis acids or bases, other oxidants or reductants, are determined. Studies are made of chemical specles important in catalytic mechanisms including the formation, stablifty and reactions of carbenium ions, organic cation radicals, unstable or unusual oxidation states of metals and unusual metal coordinates in catalytically active halides. These investigations are made by optical spectroscopy, electron spin resonance, nuclear magnetic resonance, voltammetry, and coulometry of the melt, and byproduct separation from the melt. 
Chemical Energy

Chemical Technology Division

Total $\$ 120,000$

o

Oak RIdge National Laboratory

P. 0. Box X

Oak Ridge, Tennessee 37830

132. RINETICS OF ENZYME-CATALYZED
PROCESSES
B. Z. Egan, E. Greenbaum

The purpose of this program is to study in vitro kinetics and enyzme catalysis related to processes for gaseous fuel production, particularly hydrogen production from photooxidation and blophotolysis of water. Fundamentel problems aimed at demonstrating the oclentifio and technical feasibility of photobiological hydrogen production are addressed. The basic system studied is the chloroplast-ferredoxin-hydrogenase (CFH) system. Kinetic and mechanistic aspects of hydrogen and oxygen photoproduction are studied using a unique experimental approach. Areas of Investigation Include (1) simultaneous light driven photoproduction of hydrogen and oxygen; (2) long-term stabllity of each of the components of the CFH system; (3) the possibility of substituting synthetic analogs for components in the CFH system. An additional area of study includes the application of the technique of single saturating turnover flashes to the CFH system. This technique has been applied to the whole algae but never to the CFH system. These experiments produce absolute figures of merit of photosynthetic water splitting which are useful in comparing different approaches to photoblological hydrogen production. Results from these studies ald in the development, design, and evaluation of a potentially attractive process for utilizing solar energy to produce hydrogen from water. 
Chemical Energy

Chemical Technology Department

Pacific Northwest Laboratory

P. O. Box 999

Richl and, Washington 99352
Total $\$ 322,000$
133. MECHANISMS OF HYDROGENATION
1.6
02-1
OF COAL
J. A. Franz

This research project addresses three areas: (1) pathways of thermal dissolution of coal which involve rearrangements and fragmentations of organic.free radicals, (2) characterizations, by spectroscopic and other means, of the structural evolution of coal during dissolution in donor media, and (3) an examination of pathways and mechan isms of hydrogen. transfer during coal hydroliquefaction. Under. (1) above, the rearrangement and interconversion of 2-tetralyl, 1-indanylmethyl, 2-indanylmethyl and 1-tetraly1 and other hydroaromatic radicals under conditions related to coal hydroliquefaction are being examined. The reversibility, relative stabilities of interconverting radicals and mechanisms of radical rearrangements are also belng studied. Under (2) and (3) above, the structural evolution of cpąl during flash liquefaction in hydrogen donor solvents and deuteffum and ${ }^{3} \mathrm{C}-1$ abelled donor solvents is being examined utilizing NMR ( ${ }^{3} \mathrm{C},{ }_{\mathrm{H}}, \mathrm{I}_{\mathrm{H}},{ }^{14} \mathrm{~N}$ ) and a variety of analytical techniques. Under (2) and (3) a more sophisticated view of coal structure and reactivity is being sought.

134. CONVERS ION OF CELLULOSIC WASTES
INTO LIQUID FUELS
P. M. Molton

The purpose of this research is to determine the reaction mechanisms involved in blomass liquefaction in aqueous media at elevated temperatures. Because of the complexity and variability of composition of "biomass", individual components are being considered inftially, and concentration at present is on the chemistry of cellulose liquefaction. Compounds produced by 11 que fying cellulose at $300^{\circ} \mathrm{C}$ and up to $2700 \mathrm{psig}$ are being examined using combined GC/MS as the primary tool. It appears that the cellulose-derived oll is formed from small carbonyl compound intermedlates via aldol condensations. To check this, acetone, acetoin, and acrolein are being reacted to determine if the same compounds are produced from these intermediates as from cellulose. To date, the results confirm the theory. This work will permit prediction of the quality of the liquid product from cellulose liquefaction. Using the knowledge derived, it should be possible to predict which reaction conditions will yield the highest quality liquid fuel. The work will continue with an Investigation into the other components of blomass, Inltially, lignin. 
Chemical Energy

Physical Sclences Department

Total $\$ 155,000$

Pacific Northwest Laboratory

P. 0. Box 999

Richland, Washington 99352

135. FUNCTIONAL GROUPS OF COAL

AND MODEL COMPOUNDS

J. R. Morrey, G. L. Tingey,

W. E. Skiens

The purpose of this study is to discover the chemically important functional groups in coals and, by use of approprlate well defined model compounds, to examine the chemlstry related to these groups. The program is designed to yield information on chemical and physical parameters which affect behavior of coal during conversion proresses such as combuotion, liquefaction, dissolution, and gasification. Answers to many complex chemical problems relating to the use of coal are best obtained through studies on well-defined, coal-1ike polymers or discrete molecules known to exist in coal. For example, an understanding of the reactions of nitrogen and sulfur functional groups in coal may be obtalned by studying reactions with well defined sulfur-nitrogen polymers having coal-1ike structures, then correlating results with reactions of coal under comparable conditions. Coal, being heterogeneous and 111 defined, presents a special challenge to. chemlsts trylng to measure kinetic parameters. Thus, special techniques are required and need to be developed. Two such techniques are being developed: (1) the use of secondary emission spectroscopy to monitor reaction kinetics in small domains ( $\sim 1 \mathrm{~mm}^{2}$ surface), and (2) nonisothermal kinetic measurements. The latter method is being developed by computers interfacing to a molecular beam mass spectrometer which monttors reaction products from gas-solid reactions. The physical processes important in super-critical dissolution of coal are also being investigated. 
Chemical Energy

Chemical and Instrumental Analysis Division

Total $\$ 70,000$

Pittsburgh Energy Technology Center

4800 Forbes Avenue

P1ttsburgh, Pennsylvania 15213

136. VIBRATIONAL SPECTROSCOPIC STUDIES

1.0

$02-1$ OF COAL CONVERSION CATALYSTS

F. R. Brown, L. E. Makovsky

Supported molybdena catalysts are important because of their use in a variety of chemical processes, including the hydrodesulfurization of petroleum feedstocks and coal. The objectives of this program are to ascertain the structural characteristics of supported molybdenum oxide and other coal conversion catalysts and to determine the nature of adsorbentadsorbate interactions on the surface of such catalysts by Raman spectroscopy. Parallel structural characterlzation studies are belng performed using ESCA; parallel adsorbent-adsorbate interaction studies are belng performed using infrared spectroscopy. The structural information obtained is being correlated with activity measurements. 
Separations

Ames Laboratory

Iowa State University

Total $\$ 138,000$

Ames, Iowa 50011

137. HYDROMETALLURGICAL PROCESSING

0.91

$02-2$

R. G. Baut1sta

Research that can lead to the development of efficlent production processes for obtalning strategic industrial metals from their natural ores and secondary sources is the main objective of this work. Processes for dealing with very low grade and difficult-to-process raw materials by chemical solution techniques at near-ambient temperature are of particular interest. The studies being carried vut are directed towards development of Improved methods for leaching the desired metals from the ore, the separation of the metals values from their impurities in solution, the concentration of the metals in solution, and their reduction to high purity. Work is curreptly focused on a model for the leaching of chalcopyrite CuFes, with $\mathrm{Fe}^{+3}$ and $\mathrm{O}_{2}$ as oxidants. Homogeneous solution phase reactions are assumed to be always at equilibrium throughout the dissolution of the mineral. The disgoclatifon of $\mathrm{HSO}_{4}$ and several complexation reactions involving $\mathrm{Cu}^{+2}, \mathrm{Fe}^{+2}, \mathrm{Fe}^{+3}$ are incorporated in the model equations. A predictive multicomponent liquid-liquid extraction model originally developed for the rare earth metals system is being applied to the separation of nickel from cobalt. A liquid fluidized electrodeposition process to reduce low concentration copper sulfate leach liquor is currently being investigated. An experimental program to obtain data under well-defined conditions 18 being undertaken for the different hydrometallurgical unit processes of interest. 
Ames Laboratory, continued

138. SEPARATION CHEMISTRY

J. E. Powell
1.59

$02-2$

This research project addresses bastc problems assoclated with the utilization and/or disposal of fission products and transuranium nuclides generated in nuclear power reactors. It exploits the compleximetric, ion exchange and solvent extraction techniques useful for separating groups of elements that are very difficult to resolve by other means. The maln thrust of the research currently is toward the partitioning of actinide species, particularly Am and $\mathrm{Cm}$, from the lanthanide group of fission products; the 1on exchange behavior of $\mathrm{Am}^{3}$ compared to lanthanide cations in the presence of methyl subst1tuted 2,3-dihydroxycarboxylate antons 18 being studied. Dihydroxycarboxylate anions are unique in that their complexing ability changes from tridentate to bidentate about midway across the lanthanide series, at least in the cases of 2,3-dihydroxy-2-methylbutanoate and 2,3-dihyd roxy-2,3-dimethylbutanoate anions. Perhaps this phenomenon will prove useful in partitioning Am and heavier actinides from lanthanides obtalned from nuclear waste streams. If such ligands can be made organophilic by substitution of larger alkyl groups, 1t would appear that their unique properties can be exploited in solvent extraction as well as in cation exchange systems. 
Separations

Chemistry Division

Argonne National Laboratory

Total $\$ 713,000$

9700 South Cass Avenue

Argonne, Illinois 60439

139. CHEMICAL SEPARATION SCIENCE

9.7

$02-2$

E. P. Horwltz: G. R. Dyrkacz,

G. W. Mason, R. A, Uphaus,

G. F. Vandegrift

Th1s program has two major objectives: first, to obtaln a fundamental understanding of several important separations processes; and second, to apply basic information in separation science to the development of new separation processes and techniques. This program spans the separation of substances ranging in dimensions from molecular to colloidal and particulate, with emphasis directed primarily to separation methods pertinent to nuclear and fossil energy technologies. Four major areas of separation science are being investigated: (1) liquid-1iquid extraction and 11quid-11quid chromatography -- new systems are studied from both a theoretical and an applied standpoint; (2) 1iquid-liquid interaction kinetics -- emphasis is placed on the mechanisms of interfacial mass transfer and developing systems in which separations are based on differential rates of extraction; (3) field flow fractionation -- emphasis is placed on the separation of actinide colloids and the investigation of Inorganic polymers of importance in enviromental science; (4) development of separation techniques applicable to enriching the maceral constituents of coal and the organic constituents of ofl shale. 


\section{Separations}

Chem 1stry Department

Brookhaven National Laboratory

Upton, New York 11973
Total $\$ 105,000$

140. LASER-INDUCED REACTIONS FOR

1.4

$02-2$ ISOTOPE SEPARATION

R. $B$. Weston

The photochemical separation of 1 sotopes $1 \mathrm{~s}$ posstble because atomic and molecular energy levels depend on atomlc masses. The difference in levels permits the selective photoexcitation of a single isotopic species, which either decomposes or can be removed by a chemical or physical process leading to an 1sotopically enrlched product. . To provide information basic to laser isotope separation, unimolecular reactions, bimolecular reactions, and photodissociation processes of vibrationally excited molecules are being investigated for the selective removal of photoexcited molecules. Currently under Investigation are: (1) the IR multiphoton dissociation of $\mathrm{CF}_{3} \mathrm{Cl}$, using IR chemiluminescence from vibrationally excited $\mathrm{HCl}$ and $\mathrm{HF}^{3} \mathrm{as}$ probes; and (11) the photochemistry and photophysics of highly vibrationally excited $\mathrm{SO}_{2}$. This may be one of the first observations of "Inverse electronlc relaxation", in which vibrational energy, 18 converted to electronic energy . 
Separations

Department of Energy and Environment Brookhaven National Laboratory

Upton, New York 11973
Total $\$ 141,000$

141. CYCLIC SEPARATIONS PROCESS RESEARCH
2.3
$02-2$

F. B. Hill, Y. W. Wong

Th1s program consists of a study of the application of cyclic separation processes to separations problems arising in energy technology. The purposes of the program are two-fold: to obtain an understanding of the characteristics and basis of operation of cyclic separation proceseco as a class, and to explore the feasibility of using these processes to perform specific separations of interest in the energy field. The cyclic processes of Interest include pressure and temperature swing adsorption, parametrlc pumping, cycling zone adsorption, and various forms of preparative chromatography. Applications presently under study Involve 1sotope separations of interest in nuclear technology, specifically tritium removal and heavy water production. Future work may include applications such as hydrogen purification, pollutant removal from gases, and additional separations of interest in energy technologies. Elements of the program include development of the theory of cyclic processes, measurements of equilibrium and k1netic properties of selected fluid-solid separation systems, measurement of the characteristics of cyclic separation processes employing these systems, and process design and evaluation studies. The work accomplished in this program will permit rational design and assessment of cyclic separation processes and will identify promising methods of solution for specific separation problems in the energy field. 


\section{Separations}

Q Division

Los Alamos Scientific Laboratory

Total $\$ 25,000$

University of California

P. 0. Box 1663

Los Alamos, New Mexico 87545

142. THE FORMATION AND PROPERTIES OF

$1.0 \quad 02-2$

COMPLEXES OF HELIUM AND HYDROGEN ISOTOPES

R. D. Taylor

The experimental properties and stability conditions are being investigated for a newly discovered metastable bound-state formed between a noble gas and hydrogen. Tritium, the heaviest isotope of hydrogen, is radioactive and decays with a half life of 12.3 years, ultimately producing a pair of hellum-3 atoms and a concomitant pressure increase in a fixed volume of gas. However, at a temperature of about $21 \mathrm{~K}\left(-252^{\circ} \mathrm{C}\right)$ the helium-3 formed in liquid tritium is retained in the liquid in an amount far exceeding the ordinary solubility, suggesting that a metastable heliumtritium molecular complex is formed. Experiments now underway and a parallel theoretical effort at Harvard are aimed at providing detalled characterization and identification of this unusual bound species. Experiments so far have shown the complex is virtually stable in 11quid tritium and is definitely unstable in gaseous tritium. Preliminary experiments suggest stability of the complex in the solid phase. The complex exhibits little, if any, magnetic behavior and has an effective vapor pressure less than that of the tritium host 1lquid. Future experiments w1ll address questions of the charge and transport propertico ac well as schemes for producing the analogous molecular complexes of the other 1sotopes of hydrogen and hellum. 
Separations

Morgantown Energy Technology Center

Total $\$ 54,000$

P. 0. Box 880

Morgantown, West Virginia 26505

143. PARTICLE INTERACTIONS : SIZE

1.9

$02-2$ DISTR IBUTIONS IN COMBUSTION STREAMS

R. P. Treat

The general objective of this program is to investigate the process of adhesion or coalescence of particles when they come in contact under conditions which are comparable to those found in the post combustion zone of a coal combustion stream. Th1s process $1 \mathrm{~s}$ signiflcant in the evolution of the particles' size spectrum. Studies are underway to investigate the coagulation of aerosols involving internal or external electromagnetic forces and the effect of the electromagnetic forces on the particle size distribution in combustion streams. 


\section{Separations}

Mound Facility

P. 0. Box 32

Miamisburg, Ohio
Total $\$ 664,000$

45342
144. ISOTOPE SEPARATION RESEARCH AND DEVELOPMENT

W. M. Rutherford, B. E. Jepson, E. D. Michaels
$5.8 \quad 02-2$

This program is concerned with the Investigation of chemical exchange and 1iquid phase thermal diffusion as techniques for stable 1sotope separation. The primary objectives of the chemical exchange work are to find significant isotope effects in metal isotope exchange between aqueous and organic 1igand phases and to develop closed cycle methods of refluxing chemical exchange systems with oxidation state changes between the exchanging species. The 1iquid thermal diffusion work is directed, In part, toward developing a basic understanding of the behavior of liquid phase thermal diffusion columns and, in part, toward gaining experimental information about the isotopic thermal diffusion factor in the liquid phase. The successful development of these 1 ines of research will lead to improved methods for separating stable isotopes required for physical, chemical, biomedical, and energy applications.
145. INVESTIGATION OF THE MECHANISMS
$1.0 \quad 02-2$
OF THE REMOVAL OF RADIOACTIVE
NUCLIDES FROM WASTE STRFAMS
G. L. Silver

Waste water contaminated with radioelements such as uranium, neptunium, and plutonium is generated in commercial nuclear fuel cycles, by nuclear weapons manufacture, radiolsotope research facilities, heat source fabrication, and medical research. Before such waste water can be returned to the environment, it must be decontaminated. Although certain inorganic compounds can diminish the concentration of plutonium in waste water to the point that the water is no longer an environmental hazard, the mechanism of the decontamination process is not understood. The purpose of this project is to study the decontamination of waste water by radioelement adsorption onto inorganic compounds. Several classes of inorganic compounds have been selected for this study, the most promising of which appear to be the phosphates of the alkaline earth elements. These compounds may be used in primary or secondary waste treatment procedures, and do not present the disposal or storage problems associated with organic adsorbants such as ion exchange resins. The goals of this project are to study the adsorption process as a function of the nature of the inorganic adsorbent compound, the chemistry of the radioelement, the chemical properties of waste water which influence the decontamination process, and application of this knowledge to an efficient, economical procedure for treating waste water prior to discharge to the environment. 
Mound Facility, continued

146. ATOMIC AND MOLECULAR PROPERTIES

3.2

$02-2$

AND THE IR RELATIONSHIP TO

SEPARATION PROCESSES

W. L. Taylor

The objective of this research is to investigate the physical properties of 1sotopes and their mixtures. Currently, experiments are being conducted to measure the total scattering cross section, the thermal diffusion factor, the diffusion coefficient and vapor pressure of the permanent gases and their isotopes. The resultiug data are analyzed to probe and ascertain fundamental atomic interactions and to provide information necessary for the design and operation of 16otope separation systems. Total cruss sections have recently been measured for the Ne-Ar system and are presently underway for He-Ar. A unique velocity selector is being tested which will reduce the energy spread of the molecular beams used in this work. Thermal diffusion factors have been measured for all noble gas isotopes and their binary mixtures. Ordinary diffusion coefficients have been measured for the majority of noble gas 1sotopes and mixtures, and experiments are continuing on the remaining systems. Vapor pressure work is concentrating on the hydrogen isotopes using ultrapure deuterium In the experiments. A new and improved interaction potential for helium atoms was recently determined and published as a result in part of the current work. 
Separations

Chemistry Division

Oak Ridge National Laboratory

Total $\$ 635,000$

P. 0. Box X

Oak Ridge, Tennessee 37830

147. FUNDAMENTALS OF SEPARATION CHEMISTRY

2.5

$02-2$

C. F. Baes, Jr., W. D. Arnold,

F. Dowell, F. J. Hurst

Improved separations methods and processes for recovering strategic materials are being developed. In cooperation with TVA, the chemistry related to the recovery by solvent extraction of the approximately 4,000 tons of uranium dissolved in the phosphoric acid processed annually by the U.S. fertilizer industry is belng developed. In another study, high-resolution pressurized ion exchange is used for difficult separations such as Co-N1 and $\mathrm{Zr}-\mathrm{Hf}$. In st 111 another study, the complexing abllity of various cage-like diazopolyoxamacrocyclic molecules (cryptands) for lanthanide ions is being explored as a basis for the separation of lanthanide and actinide elements. . Because the complexes formed contain the cation inside the molecular cavity or cage, a strong correlation of stability with structure and cation size is expected. Finally, statistical-mechanical and the rmodynamic theories for liquids, liquid crystals, and other ordered fluids and polymers are being developed to explain and predict solute-solvent interactions, aggregation and phase separation important in solvent extraction processes. Particular attention is being focused on the effects of the shapes, flexibilities and specific interactions of mixture components. These theoretical and selected experimental studies are being used to predict behavior in both new and existing separation processes.

148. FLOW THROUGH POROUS BODIES

2.5

$02-2$

J. S. Johnson, S. Y. Shiao

Fluid flow through porous media is involved in such diverse topics as chromatographic columns, solution mining, filtration, membrane processes, enhanced ofl recovery, and migration of nuclides through geological formations; this program has carried out research bearing on all of these. At present, dispersion in flow through homogeneous and non-homogeneous beds, both with and without density and viscosity gradients, is a subject receiving considerable attention. Development of the axial filter for measurements of adsorption continues. This configuration is comprised of a filter mounted on a cylinder rotating rapidly in a chamber containing a suspension of adsorbent. Liquid is pumped through, and from the change in concentration of adsorbate in passage, distribution coefficients can be computed. The method, which is particularly useful for highly dispersible adsorbents, difficult to study in columns, is being successfully extended to conditions where adsorption 1sotherms are nonlinear. Separation by filtration of two substances, both dispersed in liquids as aggregates of large but different size, is under investigation. 
Chemistry Division, ORNL, continued

149. MOLTEN SALT PROCESSES FOR

HIGH LEVEL RADIOACTIVE WASTE

$1.0 \quad 02-2$

F. J. Smith

Radiation resistant solvent extraction systems are under investigation because of their potential application to short cooled fuels. Molten salt/molten metal systems appear inherently favorable from this point of view and also from the point of view of proliferation resistance. In addition, separations are being sought that will make waste management easier downstream and, where possible, scarce metals, such as palladium and rhodium, will be recovered in a non-radloactive condition from short -cooled fuels and/or process wastes. For example, ruthentum can be first separated from the fuel and other fission products, and, after appropriate decay, palladium and rhodlum are separated from ruthenlum and each other using liquid metal extraction methods. Dissolution of oxidic fuels in molten $\mathrm{LiCl}-\mathrm{AlCl}_{3}$ mixtures and the subsequent partitioning of fission products by extraction into liquid bismuth is currently under investigation.

150. SPECTROPHOTOMETR IC STUDIES OF

2.0

02-2

SOLUTIONS WITH ALPHA-ACTIVE

MATERIALS

L. M. Toth, J. T. Be11

Actinide photochemistry is being Investigated with recent emphasis on photosensitive redox reactions in aqueous solutions of plutnntim and neptunium. Spectroscopic techniques (including visible, ultraviolet, infrared, Raman, conventional and laser photochemistry) are appl led to a variety of physical states (solid, liquid, polymer, gas) and chemical mixtures (solutions, aqueous and/or organics). The concentrations and natures of species in questinn are determined in order to dearribe thu basic physical chemistry of the systems. Systems are selected for study on the basis of their pertinence to separations problems in the nuclear fuel cycle, waste management, and the environment. For example, if the ruduction of $\mathrm{Pu}$ can be done pliuluchemicaliy in fuel reprocessing, the waste management problem may be easier to handle than if a metalific reductant is added which itself then adds to the waste. 


\section{Separations}

Chemical Technology Division

Total $\$ 1,650,000$

Oak Ridge National Laboratory

P. 0. BoX X

Oak Ridge, Tennessee 37830

151. SEPARATIONS SYSTEMS RESEARCH

C. F. Coleman, W. J. McDowe11

$5.5 \quad 02-2$

This research is concerned with the origination, improvement, and investigation of chemical separations in producing and utilizing energy from both nuclear and non-nuclear sources. Solvent extraction and ion exchange procedures are emphasized. New, potentlally useful separations agents are originated or acquired, their effectiveness is examined, and their chemical characteristics and behavior are investigated. The descriptive chemistry associated with promising reagents is complled and interpreted, with recommendations made for process applications. The problem areas to which this separations chemistry research apply are the nuclear fuel cycle (ore, spent fuels, wastes), coal technology, and resource recovery: Separations being studied include metal lons ( $U$, Th, Po, actinides, alkali metals, alkaline earths, $\mathrm{Al}, \mathrm{Fe}$ ), weak and unusual acids (acetic, formic, thiocyanic, phenols), and organic molecules such as alcohols. Reagents being studied include alkyl amines; alkyl-phosphates, -phosphine oxides, and -phosphoric acids; sulfonic acids; carbamoylmethyl phosphonates; and crown ethers. A computer-searchable data base relating to this work is being collected and maintained.

152. CHEMICAL ENGINEERING RESEARCH

$5.1 \quad 02-2$

S. D. Clinton, B. R. Rodgers

Th1s program investigates fundamental chemical engineering problems involved in energy production and utilization. Of particular interest is the investigation of new engineering concepts or unique unit operations which relate to the utilization of advanced energy sources, the recovery of important resource materials, and the environmental control of waste streams. An Improved rotating annular chromatograph to continuously separate components of a multicomponent system with a relatively high throughput is used to produce more efficient separations and improved chromatograph performance. Aggregation processes in solid-1iquid suspensions are studled to derive a mechanism for solids agglomeration in coal-derived 11quids. Scouting experiments on high temperature slagging processes for purifying metals are carried out. Mass transfer rates into the slag are simulated using a gas-sparged, mercury-water contactor system operating at room temperature. Novel reactors for rapid heterogeneous reactions such as those which can occur in coal gasification and Ilquefaction processes are studied. 
Chemical Technology Division, ORNL, continued

153. FUNDAMENTAL CONCEPTS FOR RESOURCE RECOVE RY

A. D. Kelmers, R. M. Canon

This program investigates chemical concepts for recovering useful resources from energy and industrial wastes, low-grade ores, and tallings from mining operations. Metal values are recovered from wastes produced by coal utilization, especially fly ash and coal conversion ash. Ashes are potentially important sources of aluminum, iron, and titanium and could reduce our dependence upon imported aluminum and titanium ores rather than create significant disposal problems which could become especially acute with Implementation of the Resource Conservation and Recovcry Aet. Chemliul techniques are studied for recovering these materials and for removing hazardous metals which may hamper disposal of the ash or process residue. Potentially marketable trace metals are identified. Extraction of mineral values from processing residues and wastes provides an important source of several metals, reduces environmental problems assoclated with disposal of the waste, reduces requirements for fresh ores, conserves energy, and reduces the U.S. dependence upon foreign minerals.

154. WASTE STEAM PROCESSING STUDIES

2.0

02-2 M. H. Lloyd

This research provides basis suppint to nuclear fucl reprocessing in the area of loss mechanisms for plutonium into waste streams. Plutonium complexes as well as insoluble molybdates which incorporate plutonium are 1dentified. The nature of plutonium polymer is also elucidated. Spectrophotometric analyses of plutonium complexes in solutions of tributyl phosphate in $n$-dodecane are made. Complexation of radiolytic decomposition products of tributyl phosphate as well as its hydrolysis products with plutonium are studied. The relative strengths of plutonium, uranium, zirconlum and thorium complexes with monobutyl and dibutyl phosphates are determined. Formation rates as functions of nitric acid and metal concentrations as well as temperature are studied during preparation of insoluble molybdates carrying plutonium. X-ray powder patterns are ubed to 1dentify and characterize molybdate compounds that precipitate from solution. 
Chemical Technology Division, ORNL, continued

155. CHEMISTRY OF SELECTED FISSION

1.5

$02-2$ PRODUCT ELEMENTS

J. C. Mallen

The major objective of this program is to obtaln basic chemical data for potential application to nuclear fuel cycle processes. Activities include kInetic studies of the rates of solvent extraction of thorium and of zirconium as well as other fission products. These data are used to elucidate the mechanisms of extraction from which the separation performances using fast contactors are predicted. Literature reviews of the chemistry of ruthenium and zirconium in the Purex process are complled. Laboratory studies of the aqueous nitrate chemlstrles of fission products yield information that 18 used to explain both the kinetic behavior for zirconium and the equilibrium behavior during solvent extraction in the case of both zirconfum and ruthenlum. Spectrographic methods for monitoring reactions of ruthenfium species are being developed. Other studies include the identification and elucidation of the behavior of nitrosyl-nitrato, chloro, and bisulfite complexes of ruthentum.

156. TRITIUM SEPARATION TECHNOLOGY

$2.1 \quad 02-2$

J. B. Talbot, P. W. Fisher

Th1s program obtains fundamental information on separation of tritium from materials proposed for uee in fission or fusion reactors. Recovery nf. tritium from liquid lithium, the most promising material for fusion reactor blankets, is being studied using solid yttrium sorbents. The tritium recovery method must be particularly efficlent to maintain a sufficiently low Inventory of residual tritium in the blanket. Results show that yttrlum sorhent.s can remove tritium from lithlum at rates sufficlently fast to meet process requi rements. A small flowing lithium loop is used to evaluate quantitatively 1iquid and solid mass transfer resistance in the sorption process. Studies are carried out on thermal regeneration of yttrium sorbents. Equilibria sorption 1sotherms for hydrogen isotopes and helium on molecular sieves (types 5A, 13X, and NaY) at temperatures down to $4.2 \mathrm{~K}$ are measured. These data are important in vacuum pumping and fuel purification techniques for fusion energy. 
Analysis

Ames Laboratory

Iowa State University

Ames, Iowa 50011

157. ANALYTICAL SPECTROSCOPY

V. Fassel, R. Rniseley

A. D'Silva; W. Haas
Total $\$ 743,000$

6.35

$02-3$

In this project, particular emphasis is placed on the development of basic science, the investigative methods, and the hardware 80 that trace and ultratrace inorganic and organic constitutents may be characterized and quantitated in a practical manner. The major effort is devoted to the systematic observation of spectroscopic phenomena and to the development of new analytical concepts that offer promise of solving the singularly difficult analytical problems that either exist now or are 11kely to arise In the various fields of energy generation, the conversion of coal to liquid and gaseous fuels, solid state materials research, environmental pollution, and in the biomedical-nutritional sciences. Presently, emphasis is being placed on: (a) the further development and refinement of Inductivelycoupled and other plasmas as vaporization-atomization-excitation ionization sources for analytical atomic emission and fluorescence spectroscopy; (b) the analytical applications of highly selective energy transfer processe $s$ from $X-r$ ay beams to trace activators in solid state materials and from metastable gaseous specles to trace inorganic or organic specles; (c) photoacoustic spectroscopy of condensed matter, especially optical materials, and solar conversion and energy conservation materials; and (d) application of new developments emerging from (a) to (c) to critical unsolved problems in analytical characterization and quantitation. 
Ames Laboratory, continued

158. ANALYTICAL SEPARATIONS

$2.95 \quad 02-3$

J. S. Fritz

The primary objective of this research is to develop innovative methods of separation and chemical analysis. A unique and effective system for separation and measurement of anions in aqueous samples is being developed. The most essential parts of the new system are an anion exchange column for separation and a conductance detector. Success is achleved by two principal innovations: (1) use of new, low-capacity anion-exchange resin developed by this group, and (2) use of an eluent having a very low conductance. Many successful separations have been obtalned with samples containing anions of very low concentrations, and the applicability to analysis of real samples 18 belng proven. Other work in progress concerns development of a method for determination of organic pollutants in water, and in synthesizing new resins for removal of polsonous or valuable metal ions from aqueous solutions. The method for analyzing organic pollutants solves most of the existing water sampling problems and permits concentration and analysis of pollutants presept in water at concentrations as low as $0.01 \mathrm{ppb}$ (one part pollutant

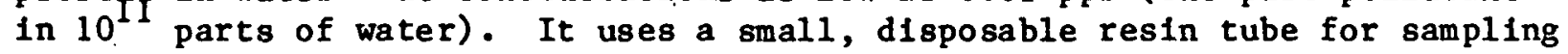
followed by thermal desorption of the concentrated organic pollutants into a gas chromatograph.

159. ANALYTICAL MASS SPECTROSCOPY

$3.21 \quad 02-3$

H. J. Svec, R. Conzemius,

G. Junk

This program concerns the further development and refinement of a laser-mass spectrometer probe capable of spatial resolution to $\sim 25 \mu \mathrm{m}$ with trace level analytical sensitivity. Teses with LwU NB3 biasses and one NBS otoel Indicate analytical results for 21 elements in the two metallic matrices in good agreement with values certified by the NBS. The results also confirm suspicions that arsenic is inhomogeneously distributed in the steel sample. The probe gives excellent analytical results when tested with rocks containing small grains of feldspars, micas, and silica, demonstrating distinct differences in elemental composition in various grains. Another interesting analysis is that of $20 \mathrm{~mm}$ layers of silicon deposited on sapphire. First the silicon is analyzed layer by layer and then the sapphire. When photographic ion detection is used in these tests, complete periodic table coverage at sub parts-permillion levels is obtained. Another project concerns a separation scheme for complex organic mixtures. Mixtures of strong and weak acids, aldehydes, ketones, and non-polar and polar compounds are separated and these fractions are subjected to further separation via gas chromatography and/or 11quid chromatography. Identifications are made using mass spectrometry and allied instrumental techniques. The scheme works well with a mixture of 50 selected compounds each at the $10 \mathrm{ppm}$ level and is being tested further with real camples from fossil fuels. 
Ames Laboratory, continued

160. ACTIVATION ANALYS IS

0.29

$02-3$

A. F. Volgt

Several approaches have been trled toward the use of prompt gamma rays from neutron capture for on-line monitoring, particularly of coal for its sulfur content. In previous systems fast neutrons from the spontaneous fission of californium-252 have been used directly, and the target material, coal, has served as moderator as well as analyte. In the current work an external moderator, zirconium hydride, is placed between the neutron source and the target. Several different placements of a 5mg Cf source, target materlal, shielding and detector have been tried but no satisfactory response was nht af ned. Shiolding materlal sufficient to reduce the background radiation from the source, Cf fission product gamma rays, to acceptable levels also reduced the signal from the target material to levels too low to be useful. No arrangement of shielding thickness and source and detector distances was found to give favorable results. The use of a large source and external moderation does not appear to 1mprove on the previous arrangements.

\section{LASERS IN ANALYTICAL CHEMISTRY} E. S. Yeung

W1th the projected increase in the use of coal and other fossil fuels. the emission of various forms of pollutants into the environment can become a serlous problem. The need for sensitive, selective, and rellable monitoring methods for these pollutants therefore also increases. Several laser analytical techniques are belng developed so that one can gain some unique insights into the production and the transport of trace elements, organics, and gaseous pollutants resulting from fossil fuel utilization. Emphasis is on (1) atomic emission and atomic fluorescence studies on the disposition of trace elements; (2) liquid chromatographic determination of organic pollutants using more selective detectors; (3) inverse Raman excitation and acoustic detection of trace gases; (4) timesynchronous Raman spectroscopy as a remote monitorin\% "ool for combustion chambers; (5) studies of opectral interference. In lous path infrared absorption and infrared photoacoustic measurements of gaseous pollutants with the hope of eliminating such interferences; (6) evaluation of practical pollution monitoring instruments based on lasers at representative pollution sources, including smokestacks and automobile exhausts. 
Analy818

Chemistry Division

Argonne National Laboratory

9700 South Cass Avenue

Argonne, Illino1s 60439
Tota1 $\$ 320,000$

$0.7 \quad 02-3$

162. RADIOACTIVE ISOTOPES AND NUCLEAR TECHNIQUES AS ANALYTICAL TOOLS FOR BIOLOGICAL PROBLEMS
A. M. Friedman

These studies, in collaboration with faculty members at Governors State University, have concentrated on the development of techniques using radioactive sulfur compounds, which will help delineate the pathway and mechanisms of the uptake of sulfur into peat. A longer term objective is gaining understanding of the pathway for incorporation of sulfur into coal. Methods of preparing the radloactive sulfur compounds in pure form, introducIng quantitative amounts of these compounds into living peat samples, and separating and quantifying the amount of radloactive sulfur in each peat chemical fraction have been developed. These techniques have now been shown to be useful and reproductble and have been utilized to show that elemental sulfur, amino acid and inorganic sulfates are all used by the peat and are converted into compounds which include sulfate esters, organic sulfur fractions, and acid fractions. It is hoped that a knowledge of the eventual chemical fate of these sulfur containing fractions may lead to improved methods for the desulfuration of coal. 
Chemistry Division, ANL, continued

163. STUDY OF ATMOSPHERIC TRACE

$2.0 \quad 02-3$

GASES B BY MASS SPECTROMETRY

C. M. Stevens

The major objective of this program is to determine the sources and production rates of atmospheric $\mathrm{CO}$ on a global scale by means of isotopic distribution measurements. Another very important objective of this work is the determination of the atmospheric concentration of the $\mathrm{OH}$ radical and any changes in this key species over the last decade. These studies of atmospheric CO produce what may be the only existing data for determining whether the concentration of $\mathrm{OH}$ has decreased over the past decade due to the increasing amounts of pollutant trace gases. Since oH $1 \mathrm{~s}$ the principal scavenger of almost all pollutants such as $\mathrm{CO}, \mathrm{SO}_{2}$ and NO, any significant reduction in its concentration would result in increased residence times and higher concentrations of these pollutant gases with possible long-range deleterious effects on agriculture, health and climate. Since the atmospheric methane cycle is related to the atmospheric $\mathrm{CO}$ and $\mathrm{OH}$ cycles, another phase of the experimental program is to determine the sources and production rates of this trace gas more accurately. The determination of carbon-14 in atmospheric CO is a long-range objective. Such determinations will give an independent measure of the production rate of natural CO from the isotopic dilution effect on cosmogenicallyproduced ${ }^{14} \mathrm{Co}$.

164. ANALYTICAL DEVELOPMENTS IN MASS
SPECTROMETRY-CHROMATOGRAPHY AND
SUPPORTING SYSTEMS
M. H. Studier, R. Hayatsu,
R. E. Wluans

Instruments, procedures, and data handling techniques for the analysis of very complex organic systems are being developed and improved. The primary emphasis is on the characterization of the structural features of fossil fuels and their conversion products, especially the macromolecular components; some problems in fossil energy research are so complex that they tax the most sophisticated analytical systemo. Instrumentation requiled for photosynthesis, catalysis, and separation research programs is also being developed. These programs have a continuing need for new instruments and chemical procedures and for improvements in the efficiency of collection and interpretation of pertinent data. These operations are unique in that a variety of separations and diagnostic techniques have been coupled to extremely sensitive mass spectrometers. As a complement to the mass spectrometers, this program utilizes a microwave plasma emission spectrometer, interfaced to a gas chromatograph, which quantitatively and simultaneously measures carbon, hydrogen, deuterium, oxygen, nitrogen, sulfur, chlorine and fluorine with high sensitivity. This new instrument is proving to be useful in identifying compounds contalning heteroatoms and in deuterfum labeling experiments. 
Analysis

Chem1stry Department

Total $\$ 220,000$

Brookhaven National Laboratory

Upton, New York 11973

165. APPLICATIONS OF NUCLEAR METHODS

2.0

$02-3$

TO ANALYSIS

G. Harbottle, E. V. Sayre,

R. W. Stoenner

The basic thrust of this program is to extend and improve nuclear methods of elemental analysis, particularly those methods which permit the determination of many components (Including trace impurities) quickly and efficlently, and to develop methods of computer-based multivariate statistical analysis which will permit the efficient and effective analysis of large asemblages of such analytical data. These methods are being applied to a wide varilety of materials for which geographic origins are of significant interest, or for which the sources of environmental pollution that have affected the trace impurity pattern of the materials analyzed are a matter of concern. Specific examples of these investigations range from the determination of 38 chemical elements in pine needles from living trees, the concentration levels of which have been found to be indicators of the ambient levels of air pollution, to the correlation of trace impurity patterns with geographic origin in metals, clays, and other minerals and in man-made artifacts fabricated from these materials. Improved dating techniques by thermoluminescence, lead 210 , and carbon 14 are being investigated and applied to a varlety of problems: thermoluminescence as an indicator of geographic origins and as a mineral resources prospecting method; lead-210 methods to study lead uptake from the atmosphere and to differentiate between its introduction into the atmosphere, elther naturally or artificially; and carbon-14 dating for analysis of samples as small as $10 \mathrm{mg}$. 
Analysis

Department of Energy and Environment

Total $\$ 157,000$

Brookhaven National Laboratory

Upton, New York 11973

166. TRACE ELEMENT ANALYS IS USING

0.7

$02-3$ SYNCHROTRON RADIATION

B. Gordon, M. Hillman

This project has as its goal the development of an $x$-ray fluorescence system for multielemental trace analysis using synchrotron radiation from the National Synchrotron Light Source (NSLS). The properties of synchrutrun radlation-a continuous tunable spectrum, high intensity and collimation, highly polarized, and low radiation damage-make possible an $x$-ray microprobe with one micrometer spatial resolution and sensitivites in the part per milion concentration range in solid samples. Calculations have been initiated to study beam demagnification techniques to obtain the highest microprobe beam fluxes possible in the energy range of interest. These ray-tracing calculations take into account the structure of the NSLS stored electron beam which emits the synchrotron radiation. Calculations of sensitivities using synchrotron radiation for bulk sample analyses using a solid state detector have been completed. These calculations indicate that use of the tuning features of synchrotron radiation and the reduction of background counts using polarized radiation allows determination of most trace elements at the 50 to 100 parts per billion concentration 1 evel with one minute irradiations. Sensitivity calculations are being extended to include the use of crystal spectrometer detection systems. Since the NSLS is to be a national users' facility, considerable effort has gone into establishment of a users' organization whirh wi1 bo responoiblc for operation of the $x$-ray fluorescence program. 
Department of Energy and Environment, BNL, continued

167. DETERMINATION OF FRAGILE MOLECULES

2.6

$02-3$

IN THE ENVIRONMENT

R. Tanner

This research project has the long-term goal of devising and developing fundamentally new analytical methods which are sufficiently sensitive and selective to determine traces of potentially reactive substances in the environment. The fundamental approach is the use of derivatizationchromatographic separation-selective detection techniques. Development of a method for the detection of nanogram quantities of nitrate in a variety of environmental samples by nitro-derivatization-GC has been essentially completed. A new techinique for the determination of atmospheric levels of ammonia and primary amines is being developed, based on fluorescent derivatization with o-phthalaldehyde. Optimization of a continuous analysis system for ammonia is well advanced and the incorporation of a gaseous scrubber of known, reproductble efficiency in the analysis system is in progress. Preliminary studies on the determination of acidic sulfur compounds by methylation-GC with flame photometric detection and of trace carboxylic acids by ion pair extraction and derivatization with an electron-capture sensitive alcohol have begun. 
Analysis

Physics Department

Brookhaven National Laboratory

Total $\$ 125,000$

Upton, New York 11973

168. DEVELOPMENT AND APPLICATIONS OF

$1.9 \quad 02-3$

NUCLEAR PARTICLE MICROSCOPY

K. W. Jones, H. Kraner

The methods of nuclear and atomic phyeics are used to develop and apply techniques for the quantitative measurement and precise spatial localization of stable isotopes. Particle beams from a $3.5 \mathrm{MV}$ Van de Graaff, MP Tandem Van de Graaff facility and high flux reactor are used to identify isotopes through production of unique atomic and nuclear signatures and Include the use of proton Induced x-ray fluorescence, Rutherford backscattering, and nuclear reactions. Spatial localization is achleved by use of particle microbeams of position-sensitive detectors. For example, femtogram quantities of deuterium can be determined with a spatial resolution of $20 \mu \mathrm{m}$ by use of the $D(t, \alpha) n$ reaction and a plastic track detector. Typical collaborative work in progress includes studies of the genetic effects arising from exposure to tritium at low concentrations, amounts of trace and minor elements contained in coal and fly ash, diffusion of heavy metals in graphite at high temperatures, effects of chelation therapy on trace elements in bone, and the distribution of zinc and copper in various types of bone and cartilage. 


\section{Analysis}

Energy and Environment Division

Total $\$ 108,000$

Lawrence Berkeley-Laboratory

University of California

Berkeley, California 94720

169. CHEMICAL ANALYS IS

$1.6 \quad 02-3$

R. Clem

The overall goal of this program is the development of a trace element methodology that can routinely be used in energy-related research. Exploratory studies are undertaken to point the way toward possible applications of this methodology. Trace multi-element X-ray fluorescence analytical techniques are being developed. Presently up to forty two elements are determined in a variety of samples, including raw and spent oll shales, shale o1ls, oil shale retort waters, industrial waste 11quids, coal, and industrial solid wastes. Improved sensitivites for a broader range of sample types will be obtained. Electroanalytical techniques are being developed for use in energy-related research. Ozone, in conjunction with UV irradiation, is belng assessed as a means to destroy organic matter in oil-shale retort waters, prior to trace metals analysis. Chemically modified glassy carbon surfaces, on which quarternary ammonium bases are synthesized, are used for trace determination of metal chloro-anions. 
Analys 18

Analytical Chemistry Division

Oak Ridge National Laboratory.

P. 0. Box X

Oak.Rldge, Tennessee 37830
Total $\$ 1,004,000$

,

170. ION MICROPROBE MASS ANALYZER

R/D: SURFACE CHARACTERIZATION

$1.5 \quad 02-3$

W. H. Chrlstie, R. J. Warmack

R. W. Stelzner, R. E. Eby

The overall objectives of this program are to develop state-of-the-art methods for acquiring, processing, and quantifyling secondary ion mass spectrometric data, and demonstrate the applicability of SIMS to the solution of surface analytical problems in on-going DOE research programs. A variety of quantification methods are belng investigated. Relative sensitivity factors indexed by a matrix ion species ratio are being explored in conjunctIon with oxygen flooding techniques to quantify ion ylelds from oxidizable metal surfaces. Ion implantation standards are being used as a means of studying the way chemical effects alter ion yields. A cesium ion source $1 \mathrm{~s}$ belng developed for use with the microprobe. The source currently develops current densities in the $1 \mathrm{ma} / \mathrm{cm}^{2}$ range and work $1 \mathrm{~s}$ underway to increase this to $10 \mathrm{ma} / \mathrm{cm}^{2}$. This source will provide a means for significantly enhancing negative ion yields of elements with appreciable electron affinities. Preliminary studies show that this source will allow quantitative depth profiling of n-type dopants in photovoltalc devices. 
Analytical Chemlstry Division, ORNL, continued

171. ADVANCED SPECTROSCOPIC METHODS FOR CHEMICAL ANAL, YS IS

L. D. Hulett, J. M. Dale,

H. W. Dunn, E. Ricci

The purpose of this work is to use electron and X-ray physics in the development and application of analytical methodology and to complement these techniques with other spectroscoples selected according to problem solving requirements. Five techniques are being used in development and application of analytical methodology: (1) X-ray induced X-ray fluorescence (XRF); (2) X-ray diffraction (XRD); (3) electron spectroscopy (ESCA, . Auger) (4) scanning electron microscopy, with its associated energy dispersive $X$-ray fluorescence (SEM-EDX); (5) transmission electron microscopy (TEM). All of these methods are simflar, in that they involve the flelds of either electron physics or X-ray. physics, or both; by understanding and applying fundamental principles, analytical utilities can be enhanced. Recent examples of this approach are Improved sensitivities in XRF and XRD by means of monochromatized excitation and scattering beams and an absolute method of quantitative XRF analysis that used fundamental constants for matrix correction. A micro-ESCA technique, using a miniature electron spectrometer in an SEM, is being tested. The practicality of surface analysis by positron scattering is being evaluated. Current research programs utilizing the above methodologles are the chemical spectation of fly ash, the adsorption of trace elements on metal oxides and solls, corrosion Inhibition of titanium, defect structures at the surfaces of solar energy converters, and the poisoning of cathodes used as electron cources in ancelerators, Long-term goals of this program are directed toward coal and solar energy research. 
Analytical Chemistry Division, ORNL, continued

172. MASS SPECTROMETRY R/D FOR ORGANIC ANALYSES

W. T. Rainey, D. C. Canada,

D. H. Russe1l, C. A. Pritchard,

E. H. McBay

This program has the following primary objectives: 1) to study lonization processes and the chemistry of gas-phase ions in the mass spectrometer, including both unimolecular field-free dissociations and dissociations induced by collision or photon activation; 2) to develop instrumentation and methodology for carrying out these studies; and (3) to develop new techniques for organic analyses, with particular emphasis on problems involving structural configurations. A oystem with ullid high sensitivity and mass resolution and various scanning modes is being used to rigorously study the chemistry of tons such as the $\mathrm{C}_{7} \mathrm{H}_{7} \mathrm{O}^{+}$Ion as obtained frum a variety of precursor molecules. The capabilities of the mass spectrometer are being further expanded by the addition of a mass marker and circuitry for scanning of the magnet (B) and electric sector (E) voltage maintaining the ratio $\mathrm{B} / \mathrm{E}$ constant, yielding higher sensitivity without source defocusing. The ORNL double focusing instrument has been converted to a three-sector instrument by adding a second electric sector and, with the addition of gas collision cells and a xenon arc lamp, is being used in the study of induced dissociation reactions. The three-sector instrument is capable of high resolution mass analysis prior to the dissociation process with high energy resolution performed by the second electric sector. 
Analytical Chemistry Division, ORNL, continued

173. ADVANCED SPECTROMETRIC METHODS

$02-3$ FOR CHEMICAL ANALYS IS

H. H. Ross, C. Feldman,

J. M. Ramsey, R. W. Shaw,

W. B: Whitten, J. P. Young,

L. N. Klatt

The objective of this effort is the development of state-of-the-art spectroscopic methods for general application. Time-of-flight optical spectroscopy using fiber optic waveguides has been advanced by the development of a dual beam measurement system. The resulting time domain data can be developed into high quality, background corrected spectra. A simple power meter for pulsed lasers is under development. Th1s high senisitivity meter is based on the use of an optoacoustic Helmholtz resonator cell: A laser-induced nuclear polarization (LINUP) technique is being developed to study short-lived ( $<10 \mathrm{~ms}$ ) nuclel. Stydies are underway to define the nuclear shape of the fission isomer ${ }^{240 \mathrm{~m}} \mathrm{Am}$ using the LINUP method. A combination of rapld scan spectrometry and electrochemistry is being used to study the chemistry of sulfur in molten $\mathrm{AlCl}_{3}-\mathrm{NaCl}$. This work will lead to a better understanding of the sodium-sulfur molten salt battery. A glow discharge detector is being developed as a high-sensitivity, fluorine-specific detector. The development of a background correction device virtually eliminates band emission interference. A microspectrophotometry system ${ }_{2}$ is being used to study transuranium compounds (solids) as small as $5 \mu \mathrm{m}$. These studies are used to infer the chemistry and radiochemistry of the transuranium elements. A theoretical model is being developed to define the important parameters of atom cell geometry in atomic absorption spectroscopy. The result of this work will be used to predict the optimum burner design for a given optical configuration and also point out the importance of reducing analyte flicker notse. 
Analytical Chemistry Division, ORNL, continued

174. MASS SPECTROMETRIC R/D FOR

$$
2.5 \quad 02-3
$$

INORGANIC AND ACTINIDES

ANALYSES

R. L. Walker, D. H. Smith,

D. L. Donohue, T. R. Mueller,

R. J. Warmack

This research involves the use of thermal emission mass spectrometry (TEMS) for 1sotopic composition and isotope dilution measurements, and s park source mass spectrometry (SSMS) for elemental measurements of nuclearand fossil-related materials. Studies to improve TEMS measurement of small samples using lon exchange resin beads are belng emphasized which are applicuble to energy, environment, and safeguards programs. Fractionation effects, sources and source geometry, scanning modes, improved electronioo, and data acquisicion systems are major areas where work is underway to Improve the precision of thermal emission measurements. New mass spectrometer designs are also being considered which will optimize the dispersion and mass coverage with a channel electron multiplier array detector. Work is progressing in the development of a channel electron multiplier array detector for SSMS. Studies are being initiated into the basic processes in the r.f. spark ion source so, as to improve the analytical results in SSMS. Boxcar averaging and fast electronic gating are being used to study the time resolved behavior of the r.f. spark. 
Analysis

Physical Sciences Department

Tota $1 \$ 605,000$

Pacific Northwest Laboratory

P. 0. Box 999

Richland, Washington 99352

175. ULTRASENSITIVE RADIOMETRIC

$0.8 . \quad 02-3$

ANALYT ICAL TECHNIQUES

F. P. Brauer, J. H. Kaye

The objective of this program is to develop new and improved ultrasensitive and selective nuclear emission energy measuring techniques for analysis of radionuclides produced in nuclear processes and in activation analysis applications. Currently, both new low-background detector systems and new low-level data acquisition and reduction methods are being investigated. Studies are being conducted with phoswich detectors which consist of two separate scintillants. One such detector is a $0.25 \mathrm{~mm}$ thick europium-activated calcium fluoride [CaF $(\mathrm{Eu})]$ crystal for sensing alpha and beta particles. It is optically coupled by means of a quartz light pipe to the second detector, a thallium-activated sodium lodide [NaI(T1)] gamma-ray crystal. With this detector system signals arising in the $\mathrm{CaF}_{2}(\mathrm{Eu})$ detector can be separated from those from the NaI(T1) detector by the difference in the pulse shapes of the two materials. This permits operation of the detector system as a very large area beta anticoincldence shielded counting system, or as a low-background beta-gated colncidence counting system for gamma-ray spectrometry. A method is being developed for very low-level radioactivity measurements. It requires storing on magnetic tape the time at which decay events occur which meet specific constraints with regard to energy, time coincidence and/or pulse shape. After measurements on a sample are completed a computer analysis of the time-of-event data is conducted. This technique will be especially valuable for cases where only a few events of interest occur during the measurement interval and it is necessary to obtain as much information as possible from these events. 
Physical Sciences Department, PNL, continued

\author{
176. ULTRASENSITIVE LASER-BASED \\ 1.0 \\ 02-3 \\ SPECTROMETRIC ANAL YTICAL \\ TECHNIQUES \\ R. W. Goles
}

The objective of this work is to develop ultrasensitive and selective laser-based analytical techniques for detection, identification and measurement of trace substances. Currently a highly sensitive technique developed for nuclear property determination of rare, short-lived isotopes is being analytically exploited. The basts for this analytical technique lies in the fact that a single atom passing transversely through a laser beam can resonantly scatter many photons over a relatively short period of time. The number of scatter photons per atom is determined by the transit time of the atom, the lifetime of the excited state and the laser photon flux. For allowed transitions, a laser beam diameter of $1 \mathrm{~mm}$, and atoms having ambient thermal velocity, one can expect 30 photons/atom to be scattered. Thus, the passage of a single atom through a laser beam can, under the right conditions, be characterized by a time-correlated group of scattered photons. By recording such grouplngs, a significant discrimination against the random part of background 18 achleved, resulting in a dramatic improvement in analytical detection sensitivity. Analtyical development of this multi-photon, single atom detection technique is currently underway. 
Physical Sciences Department, PNL, continued

177. ULTRASENSITIVE MASS SPECTROMETRIC

ANALYTICAL TECHNIQUES

R. L. Gordon, C. R. Lagergren

This program examines factors important to surface ionization and conducts instrumentation research and development with an emphasis on new methods for real-time monitoring of atmospheric pollutants using mass spectrometry. Research in surface ionization encompasses development of new materials for application as sources for both positive and negative thermal lonization mass spectrometry and investigation of the kinetics of ion generation using thermal desorption spectroscopy. Investigations of the dependence of surface work function on alloy composition are being conducted in an Auger spectrometer. In addition to potentlal for identifying new surface Ionization sources, this work is expected to contribute to the understanding of factors important to the determination of the work functions of alloys. Investigation of the kinetics of $\mathrm{Pu}$ production on carburized Re filaments indicates that complicated temperature-dependent flow of carbon between the filament and the sample is responsible for observed behavior. A theoretical model which includes a chemical reaction involving $P u$ and $C$ gives results which qualitatively reproduce all observed ion production behavior, but does not yet include a proper description of carbon flow. A second part of this program concerns the development of instrumentation to investigate a new analytical technique, direct-inlet mass spectrometry. A first concept of distributed detector which is based on electro-optical components is being installed. This detector consists of an $20 \mathrm{~cm}$ long channel electron multiplier array backed by a phosphor coated fiber optics foreplate which al so serves as a vacuum barrier. Fiber optic reducers are used to conduct the output light to 4 charge-coupled photodiode arrays which in turn' are "read" by a minfcomputer. The performance of the entire instrument equipped with a source designed to sample particles in air directly is being determined. 
Physical Sciences Department, PNL, continued

178. COMBINED ATOMIC ABSORPTION-
MASS SPECTROMETR IC ANALYT ICAL
TECHNIQUES
D. L. Styr18, J. H. Kaye

Atomic and molecular species emitted from reststively heated high temperature surfaces are belng investigated with a novel apparatus which monitors simultaneously the atomic absorption of selected atomic species and the mass spectrum of any other atomic or molecular species emitted. Present efforts are concerned with understanding how furnace atomic absorption signals are Influenced by the sample type and its immediate environment, e.g., gaseous environment, material composing the sample contalner and adsorbed impurtites. The ultra-high vacuum apparatus designed for these experiments allows control of the gaseous environment; this capability is being used to: determine the influence of this environment. For these experiments, the atomic and molecular emissions from rubidium chloride samples heated in high purity graphite, rhenium and tantalum cuvettes are being monitored and analyzed. The transient atomic absorption, mass spectrometer and cuvette temperature signals are monftored and correlated in time. Analyses of the se time correlated signals are then used to develop models which explain the observed emissions of neutral atoms, ions and molecular species. 
Chemical Engineering Sciences

Department of Energy and Environment

Total $\$ 25,000$

Brookhaven National Laboratory

Upton, New York 11973

179. THE ROTATING FLUIDIZED

0.7

$02-4$

BED COMBUSTOR

F. B. Hill

This program consists of a study of the rotating fluidized bed as a chemical reactor for the conduct of fast reactions such as combustion and includes experimental and theoretical studies of the fluld dynamics and reaction properties of the rotating fluidized bed. Measurements are being made of the properties of gas bubbles in rotating 11 quids and in rotating gas-solid fluidized beds. These will be followed by measurements of the exchange between bubbles and the emulsion phase and by studies of the chemical reaction properties of the rotating system using a well characterized model fast reaction. A parallel theoretical effort on the influence of rotation on fluidization 18 underway. 
Chemical Engineering Sciences

Energy and Environment Division

Total $\$ 100,000$

Lawrence Berkeley Laboratory

University of California

Berkeley, California 94720

180. TURBULENT COMBUSTION IN A

$2.0 \quad 02-4$ HEATED WALL BOUNDARY LAYER

F. Robben

Practical combustion, such as in automobile engines, coal and ofl fired boilers, and household heating furnaces takes place under turbulent flow conditions. This means that the temperature time history of a burning element of air and fuel is romplex and has large variation in time and space. Thus, even when the chemistry of combustion and pollutant generation is known, prediction of the combustion performance, efficiency and pollutant generation in practical combustors requires suitable approximations for combustion with turbulent fluid flow. It is belleved that approximate numerical computation, or numerical modeling, is capable of predicting turbulent combustion phenomena, and that well-chosen 1 aboratory experiments are the key to the development and testing of numerical modeling approximations. One classical turbulent flow which has been studied in great depth is the wall boundary layer, and the present experimental program consists of the measurement of the properties of lean premixed combustion in a turbulent heated wall boundary layer. Time and space resolved measurements of density and velocity, using Rayleigh scattering of laser light and laser Doppler velocimetry, are being carried out. Preliminary results from a $2.5 \mathrm{~cm}$ square channel at a Reynolds number of $10^{5}$ have been obtalned. The overall observation is that these results indicate a reduction in. the velocity turbulence level in the presence of combustion heat release. Study of the turbulent boundary layer with combustion in a larger $10 \mathrm{~cm}$ square channel at higher Reynolds numbers is presently underway. 
Chemical Engineering Sciences

Materials and Molecular Research Division Lawrence Berkeley Laboratory

University of California

Berkeley, California 94720
Total $\$ 48,000$

0.6

$02-4$

181. HIGH-PRESSURE PHASE EQUILIBRIA IN HYDROCARBON-WATER (BRINE) SYSTEMS

J. M. Prausnitz

The purpose of this project is to obtain quantitative information on the phase behavior of aqueous (or brine) solutions to methane (or natural gas) at high pressures. Such information is of interest for increasing the fundamental. understanding of strongly nonideal solutions and for rational design of processes for extracting natural gas from deep (aquifer) deposits found in Loulsiana and Texas. Experimental apparatus is under construction for measuring vapor-11quid equilibria in mixtures of methane and water (or brine) in the region $25-400^{\circ} \mathrm{C}$ and at pressures to 2 kilobars. This project's theoretical studies for aqueous solutions of methane are based on the perturbed-hard-sphere theory of flulds, extended to mixtures . Varlous theoretical models of Gmehling-Liu and a two-fluid theory using local compositions to take non-randomness into account are being studied. Extension to brines is expected to be based on Pitzer's theory of aqueous electrolytes. 
Chemical Engineering Sciences

Chemical Technology Department

Total $\$ 75,000$

Pacific Northwest Laboratory

P. O. Box 999

Richl and, Washington .99352

182. DEVELOPMENT OF PREDICTIVE MODELS

0.6

$02-4$

FOR FLUIDIZED BED AND ENTRAINED

SUSPENSIONS IN COAL CONVERSION

C. T. LI

The purpose of this program is to develop mathematical models which allow reliable design and evaluation of fluidized hed and entrained-suepenoton systems used in coal conversion processes. Models developed in this project can predict the performance of fluldized beds and entral nedsuspension reactors as a function of system size and configuration, chemical reactions, and physical changes occurring within various coal conversion reactor systems. The main concern is to develop a mathematical model to describe the phenomenon of bubble coalescence in fluidized beds. The model is based on the collision equation and physical parameters measured from laboratory-scale gas fluldized beds. The model is mathematically solved by the similarity method, and is belng combined with the gas-jet model developed in previous work and checked for overall rellability. 
Photochemical and Radiation Sciences

VIRGINIA POLYTECHNIC INSTITUTE AND STATE UNIVERSITY

Blacksburg, Virginta 24061

183. RECOIL PARTICLES FOLLOWING

$\$ 55,000 \quad 01-1$

NUCLEAR, TRANSFORMATIONS

H. J. Ache - Department

of Chemistry

An Important but still little understood field of fundamental chemical kinetics is the area that deals with those chemical reactions that occur above the threshold or activation energy. In this program translationally hot species (atoms or lons) are generated following nuclear reactions and their interactions with various substrates are studied in order to assess the reaction efficiencies as a function of the kinetic energles assoclated with the reactants. Studies of the nuclear decay induced reactions of halogen specles with organic compounds include the evaluation of the reaction mechanisms leading to halogen-for-halogen (or hydrogen) exchange and the stereochemistry of these processes. Studies are being conducted of non-synthetic methods to incorporate radioactive nuclides into compounds of biological interest, e.g. by nuclear decay Induced exchange. The energetics, mechanisms and the exact nature (i.e. spin state etc.) of the species involved in the reactions of energetic carbon-11 atoms with organic substrate molecules, the crystallochemical reactivity of trapped recoll particles and Implanted spectes, and the properties of micellar systems by nuclear probes are also being investigated.

PURDUE UNIVERSITY

West Lafayette, Ind1ana 47907
184. STUDY OF INJECTED ELECTRONS IN NON POLAR CLASSICAL LIQUIDS
G. Ascarelli
Department of Physics

Measurement of the Hall mobllity in high mobllity insulating liquids using transient techniques developed for the study of insulating solids are being conducted. The comparison of the Hall mobility and the drift mobility (obtained by a time-of-flight technique) indicates whether trapping effects suggested by other measurements are important. An optical study of the trapped electron will follow if the indication of trapped states is confirmed. 
Photochemical and Radiation Sciences, continued

UNIVERSITY OF MINNESOTA

Minneapolis, Minnesota 55455

\author{
185. STUDIES IN CHEMICAL REACTIVITY \\ Robert W. Carr \\ Department of Chemtcal \\ Englneering and \\ Materials Sclence
}

The kinetics and mechanism of the reaction of $\mathrm{CF}_{2} \mathrm{Cl}$ radicals with oxygen are being investigated. The photolysis of 1,3-dichlorotetrafluoroacetone is used as the source of $\mathrm{CF}_{2} \mathrm{Cl}$. The investigation is done by two different techniques: flash spectroscopy, and conventional photochemical methods using gas chromatography for end-product analysis. The reaction of $\mathrm{CF}_{2} \mathrm{Cl}$ with $\mathrm{O}_{2}$ plays a role in the stratospheric release of chlorine from $\mathrm{CF}_{2} \mathrm{Cl}_{2}$, as well as in directing the environmental fate of chlorine and fluorine following the tropospheric H-atom transfer reaction of $O H$ with $\mathrm{CHF}_{2} \mathrm{Cl}$. Experiments to detect the production of $\mathrm{CH}_{2}\left(\mathrm{~B}_{1}\right)$, the second excited state of methylene, from photolysis of ketene and diazomethape are peing done. $\mathrm{CH}_{2}\left({ }_{B_{1}}\right)$ is detected by the observation of the $\mathrm{CH}_{2}\left(\mathrm{~B}_{1}\right) \overrightarrow{1}_{1}$ $\mathrm{CH}_{2}\left(\mathrm{~A}_{1}\right)$ emission spect rum. Observation of the threshold energy for $\mathrm{CH}_{2}\left(\mathrm{~B}_{1}\right)$ production from ketene provides inforpation on the heat or formation of $\mathrm{CH}_{2}\left(\mathrm{~A}_{1}\right)$. Quenching studies of $\mathrm{CH}_{2}\left(\mathrm{~B}_{1}\right) \rightarrow{ }_{1} \mathrm{CH}_{2}\left(\mathrm{~A}_{1}\right)$ emission provide information of interest on the kinetics of ${ }^{1} \mathrm{CH}_{2}\left({ }_{\mathrm{B}}\right)_{1}$. A program of experiments aimed at direct detection of highly vibrationally excited molecules by photolonization is being undertaken. The vibrationally excited species is produced by chemical activation techniques. Information on the energy distribution and average energy of the chemically activated species is obtained. This type of data has not previously been obtained by direct methods, but rather has been inferred from final product ylelds. 
Photochemical and Radiation Sclences, continued

UNIVERSITY OF KANSAS

Lawrence, Kansas 66045

186. STEREOELECTRONIC PROPERTIES OF AGGREGATED CHLOROPHYLL SYSTEMS

$\$ 80,000 \quad 01-1$

Ralph E. Christoffersen, G. M. Maggiora

Department of Chemistry

$A b$ Initio quantum mechanical and other theoretical techniques are being employed in a comprehenstve investigation of the electronic structure and properties of ethyl bacterlochlorophyllide a, ethyl bacteriopheophorbide $a$, and the $\pi$-cation and $\pi$-anion radicals of ethyl chlorophylilde a and ethyl bacteriochlorophyllide a. These studies effectively complete studies on monomeric chlorophyll and related systems. Empirical potential functions currently under development are to be used to investigate the geometrical structural properties of chlorophyll and bacteriochlorophyll "special-palr" dimers found in the reaction centers of plants and photosynthetic bacteria, respectively. Particular attention is directed towards the role of water or other bifunctional ligands in determining the structure of the spectal-pairs. Finally, an assessment of the adequacy of the currently employed theoretical methods and, where appropriate, development of refined procedures to deal with large molecular systems are beling undertaken, including an investigation of mini-computer capabilities.

BOSTON UNIVERSITY

Boston, Massachusetts 02215
187. INVESTIGATION OF THE TRIPLET
STATES OF CHLORUPHYLLS
$\$ 65,700 \quad 01-1$
Richard H. Clarke
Department of Chemistry

This program continues the investigation of chlorophyll dimer structure by utilization of the photoexcited triplet state. The research program focuses on the optically-detected zero-field magnetic resonance spectroscopy of photosystem I and photosystem II particles and on mixed dimers of pheophyt in and chlorophyll in hydrocarbon solutions. Measurements of the triplet state zero-field splittings, overall triplet lifetimes and individual spin sublevel intersystem crossing rate constants are utilized to assess the makeup of the molecular aggregates present in these systems. The overall goal of this program is to evaluate the properties of photosynthetic pigment dimers in vitro as models for the reaction center in in vivo photosynthesis. 
Photochemical and Radiation Sciences, continued

UNIVERSITY OF COLORADO

Boulder, Colorado 80309

\author{
188. SENSITIZATION AND QUENCHING \\ IN PHOTOCHEMISTRY \\ Stanley J. Cristol \\ Department of Chemistry
}

$\$ 40,000 \quad 01-1$

Photosensitization and 1 ts obverse, photochemical quenching are being studied in a variety of organic photochemtcal. reactions. These studies attempt to define the factors affecting quantum ylelds and chemical ylelds in sensitized (and analogous unsensitfied) reactions, with particular attention belng paid to the phenomenon of energy wastage in such reactions. The effects of different sensitizers upon the varlety of reaction paths avallable to selected reactants and also the effects of quenchers upon such systems, are being studied. Using recently developed new kinetic procedures for studying triplet-sensitized reactions, fundamental data on reaction-rate constants and exc1tation (energy). transfer rate constants for excited-state reactions are being studied, to see if structure-reactivity correlations may be derived.

THE OHIO STATE UNIVERSITY

Columbus, Oh1o 43210

189.
PULSE RADIOLYSIS STUDIES OF FAST
REACTIONS IN MOLECULAR SYSTEMS
Leon $M$. Dorfman
Department of Chemistry

$\$ 80,200$

$01-1$

The fast reaction kinetics of elementary processes in irradiated solutions are being studied by the pulse radiolysis technique. Among the principal Interests of the current work is the investigation of the optical properties and chemical behavior of molecular ionic specles in organic liquids. While these investigations relate to radiation chemical systems, the information about the reactive transients $1 \mathrm{~s}$ also relevant to the chemistry of fossil fuels and to the chemistry of organic reaction systems generally, since the lonic species observed (carbonium Ions and carbantons) play a role in the chemical transformations which can be induced in hydrocarbons by catalytic and other means. We are determining, in selected systems, the mechanism of chemical change and the specific reactivity of the reactive transients which determine the chemistry. Optical absorption spectra of these intermediates are also being determined. Detection is by fast optical absorption measurement. Specific areas of current interest are: Identity of positive charge carriers In Irradiated organtc liquids, and rates and mechanism of positive charge transport to solutes; reactivity of carbontum lons and carbanions in solution, including the effect of molecular and electronic structure on reactivity and the effect of lon-pairing on reactivity; optical properties and reactivity of crganotransition metal carbonyl radicals. 
Photochemical and Radiation Sciences, continued

THE OHIO STATE UNIVERSITY

Columbus, Ohio 43210

190. KINETICS OF FAST REACTIONS OF

$\$ 54,000$

$01-1$

EXCITED SPECIES

Richard F. Firestone

Department of Chemistry

The goal of this research is to elucldate mechanlsms for decay. of excited rare gas atoms and for growth and decay of excited molecular species (excimers) in pure rare gas samples and in mixtures of rare gases with forelgn molecules and atoms. Direct excitation of highly excited rare gas atoms and lons is effected by irradiation of rare gas samples with pulsed high energy electron beams. Formation of Paschen(1s) atoms occurs via radiative cascade. At pressures from ca. 100 to ca. 1000 torr, excimer species form predominantly via collisional mechantsms and decay via radiative transitions. Energy transfer from excited atoms and excited molecules to quenching agents as well as mechanisms for decay of excited atoms in pure rare gases are being examined in detail. All species are monitored by means of fast absorption spectrophotometry.

COLUMBIA UNIVERSITY

New York, New York 10027

191. LASER ENHANCED CHEMICAL REACTION STUDIES

$\$ 87,400 \quad 01-1$

George W. Flynn

Department of Chemlstry

The objective of this work is to Investigate the chemical reactivity of laser pumped polyatomic molecules. Particular emphasis is being placed on efforts to understand the role of collisions in creating and destroying non-equilibrium energy distributions. Many molecules are expected to exhibit enhanced reaction rates when vibrational excitation levels are high. Collision processes can lead to unusual intermode energy distributions in laser pumped molecules but also provide a channel for overall relaxation. The experimental procedure used is infrared laser excitation of molecules such as $\mathrm{COF}_{2}, \mathrm{SF}_{6}$, and $\mathrm{BCl}_{3}$ in both molecular beam and simple gas bulb experiments. Fluorescence and mass spectrometry are employed to monitor products and energy distributions following

laser excitation. 
Photochemical and Radiation Sctences; continued

UNIVERSITY OF TEXAS

Austin, Texas 78712

192. SOLAR ENERGY UTILIZATION BY

$\$ 42,600 \quad 01-1$

CARBANION PHOTOLYSIS

Marye Anne Fox

Department of Chemistry

A research program is being conducted in which two aspects of photochemical conversion of solar energy are studied. Organic photoelectrochemtcal techniques are applied to a series of highly absorptive carbanions, radical anions, and aromatic hydrocarbons. The use of excited states in constructing stable photogalvanic cells is anticipated. A series of modified semiconductor electrodes are being synthesized and their photoelectrochemical properties are being examined. A mechanistic study of the photoinduced sequence of events ultimately leading to photoejection is being conducted. Quantum processes in these antons are being examined and new routes for the formation of strained compounds by intramolecular photochemical ring closures or by intermolecular photochemical bond-forming reactions are being sought. The photochemlcal reactions of several classes of highly-colored carbanions and polycyclic aromatic hydrocarbons are being investigated to determine the factors which influence the efficiency with which photoinduced electron exchange occurs at appropriate electrodes as a method of solar-toelectrical energy conversion and to explore the posstble formation of strained aniontc photoproducts as a method of solar energy storage by chemical bond formation. In a series of photoelectrochemical experiments, the electrical currents generated upon photoejection from carbanions are being measured at semiconduct or and at chemically-modified and film-coated electrodes. The effects of molecular structure and environment on the chemical behavior of the excited antons are being determined and a search is being conducted for new photoreactions in which highly strained anions are produced. 
Photochemical and Radiation Sclences, continued

WASHINGTON UNIVERSITY

St. Louls, Missour1 63130

193. REACTION STUDIES OF HOT SILICON
AND GERMANIUM RADICALS
Peter Gaspar - Department
of Chemistry

Investigations are befpg condycted $\beta_{f}$ reactigns of $7 f_{\text {ecolling }} \xi_{11 \text { icon }}$ and

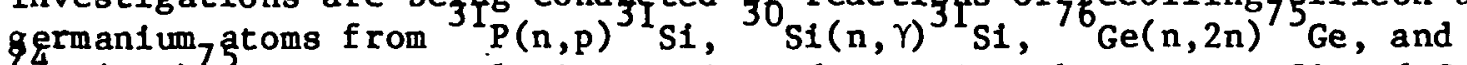
$\mathrm{Ge}(\mathrm{n}, \gamma){ }_{\mathrm{Ge}}$ with simple inorganic and organic substrates. Si and $\mathrm{Ge}$ atoms, ions and radicals produced chemically are also studied and compared with recoll experiments. Goals of the research are to determine what the chemistry of recolling $S i$ and Ge atoms is, how reactions take place, and what the relationshtp among structure, energy, and reactivity is. The research program examines reaction products and determines reaction mechanisms. Focus is on the primary steps in reactions of recolling $S i$ and Ge atoms, structure, energy and electronic states of reaction intermediates and the role of ions in recoll reactions.

UNIVERSITY OF FLORIDA

Galnesville, Florida 32611

194. RADIATION CHEMISTRY OF HYDROCARBON

AND ALKYL HALIDE SYSTEMS

$\$ 48,500 \quad 01-1$

Robert $j$. Hanrahan

Department of Chemistry

Studies in radiation chemistry provide the background information necessary not only to avold deleterious effects from nuclear radiation but also to develop practical applications of this unique form of energy. Work at the University. of Florida is directed toward understanding of the primary and secondary chemical processes which lead to formation of net products in the gamma or pulsed electron radiolysis of simple chemical systems. The methods used include chemical analysis for net products in the presence and absence of scavengers for free radicals or other intermediates, effect of physical variables such as pressure, temperature, radiation dose, or phase, and comparison with other methods of activation such as photolysis or electron bombardment in the mass spectrometer, in order to shed light on primary processes. Systems are chosen for study on the basis of both chemfcal sultability and relevance to current energy or environmental problems. An investigation of the radiolysis of $\mathrm{H}_{2}-\mathrm{CO}$ mixtures is directed, at characterlzation of hydrocarbon and oxygenated products formed in both the gas phase and on various types of reactive surfaces. Pulse radiolysis studies of $\mathrm{CF}_{3} I$ and $\mathrm{CH}_{n} \mathrm{I}$ systems are expected to yleld detalls of atomle lodine reaction dynamičs relevant to chemical laser work. Comparattve studies of the mass spectrometry and radiation chemistry of $\mathrm{CF}_{3} \mathrm{I}-\mathrm{CH}_{3} \mathrm{I}$ mixtures are designed to reveal. the role of ion-molecule reactions 1 th th system. 
Photochemical and Radiation Sclences, continued

FLORIDA STATE UNIVERSITY

Tallahassee, Florida 32306

195. RADIATION INDUCED EFFECTS IN
ORGANIC SYSTEMS
Russe11 H. Johnsen
Department of Chemistry

The goal of this research continues to be the elucidation of kinetics involving reactive intermediaces. Emphasis is in three areas: (1) reactions of the hydroxyl radical with a variety of aromatic hydrocarbons found in the atmosphere, (2) the structure of molecular lons as determined by collisionally activated mass spectrometry, (3) reaction of radicals and radical pairs in irradiated organic solids. Procedures utilized in these Investigations Include conventional and tandem mass spectrometry, electron spin resonance spectrometry and photochemical techniques. Systems investigated include the lower molecular weight aromatic hydrocarbons, 1someric alkanes, azoxy compounds and amino actds.

BOSTON UNIVERSITY

Boston, Massachusetts 02215

196. ORGANIC PHOTOCHEMICAL STORAGE OF SOLAR ENERGY

$\$ 65,900 \quad 01-1$

Guilford Jones, II

Department of Chemistry

Photoisomerization reactions capable of storing radiant energy in stable molecules are belng studied. Photosensitization mechanisms which allow use of long wavelength (visible) radiation are of principal interest. New sensitizing agents for presently known exciplex isomerizations are being proposed. Sensitized isomerization yleld and storage capacity are to be Improved through study of derivatives of currently promising substrates. Mechanistic work includes a survey of factors directing the diabatic and novel adiabatic exclplex isomerization of dewarbenzenes. Study of ground state (charge transfer) complexing agents and their ability to induce photolsomerization reactions is underway. The energy transfer mechanism of photosensitization is being studied with emphasis on construction of a norbornadiene derivative with an exceptionally low energy triplet excited state. The temperature dependence of energy transfer to, and isomerization from this state is being assessed. 
Photochemical and Radiation Sciences, continued

UNIVERSITY OF ILLINOIS

Urbana, I11inois 61801

197. ELECTRON TRANSFER IN SYSTEMS

OF WELL DEFINED GEOMETRY

Kenneth J. Raufmann

Department of Chemistry
$\$ 50,000 \quad \cdot 01-1$

Studies of exclted state electron transfer in systems of well-defined geometry are being conducted to learn what parameters are important In efficient conversion of excited states to a separation of charges. To do this a number of dimers of pheophytin are being synthesized. These dimers are folned by two covalent 11nkages. Metal atoms such as $\mathrm{Mg}, \mathrm{Cu}$, $\mathrm{Zn}, \mathrm{Mn}$ and $\mathrm{Fe}$ are added to only one of the two porphyrin molecules in the dimer. The dimers are excited with a picosecond pulse and there is then observed the rate of electron transfer from the metal containing molecule to the pheophytin molecule. Electron transfer is monttored via time resolved absorption and fluorescence. The distance between the acceptor and the donor is changed by modifying the length of the two covalent 11nkages. Changes in the fluorescence lifetime as a function of separation between the two porphyrin rings are being used to discover which complexes quench the singlet excited state. Time resolved absorption spectroscopy is then used to monitor the rate of anton and cation formation. Absorption studies also Indicate the rate of decay of the charged complex via formation of triplets and ground state molecules. Information is obtained on what distances permit rapid forward reactions, yet stabllize the charge separation.

UNIVERSITY OF CALIFORNIA

Eanta Barbara, California 93106

198. PHOTOELECTROCHEMISTRY AT IRON OXIDE ELECTRODES

John H. Kennedy

Department of Chemistry

The obfect of this research program is to extend the knowledge of semiconductor photoelectrochemistry for the decomposition of water into hydrogen fuel and oxygen. In particular, a study of iron oxide electrodes in various electrolytes is being investigated. Previous work has shown that solutions containing EDTA or citrate enhance photocurrents; therefore solute effects are being studied in greater detail including other carboxylic acids. Chemical analysis of the photoproducts is being carried out. The project is also exploring other metal. nxides which might exhibit desirable photoelectrochemtcal characteristics. Materials which are being explored include ferrates, manganates and plumbates. 
Photochemical and Radiation Sciences, continued

LOUISIANA STATE UNIVERSITY

Baton Rouge, Loulsiana 70803

199. THEORETICAL STUDIES OF EXCESS

ELECTRONS IN FLUIDS; STRUCTURE

$\$ 33,400 \quad 01-1$

AND ELECTRON TRANSFER

N. R. Kestner

Department of Chemistry

This program is extending "ab initio" and model calculations of the solvated electron to systems other than water as well as exploring alternative ways to introduce properly the long range electron-medium interaction. The older models are deficient in this area. Emphasis is on line shape and electrons in dense polar gases, mixed polar solvents as well as pure and mixed alkall halide fused salts. At least half of the efforts involve the continuing study of electron transfer (and its related energy transfer) phenomena in liquids and frozen media using multiphonon theory. The trapping process, the effects of electric flelds and pressure, the calculation of medium rearrangement energies for electron transfer between inorganic complexes, and the role of long range "super-exchange" electron transfer are all being investigated. Studies concentrate on ways to characterize the rates and their temperature dependences with an aim toward predicting experimental behavior. Such results will have applications to catalysis, modern electrical devices and electrode processes as well as to electron transfer processes in inorganic chemistry and blology.

WAYNE STATE UNIVERSTTY

Detroit, Michigan 48202

200. RADIOLYSIS STUDIES ON REACTIVE
INTERMEDIATES
Larry Kevan
Department of Chemistry

This research is oriented toward quantitative characterization of presolvated electron structure and reactivity, metal atom and ion solvation and radical and molecule orientation on surfaces. The geometrical and electronic structure of presolvated electrons formed at 1.5 and $4.2 \mathrm{~K}$ in aqueous and organic matrices is being studied by electron spin resonance, optical absorption and photoconductivity methods. Metal atom solvation and radical orlentation on zeolite surfaces are being studied by electron spin echo spectrometry and other advanced electron spin resonance methods. Electron reactivity is being studied at temperatures below $4 \mathrm{~K}$. 
Photochemical and Radiation Sciences, continued

UNIVERSITY OF ALABAMA

University, Alabama 35486

201. ELDOR INVESTIGATIONS OF RADIATION PROCESSES

$\$ 46,000 \quad 01-1$

Lowell D. Rispert

Department of Chemistry

The objective of the present research is to examine the role of. the host matrix as a function of temperature in determining the type and yield of radicals produced by X-irradfation of a crystalline or glass material using electron-electron double resonance (ELDOR), electron-nuclear double resonance (ENDOR), electron spin resonance (ESR) and heavy atom substitution techniques. After many years of research on the effects of radiation on crystaline materials, it is still difficult to predict from the thermal history, nature of radiation, crystal structure or form of the parent molecule what radical spectes will be stable at any given temperature. However, an examination of the ELDOR spectra of an irradiated substance results in a partial or complete measure of the relaxation mechanisms which, in turn, are related to the host matrix itself. The host matrix can be changed slightly by using the heavy atom substitution technique, by using different methods of crystallization, and by including radical precursors in clathrates, permitting a study of the relation among host matrix varlation, radical yleld and relaxation parameters.

THE JOHNS HOPKINS UNIVERSITY

Baltimore, Maryland 21218

202. STUDIES IN RADIATION AND HOT. $\$ 66,000 \quad 01-1$ ATOM CHEMISTRY

Walter S. Koski

Department of Chemistry

Studies of the reaction $\mathrm{B}^{+}\left(\mathrm{H}_{2}, \mathrm{H}\right) \mathrm{BH}^{+}$using $\mathrm{B}^{+}$in 1 ts ground and first excited states are being continued. Product states $+{ }^{\circ} \mathrm{BH}^{+}$are being identified. A study of the reactions of $\mathrm{D}_{2}$ with $\mathrm{Br}^{+}$in its ground and first excited electronic states is being initiated. The ionchemistry of the hot atom system $\mathrm{Br}_{-} \mathrm{C}_{2} \mathrm{H}_{6}$ activated by the $(n, \gamma)$ and isomeric transition is being investlgated using tandem mass spectrometers. Work on the factors that influence the experimental determination of the translational exoergicity of ion-molecule reactions is being continued. 
Photochemical and Radiation Sclences, continued

CALIFORNIA INSTITUTE OF TECHNOLOGY

Pasadena, California 91125

203. STUDIES IN CHFMICAL DYNAMICS Aron Kuppermann Division of Chemistry and Chemical Engineering

Th1s program studies collisions of molecules with other molecules, electrons and photons, including the determination of intermolecular forces and energy transfer crossi sections, electron-1mpact energy-1oss spectra at variable angle, and angular distributions of molecular photoelectrons. Spectroscoplc studies of optically forbidden transitions by multiphoton photolonization and photoacoustic detection laser spectroscopy, and stud les. of the effect of photon energy on photochemical pathways are also being conducted. The unifying goal of these studies 18 the understanding of the dynamical consequences of the collisions of molecules with other particles. 
Photochemical and Radiation Sclences, continued

PENNSYLVANIA STATE UNIVERSITY

Untversity Park, Pennsylvanta 16802

204. THE . PHOTOCHEMISTRY AND RADIATION

CHEMISTRY OF VOLATILE SILANES

AND GERMANES

F. W. Lampe

Department of Chemistry

The mechanisms of photochemfcal decomposition of sllanes, germanes, phosphines, arsines and mixtures of these components using 147 nanometer radiation and 9-11 micrometer infrared radiation are studied in a photolysis cell that is directly coupled to a time-of-flight mass spectrometer. Particular attention is directed to the possibility of useful photochemical. synthesis by the room-temperature reactions of divalent silylene and germylene radicals with substrates containing halogen and oxygen atoms. The solid hydridic films of silicon and germanium that are formed in all decompositions of gaseous stlanes and germanes, the chemical nature of the films formed by gamma, vacuum ultraviolet and infrared irradiations and dependence of this nature on reaction conditions, and the effect of the presence of phosphine and arsine in the reactant gas on the nature and properties of the films are being examined. Ion-molecule reactions characteristic of silane and germane systems are being studied in a tandem velocity-filter-mass-filter apparatus in which reactant ions of a given mass, with energles of 0.5-20 electronvolts, are focused into a target gas and the resulting product lons are analyzed with respect to both mass and energy. Particular attention is directed towards a study of the 11fetimes, rates of unimolecular dissociation, and collisional stabllization of energy-rich collision complexes. The ion-molecule reactions characteristic of silane-halocarbon and germane-halocarbon mixtures are also being examined in the tandem mass spectrometer. Speclal attention is directed towards the role played by intermediate complexes bound together by halide and hydride bridges in the overall reactions of hallde and hydride transfer. 
Photochemical and Radiation Sclences, continued

BOSTON UNIVERSITY

Boston, Massachusetts 02215
205. ELECTRON TRANSFER REACTIONS OF EXCITED DYES WITH METAL COMPLEXES
Norman N. Lichtin, M. Z. Hof fman
Department of Chemistry

$\$ 70,000 \quad 01-1$

The general objectives: of this program are, systematically, to study, correlate and interpret factors which determine quantum effictency of transfer of reducing equivalents botwoon orclted dye molecules and metal complexes in the1r ground state as well as other factors whtch determino the composition and dynamics of formation and decay of the photostationary state of such photoredox systems. Aspects of interest include structures of dyes and ground state reagents, photophysical properties of dyes, ground state redox potentials of dyes and metal complexes, and the influence of solvent and solution composition on dynamic and steady state properties. Specifically, chemlcal and physical mechantsms are studied of photoredox systems incorporating thiazine or other dyes as absorbing specles and complexes of Iron or cobalt, using flash-photolytic, spectrofluorometric, steady-state spectrophotometric and pulse-radiolytic techniques.

WAYNE STATE UNIVERSITY

Detroit, Michigan 48202

206. PHOTOCHEMICAL ACTIVATION AND REACTIVITY OF POLYNUCLEAR TRANSITION

$\$ 76,000 \quad 01-1$ MFTAI. COMPLEXES

Richard L. Lintvedt, John F. Endicott

Department of Chemistry

Photoinitiated reactions of molecules or molecular fons contalning.two or more metal atoms, 1.e. polynuclear complexes, are belng investigated. Photoexcitation of such molecules should result in intermediates capable of multi-electron transfer, mu1ti-photonic proccoara and unusial uxcited otace, reactions. A principle objective is to generate photochemically such excited state species and study their reactions with a variety of substrates that react by way of multi-electron transfer processes or by transfer of reactive intermediates. Several new polynuclear transition metal complexes contalning many different metal ions in a series of related ligands are being synthesized and characterized. The redox properties, photochemical reactivity, and photophysical processes assoclated with these polynuclear complexes are being studied in detail. A fundamental goal is to study light-driven redox-type reactions in which deleterious radical formation is avolded by the simultaneous transfer of two electrons. 
Photochemical and Radiation Sclences, continued

BRANDEIS UNIVERSITY

Wa1tham, Massachusetts 02254

207. PHOTOCHEMICAL REACTIONS OF

$\$ 92,800 \quad 01-1$

COMPLEX MOLECULES IN CONDENSED

(18 months)

PHASE

Henry Linschitz

Department of Chemlstry

In photosynthesis, solar energy is stored via a photoredox process involving electron transfer from an exclted molecule (chlorophyll) to suitable acceptors, followed by trappling of high energy products. Analogous processes in vitro encounter the basic difficulty that the same kinetic intermediate leading to radicals in the primary electron-transfer step can lead also to quenching to the ground state and energy 108s. Th1s work 18 directed toward understanding the factors controlling this branching ratio between energy storage and dissipation. Toward this end, laser flash photolysis is being used to measure the quantum yields of radicals (or radical-ions) formed in excited state redox reactions, under different conditions. The basic parameter of the situation is considered to be the iffetime of the exciplex or spin-coherent radical-ion pair formed in the primary step, relative to the time required for "escape" of the geminate radical products into bulk solution. Temperature and sólvent viscosity and polarity are relevant variables. Particularly important is the spin multiplicity of the excited state, since quenching must lead to the singlet ground state. Studies are also in progress on the characterization and photochemistry of chlorophyll aggregates, related to the photosynthetic reaction center. 
Photochemical and Radiat Ion Sclences, continued

UNIVERSITY OF MINNESOTA

Minneapol18, Minnesota 55455

208. THE CONTRIBUTION OF ELECTRONICALLY

$\$ 78,000$

$01-1$ EXCITED STATES TO THE RADIATION

CHEMISTRY OF ORGANIC SYSTEMS

Sanford Lipsky

Department of Chemistry

The wavelength dependence of the photolonization yield of colutes in organtc fluids is being measured using electric fleld quenching of the solute fluorescence in order to seek evidence for trangitions in 11quids that converge on the second Ionization limit. Additionally the effect of electric fleld strength on the chemical quenching of the emission is studied in order to elucldate the nature of the precursor of escaped electrons and to reduce the number of vlable models of the photolonization process. Electron Impact energy-loss spectra of saturated and mono-olefinic cyclic hydrocarbons are obtained at $0^{\circ}$ and $90^{\circ}$ scattering angles and over a range of impact energies from $20 \mathrm{eV}$ to $200 \mathrm{eV}$ in order to assist the interpretation and assignments of Rydberg transitions observed in optical absorption spectroscopy. Two photon laser excited fluorescence of saturated and mono-olefinic hydrocarbons is studied in order both to obtain better spectra than have heretofore been avallable and to seek the emissions from molecules not prevlously observed to fluoresce (e.g. ethylene, cyclopropane, 2-methylpropane; etc.). With fluorescence located from the simpler molecules and better spectra available for the more complex, assigments of the emftting states should become more feasible. 
Photochemical and Radiation Sclences, continued

UNIVERSITY OF NEBRASKA

Lincoln, Nebraska 68588

209. PRINCIPAL PROCESSES IN THE RADIOLYSIS $\cdots+\$ 8,000$
OF GASES WITH FISSION RECOILS AND
GAMMA RAYS
G. G. Meisels
Department of Chemistry

Thls research falls into three categories; 1. The evaluation of processes, temperatures and time scales in fission recoll radiolysis which lead from the energy. deposition process to chemtcal reactants. This involves irradiation of hydrocarbon gases with recolling fission fragments from a Pt clad Pd-U-235 foil, using rates of hydride transfer processes and final product analysis to infer the desired information; 2. the determination of rate constants and thermodynamic properties of gaseous lons, an elucidation of association and fragmentation mechanisms, and comparison with recently developed theory. This involves principally the use of a pulsed high pressure mass spectrometer, operated at one torr, capable of measuring ion drift time distributions; 3 . an investigation of the formation and reactions of Ions prepared in specific energy states, with particular emphasis on assessing angular momentum and spectfic vibrational state effects, and comparison with recent theory. The principal instruments are a threshold photoelectron-colncident photolon mass opectrometer, and a high resolution double focusing mass spectrometer specially modified for the study of metastable Ion decompositions.

UNIVERSITY OF NORTH CAROLINA

Chapel Hill, North Carolina 27514

210. ENERGY CONVERSION BASED ON
MOLECULAR EXCITED STATES
T. J. Meyer
Department of Chemistry

The photochemfcal and photophysical properties of metal complex excited states are belng investigated for systems which show promise in solar energy applications. A number of interesting applications have been developed based on Metal Ligand Charge Transfer Exclted States of polypyridyl complexes of ruthenium. They include the photoelectrochemical production of $\mathrm{H}_{2}$ and $\mathrm{O}_{2}$ from water and the development of prototypes for solar energy synthesis cells. Luminescing polymers based on attachment to polyvinylpyridine have been prepared and their properties studied. Detalled photodegradation studies on a series of related complexes have been carried out which give insight into the degradation mechanisms and inco the design features which minimize the importance of such pathways. 
Photochemical and Radiation Sclences, continued

PURDUE UNIVERSITY

West Lafayette, Indiana 47907

211. FLASH PHOTOELECTROCHEMICAL STUDIES OF TRANSIENT ELECTRODE PROCESSES

IMPORTANT IN SOLAR ENERGY CONVERSION

Sam P. Perone

Department of Chemistry

It is the objective of this research program to apply electroanalytical and spectroscopic measurement techniques to the study of transient photolytic, photoemission, and photoelectrolytic processes associated with IIV-visthle Irradiation of an electrode/solution interface. Both semiconductor and metallic electrodes are employed. Because of concern for the characterization of transient phenomena, the general methodology of flash photolysis is employed (including both xenon flash lamp and tunable pulsed dye laser sources). The novel perspective afforded by transient electroanalytical/ spectroscopic measurements of photoinitlated electrode processes allows more definitive mechanistic studies of solar conversion phenomena.

HARVARD UNIVERSITY

Cambridge, Massachusetts 02138

212. PICOSECOND DYNAMICS OF

$\$ 51,400 \quad \cdot 01-1$ PHOTOCHEMICAL SYSTEMS

Revin S. Peters

Department of Chemistry

The photochemical and subsequent structural rearrangements of 4-methylene1-pyrazoline, 2,3-dlazabicyclo (2.2.1)-hept-2-ene, 3-methydlazirine, dimethyldiazirine, and ketene are being investigated utilizing time resolved picosecond absorption and Raman spectroscopy. The Information to be obtalned from these studies includes the dynamics of dissociation, the distribution of energy among the resulting fragments, the vibrational characteristics of highly excited molecules, and the rateo of intramolecular and intermolecular vibrational relaxation. These results provide critical new data for the mechanisms and dynamics of photochemical reactions, as well as for the basic assumptions of unimolecular reaction theory. 
Photochemical and Radiation Sciences, continuèd

UNIVERSITY OF NEBRASRA

Lincoln; Nebraska 68588
213. HIGH ENERGY HALOGEN ATOM REACTIONS ACTIVATED BY NUCLEAR TRANSFORMATIONS
Edward P. Rack
Department of Chemistry

$$
\$ 45,000 \quad 01-1
$$

Studies of high energy halogen atoms or Ion reactions, actlvated by various nuclear transformations in gaseous, high pressure and condensed phase saturated and unsaturated hydrocarbons, halomethanes and other organic systems continue in order to better understand the mechanisms and dynamics of high energy monovalent species. The experimental and theoret $68^{1}$ 88 als 85 syste $\mathrm{Br},{ }^{82} \mathrm{Br}^{\mathrm{m}}+{ }_{\mathrm{Br}},{ }_{\mathrm{Br}},{ }^{128} \mathrm{I},{ }_{\mathrm{I}}$, and ${ }^{3} 0_{\mathrm{m}}+{ }_{\mathrm{I}}$ actlvated

by radiative neutron capture or isomerlc transition in saturated hydrocarbons and halo-substituted alkanes. The reactions of lodine with alkanes and alkynes activated by radiative neutron capture and isomeric transition. The gas to condensed state transition in halogen high energy chemistry, involving chlorine, bromine, and lodine activated by the (n,Y) and (I.T.) processes in halomethanes, saturated and unsaturated hydrocarbons, kinetic theory applications of high energy reactions and mathematical development

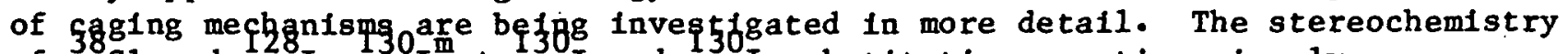
of ${ }^{38} \mathrm{C} 1$ and ${ }^{2} 8_{I},{ }^{13}{ }_{I}{ }^{m}+{ }_{I}$ and ${ }^{3}{ }_{I}$ substitution reactions involvIng diastereomeric and enantiomeric molecules in the gas and condensed phase, and the applications of high energy chemistry techniques and theory to neutron activation analysis of biological systems are being studied.

CARNEGIE MELLON UNIVERSITY

Pittsburgh, Pennsylvania 15213
214. PHOTODECOMPOSITION OF WATER IN
$\$ 49,200$
$01-1$
HOMOGENEOUS SOLUTION
Robert M. Richman
Department of Chemistry

This research involives spectroscopic, photophysical, chemical, photochemical, and electrochemical studies of transition metal complexes likely to be useful in solar energy conversion schemes. Workable schemes may be devised that are based on splitting water into hydrogen and oxygen. Because it is unlikely that a single photon of visible light can provide this energy without waste, schemes are considered which utilize one photon to reduce water to hydrogen and another photon to oxidize water to oxygen. The program includes an extensive consideration of the factors that appear to be important in choosing the appropriate photocatalysts, such as two $2+$ specific compounds (and their analogs): $\mathrm{Mo}(\mathrm{O})_{2}\left(\mathrm{~S}_{2} \mathrm{CNR}_{2}\right)_{2}$ and $\mathrm{Cp}_{2} \mathrm{TI}_{1}\left(\mathrm{H}_{2} \mathrm{O}\right)_{2}{ }^{2+}$. 
Photochemical and Radiation Sciences, continued

THE JOHNS HOPRINS UNIVERSITY

Baltimore, Maryland 21218

215. FAR INFRARED CHEMICAL LASERS

$\$ 67,100 \quad 01-1$

Dean W. Robinson

Department of Chemistry

The objectives of these studies on rather diverse systems are to probe the dynamics of reacting and inelastically colliding molecules through observation of laser oscillation resulting from non-equilibrium distributfons in the products. The work Involves far infrared technology because many polyatomic molecules exhtbit vibration-rotation level oscillation in this region, and pure rotational transitions also reside there. Previous to this work no polyatomic lasers beyond $10 \mu \mathrm{m}$ wavelength had been pumped chemically, and it had been widely predicted that pure rotational lasers would never be pumped this way because of the rapld collisional relaxation of rotational disequilibria. The overwhelming sclentific advantage of chemical over discharge pumping is the (usually) preclse knowledge of the composition of the system in the chemical case. There 18 also the practical advantage that knowledge of the mechanisms might well point the way to Increasing the laser power. The polyatomic examples such as $\mathrm{HCN}, \mathrm{H}_{2} \mathrm{O}$, and $\mathrm{H}_{2} \mathrm{~S}$ are often not simply pumped by energy diverted into the upper lasing level. The Inftial distribution 18 "overpumped" and the establishment of the required inversion must await intermolecular and intramolecular energy transfer among the three vibrational modes. Rinetic work on these molecules will continue. In the diatomic, pure rotational field, the next hydride being probed is $\mathrm{HF}$, but this $1 \mathrm{~s}$ expected to be anticlimactic after the performance of NH. HF does have the advantage of being preparable from a vast number of reactions with known vibrational distributions. Thus it would be a good test of the theories already invoked for OH and NH. The work is to be extended to the nop-hydrides So and $\mathrm{ClO}$. The former 18 preparable by the rapid reaction $0\left({ }^{D}\right)+O C S$, and the latter from photoIysis of $\mathrm{FClO}_{3}$. 
Photochemical and Radiation Sclences, continued

UNIVERISTY OF CALIFORNIA

Davis, California 95616

216. NUCLEAR METHODS IN CHEMICAL KINETICS

$\$ 60,000 \quad 01-1$

John W. Root

Department of Chem1stry

Tis research program includes classical kinetic studies of thermal

F elementary hydrogen abstraction and olefinic addition reactions, and experimental investigations of the effects of $\mathrm{H}_{2}$ and $\mathrm{Cl}$ reactive additives upon energetic F-for-F substitution reactions in $\mathrm{CF}^{\circ}$. Thermal F-to-HF absolute rate constants are being determined at $273 \mathrm{~K}^{4}$ for selected alkane hydrogen and deuterium atom donors in conjunction with the continued development of new extended collision theorles for gasand 1iquid -phase bimolecular processes. Sensitive mass balance and deuterium kinetic isotope effect tests are utilized in an attempt to demonstrate the 1mpprtance of a complex HF-producing mechanistic pathway in the thermal $18 \mathrm{~F}+\mathrm{C}_{2} \mathrm{H}$ reaction system. Competitive experiments in the nonthermal ${ }^{18} \mathrm{~F}$ v8. $\mathrm{H}_{2} / \mathrm{CF}_{4}$ and $\mathrm{Cl}_{2} / \mathrm{CF}_{4}$ systems are employed to demonstrate center-of-mass reactive collision energy distribution shifts as predicted by the steady state hot atom kinetic theory. 
Photochemical and Radiation Sciences, continued

UNIVERSITY OF CALIFORNIA

Irvine, California 92717
217. RESEARCH IN CHEMICAL KINETICS
$\$ 145,000 \quad 01-1$
F. Sherwood Rowland
Department of Chemistry

The techniques of radiochemfstry and photochemistry are applied primarily to the study of small molecules in the gas phase in order to understand the mechantsms and rates of chemical reactions. Many of the molecules and chemical reactions have geochemical significance because of their occurrence in the atmosphere of the earth or other planets. The program primarily depends upon laboratory measurements, but has lesser components of theoretical calculation and atmospheric field measurements. The molecules under study include hydrocarbons, halocarbons, and organometallic species. Some specific topics Include (a) absolute calibrations of electron capture detectors for $\mathrm{CCl}_{3} \mathrm{~F}, \mathrm{CCl}_{2} \mathrm{~F}_{2}, \mathrm{CCl}_{4}, \mathrm{CH}_{3} \mathrm{CCl}_{3}, \mathrm{CHCl}_{2} \mathrm{CCl}_{2}$ and $\mathrm{CCl}_{2}=\mathrm{CCl}_{2}$ as the basis for continuea monttoring of these compounds in the troposphere; (b) ultraviolet absorption measurements of $\mathrm{CCl}_{2}, \mathrm{CClFO}$, and $\mathrm{CF}_{2} \mathrm{O}$ plus mechanistic studies of their photodecomposftion with reference to stratospheric processes; (c) addition of thermal ${ }^{\mathrm{F}}$ and ${ }^{3 \mathrm{Cl}}$ to asymmetrlc alkenes and alkynes to determine the directional factors controlling such reactions; (d) direct substitution reactions of $\mathrm{F}$ and $\mathrm{Cl}$ at $\mathrm{C}-\mathrm{M}(\mathrm{M}=\mathrm{Pb}, \mathrm{S} \mathrm{n}, \mathrm{Ge}, \mathrm{Si})$ bonds in organometallic compounds (e) reactions $3 \mathrm{f}^{1} \mathrm{CH}_{2}$ and ${ }^{3} \mathrm{CH}_{2}$ with simple hydrocarbons and methyl halides; (f) thermal ${ }^{38} \mathrm{Cl}$ reactions with $\mathrm{CH}_{4}$ and $\mathrm{C}_{2} \mathrm{H}$ for stratospheric comparisons; and $(g)$ observation of the reactions of non-kRKM radicals formed by thermal ${ }^{2}{ }_{F}$ addition to tetraallyl organometallic compounds. 
Photochemical and Radiation Sciences, continued

WORCESTER POLYTECHNIC INSTITUTE

Worcester, Massachusetts 01609

218. THE GAS PHASE RADIOLYSIS AND VACUUM

ULTRAVIOLET PHOTOLYSIS OF HETEROCYCLIC

$\$ 39,400 \quad 01-1$

ORGANIC COMPOUNDS

Alfred A. Scala

Department of Chemistry

Studies of the gas phase $\gamma$-radiolysis and vacuum ultraviolet photolysis of complex organic molecules are continuing. The objective is to determine with a greater degree of certainty the primary and secondary modes of decomposition of complex organic molecules and to understand and codify the factors which affect the reactions in these systems. The concern 18 with Ions as well as neutral excited molecules. It is expected that by careful study of secondary. reactions one can deduce information concerning energy distributions in the decomposing molecules. Studies in these systems have led to the proposition of a quasi-equilibrium situation which allows thermodynamic factors such as bond energles to be significant in determining. reaction channels. These observations, derived from a study of more than twenty molecules have produced confidence that areas of absorption, photoelectron and mass spectroscopy, vacuum ultraviolet photochemistry and radiation chemistry can all be correlated to Improve understanding of high energy processes in organic molecules. A reasonably clear picture of the interaction between high energy radiation and heterocyclic organic compounds has been developed. Studies suggest that nelther decomposition nor ionization occurs immediately upon energy absorption. Energy is transferred from the electronic and vibrational modes initially excited Into the degrees of freedom involved in the observed reactions. Dissoctations are mainly predissociation, ionizations, malnly autoionization. This quasi-equilibrium situation permtts excited molecules to sample the avallable potential energy surfaces and react by patterns which are predictable based upon thermodynamics and structural factors. Definite simflarities are evident between the neutral and Ionfc fragmentation reactions which occur In these systems. 
Photochemical and Radiation Sclences, continued

UNIVERSITY OF UTAH

Salt Lake City, Utah 84112

219. DYNAMICS AND MECHANISMS OF HOT CHEMI STRY

Leonard D. Spicer

Department of Chemistry

Reaction kinetics, atomic and molecular collision dynamics, and energy transport at energles significantly above thermal thresholds are being studied. Intramolecular energy transfer following nuclear recoll chemical activation is being explored. Recoll chlorine atom replacement reactions are being used to activate. molecules in the studies. Apparent concurrent reactions of chlorine ions in selected bath gases are also being investigated. Intermolecular energy transfer from molecules chemically activated by the kinetic techniques of hot atom reaction 18 being further characterized in an effort to explore the generality and precision of the method already developed. The sequential trajectory analysis of average hot recoll reaction energles is being generalized to take into account reactive processes with thermal or near thermal thresholds in order to quantify the effects of nonreactive moderators on low energy processes. The kinetics and mechanisms of photochemical reactions between sulfur dioxide and saturated hydrocarbons are being investigated. Ultraviolet radiation in the energy range of natural sunlight at the surface of the earth is being used to excite the sulfur dioxide, and laser induced ultraviolet fluorescence at higher energies 18 used to follow the reaction. Analytical techniques for product detection including stimulated fluorescence, chromatography, and mass spectroscopy, both directly on the molecules, and on silyl derivatives, are being developed. 
Photochemical and Radiation Sciences, continued

TEXAS A\&M UNIVERSITY

College Station, Texas 77843

220. HOT ATOM REACTIONS INVOLVING MULTI-

VALENT AND UNIVALENT SPECIES

$\$ 39,000 \quad 01-1$

Y1-Noo Tang

Department of Chemistry

For univalent hot atoms, the reactions of recoll tritium with aromatic hydrocarbons such as benzene, toluene, and other polynuclear spectes are being studied. The interactions of tritium.with the delocalized pi-bonds in those molecules are of special interest. In addition, the interactions of molecular tritium on solid surfaces such as $C$, SiC, and Al are also being Investigated. Among multivalent hot atoms the reactions of $\mathrm{Si}-31, \mathrm{C}-11$ and $\mathrm{P}-32$ formed by the nuclear recoll method are belng pursued. The study includes the abstraction, addition, and insertion reactions of these hot atoms and their derived radicals in organic as well as inorganic systems. Moderator studies with inert gases as additives provide insight about the energetics and/or electronic states of interacting recoll atoms. Experimentally these hot atoms are produced by irradiation elther with a nuclear reactor or with a cyclotion. The products are analyzed by radio-gas chromatography.

UNIVERSITY OF KENTUCKY

Lexington, Kentucky 40506
221.
ELECTRON PHOTOEJECTION IN CARBANIONS
Laren $M$. Tolbert
$\$ 44,100$
$01-1$
Department of Chemistry

Electron transfer processes from photoexcited carbantons are being studied as models for solar conversion reactions. Resonance-stabilized carbanions transfer electrons at high potentials using visible light. The effects of pR, oxidation potential, aromaticity, and other components of carbanion st fucture on the efficlency and rate of electron transfer are being investigated. Additional considerations are the structure of the electron acceptor, and the wavelength and intensity of the light source used. A computer-controlled multtpurpose optical bench provides precise vartation and measurement of experimental data with simultaneous correction for nonlinear responses in the photodetection system. 
Photochemical and Radiation Sciences, continued

UNIVERSITY OF ARIZONA

Tuscon, Artzona 85721

222. MECHANISMS OF PHOTOCHEMICAL ENERGY

$\$ 50,000$

$01-1$ CONVERSION BY CHLOROPHYLL

Gordon Tollin

Department of Blochemistry

The excited state dynamics and the yleids and lifetimes of radicals are being inveotigated in oystems containing chlorophyll and electruu acceptors dissolved in lipld bilayers or polymer films. Laser photolysis and electron opin resonance are being used in these studies. The work 1nvolves the effects of variations in the lipid composition of the bllayers, espectally as related to viscosity and surface charge, the use of quinone polymers as media, the effect of variations in acceptor structure and redox potential, and variations in donor properties $(\mathrm{e} \cdot \mathrm{g} \cdot \mathrm{use}$ of pheophytin or bacterfochlorophyll in place of or in addition to chlorophy11). Particular emphas $1 \mathrm{~s}$ is being placed upon developing strategles to increase radical yields and lifetimes with a view towards the possible construction of solar energy conversion systems. 
Photochemical and Radiation Sciences, continued

UNIVERSITY OF CALIFORNIA

Santa Barbara, Cal1fornia 93106

223. CHEMICAL INTERMEDIATES IN THE PHOTOCHEMICAL CLEAVAGE OF WATER: A STUDY OF $\$ 35,000 \quad . \quad 01-1$ TRANSITION METAL COMPLEXES CONTAINING MONODENTATE 2,2 -BIPYRIDINE

Richard J. Watts

Department of Chemistry

A continued study of transition metal complexes which contain monodentate 2,2 -bipyridine is underway. The objective of the program is to investigate the potential storage of solar energy as a result of interaction of visible light with this class of compounds. The primary scientific background for the study lies in the previous isolation and characterization of a complex of Ir(III) which contains monodentate 2,2 -bipyridine as well as coordinated water. This has led to the characterization of an analogous complex of $\mathrm{Ru}$ (II) which is formed in the high temperature aqueous solution photolysis of $\mathrm{Ru}(\mathrm{bpy}) 3+$. Further studies of the se complexes have been spurred on by extengfve investigations of the photoredox sensitization properties of $\mathrm{Ru}(\mathrm{bpy}){ }_{3}$ and recent demonstrations of its effectiveness in hydrogen géneration under irradiation in mixtures containting electron donors and acceptors. The research focuses attention on photoinduced electron transfer processes in complexes of $\operatorname{Ir}($ III) and $\mathrm{Ru}$ (II) which contain monodentate 2,2 -bipyridine with a variety of electron donors and acceptors. These complexes, like the tris-bipyridyl ruthenium(II) complex ion, may have excited state potentials which are favorable with respect to decomposition of water into hydrogen and oxygen. A study of luminescence quenching by electron donors and acceptors is being made to identify potential electron transfer systems, and flash photolysis experiments are being performed in order to further characterize potentially active systems. 
Photochemical and Radiation Sclences, continued

UNIVERSITY OF WISCONSIN

Madison, W1sconsin 53706

224. STUDIES IN HOT ATOM CHEMISTRY AND RADIATION CHEMISTRY

John E. Willard

Department of Chemistry
$\$ 53,400 \quad 01-1$

The objectives of this profect are to obtain a better understanding of: the production, migration, trapping, reactions and spectra of free radicals, hydrogen atoms, electrons, ions, and complexes formed in solid organlc matrices by lonlizing radiation, by photolysis, and by metal photosensitisation. The reactions under study are lilliated by irradiation with gamma rays from ${ }^{C o}$; and by ultravlolet, visible and infrared radiation from continuous sources, flash sources and a tunable laser. Electron spin resonance, infrared, visible, ultraviolet and mass spectrometry, gas chromatography, electrical conductivity, luminescence, differential thermal and radfochemical analytical techniques are used. The systems under Investigation include hydrocarbon and other organic matrices with and without scavengers. The reactions in matrices are studled in the range of $4 \mathrm{~K}-200 \mathrm{~K}$. Extensive information has been obtained on factors controlling the trapping and reactions of electrons, hydrogen atoms and free radicals produced by radiation in organic matrices at $4 \mathrm{~K}$ to $200 \mathrm{~K}$, the chemical reactions of halogen atoms activated by nuclear processes, variables controlling the production of free radicals and stable products from molecules adsorbed on silica gel undergoing gamma frradiation, and the reactions of hot atoms, radicals and excited molecules formed by photolyses In gas, 11quid and solid phases. 
Photochemical and Radiation Sclences, continued

THE UNIVERSITY OF TENNESSEE

Knoxville, Tennessee 37916

225. RESEARCH CONCERNING IONIC AND FREE
RADICAL REACTIONS IN RADIATION
CHEMISTRY
T. Ff rancon Williams
Department of Chemistry

Recent work of this group has shown the usefulness of certain solid matrices ( $\mathrm{SF}_{6}$, neopentane, and especlally tetramethylsilane) for ESR studies of trapped radical anions. The radicals are generated by irradiation or by photoionization of organic molecules, and are observed at low temperatures. The ESR spectra are frequently well resolved and this generally allows a stralghtforward analysis to be made of the spectral patterns. We are extending the studies of radicals derived from fluorocarbons and related compounds by preparing the radical antons of fluoro-olefins such as the perfluorocycloalkenes $c-C_{n} F_{2 n-2}(n=3-6)$, the halof luoroethylenes, and other fluorocarbons. By means of these studies further information is sought about the nature of the semi-occupled orbitals and the geometries of these radical anions. The study of the reactions between electrons and chlorofluorocarbons is also relevant to the practical problem of the effect of fluorocarbons on the depletion of ozone in the stratosphere. The role of quantum-mechanical tunneling in hydrogen-atom transfer reactions at low temperatures is also belng investigated as part of a general study of $H / D$ lsotope effects in radiation-induced reactions.

GENERAL ELECTRIC CORPORATE RESEARCH AND DEVELOPMENT

Schenectady, New York 12301

226. STUDY OF PHOTOCHEMICAL EFFECTS USING
STABLE SEMICONDUCTOR ELECTRODES
R. H. W1lson
Energy Sclences Branch

Studies are underway in which a new technique for investigating layers of organometallic compounds is belng evaluated. The material being Investigated is deposited on the surface of stable semiconductor electrodes of known behaytor. The semiconductor is excited by light of sufficient energy to produce bandgap transitions. The excitation is transferred via minority carriers to the surface coating. Electron transfer to and from these layers is investigated ' In the context of a previously developed model for charge transfer at semfconductor-electrolyte interfaces. Chemlcal and physical properties of the layers is inferred from these investigations. Using these techniques previously investigated materlals such as rhodamine-B and ruthenium tris-bipyridyl are under study and the usefulness of these techniques $1 \mathrm{~s}$ belng established. 
Photochemical and Radiation Sclences, continued

MASSACHUSETTS INSTITUTE OF TECHNOLOGY

Cambridge, Massachusetts 02139

227. PHOTOCHEMICAL ENERGY STORAGE: STUDIES
OF INORGANIC PHOTOASSISTANCE AGENTS
Mark S. Wrighton
Department of Chemistry

Studies of chemlcally derlvatized semiconductor photoelectrodes are underway. The objective is to destgn photosensitive ourfaces capable. of sustaining the conversion of light to chemical and/or electrical energy by explotting light-Induced Interfactal charge transfer processes. Specific aims concern the derivatization of p-type $S 1$ and GaAs using hydrolytically unstable dinuclear ferrocene molecules as the surface derivatizing reagent. Study of the use of derivatized n-type Si as the photoanode in aqueous solution is being pursued to determine what redox rections can be affected by light at contrathermodynamic potentials. The use of electroactive derivatizing reagents as electron transfer mediators to solution redox reagents is being studied, and the utility of derivatization in passivating electrode surfaces is being evaluated. Work on the use of hydrolytically unstable ferrocenes as derivatizing reagents to n-type $S i$ is being continued with an aim toward establishing factors controlling reproducibility and durability of such surfaces. Exploratory studies on the derivatization of other visible light responsive semiconductors such as $\mathrm{GaP}$, InP, and $\mathrm{CdX}(\mathrm{X}=\mathrm{S}$, Se, Te) are being undertaken and new derivatizing reagents are being synthesized for attachment to these and previously studied surfaces. 
Photochemical and Radiation Sclences, continued

The following ten contracts are technically monitored by the Solar Energy Research Institute under the SERI Univers1ty Research Program, and are funded by the Division of Chemical Sciences, For further information about this program, contact Dr. Alex Kotch, Manager, University Programs Office, SERI, 1536 Cole Boulevard, Golden, Colorado 80401. Telephone 303-231-1823 or FTS 327-1823.

WESTERN CONNECTICUT STATE COLLEGE

Danbury, Connect1cut 06810

228. PHOTOELECTROCHEMICAL STUDIES ON $\$ 23,500 \quad 01-1$ CHLORINS, PORPHYRINS, AND METALLODERIVATIVES

Alan D. Adler

Department of Chemistry

A large number of representative porphyrin, chlorin, and metalloderivative structures thereof are being prepared and purffied for electrochemical studies. Using cyclic voltammetry as a means of obtaining an observed redox' potential, the effect of several system parameters 18 being systematically investigated. These will include variation of the porphyrinold structure, solvent, electrode composition, temperature, and Irradiation (UV, VIS, near IR). This body of data serves as the basic information necessary to the possible potential use of these materials in such solar energy conversion devices as photovoltalc cells, photogalvanic cells and photocatalytic cells - perhaps mimicking some of the naturally occuring prucesses employing these same molecular structures. 
Photochemical and Radiation Sciences, continued

UNIVERSITY OF DELAWARE

Newark, Delaware 19711

229. PHOTOSENSITIVE MOLECULAR ARRAYS: SYNTHETIC METHODS, PHOTOELECTRIC

$\$ 64,700 \quad 01-1$ PROPERTIES, AND ENERGY TRANSFER

John E. Bulkowsk1

Department of Chemistry

Th1s research is directed at synthet1c approaches to the preparation of novel photoelectrochemtcal cells for the conversion of sunlight into electricity or fuels. The concept involves spectral sensitization of electrode surfaces to visible light by utilization of metal-containing dye molecules arranged in a known and controlled molecular architecture. The synthet lc strategy relles on methods developed to generate template surfaces on solid supports using specially designed surfactant coordination complexes. Substitution reactions at the metal sites of the template should result in formation of successive dye layers one layer at a time. A significant advantage of this method arises from an ability to tallor the film's structure, and consequently 1 ts propert1es, on a molecular level by incorporation of different chemlcally modified dyes into the assembly in a precisely controlled manner. This feature should provide a powerful means for tuning the optical and electrical properties. As a result of the construction tech1que, chains of metal atoms interconnect the layers. Fac1le charge transfer along these chains could provide a mechanism for rapld and efficlent removal of energy from the excited dyes to sultable acceptors, giving enhanced cell efficlencies. The purpose of this work is to test these Ideas by synthesizing photosensitized assemblies of the type described and Investigating their optical and electrical propertles. 
Photochemical and Radiation Sclences, continued.

UNIVERSITY OF SOUTHERN MISSISSIPPI

Hattiesburg, M1ss1s81pp1 39401

230. PHOTOGALVANIC CELLS DRIVEN BY

ELECTRON TRANSFER QUENCHING OF

$\$ 50,900 \quad, \quad 01-1$

EXCITED SINGLET STATES

Dav1d Creed \& Newton C. Fawcett

Department of Chemlstry

The objective of this work is to develop more efficient photogalvanic cells for solar energy conversion based on electron transfer quenching of monomeric singlet excited states and singlet excimers of visible. light absorbing dyes. Fluorescence spectroscopy 18 being used to characterize the dye exc1ted states and fluorescence quenching indicates the possibility of electron transfer quenching. Dye reduction and oxidation are being Investigated polarographically using different electrode materials. Demonstration of the reversibility of dye redox reactions is essential to achleving the photogalvanic effect. Achieving selectivity of electrode response to different redox reagents is important to the overall efficiency of photogalvanic cells. Spectroscopic and polarographic measurements establish the formal redox potentials of the excited singlet states of the dyes. This parameter alds in selection of the quenchers. Promising combinations of dyes and redox quenchers are to be tested in totally 1lluminated thin layer photogalvanic cells. Finally, the wavelength dependence and power conversion efficiencies of new cells are to be measured. It is hoped to develop photogalvanic cells with power conversion efficiencies olgnificantly better than the best $(0.03 \%)$ so far achleved with the well known 'Iron-Thtontne" photogalvanic cell. In theory, power conversion efficlencles of about $20 \%$ can be achleved. 
Photochemical and Radiation Sciences, continued

OHIO STATE UNIVERSITY

Columbus, Oh10 43210
231. A FLAVIN MONONUCLEOTIDE-PHOTOSYSTEM
$\$ 60,400$
01-1
I SOLAR CELL
Elizabeth L. Gross
Department of Biochemistry

A solar battery using Photosystem I (PSI) subchloroplast particles plus a photoreactive dye such as flavin mononucleotide (FMN) is to be constructed. The PSI particles are placed on a fliter betwecn two coüpal lwenţs which contain an clectron duuur [ $\mathrm{K}, \mathrm{Fe}(\mathrm{CN})_{6}$ or dichlorophennl-indophenol] and ail electron acceptor (FMN), respectlvely. When the FMN side is 11luminated with white light $\left(80 \mathrm{~W} / \mathrm{m}^{2}\right)$, a current is observed in the external circult. Between 0.1 and $0.5 \mathrm{~W} / \mathrm{M}^{2}$ power with a power conversion efficiency of 0.1 to $0.7 \%$ has been observed. Goals of this program are to (1) Increase the efficlency of the cell, (2) Increase its 11fespan and (3) decrease its cost. The efficiency is to be Increased by increasing the activity of the PSI particles, choosing better electron donors and acceptors, and Improving the cell design.

UNIVERSITY OF GEORGIA

Athens, Georgia 30602
232.
DEVELOPMENT OF
Richard R. Hautala
Department of Chemistry

A solar energy storage system based upon the interconversion of norbornadiene and quadricyclene possesses several attractive features, including high specific energy storage capactiy, long-term kinetic stabllity of the energy-rich photoproduct of ambient temperatures, and relatively inexpensive reactants. Two steps are required in this cyclical system: (1) Energy storage through the sensitized photolysts of norbornadiene to quadricyclene In an enduthermic reaction;. (2) Energy release through the catalyzed reconversion of quadricyclene, to norbornadiene in an exothermic reaction. The purpose of this research program is the exploration of several fundamental areas which are related to the development of the norbornadiene-quadricyclene energy storage system. Speciflcally, plans are underway to undertake detalled studies of the properties of several sensitizers, particularly with regard to the mechanism of sensitization, to develop catalysts with high activity, high product specificity, long 11fetimes, and low cost; and to examine the feastbility of using various immobilized sensitizers and catalysts in the energy storage and energy release steps of the system. 
Photochemical and Radiation Sciences, continued

UNIVERSITY OF GEORGIA

Athens, Georgia 30602

233. MICROEMULSIONS FOR SOLAR ENERGY STORAGE

Smith L. Holt

Department of Chemistry
$\$ 38,400 \quad 01-1$

Microemulsions are belng investigated for use in solar energy storage systems. In order to ascertaln whether such solutions are of general utility, the exothermic conversion of quadricyclane to norbornadiene catalyzed by the hydrocarbon 1nsoluble tetra(p-sulfopheny1)porphinecobalt(II)anton is being studied. Attempts are being made to microemulsify quadricyclane, and factors, affecting microemulsion stability are being investigated. The kinetics of the conversion process are being compared.with kinetics obtained on homogeneous and supported catalyst systems. Removal of the water soluble catalyst from contact with the organic storage component $1 \mathrm{~s}$ being attempted through thermally induced phase separation. The results may be applicable to any solar storage cycle which Involves hydrophobic and hydrophilic components.

COLORADO STATE UNIVERSITY

Ft. Collins, Colorado 80523

234. SOLAR-CHEMICAL ENERGY CONVERSION
VIA REVERSIBLE I,TQIITD PHASE .
DIELS ALDER REACTIONS
Terry G. Lenz
Department of Agriculture
$\quad$ and Chemical Engineering

An Ideal solar-chemical energy conversion system would be one based on a high-yield reaction in the liquid phase, meeting specific thermodynamfc, reaction kinetics and physical property criterla. Such chemistry is not currently a part of solar thermochemical research. Liquid phase Diels-Alder chemistry has been identified as a potentially important area of solar thermochemlcal research, with reversible catalytic reactions avallable over the temperature range of $100-500^{\circ} \mathrm{C}$. For example, the 1,3 mcyclonrtadiene-diethyl maleate-adduct system has a $\mathrm{H}$ of about 17 Kcal/g-mole, a $\mathrm{T*}$ (where $\mathrm{Keq}=1$ ) of $700 \mathrm{~K}$, and meets virtually all othei criterla used in screening solar thermochemical systems (based upon best estimates). However, there is a serlous lack of fundamental thermodynamic, kinetic, and physical property data for this and other potentially important Diels-Alder systems. The present research program is directed toward generating fundamental knowledge for Diels-Alder chemical systems, and later testing them in small solar recelvers., 
Photochemical and Radiation Sclences, continued

ROCKEFELLER UNIVERSITY

New York, New York 10021

235. STRATI-BISPORPHYRINS: A GAUGE
FOR THE STUDY OF PHOTO-INDUCED
ELECTRON TRANSFER
David C. Mauzeral1
Faculty for Chemistry

In order to model the activity of the priwary electron donor of the photosynthetic reaction center, a method for synthesizing well-defined co-axial stacked porphyrin dimers-termed strati-bis porphyrin dimers (abr) has been devised and experimentally proven. This model system is ideally sulted for gauging the rate of electron transfer as a function of distance between sites of known orientation. This rate is of great importance in determining the efficlency of conversion of solar photons to electriclty. Several homologous serles of these dimers are belng synthesized with differing transannular separations, and their electron transfer rates, excited state properties, and redox behavior are being examined. These dimers are also of interest in characterizing the distance dependence of metal-metal interactions which are of importance in catalysis.

ARIZONA STATE UNIVERSITY

Tempe, Arizona 85281

236. ENHANCED SOLAR ENERGY COLLECTION IN PUKPHYYLIN BASED PHOTOCONNEERSION

$\$ 43,500.01-1$ SCHEMES

Thomas A. Moore \& Devens Gust

Department of Chemistry

Although porphyrin based pigment systems are belng used in a variety of solar energy conversion schemes, the absorption cross section of the porphyrin at the solar irradiance maximum is very low. Therefore, any system based on monolayers of porphyrin at a phase boundary only aboorbs a small fraction of the incldent sunlight. In natural photosynthetic membranes this problem is overcome by extensive use of accessory antenna pigments which transfer excitation energy to sites for conversion to chemlcal potential. Following this 1dea, selected pigments are to be consistently attached to porphyrins. The resulting compounds may yleld a large Increase in the absorption cross sections at the solar maximum with only a small increase in the area per molecule in a monolayer. Such an antenna could be adapted for use in essentially any porphyrin-based photoconversion scheme and would Increase the yield of electrochemical potential energy based on incident sunlight by a factor of at least $80 \%$. 
Photochemical and Radiation Sclences, continued

CALIFORNIA STATE UNIVERSTTY

Fullerton, California 92634

237. SOLAR ENERGY STORAGE VIA

ENDOTHERMIC PHOTOCHEMICAL

$\$ 65,400 \quad 01-1$

REACTIONS

John A. Olmsted

Department of Chemistry

The potential for solar energy storage of several unimolecular photoisomerization reactions is being investigated. The photolsomerization of aromatic molecules to their Dewar analogues and the trans-cis photo1somerization about the aromatic azo linkage, both of which have previously been shown to have the potential for energy storage, are being given particular attention. Energy storage potential is being directly determined using a photomicrocalorimeter, which assays the fraction of incident photon energy converted to chemlcal energy. The possibilities for enhancing the efficlency of sultable photolsomerization reactions. are also being explored utilizing photosensitizers, in particular polymerbound photosensitizers which perwlt easy separation of the energy storage phase from the sensitizer. The project is being carried out in three phases: synthesis of the compounds and systems to be studied, characterization of their photochemical products and quantum yields under sensitized and unsensitized conditions, and determination of the net endothermicities and storage efficiencies. 
Chemical Phystcs

SRI INTERNATIONAL

Menlo Park, California 94025

238. ENERGY TRANSFER STUDIES USING

$\$ 60,000 \quad 01-2$

LARGE, HIGHLY VIBRATIONALLY-

EXCITED MOLECULES

J. R. Barker

Department of Chemical

Kinetics

Experiments are being performed to study the energy-transfer properties of large polyatomis molecules that are hiflily vibrationally excited. This information is important for understanding high-temperature pyrolysis and combustion, as well as phenomena such as laser 1sotope separation. The unique electronic and spectroscopic properties of azulene combined with visible laser excitation enable the preparation of electrónic ground state azulene molecules with known vibrational energies. The time dependent thermal lensing technique has been employed to show that energy transfer in the gas phase is extremely rapid and probably occurs mostly through $V-V$ processes. Experiments using Infrared fluorescence are addressing questions concerning energy-transfer cross sections and average amounts of energy transferred on each collision. Fluorescence studies exploring possible V-E energy transfer are also being undertaken.

STATE UNIVERSITY OF NEW YORK AT BUFFALO

Amhers t, New York 14260

239. STUDY OF DYE LASER INTRACAVITY ABSORPTION
AS A DETECTOR OF LOW DENSITY SPECIES
G. O. Brink
Department of Physics
and Astronomy

The objective of this research is to investigate the technique of dye laser intraravity abeorptinn as a wane of detectlon of low density atoms, Ions and molecules as might be present in a combustion system. At tempts are being made to understand the ICA process itself so that the laser system can be optimlzed for maximum sensitivity. An atomic beam of sodium is being used as an absorber whose properties are well known to probe the behavior of the tunable dye laser. Data have been obtained so far on the intensity of the ICA signal as a function of pump laser power and sodium density. Previous results are being extended to the varlation of other laser parameters. An attempt is being made to lock one of the laser longitudinal modes to a hyperfine transition in sodium so that the time behavior of other modes may be studied. 
Chemical Physics, continued

UNIVERSITY OF WISCONSIN/MADISON

Madison, Wisconsin 53706

240. INELASTIC MOLECULAR COLLISIONS APPLICATIONS OF THEORETICAL METHODS TO PROBLEMS IN RELAXATION PHENOMENA, LASER OPERATION \& COMBUSTION KINETICS R. W. Conn

Department of Nuclear Engineering

$$
\$ 35,000 \quad 01-2
$$

The development of theoretical methods for the treatment of inelastic $(V-R-T)$ molecular collision processes continues. In particular, a new generalized distorted wave (GDW) treatment which uses numerically generated input functions, as produced for example from a diagonal close coupling calculation, is being fully implemented. Inttlal test calculations have demonstrated the promise of this technique. Larger $V-R$ problems can be treated more accurately than was previously possible. The potential of handling even larger problems is being explored by incorporating dimensionality reducing schemes like effective potentials and coupled states with the GDW theory. The molecular systems of interest are being expanded to Include systems Important to laser operation, e.g. He-HF, He-CO, $\mathrm{Ar}-\mathrm{HF}$, $\mathrm{Ar}_{\overline{3}} \mathrm{CO}$, and to other systems 1mportant in combustion problems, e.g $\cdot 0\left({ }^{3} \mathrm{P}\right)+\mathrm{NO}$, $O\left({ }^{3} \mathrm{P}\right)+\mathrm{CO}$. Ab inftio potential surfaces for these latter systems have already been generated; additional ab initio calculations will be required before these surfaces are suitable for dynamical calculations. 
Chemical Physics, continued

RICE UNIVERSITY

Houston, Texas 77001

241. INFRARED ABSORPTION SPECTROSCOPY \& $\$ 50,000 \cdot \quad \cdot \quad 01-2$ WITH COLOR CENTER LASERS

R. F. Cur1

Department of Chemistry

The recent development of $\mathrm{CW}$ single mode color center lasers with wavelengths as long as 3.1 $\mu \mathrm{m}$ opens new possibilities for high sensitivity, high resolution infrared spectroscopy of $X-H$ stretching fundamentals ( $X$ = $0, N, C)$. New spectroscopic methods are needed to exploit these possibliftes. Two absorptiou spectroscopy methods utllizing these lasers are being developed. One is intracavity Zeeman modulated absorption spectroscopy which is being used to observe and identify the free radicals generated in combustion. 8 This methgुd should have an ultimate sensitivity for concentrations of $10^{8}-10^{9} / \mathrm{cm}^{3}$ with path lengths of a few centimeters, and have the resolution and versatility to provide a powerful tool for observing, ldentifying, and monitoring a wide range of translent free radicals. The second spectroscopic method being developed is almed at situations where the modulation of the molecular absorption (e.g. Zeeman modulation as above) is not possible, for example, in spectroscopic studies of closed shell molecular Ions in plasmas (MHD), In these situations detection of small amounts of absorption $1 \mathrm{~s}$ best done by frequency modulation of the source using the molecular absorption as a discriminator. A novel method of doing this using the phase modulation obtalnable with an electro-optic crystal is under development. 
Chemical Physics, continued

UNIVERSITY OF CALIFORNIA/LOS ANGELS

Los Angeles, Callfornia 90024

242. TIME RESOLVED RESONANCE RAMAN AND

ENERGY TRANSFER STUDIES ON BACTERIO-

$\$ 69,500 \quad 01-2$

RHODOPSIN AND OTHER PHOTOCHEMICAL

SYS TEMS

M. A. E1-Sayed

Department of Chemistry

The photosynthetic cycle of bacterlorhodopsin 1s belleved to be based on a proton pump system in which an absorbed photon lonizes two protons that appear on the exterior of the membrane. This leads to a proton gradient. which drives the synthesis of the high energy ATP molecules. An understanding of the mechanism of photogeneration of the protons not only will be useful In understanding the mechanism of the primary process in the cycle but it might give a new way to photoproduce $\mathrm{B}^{+}$(and thus $\mathrm{H}_{2}$ gas) from solar energy. Time resolved resonance Raman techniques developed during the past year are being used to record the spectra of the retinal in the different intermediates appearing during the cycle: The point in the cycle where the proton of the Schlff base lonizes is belng located. Furthermore, the question of whether or not the retinal changes its conformation during the cycle 18 belng examined.

UNIVERSITY OF OREGON

Eugene, Orogon 97430

243. LASER SPECTROSCOPY OF COMBUSTION
INTERMEDIATES
P. C. Engelking
Department of Chemistry

An investigation of the spectroscopy of polyatomic radicals is underway. This spectroscopic information 18 of value for the determination of these reactive intermediates with laser probes in processes such as combustion. One of these new methods, laser induced fluorescence, is being used in this investigation to produce the spectrum of the radicals prepared in an inert gas flow system. Molecular constants are belng determined for both the upper and lower electronic states. As a specific application of this technlque, the spectroscopy of the methoxyl radical, $\mathrm{CH}_{3} \mathrm{O}$, is being Investigated. Besides deriving the rotational constants and hence the geometry of this radical, both the spin-orbit and Jahn-Teller couplings in the lower state of this radical are being determined. Further studies of the application of laser Induced fluorescence to the spectroscopy of radicals are beling carried out. One advantage of preparation of the radicals in an inert gas flow system is the possibility of investigating their quenching and their reactions with other specles. A number of reaction rates applicable to combustion kinetics are belng measured. 
Chemical Physics, continued

UNIVERSITY OF ROCHESTER

Rochester, New York 14627

244. LOW ENERGY ION-MOLECULE REACTION DYNAMICS AND CHEMIIONIZATION RINETÍCS

$\$ 46,000 \quad 01-2$

J. M. Farrar

Department of Chemistry

This work is studying, via molecular beam techniques and laser detection teçhniques, the dynamics of 1on-neutral collisions. The reactions of $\mathrm{H}^{+}$with $\mathrm{CO}, \mathrm{N}_{2}, \mathrm{O}$, and $\mathrm{Ar}$ are heing studled with a viow toward efucldating the cule of Intcial vibrational excitation in product otate distributions. Energy and angular distributions of products are being measured in the 1-30 eV range to learn about preferred collision geometries, energy disposition in reactive collisions and the role of vibration energy of the reactants. The work of Herman 18 belng exploited to quench excited vibrational states of $\mathrm{H}_{2}{ }^{+}(\mathrm{v}>2)$ to determine the role of this initial energy_on reactivity. Studies of associative detachment reactions of the form $\mathrm{X}^{-}+\mathrm{Y} \rightarrow \mathrm{XY}+\mathrm{e}^{-}$, employing multiphoton fonization (MPI) as a state selective detection scheme are belng conducted. The final rotationalvibrational states yleld information on reaction probability v8. initial orbital angular momentum. The final vibrational states yield information on Franck-Condon factors in relation to autolonization lifetime as a determinant in final state distributions. 
Chemical Physics, continued

AEROCHEM RESEARCH LABORATORIES, INC. Princeton, New Jersey 08540

245. EXPERIMENTAL DETERMINATION OF RATE
COEFFICIENTS FOR IMPORTANT COMBUSTION/
FUEL CONVERSION REACTIONS BY A NOVEL
HIGH-TEMPERATURE PHOTOLYSIS TECHNIQUE

A. Fontijn

The development of fossil-fuel burning devices/englnes having more efficient fuel combustion and/or less, pollutant formation than is currently possible, requires modeling and scaling studies based on rellable information on the kinetics of the Important elementary reactions 1nvolved. Such data are generally not available; the few pieces of reliable data that do exist are applicable malnly over very limited temperature ranges. The goal of this program is to measure the rate coefficients of combustion reactions over a wide temperature range, 1.e.; from about 1800 to $300 \mathrm{~K}\left(2800\right.$ to $\left.100^{\circ} \mathrm{F}\right)$ or to as low a temperature as is of practical interest. Prior to this work no technique capable of performing such measurements existed; Indeed, for many pertinent reactions no techniques at all were avallable for making measurements at realistic temperatures. In order to fill this gap, a new experimental technique has been developed, High-Temperature Photolysis (HTP). HTP combines two Individually well-tested techniques: (1) the High-Temperature Fast-Flow Reactor developed to study the kinetics of metal atom/oxide reactions over about the 300 to $1800 \mathrm{~K}$ temperature range and (1i) the pulsed photolysis resonance fluorescence/absorption technique used in many laboratories for kinetic measurements of combustion intermediates (free radicals), but only near room temperature. The first HTP study concerns the reaction of oxygen atoms with methane, a reaction of major interest and one that is also conducive to development of the HTP technique. Subsequent studies focus on reactions of increasing complexity, culminating in radicalradical reactions of higher hydrocarbon and oxidizer radical combinations. 
Chemical Physics, continued

UNIVERSITY OF MINNESOTA

Minneapolis, Minnesota 55455

246. REACTIONS OF IONS WITH ATOMIC AND

MOLECULAR FREE RADICALS

$\$ 45,000 \quad 01-2$

W. R. Gentry

Department of Chemistry

Studies of microscoplc reaction dynamics in collisions of lons with atomic and molecular free radicals continue using the merged molecular beam technique. Systems in which there are unusually important angular momentum constraints on reaction dynamics are being examined. The most favorable examples are chosen from the set of reactions $\mathrm{X}^{+}+\mathrm{YH} \rightarrow \mathrm{XY}^{+}+\mathrm{H}$ and $\mathrm{XH}^{+}$ $+\mathrm{Y} \rightarrow \mathrm{XY}^{+}+\mathrm{H}$ where $\mathrm{X}$ and $\mathrm{Y}$ are first-row atoms, $\mathrm{B}, \mathrm{C}, \mathrm{N}, 0$ or $\mathrm{F}$. None of these reactions have previously been observed. Fundamental information on the nature of the chemfstry in these open-shell systems, as well as on the microscopic detalls of the reactions dynamics, is being obtained.

UNIVERSITY OF ILLINOIS AT CHICAGO CIRCLE ChIcago, Illinots 60680

247. MEASUREMENTS OF GAS PHASE REACTION RATE CONSTANTS: $\mathrm{D}+\mathrm{HX}$ AND NO $+\mathrm{O}_{3}$

- R. J. Gordon

Department of Chemistry

$$
\$ 40,000 \quad 01-2
$$

Research is belng carried out in two areas of gas phase chemical kinetics. The first deals with atomlc reactions of the type $D+H X$, where $X$ may be $a$ halogen atom or $\mathrm{CN}$. The objective is to measure the rate constants of the exchange and abstraction reactions over a wide range of temperatures, using the method of flash photolysis with resonance fluorescence detection.

Preliminary data for $\mathrm{H}+\mathrm{HCl}$ have been obtalned. $\mathrm{HCl}$ and $\mathrm{HBr}$ measurements and examination of some more complex systems such as $\mathrm{Cl}+\mathrm{CH}_{3} \mathrm{Br}$ are underway. The second problem deals with the chemfcal $r^{\prime}$ :tions and vibrational relaxation of osone. A large capactty flow chactor 1s jelng used to measure the rate constants of chemiluminescent reactions such as NO+ $0_{3}$. In particular, the temperature dependence of the visible and ir emission of $\mathrm{NO}_{2}$ in this reaction is being studied. Using the chemiluminescent reaction as an indicator, the rate of vibrational relaxation of ozone by various buffer gases is being measured using $\mathrm{H}_{2} \mathrm{O}$ or $\mathrm{D}_{2} \mathrm{O}$ as a relaxing gas. 
Chemical Physics, continued

GEORGE WASHINGTON UNIVERSITY

Washington, D.C. 20006

248. CHARACTERISTIC PARAMETERS IN

COMBUSTION PROCESSES AND THEIR

$\$ 20,000 \quad 01-2$

ACCESSIBILITY TO CURRENT AND

FUTURE DIAGNOSTICS

R. Goulard

Department of Civil, Mechanical

and Environmental Englneering

The plan in this project is to evaluate combustion diagnostics with a view to 1dentifylng which diagnostic techniques are best sulted to each particular set of experiments. It 18 important not only to establish the parameters to be measured in each case, but also their quantitative range; only thus can an appropriate measurement device be selected, or, if none is avallable, can the need for further instrumentation development be established. The criteria used for this evaluation are most affected by several areas in rapid development in the instrumental fleld (e.g. sensor nolse limitation and real time data processing) and also by the new technological demands for scientific information (e.g. turbulence structure and particulate formation or destruction). A complete review and set of evaluation criteria will be avallable soon.

BROWN UNIVERSITY

Providence, Rhode Island 02912

249. INTERACTIONS OF MOLECULES
WITH SURFACES
E. F. Greene
Department of Chemistry

A beam of $\mathrm{Kr}$ atoms is velocity selected, scattered from the (0001) surface of crystalline graphlte and velocity analyzed. The variation of the elastically scattered intensity with angle and kinetic energy is interpreted by comparison with the predictions of a simple, classical model to give Information about the structure of the surface. The yleld of positive 1ons formed when neutral alkall metal atoms hit hot surfaces of $\mathrm{Si}$ and $\mathrm{Al}_{2} \mathrm{O}_{3}$ is befing studied to provide 1ncreased understanding of the interaction of these atoms with the surface. Of special interest are the range of usefulness of the quasi-equilibrium model for the lonization and information to be found about kinetic processes when the model is inadequate. Molecules such as $\mathrm{CCl}_{4}, \mathrm{C}_{2} \mathrm{Cl}_{6}$ and trioxane are accelerated to high kinetic energles in seeded molecular beams and then suddenly brought to rest by collision with a glass surface. The relative effectiveness of the kinetic energy and the internal energy in causing reactions to occur is measured to help show how molecules behave in violent collisions. 
Chemical Physics, continued

UNIVERSITY OF UTAH

Salt Lake City, Utah 84112

250. INFRARED LASER-INDUCED PHOTOCHEMISTRY
W. A. Guillory
Department of Chemistry

The objective of this program is to use the phenomenon of infrared multiphoton absorption (IMA) to study elementary photophysical and photochemical processes related to flame and combustion systems. At collisionless pressures, IMA has recently been shown to be a statistical process, occurring almost exclusively in the vibrational degrees of freedom, resulting in what appears to be unimolecular dissociation from several surfaces of the ground electronic state. The focused radiation of a pulsed $\mathrm{CO}_{2}$ TEA 1 aser (70-250 nsec, FWHM) 18 used to Inftiate these flame and combustion processes. This method of reaction Initiation provides a significant and important advancement in time-resolution, so that mechanisms and energy distributions can be more effectively determined. Stable and unstable (free radicals) species generated are monitored by wavelength and temporally resolved spectroscopy using laser-induced fluorescence, resonance lamp Induced fluorescence (atom detection), and Infrared emission.

ILLINOIS INSTITUTE OF TECHNOLOGY

ChIcago, Illinols 60616

251. STUDIES IN COMBUSTION KINETICS
AND MECHANISMS
D. Gutman
Department of Chemistry

The purpose of this research is to develop a new method of generating polyatomic free radicals under controlled conditions and to quantitively study those reactions that they undergo which are important in combustion processes. The method involves the use of a pulsed $\mathrm{CO}_{2}$ TEA laser to dissoclate radical precursors in a fast-flow reactor. The concentration profiles of reactants and products are monitored using dynamic photolonization mass spectrometry. The experimental facility has been constructed and several design parameters have been varied to achieve optimum performance including laser power and beam focusing, reactor shape and flow velocitles, special differential pumping in the mass spectrometer, and gas sampling geometries. The laser-induced decomposition of the radical precursors is homogeneous throughout the reactor and conversions to up to 20 per cent in each laser pulse are being observed, depending on laser power. Expected behavior has been achieved using precursors which do not produce free radicals, indicating the facility is ready for the kinetic studies. Experiments are in progress to generate alkoxyl (RO) free radicals from nitrites and nitrates and:to subsequently study their reactions with $\mathrm{O}_{2}$, NO and organic molecules. 
Chemical Physics, continued

STANFORD UNIVERSITY

Stanford, Ca1ifornia 94305

252. COMBUSTION GAS MEASUREMENTS USING

TUNABLE LASER ABSORPTION SPECTROSCOPY

$\$ 50,000 \cdot 01-2$

R. K. Hanson

Department of Mechanical Engineering

The objectives of this research are: (1) to develop tunable laser absorption techniques for measuring species concentrations and temperature in combustion flows; and (2) to measure spectroscopic parameters. (IIne strengths and collisIon halfwidths) of critical combustion species. The emphasis of the work hes been on the use of tunable infrared diode lasers, although new work to utilize tunable dye lasers for absorption spectroscopy at ultraviolet and visible wavelengths has been 1nitiated. Experiments Involve passing the laser beam through gases produced in a flat flame burner or a shock tube and subsequently tuning the laser wavelength across individual absorption lines. If the species concentration and temperature are known, the fully-resolved absorption line data yleld line strengths and collision halfwidths. If these parameters are known, then the same measurements can be used to infer the absorbing species concentration and temperature. The narrow. 11newidth of diode lasers enables orders of magnitude improvement in spectral resolution over conventional infrared spectroscopy, while the small size of the laser elements allows extremely fast tuning rates. Work includes: (1) continued measurements of $\mathrm{CO}$ and temperature, and new measurements of $\mathrm{CO}_{2}$, in steady flat flames; (2) completion of a low-pressure flat flame facility; and ( 3 ) continued development of a tunable uv/visible dye laser absorption system for the measurement of radical spectes and their spectroscoplc parameters in eombustion flows.

STANFORD UNIVERSITY

Stanford, Cal1forn1a 94305

253. RINETICS OF SOME REACTIONS OF HCN
AT HIGH TEMPERATURES
R. R. Hanson and C. T. Bowman
Department of Mechantcal Engineering

Research is underway to Investigate the gas-phase kinetics of several HCN decomposition reactions at high temperatures. A shock tube 18 used to shock heat vartous gas mixtures contalning HCN, and spectroscopic diagnostics are employed to monitor time histories of important species during reaction. Reactions of particular interest include the thermal decomposition of HCN and the reactions of BCN with $\mathrm{B}, 0$, and NO. Results from the study include high-temperature rate coefficient data currently of interest in studies of pollutant kinetics in flames. A unique feature of the research is the application of a tunable diode laser to measure the time history of HCN using new techniques being developed in this laboratory. 
Chemical Physics, continued

HOWARD UNIVERSITY

Washington, D.C. 20059

254. LASER STUDIES OF THE DYNAMICS OF ATOM-MOLECULE REACT IONS

$\$ 41,000 \quad 01-2$

W. M. Jackson

Department of Chemistry

The objectives of this work are to measure the partitioning of excess reaction energy into the vibrational degrees of freedom of a particular radical and to determine rate constants for the reactions of free radicals with $\mathrm{O}_{2}$ and saturated hydrocarbons. Both of these questions are 1mpurtant for the understanding of the kinetics of combusclon reactions. Some of the techniques that are being used in the laboratory studies may be useful for the detection and characterization of atmospheric pollutants such as $\mathrm{NH}_{3}$, $\mathrm{NO}$, and $\mathrm{SO}_{2}$. Laser induced detection $1 \mathrm{~s}$ used to characterize the unstable intermediates produced by the flash photolysis with an ArF laser. The reactions are then studied by monitoring the chemiluminescent signal or detecting the product with a quadrupole mass spectrometer.

CALIFORNIA INSTITUTE OF TECHNOLOGY

Pasadena, California 91125

255. HIGH RESOLUTION INFRARED SPECTROSCOPY:
DISCRETE STATES IN THE QUASICONTINUUM
R. C. Janda
Department of Chemistry

In order to understand elther combustion or 1sotope selective multiphoton dissociation from a microscoplc point of view, great progress 18 necessary in the understanding of vibrationally highly excited states. To meet this very basic need, two types of high-resolution spectroscopir experiments are planined: 1) SIngle photon Infrared dissociation of weakly bound molecules and clusters; 2) High-resolution overtone and combination band laser-induced fluorescence of stable molecules at vibrational energies characteristic of the quasicuntinuum. The experiments are being carried out using a supersonic molecular beam with four levels of differential pumping and quadrupole mass spectrometer detection. The laser source 18 a $\mathrm{Kr}$ ion pumped color center laser capable of $1.0 \mathrm{MHz}$ line width and tunable between 2.2 and $3.3 \mu \mathrm{m}$. In addition to furthering the understanding of the dynamics of vibrationally hot molecules, sensitive probes for internal excitation of large molecules which may later prove to be useful in the analysis of complex chemtcal reactions, including combustion, are to be developed. 
Chemical Physics, continued

UNIVERSITY OF NEW ORLEANS

New Orleans, Loutsiana 70122

256. IDENTIFICATION AND TEMPORAL BEHAVIOR

OF RADICAL INTERMEDIATES FORMED DURING

THE COMBUSTION AND PYROLYSIS OF GASEOUS

$\$ 43,500 \quad 01-2$

FUELS: RINETIC PATHWAYS TO SOOT FORMATION

R. D. Kern, Jr.

Department of Chemistry

A shock tube coupled to a time-of-flight mass spectrometer is being used to Identify and record the time history of those species which lead to soot formation in pyrolytic and combustion systems in which the fuel has a low H/C ratio. The problem of soot formation during the burning of synthetic fuels has become a subject of great Interest. Measurements of the rates at which key species react are being made with the goal of understanding the molecular pathways utilized in the formation of carbon polymers. The varlance of these rates is being studied as a function of the fuel/oxygen rat 10 and the presence of certain inhibitors present in trace amounts. The Investigation began with a serles of $\mathrm{C}_{6}$ compounds (propane, propene, propyne, and cyclopropane) progressing to a series of $C_{6}$ compounds (hexane, cyclohexane, cyclohexene, and benzene). This selection of compounds offers a wide range of the $\mathrm{H} / \mathrm{C}$ ratio and drastic differences in molecular structure which promises to yield significant new Information pertaining to the molecular formation of soot.

UNIVERSITY OF ILLINOIS AT CHICAGO CIRCLE

ChIcago, Illinois 60680

257. KINETICS OF FUEL HYDROCARBONS

$\$ 46,000 \quad 01-2$

J. H. Kiefer

Department of Energy Engineering

The objective of this work is understanding of the pyrolysis kinetics of several fuel hydrocarbons (ethane, propane, butanes) at combustion temperatures. The technique uses the shock tube in conjunction with a narrow-beam, laser 8 chlleren technique responsive to the rate of endo- and exothermic reactions. Computer modeling allows extraction of fundamental data relevant to oxidation and Ignition. 
Chemical Physics, continued

PURDUE UNIVERSITY

W. Lafayette, Indiana 47907

258. LASER INDUCED FLUORESCENCE OF

$\$ 50,000 \quad 01-2$

RADICALS IN FLAMES

N. M. Laurendeau, D. W. Sweeney

School of Mechanical Engineering

A tunable dye laser and Nd-YAG pump laser are being used in experiments to determine local radical species concentrations in flames by measuring laser Induced fluorescence from the particular specles of interest. The Nd-YAG laser and dye laser supply tunable, high Intensity, narrnwhand laser radiation in the visible and ultraviolet spectral region. The spectral intensity of the focused dye laser beam is sufficient to saturate various exclted states of the radical species in flames. Measurement of the fluorescence emission from a saturated state provides a sensitive point measurement of the radical species number density. Knowledge of the local species concentration is important because radicals control combustion chemistry. The radical species of greatest interest include $\mathrm{CH}, \mathrm{CN}, \mathrm{NH}$, and $\mathrm{OH}$. A two level model for saturated fluorescence in diatomic models has been developed. A dye laser system has been used to partially saturate fluorescence transitions in $O H$ radicals in flames.

NORTHWESTERN UNIVERSITY

Evanston, Ill1nols 60201

259. THEORETICAL STUDIES ON HETERO-

$\$ 40,000 \quad 01-2$

GENEOUS COMBUSTION

C. K. Law

Department of Mechanical

Engineering

The complex processes occurring within 11quid-fueled chemical combustors utflizing spray infection techniques are primarlly heterogeneous in nature, involving the vaporization, combustion, and motion of an ensemh1e of droplets which interact with the gaseous medium through heat, mass, and momentum transfers. The present program aims to gain fundamental understandIng on these heterogeneous processes and their effects on the combustor efficlency and exhaust purity. Particular emphasis is on (1) the vaporization, ignition, deflagration, and extinction of fuel droplets in a reactive fuel/oxidizer environment simulating the spray interior; and (2) the vaporization of the spray jet in the hot combustor environment. Significant advances have already been made on Task (1). Work continues with Task (1), particularly on the development of a complete numerical code, and research on Task (2) has been initiated. 
Chemical Physics, continued

UNIVERSITY OF CALIFORNIA/IRVINE

Irvine, Callfornia 92717

260. INTERMOLECULAR ELECTRONIC ENERGY

$\$ 60,000 \quad 01-2$

TRANSFER PROCESSES

E. K. C. Lee

Department of Chemistry

Interactions of radiation with matter produce exclted states as do chemical reactions. Chemlcal dynamics of energy transfer and energy storage involving the molecular excited states which are important in the energy conversion processes (combustion, flame, radiative transfer, solar energy, etc.), atmospheric chemistry, and photochemical isotope separation are being Investigated. Molecular electronlc energy transfer of ten accompanies the excitation of molecular vibrations and rotations, and therefore the resulting vibrational and rotational energy distributions are being experimentally studied in order to understand the physical and chemical mechanisms involved. Since the initial conditions of the excitation must be specifled in as much detall as possible for adequate understanding, tunable dye laser radiation is employed. The rates of energy transfer (ultimately state-to-state rates) are being measured by luminescence spectroscopy (steady-state as well as time-resolved) and chemical kinetic studies. Chemical quenching, excimer/exciplex formation and isotope effects in energy transfer are being studied with systems containing small molecules such as formaldehyde, $\mathrm{SO}_{2}$, HNO, and others. Reactive intermediates in combustion processes are being studied by low temperature matrix photolysis and spectroscopy. 
Chemical Physics, continued

UNIVERSITY OF COLORADO

Boulder, Colorado 80309

261. FREE RADICAL STUDIES BY ULTRAVIOLET

EXCIMER LASER PHOTOLYSIS

$\$ 37,000 \quad 01-2$

S. R. Leone

Department of Chemlstry

A new experimental technique is befing used to produce and directly study free radicals. Short pulses $\left(10^{-8} \mathrm{sec}\right)$ of ultraviolet 11 ght from a rare gas hallde excimer laser photodissoctate small molecules to produce free radicals. The radicals in many cases are generated with high foltial vibrational excitation. The radicals are detected directly by wavelength and tIme-resolved Infrared emission spectroscopy using a background-1imited copper-doped germanlum infrared detector. The detalled kinetics of rapld vibrational deactivation of radicals and also fast reactions of excited and ground state radicals are measured by fully time-resolved techniques. In addition, wavelength-resolved measurements of the radical emission allow the assignment of numerous vibrational frequencies. These studies provide not only immediate and practical information involved in radical chemistry, but also a fundamental data base concerning the vibrational levels of radical species, the general phenomena of radical deactivation, reactions, and detection.

UNIVERSITY OF MISSOURI/ST. LOUIS

St. Louls, Mis8ouri 63121

262. OBSERVATIION OF LUMINESCENT SPECTRA IN

$\$ 55,000 \quad 01-2$

LOW ENERGY ION-NEUTRAL COLLISIONS

J. J. Leventhal

Department of Physics

The objective of these experiments 18 to obtaln detalled information on the internal excitation energy of atoms and molecules after undergolng nonviolent (low energy) collisions. The experiments are performed by spectral analysis of the light emltted by the atoms and molecules following colliaion. From these spectra microscoplc detalls of the collision mechanism can be determined; that 1s, the amount of energy stored in the molecular collision products as well as the partitioning of energy among the avallable internal energy levels. Work in progress is concentrated on collisions in which the colliding spectes are laser excited to a spectfic internal energy state. Collisions of thls type are, In some cases, expected to react in a highly selective fashion and have been mentioned as a possible method of isotope separation. Data on energy transfer in atomic interactions between energetically excited species have been obtained. Using laser excitation it has been shown that energy from the laser beam can be stored in sodium atoms and returned to the system in subsequent interactions between energetically exc1ted specles. These interactions result in more highly excited atoms and in some cases lonic species. 
Chemical Physics, continued

UNIVERSITY OF CHICAGO

Chicago, Illinols 60637

263. LASER INDUCED CHEMICAL REACTIONS

$\$ 50,000 \quad 01-2$

AND LASER-COLLISION PROCESSES

J. C. Light

Department of Chemistry

Th1s research deals with laser-collision processes by quantum scattering methods. Methods to be developed Include an improved R-matrix scattering code for handling multiple curve crossing problems efficiently, in order to consider laser collision induced excltation and charge transfer in atomic collisions, laser collision induced multiphoton (IR) absorption processes for diatom-atom collisions, and methods for treating single photon molecular (triatomic) photodissociation.

WAYNE STATE UNIVERS ITY

Detro1t, Michigan 48202

264. ELECTRONIC RELAXATION PROCESSES IN POLYATOMIC MOLECULES

$\$ 52,000 \quad 01-2$

E. C. Lim

Department of Chemistry

The overall objective of this program is to elucidate mechanisms of radiation1 ess transitions in polyatomic molecules and the factors affecting their rates. Althuigh fundamental in nature, the research is of practical importance to the design of laser dyes and materlals for conversion of light into heat. Three programs are underway. The first explores the radiationless transitions in molecular excimers, as related to their lasing ability. As molecular species whose ground state 18 unstable, excimers are Ideal laocr compounds, provided the fluorescence efficlency is high (therefore, efficiencles of radiationless transitions are 10w). The radiationiess transitions from singlet excimers of various aromatic and heteroaromatic compounds are characterized and the manner in which their rates vary with experimental conditions 18 determined. In the second program experimental tests of theoretical predictions concering the proximity effect in radiation1 ess transitions are performed, which have been the subject of extensive past studies in this laboratory. Isotope, solvent and substituent dependence of triplet spin sublevel dynamics, and temperature effects on the $S_{1} \rightarrow$ $S_{0} / S_{1} \rightarrow T_{1}$ branching ratio, are some of the new approaches to gain a better understanding of this important phenomenon. Finally, in the third program, high resolution spectral studies of azulene are carried out in order to deduce major configurational differences, between the exclted singlet states and the ground state, that may be responsible for the ultrafast internal conversion from the excited states of this molecule. As the only example of an aromatic hydrocarbon which exhibits extremely fast radiationless transitions to the ground state, the origin of the ultrafast internal conversion in this molecule 18 important to the understanding of radiationless processes. 
Chemical Physics, continued

UNIVERSITY OF CALIFORNIA/SANTA BARBARA

Santa Barbara, Californta 93106

265. METASTABLE RARE GAS CHEMILUMINESCENT

REACTION CROSS SECTIONS

$\$ 44,000 \quad 01-2$

R. M. Martin

Department of Chemistry

The optical emission spectra of metastable rare gas reactions in crossed molecular beams are being studied in order to determine the electronic state reaction channels, vibronic state distributions, and reaction cross sections as a function of collision energy. Studies are made of rare gas excited halide and oxide formation and of metastable excitation transfer reactions. Specific systems studied with this apparatus include $\mathrm{Ar}$, $\mathrm{Kr}$ * and $\mathrm{Xe}^{*}$ metastable atoms with varlous halogen and hallde target molecules to give the corresponding fluoride, chlorlde and bromide excimers, and excltation transfer reactions of these metastables as well as $\mathrm{He}^{*}$ and $\mathrm{Ne}^{*}$ metastables with atomic, diatomic and triatomic targets. Information on these systems is needed to understand the mechanisms of energy transfer in gas phase exclmer and excitation transfer lasers. A crossed nozzle beam spectrometer has been bullt for this work which permits the study of rare gas chemiluminescent reactions in the visible, ultraviolet and vacuum ultraviolet reglons of the spectrum down to $120 \mathrm{~nm}$.

CORNELL UNIVERSITY

Ithaca, New York 14853

266. HYDROGEN CYANIDE REACTIONS IN COMBUSTION SYSTEMS

W. J. McLean

Sibley School of Mechantcal

\& Ae rospace Engineering

The ongoing research program is concerned with chemical processes associated with HCN in combustion environments. The objective of the research is to determine the rates and mechanisms of those reactions responsible for the formation of $\mathrm{HCN}$ and $i t s$ subsequent conversion to other undesirable compounds. The experimental techniques employed in these studies involve the use of a high temperature fast flow reactor with product analysis by quadrupole mass spectrometry and gas chromatography. The fabrication and callbration of the flow reactor oystem is complete. Experiments at 200 torr indicate that isothermal operation at temperatures up to $1800 \mathrm{~K}$ is readily achlevable. Reaction times down to about $2 \mathrm{~ms}$ can be studied. Initially, the $\mathrm{NH}_{3}$-NO reaction is being studled both with and without accelerating additives such as $\mathrm{H}_{2}$ and $\mathrm{O}_{2} \cdot$ Analytical methods have been developed for gas chromatographic determination of $\mathrm{NH}_{3}$ and NO. The sampling system rellability has been confirmed, demonstrating that $\mathrm{NH}_{3}$ does not catalytically decompose on the reactor walls or during the sampling process. Data on the $\mathrm{NH}_{3}-\mathrm{NO}$ reaction is currently being acquired. 
Chemical Physics, continued

UNIVERSITY OF PITTSBURGH

Pittsburgh, Pennsylvanta 15260

267. MICROWAVE-OPTICAL DOUBLE RESONANCE
SPECTROSCOPY
D. W. Pratt
Department of Chemistry

The principal objective of this research project is to develop basic knowledge about the structure of matter and its interaction with radiation through the exploration of new physical and chemical phenomena. of particular interest are short-1ived chemical species which are produced by irradiation of solids with $x$-rays, $\gamma$-rays, and ultravlolet light, and include electronicallyexcited molecules, free radicals and collective excltations in solids. Because of their short iffetimes, the development of new experimental techniques such as optical detection of magnetic resonance spectroscopy forms an integral part of the project. The results of this research will find application in environmental chemistry, laser-induced isotope separation, natural product synthesis, and energy generation, storage, and conversion devices.

PRINCETON UNIVERSITY

Princeton, New Jersey 08544

268. THEORY OF CHEMICAL RINETICS AND

$\$ 55,000,01-2$ MOLECULAR DYNAMICS

H. A. Rabitz

Department of Chemistry

Th1s work studies molecular collisions, associated relaxation phenomena, and chemlial kinetica. In general the research can be divided into three categorles:

(a) the theoretical treatment of individual molecular collision events, (b) the analysis of macroscopic kinetic relaxation phenomens, and (c) studies of critical parameter dependencies in chemical kinetics. The work in category (a) involves the Implementation of new practical means for rellably calculating collision information, and the development of sensitivity theory to ascertain which key molecular parameters are controlling collision behavior. The raw collision information and Insight generated by these studfes can be used to correlate and analyze experimental data. In this regard, part (b) of the research on kinetic relaxation phenomena involves (1) the development of scaling relations connecting different molecular rate constants, (2) the deconvolution of experimental relaxation data to yleld state-to-state rate constants, and ( 3 ) the analysis of highly non-equilibrium behavior in flowing gases. Finally part (c) of the research involves further development and implementation of the work in sensitivity analysis for chemical kinetics. The goal here is the assessment of how particular rate constants and initial species concentrations critically control combustion and related kinetic phenomena. All aspects of the research utilize a varlety of techniques, many of which are currently under development. 
Chemlcal Physics, continued

CALSPAN ADVANCED TECHNOLOGY CENTER

Buffalo, New York 14225

269. VIBRATIONAL ENERGY TRANSFER RINETICS. IN MOLECULAR DISEQUILIBRIUM

$\$ 50,000$

$01-2$

J. W. RIch

Physical Sciences Group

This program is an experimental study of laser-induced chemistry und molecular energy transfer. The experiments use a flowing-gas absorption cell, optically pumped by a $\mathrm{cw}$ supersonic flow carbon monoxide laser. In this apparatus, carbon dimer $\left(\mathrm{C}_{2}\right)$ formation and carbon thirteen ( $\mathrm{C}^{13}$ ) 1 sotope enrlchment resulting from the vibration-vibration pumping of carbon monoxide to carbon disulfide $\left(\mathrm{CS}_{2}\right)$, and accompanylng vibration-vibration pumping effects and related transfer phenomena are belng investigated. Energy transfer from $C O$ to additional molecular species 18 also being investigated. Supporting analytical studles are being performed.

MASSACHUSETTS INSTITUTE OF TECHNOLOGY

Cambridge, Massachusetts 02139

270. THEORY OF CHEMICAL RINETICS

J. Ros8

Department of Chemistry

Research 18 conducted in the theory of chemical dynamics on the application of Franck-Cond on approximations to rearrangement collisions and hence chemical reactions, and on the stochastic theory of intramolecular energy transfer. Further research is belng conducted on the stability of binary reacting flulds in temperature and gravitational gradients and the role of fluctuations in the onset of instabilities in the kinetics of first-order phase transitions. Substantial progress has been made in the simple and fast prediction of reaction probabilities and product energy and angular d1stributions by means of a Franck-Cond on approach, in the theory of a gymmetric random walks, in instabilities in binary mixtures, and in the thermodynamic analyuls of the efficleucy of thermal and chemical engines. 
Chemical Physics, continued

WRIGHT STATE UNIVERSITY

Dayton, Oh10 45435

271. DETERMINATION OF ATOM AND RADICAL CONCENTRATIONS IN THERMAL REACTIONS OF

$\$ 45,900 \quad 01-2$ HYDROCARBONS AND OTHER GASES

G. B. Skinner

Department of Chemistry

A serles of experiments is belng carried out in which concentrations of species such as $\mathrm{H}, \mathrm{O}, \mathrm{OH}$ and $\mathrm{CH}_{3}$ are determined in shock-heated mixtures of smaller hydrocarbons and related substances, diluted with argon. The method of analysis is atomic (or molecular) absorption spectroscopy, which has a good combination of high sensitivity and high space and time resolution. Scientifically, these experiments help to clarify the understanding of the high temperature reactions of several hydrocarbons, reducing a major area of confecture to experimental fact, and helping to resolve conflicting views as to the detalled kinetics of the reactions. Practically, the results of this work should lead to higher efficlency and lower atmospherlc pollution in the use of hydrocarbons as fuels and as raw materials for chemical processes.

RICE UNIVERSITY

Houston, Texas 77001

272. HYPERSONIC BEAM LASER PHOTOLYSIS

$\$ 50,000 \quad 01-2$

R. B. Smalley

Department of Chemistry

Using laser photolysis.within a pulsed hypersonic nozzle, the techniques of hypersonic molecular beams are belng extended to a broad new range of free radicals, complexes, and reaction intermedlates. Taking advantage of the extreme cooling and nearly ideal spectroscopic conditions afforded in collimated molecular beams obtalned from these expansions, the structure and photophysics of molecular systems studied as test cases for the development of this technique Include (1) the rare gas halldes such as RrF; (2) the mercury monohalides; (3) the heavy metal fluorides $\mathrm{MF}_{6}, \mathrm{MF}_{5}, \mathrm{MF}_{4}$ ' where $M=U, W, M o, R e, T c$, etc; and (4) organic free radicals such as methylene, trimethylenemethane, and derivatives. Information obtained for these systems includes ( 1 ) accurate measurement of ground and exc1ted potential energy surfaces (both attractive and repulsive portions) which are optically accessible via one or two photon transitions from the ground state and (2) cross sections and spectral dependence of the various possible photodissociation and photolonization channels for the molecules under collision free, single quantum state conditions. 
Chemical Physics, continued

UNIVERSITY OF CALIFORNIA/SANTA BARBARA

Santa Barbara, Callfornia 93106

273. LASER FLUORESCENCE STUDIES OF THE DETAILED COMBUSTION OF NITROGEN AND

$\$ 50,000$

$01-2$

SULFUR BEARING FUELS

M. SteInberg - Quantum Institute

D. 0. Harris - Department of Chemistry

Laser fluoreocence monttoring capabllity, which at present enables measurement of $\mathrm{SH}, \mathrm{S}_{2}, \mathrm{SO}, \mathrm{SO}_{2}$ and $\mathrm{OH}$ in $\mathrm{flames,}$ is being extended to include species of 1mportance in the fuel nitrogen-No cycle, namely No, $\mathrm{NO}_{2}, \mathrm{NH}, \mathrm{NH}_{2}$ and $\mathrm{CN}$. This non-perturbing technique 18 being applled to valious $\mathrm{H}_{2} / \mathrm{O}_{2} / \mathrm{N}_{2}$ and $\mathrm{CH}_{2} / \mathrm{O}_{2} / \mathrm{N}_{2}$ flames doped $\mathrm{wIth}$ traces of $\mathrm{NH}_{3}$ or pyridine to permit ${ }^{2}$ detalfed studies of ${ }^{2}$ their sequential chemistry in the burnt gases in an endeavor to resolve current difficulties. An investigation of possible direct or indirect coupling between the sulfur and nitrogen combustion cycles 18 being undertaken by monitoring all the species for which capabilities have been developed in flames containing sulfur, fuel nitrogen or both together. The program not only provides an Important new diagnostic capability applicable to any combustion media but also beg ins to answer questions concerning the $\mathrm{NO} / \mathrm{NO}_{2}$ balance in flames, considers the importance of the $\mathrm{NH}, \mathrm{NH}_{2}, \mathrm{CN}$ (and $\mathrm{HCF}$ ) radicals, and I nvestigates possible interrelationsh $\mathrm{ps}_{\mathrm{P}}$ between $\mathrm{NO}_{\mathrm{x}}$ and $\mathrm{SO}_{\mathrm{x}}$.

UNIVERS ITY OF MINNESOTA

Minneapol18, Minnesota 55455

274. VARIATIONAL TRANSITION STATE THEORY

$\$ 31,000$

01-2

D. G. Truhlar

Department of Chemistry

The varlational theory of reaction rates (1.e., varlational transition 8 tate theory) 18 belng developed into a practical tool for the calculation of thermal rate constants and 18otope effects for atnm transfer reactions in the gas phase. Preliminary work has shown that the techniques are successful for collinear reactions of atoms with diatomic molecules. These techniques are belng extended to treat fully three-dimensional reactions and to treat reactions of polyatomic molecules. The results are of fundamental interest and may be useful to a large number of applications where such thermal reaction rate constants are required. 
Chemical Physics, continued

NATIONAL BUREAU OF STANDARDS

Washington, D.C. 20234

275. KINETIC DATA BASE FOR $\quad \$ 66,000 \quad 01-2$

W. Ts ang, R. F. Hampson

The objective of this project is to develop and publish an evaluated chemical kinetics data base for the modeling of combustion based processes. To carry out this task, existing data in the literature are being collected, compiled, and evaluated by comparison with analogous systems, through chemical kinetics modeling and by use of available theory. For systems where data are not directly available, estimates are made via correlational schemes and theory. The final results will be published in tabular form and in archival publications. Currently, efforts are being concentrated on methane pyrolysis. Work is beginning on the oxidation processes involving methane, general aliphatic hydrocarbon pyrolysis and oxidation.

GEORGIA INSTITUTE OF TECHNOLOGY

Atlanta, Georgia 30332
276.
A KINETIC STUDY OF RADICAL-AROMATIC
HYDROCARBON REACTIONS
$\$ 46,000$
$01-2$
F. P. Tully and A. R. Ravishankara
Engineering Experiment Seation

Chemical kinetic and mechanistic investigations of free radical-aromatic hydrocarbon reactions of importance to optimization of energy production from alcernative fuel sources are baing pursued. Improvement in the fundamental understanding of the rates and pathways characteristic of these gas-phase reactions is the principal objective of this program. Specifically, using the technique of (laser/spark discharge) flash photolysis-(resonance) laser induced) fluorescence, absolute rate constant measurements for the oxidation-and pyrolysis chain step reactions $\mathrm{O}(\mathrm{OH}, \mathrm{H})+$ aromatic hydrocarbons are being made as functions of temperature and, when appropriate, pressure. Particular reaction pathways in the above processes are being probed either via measurements of reaction product concentration-time profiles or through the application of kinetic isotope effect theory to rate constant measurements on isotopically substituted analogues of the above reactions. Information gained from these studies is expected to facilitate improved utilization of aromatic hydrocarbons both as combustibles and as feedstocks for production of substitutable synthetic fuels. 
Atomic Physics

UNIVERSITY OF PITTS BURGH

Pittsburgh, Pennsylvanta 15260

277. CHARGE EXCHANGE COLLISIONS OF

HIGHLY STRIPPED IONS WITH

$\$ 93,000 \quad 01-3$

ATOMIC HYDROGEN

J. E. Bayfield

Department of Physics and Astronomy

The newly-developed, three-stage, double-tandem 1on beam accelerator/ decelerator facllity at Pittsburgh is belng used to measure charge exchange cross sections for collisions of hydrngẹn atoms and hellum atoms with totally-strlpped, one-electron, and two-electron lons of boron, carbon, nitrogen and oxygen. The collision energy range of 10 to $250 \mathrm{keV}$ per atomic mass unit 18, for the totally-stripped and one-electron lons, in a region untquely accessed by the accel/decel techptqugf Thref 5 stage operation of a double-tandem accel-decel source of $0^{5+}, 0^{6+}, 0^{+}$and $0^{8+}$ Ions has been achleved, for energles as low as $15 \mathrm{keV} / \mathrm{Amu}$. Charge exchange cross sections have been measured for collisions of these lons with hellum atoms.

NEW YORR UNIVERS ITY

New York, New York 10003
278. ENERGY-RELATED ATOMIC AND
$\$ 70,000 \quad 01-3$
MOLECULAR STRUCTURE ANT
SCATTERING STUDIES
B. Bederson
Department of Physics

This 18 a program to study basic properties and interactions of selected a toms and polar molecules using beam techniques. The program includes 1) measurements of the electric dipole polarizabilities of alkall halide molecules, of their dimers and higher order clusters, 2) measurements of absolute total and differential cross sections for the scattering of 10 w energy electrons by alkall halides, using the atomic beam recoll technique, 3) a study of methods for directly measuring hyperpolarizabilities and the extension of cross section measurements to $0, C, N$, and $U$, and to other polar molecules such as $\mathrm{KOH}$ and $\mathrm{H}_{2} \mathrm{O}$. Methods for single particle detection of systems such as $O, C, N$, and $S^{2}$ are under study using laser excitation. 
Atomic Physics, continued

UNIVERSITY OF NEW MEXICO

Albuquerque, New Mextco 87131

279. ATOMIC PHYSICS WITH RELATIVISTIC
BEAMS
H. C. Bryant
Department of Phys Ics and Astronomy

Work, presently_underway, on single photodetachment in the resonance region of the $\mathrm{H}^{-}$continuum, using a laser beam Doppler tuned into the vacuum ultroviolet, is belng continued. In addition, a new series of measurements is belng inaugurated to Investigate double photodetachment in the $\mathrm{H}$ system. Th1s study, spanning continuously the barycentric energy range from 14 to $21.8 \mathrm{eV}$, determines, with $0.005 \mathrm{eV}$ resolution, the energy dependence of the cross section for double photodetachment near threshold. The single photodetachment measurements are also belng extended into this two-electron continuum region.

COLLEGE OF WILLIAM AND MARY

Williamsburg, Virginia 23185

280. MEASUREMENT OF ABSOLUTE TOTAL DETACHMENT

$\$ 50,000 \quad 01-3$ CROSS SECTIONS OF NEGATIVE IONS

R. L. Champion, L. D. Doverspike

Department of Physics

Absolute total cross sections and rate constants associated with negative Ion-molecule collisions are belng measured with an lon beam-gas target apparatus. The collisional detachment of negative lons is beling emphasized and the energy range for these experiments is from the electron affinity of the negative ion upwards. Reactants include such negative lons as $U F_{6}$ and $\mathrm{H}^{-}$in collisions with $a$ variety of atomic and molecular targets. The resulting cross sections should be of interest, for example, to the fields of 18otope separation (UF ${ }^{-}$) and neutral beam heating of magnetic containment fusion devices $\left(\mathrm{H}^{-}\right)$. 
Atomic Physics, continued

TEXAS A\&M UNIVERSITY

College Station, Texas 77843

281. STORED-ION COLLISION MEASUREMENTS
D. A. Church
Department of Physics

The objectives of this project are to develop and to extend measurement techiniques based on the Ion storage method to near-thermal reactinn rate constants fur mulc1-charged lons reacting with atoms and molecules, and to cross sections for electron lonization and excitation of lons, culminating In measurements of particular collision proresses of reactants occurring In magnetic fusion plasmas. Ions are created by electron collision lonization and stored in an lon trap at near-thermal energies. The trap consists of shaped electrodes with applied dc or ac potentials and an extèrnal uniform magnetic field. Changes with time of stored ton number, or other parameters, resulting from collisions with known densities of atoms or molecules, electrons or photons, are used to determine characteristic parameters of specific collision processes. The developmental research results in measurements of rate constants and cross sections of several types of ion collision processes, using a single basic apparatus. Emphasis is placed on lons found in Tokamak-type plasmas.

HARVARD COLLEGE OBSERVATORY

Cambridge, Massachusetts 02138
282. THEORETICAL STUDIES OF HIGHLY
$\$ 72,800$
$01-3$
IONIZED SPECIES
A. Dalgarno, G. Victor
Center for Astrophysics

The relativistic random phase approximation is applied to calculations of photolonization cross sections. Procedures are being developed for the prediction of resonances formed by single electron excitations of the inner shells of the magnestum and atnc looclestronic suquences. An atcempt is being made to extend the relativistic random phase approximation to spin-forbidden transitions in molecules. Model potential methods are belng used to calculate oscillator strengths of the copper and zinc isoelectronic sequences. The behavior of atoms in intense electric and magnetic fields is being studled. Charge transfer processes at thermal energles are being investigated and their effects on ionization structure of plasmas are being explored. The collision processes affecting the populations of 11thium and sodium molecules in a radiation field are being investigated. Fine structure excitation of positive ions by photon impact as a method for measuring the ion temperature of a plasma is being assessed. A quasi-molecular method is being developed and applied to calculate impact excltation cross sections. 
Atomic Physics, continued

UNIVERSITY OF CHICAGO

Ch1cago, Illinols 60637

283. BASIC STUDIES OF ATOMIC DYNAMICS
U. Fano
Department of Phys 1cs

This project attempts to unravel the correlations between the motions of different particles and the energy exchanges between different types of motion in electron collision and photoabsorption processes. A major effort is almed at elucidating the physlco-mathematical basis for unexplained circumstances that have been very helpful again and again in calculations and for the analysis of experiments. It was found that approximations based on quasi-separabllity of varlable and quasi-adiabatic behavior have proved unexpectedly successful. A new array of studles of two-electron excltations is being pursued. The study of collisions between electrons and polar molecules 18 belng brought to conclusion having ascertained the Inference that energy exchanges occur mainly at critical radial distances.

PENNSYLVANLA STATE UNIVERSITY

Untversity Park, Pennsylvania 16802

284. OSCILLATOR STRENGTHS POR HIGHLY

$\$ 56,000 \quad 01-3$

IONIZED ATOMIC SYSTEMS

C. F. F18cher

Department of Couputer Selence

The mult1-configuration Hartree-Fock procedure for Including correlation among outer electrons as well as core polarization effects in the theoretical determinuclion of $f$ values 18 belng modified to include the Breit interactions as an intermedlate coupling correction. In this way the validity of the non-relativistic model may be extended to higher Z-values. Both electric dipole and quadrupole osclllator strengths are being studled for certaln transitions between $S, P, D$, and $F$ states of the hellum sequence. Studles of $f$-value trends for $D-F$ transitions In the $\mathrm{Mg}$ sequence are being extended to the $\mathrm{Al}$ sequence for possible cascade analysis of beam-foll decay data for the $3 \mathrm{~d}{ }^{2} \mathrm{D}$ lifetime. The effect on oscillator strengths of correlation in the cpre of both initial and final states 18 being studied for transitions such as $\mathrm{d}^{10} \mathrm{~d}^{9} l$. In photolonization processes, correlation in the core for the final state 18 often neglected. Approximate relativistic f-values which include the effect of cofe polarization have been determined for the main cascade contribufion to the $P$ iffetime in beam-foll spectroscopy, namely the $484 p P_{P}-484 d d_{D}$ transition. It was found that the f-value for. this transition is large even for high states of lonization. Relativistic effects in the $3 d$ - 4 f transitions in $M g$ were 1 nvestfgated and found to be negligible up to Mo XXI, though corrections to $D_{3}-F_{4}$ were small even for W LXIII. Preliminary studies show that correlation in the core may be important in f-value calculations when the Initial and final states contain a different number of electrons in the core. 
Atomic Physics, continued

SRI INTERNATIONAL

Menlo Park, Californ1a 94063

285. STUDIES OF AUTOIONIZING STATES RELEVANT

$\$ 58,000 \quad 01-3$

TO DIELECTRONIC RECOMBINATION

T. F. Gallagher

Molecular Physics Department

A dominant $108 \mathrm{~s}$ mechanism which 11mits the performance of tokumaks $1 \mathrm{~s}$ dielectronic recombination of omnipresent impurity lons and electrons in the plasma. Unfortunately, the only experimental studies of the process have been conducted in plasmas, where the basic physics of the process is obscured by the plasma with 1 ts high lon and electron densities.e The objective of this work 18 to study the Inverse process of dielectronic recombination, autolonization of isolated atoms, and to provide the basic atomlc data necessary to reach an understanding of dielectronic recombination. There are two basic parts to the program. F1rst, the systematic measurement of autolonizing rates and branching ratios of 180 lated atoms as a function of quantum number and, second, the quantitative determination of the effects of collisions and flelds, such as are found in a plasma, on the autolonization rates. To carry out these experiments a novel multistep laser excitation scheme is used to excite neutral atoms to their autolonizing states. These experiments are designed to provide autolonizing rates and branching ratios, Information on the effects of electric flelds on autolontzation, and the effects of collisions on autolonization, all of which are of fundamental interest and important to the characterization of dielectronic recombination. 
Atomic Physics, continued

UNIVERSITY OF OKLAHOMA

Norman, Oklahoma 73019

286. STUDY OF VERY-LOW-ENERGY INELASTIC

$\$ 65,000 \quad 01-3$

PROCESSES IN ELECTRON-MOLECULE

COLLISIONS: THEORY AND EXPERIMENT

D. E. Golden and M. A. Morrison

Department of Physics \& Astronomy

Construction of the crossed electron beam-molecular beam apparatus to be used to measure absolute electron-molecule vibrational-rotational excitation differential cross sections is being completed. This apparatus will achieve the high energy resolution required at low scattered electron energy using a time of flight technique. A short burst of electrons produced by the pulsed electron monochromator travels to the molecular beam interaction region and from there to a scattered electron detector. The arrival time spectrum of scattered electrons is accumulated using a time-to-amplitude converter and a pulse height analyzer. Ab-initio cross sections for vibrational excitation of $\mathrm{H}_{2}$ are also to be calculated. This includes calculating the static potential, the vibrational wave functions, and ab-initio polarization potentials using the variationperturbation method. In addition existing computer programs are to be modified to handle vibrational close coupling in the laboratory frame. Laboratory frame close coupling calculations from threshold to several eV are also being carried out. 
Atomic Physics, continued

LOUISIANA STATE UNIVERSITY

Baton Rouge, Louisiana 70803

\section{ELECTRON EXCITATION CROSS SECTIONS FOR MULTIPLY CHARGED IONS \\ R. J. W. Henry, J. Callaway \\ Department of Physics \& Astronomy}

$\$ 58,000$

$01-3$

Theoretical calculations of the cross sections for excitation of positive ions are being performed. The energy range considered is from the threshold for excitation to approximately 4 times the ionization energy. The calculations are based on a close coupling expansion with exchange. A non-iterative integral equation method is used to solve the coupled integro-differential equations. The contribution of Rydberg series of resonances below some excitation thresholds is determined for C IV, Fe XXII, and Fe XXIII. Effects of intermediate coupling are being examined for $\mathrm{Fe}$ ions. A study of ionization is being initiated with $H$ I as the first atom to be studied. Determination of ionization and excitation cross sections for highly stripped impurity ions in high temperature plasmas of interest in thermonuclear reactors is the main objective. Collision strengths for electron impact excitation of helium-like $\mathrm{Li}, \mathrm{C}, 0$, and $\mathrm{Si}$ have been calculated and parametrized so that results may be obtained for any helium-like ion in a nonrelativistic five state close coupling approximation. It was found that extrapolating for data beyond $S i$ due to intermediate coupling effects on forbidden transitions is not dependable. Calculated angular distributions" for electron impact excitation of $n=2$ levels of He were found to be in very good qualitative agreement with experiment in the energy range 30-100 eV.

MASSACHUSETTS INSTITUTE OF TECHNOLOGY

Cambridge, Massachusetts 02139

288. PHOTOIONIZATION AND FIELD IONIZATION OF HIGHLY EXCITED ONE- AND TWO-ELECTRON $\$ 60,000 \quad 01-3$ ATOMS

D. Kleppner

Department of Physics

Studies of field ionization of simple atoms are underway revealing two separate ionization mechanisms. A high resolution study of a level-anticrossing has been carried out, and theoretical and experimental results have been obtained on the photoionization of sodium Rydberg states. Work includes the study of field ionization rates below the tunneling region, a study of the Landau-Zener effect, and the continuation of a photoionization study. 
Atomic Physics, continued

OREGON STATE UNIVERSITY

Corval11s, Oregon 97331

289. THERMAL-ENERGY SCATTERING OF ATOMS
IN HIGH RYDBERG STATES
C. A. Kocher
Department of Physics

The objective of this research is to investigate collision dynamics for thermal-energy encounters between long-lived highly exclted Rydberg states and ground-state gaseous targets. Differential cross section measurements are being made to determine interaction potentials for the Rydberg core ion, independent of 1 ts valence electron. Prevlous measurements have demonstrated that high-Rydberg atoms are deflected in collisions with atomic and non-polar molecular targets. The cross sections are virtually independent of the principal quantum number and in numerical agreement with calculations for scattering of the core lon alone. These results suggest a new method for very low-energy lon-atom scattering experiments. Excited states in an atomic beam are detected by fleld lonization, with velocities resolved by a time-of-flight technique using an on-1ine computer. The scattered Rydberg atoms are recorded as a function of deflection angle after the primary beam has passed through a locallzed target reglon. Systems being studied are atomic and molecular gases and vapors. Core-ion scat tering experiments with high-Rydberg states were found not to suffer from the complications of space charge repulsion and stray flelds, which have precluded traditional lon beam scattering at thermal energies.

KANSAS STATE UNIVERSTTY

Manhattan, Kansas 66506

290. ATOMIC PHYSICS OF STRONGLY

$\$ 30,000 \quad 01-3$

CORRELATED ELECTRONS

C. - D. LIn

Department of Physics

A new theoretical approach based upon hyperspherical harmonics is being developed to study atoms and electron-atom collisions in which electronelectron correlation plays a dominant role. These problems occur in the doubly excited states of atoms or in electron Impact excitations and electron Impact Ionlzations where a rigorous description of electronelectron correlation is essentlal. An understanding of these processes is important in the modeling of laboratory thermonuclear plasmas. In its initial phase the present approach treats the two correlated electrons as a point particle in a six-dimensional hyperspherical space. By studying the various hyperspherical harmonics as the "size" of the atoms increases, 1t Is possible to view the inelastic transitions, whether incurred by photon Impact or by electron Impact, as due to the coupling between these normal modes as the system expands. In this project, this approach is being developed to study resonances in electron-alkali atom collisions. In the future it is hoped to generalize this approach as a practical method for calculating electron-atom and electron-ion impact excitations in situations where experimental data are diffleult tu ublalin. 
Atomic Physics, continued

UNIVERSITY OF NEBRASKA

Lincoln, Nebraska 68588

291. CHARGE TRANSFER CROSS SECTION DETERMINATIONS IN HEAVY ION -

$\$ 35,000 \quad 01-3$

COLLISIONS IN THE 0-600 $\mathrm{keV}$ RANGE

J. Macek, G. Gallup

Department of Physics

In this project, cross sections are computed for the electron transfer process $\mathrm{Ba}^{+}+\mathrm{Ba}^{+} \rightarrow \mathrm{Ba}+\mathrm{Ba}^{++}$. Knowledge of electron transfer cross sections is essential to the development of the heavy. ion method of controlled fusion. This method requires that intense ion beams be electromagnetically manipulated over significant times and distances. Any charge-changing collisjons ofcurring in the beam will limit the beam's useful lifetime. The $\mathrm{Ba}^{+}+\mathrm{Ba}^{+}$collision is treated because it probably represents a

"worst possible case" for fusion applicability. The calculation uses the straight line classical trajectory method. The molecular eigenstates used as basis functions are obtained, as functions of internuclear distance, by the multiconfiguration valence bond method. The electron transfer probability is computed for both singlet and triplet collisions, as functions of impact parameter and collision energy. The impact parameter and energy ranges are $3 a$ to $20 \mathrm{a}$ and $25 \mathrm{keV}$ to $500 \mathrm{keV}$, respectively. The cross section for each energy is obtained by integrating the probabilities with respect to impact parameter, and forming a statistically weighted sum of the singlet and triplet results. The computer electron transfer cross section is 0.13 $x 10^{-1} \mathrm{~cm}^{-15}$ for 2011 ision energy $25 \mathrm{keV}$, and increases monotonically to
$2.35 \times 10^{-1} \mathrm{~cm}$ for energy $500 \mathrm{keV}$. Thus it has been shown that charge-changing cross sections in heavy ion collisions can be several times larger than the ions' geometric cross sections. 
Atomic Physics, continued

U.S. NATIONAL BUREAU OF STANDARDS

Boulder, Colorado 80309

292. THEORETICAL STUDIES OF ATOMIC AND -

$\$ 80,000 \quad 01-3$

MOLECULAR COLLISION PROCESSES

D. W. Norcross

Quantum Physics Division

This program is directed toward increasing the ability to calculate accurately and efficlently cross sections for collision processes involving electrons and atoms, lons and molecules in the gas phase. The requil rements for accurate data on such processes span several areas of developing energy research and technology, e.g. the controlled thermonuclear research program. and magnetohydrodynamic electrical power generation using fossil fuels. Recent work has focused on electron impact excitation of hellum and heliumlike lons and electron collisions with polar molecules. The work involves direct numerical solution of the quantum mechanical equations describing the collision process. These equations cannot be solved exactly, and some approximations must be made. The goal is not only to provide some data of direct technical relevance, but also to further the development of critically evaluated computational algorithms for the calculation of such data. A variety of approximations are being studled for a few selected important test cases. Throughout the course of this work it $18 \mathrm{planned}$ to publish both results of the calculations, when the data are of theoretical or technical interest, and computational programs that can be used by others. 
Atomic Physics, continued

KANSAS STATE UNIVERSITY

Manhattan, Kansas 66506

293. ATOMIC PHYSICS WITH HIGHLY •

$\$ 375,000 \quad 01-3$

IONIZED IONS

P. Richard and J. R. Macdonald

Department of Physics

This research program.focusses on studies of highly ionized atoms produced in high velocity atomic collisions. Although such collisions are complicated by the presence and excitation of many atomic electrons, the work is done under the premise that processes which excite tightly-bound inner-shell electrons of the colliding atoms should provide tractable tests of basic collision physics. Through study of the theoretical framework and selected experimental measurements, the goal is to achieve an understanding of the interrelated atomic collision processes involving inner-shell electrons. A few discrete processes are being examined such as 1 . 1s to $1 \mathrm{~s}$ electron transfer for collision systems of varying charge asymmetry $\left(z_{1} / z_{2}\right), 2$. the capture of loosely bound electrons to Rydberg states of highly ionized species, 3. the excitation of well-defined states of few-electron ions, 4. the ionization of target inner-shell electrons by highly charged projectiles, and 5. the structure of the highly ionized states that are observed through deexcitation processes following ion-atom collisions. In studies of an atomic collision system, attempts are being made to define the effects of a particular excitation process by using a variety of experimental techniques to focus on different aspects of the same problem. The combined results can be compared with theoretical calculations. which use well defined initial and final states for:the particular excitation mechanism under study. This program includes operation of the Kansas State $\overline{\mathrm{E}} \mathrm{N}-\bar{T}$ andem accelerator. 
Atomic Physics, continued

UNIVERSITY OF NEBRASKA

Lincoln, Nebraska 68588

294. PHOTOIONIZATION OF ATOMS

J. A. R. Sams on and A. F. Starace

$\$ 70,000 \quad 01-3$

Department of Physics

The main aim of this experimental and theoretical research program is to unravel the effects of electron correlation and of spin-orbit interaction on atomic photoionization processes. Total and partial photoionization cross sections, photoelectron angular distributions and branching ratios, multiple excitation and ionization cross sections, and photoionization of atoms in high magnetic fields are being studied. The experimental work comprises: (1) Measurement of absolute rare gas photoionization cross sections to an accuracy of $\pm 1 \%$ using a double ion chamber. (2) Measurement of relative photoionization cross sections of metal vapors, atomic oxygen, and atomic chlorine using an atomic beam source and a time-of-flight mass spectrometer (TFMS). (3) Measurement of double and triple ionization of the heavier rare gases using synchrotron light and the TFMS. (4) Measurement of the photoelectron angular distribution of the 68 electron in Cs using a 1000 watt $\mathrm{Xe}-\mathrm{Hg}$ light source, a Czerny-Turner type monochrometer, and a calcite polarizer. (5) Measurement of the single-photon double-excitation cross section of He above the $n=2$ threshold by observing the fluorescence of the excited ionic state. The theoretical work comprises: (1) Use of a graphical procedure for calculating atomic transition matrices to obtain an open-shell random phase approximation; use is being made of the latter theory to calculate the photoionization cross section of atomic chlorine. (2) Calculation of photoabsorption and photoionization crogs sections of hydrogen atoms in uniform magnetic fields of order $10^{4}-10^{5}$ Gauss using the oblate spheroidal coordinate approach. (3) More detailed calculation of the photoelectron angular distribution of the 68 electron in $C_{s}$ including both the spin-orbit and interchannel correlations in the final state. (4) Use of the eigenchannel (R-Matrix) method to calculate the cross section of $\mathrm{He}$ above the $n=2$ threshold. 
Atonic Physics, continued

UNIVERSITY OF NORTH CAROLINA/CHAPEL HILL

Chapel Hill, North Carolina 27514

295. EXPERIMENTAL STUDIES OF ATOMIC INNER

$\$ 72,000$

$01-3$

SHELL IONIZATION PHENOMENA

S. M. Shafroth

Department of Physics

and Astronomy.

Studies of target thickness effects on projectile and target $K \times$-ray production cross sections are being emphasized. The two-component model cross section parameters are being extracted from analysis of these data. Extension to a three-component model description where double $\mathrm{K}$ vacancies are significant is being at tempted. REC (radiative electron capture) is being studied for several projectile target combinations. Target thickness dependence, the average number of target electrons which can be captured, angular distributions and multiple ionization effects as well as target electron momentum distributions are being emphasized. High resolution - $x$-ray experiments concentrate on satellites, hypersatellites, and H-like systems. The angular distribution of $\mathrm{Pb} \mathrm{L} \mathrm{x}$-rays excited by $3 \mathrm{MeV}$ protons is being measured to investigate $L$ magnetic substate d dependence of

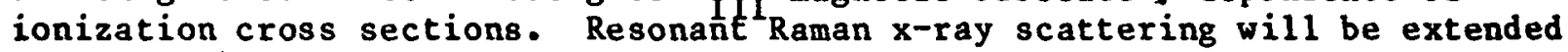
to the $\mathrm{L}$ shell of heavy elements such as $\mathrm{Pb}$. The search for resonant Raman shifted Auger electrons continues.

UNIVERSITY OF TENNESSEE

Knoxville, Tennessee 37916

296. DIF FERENTIAL CHARGE TRANSFER TO THE

$\$ 35,000$

01-3

CONT INUUM BY IONS IN ATOMIC HYDROGEN

R. S. Thoe, I. A. Sellin

Department of Physics

Studies are underway of the capture to continuum for highly stripped ions moving through an atomic hydrogen gas. In particular, measurements are heing wads of the cnergy differential cross section for this process. Such measurements are necessary to evaluate the present theoretical calculations of the size and shape of the differential cross section. The contribution of capture to the continuum to the total capture cross section is being determined to assess the role of this process in the design of neutral beam injectors. 
Atomic Physics, continued

RICE UNIVERSITY

Houston, Texas 77001

297. ENERGETICS OF ATOMIC AND MOLECULAR INTERACTIONS

$\$ 208,000 \quad 01-3$

G. K. Walters and N. F. Lane

Department of Physics

This program emphasizes studies of structure and interactions of excited atoms, molecules, electrons and ions in both gases and liquids, as well as properties of and atomic interactions with solid surfaces. Specific areas of current activity include studies of reactions and radiative 1 ifetimes in atomic and molecular systems of high-efficiency laser promise, new approaches (both experimental and theoretical) to the study of solid surfaces, and ultimately heterogeneous catalysis, and understanding of spectra and collisional effects of general interest in plasma physics and controlled thermonuclear reaction technology. The program involves 1) the use of electron and synchrotron excitation and time-resolved fluorescence spectroscopy in the study of transient excited species in dense gases of laser importance; 2) new approaches to the study of atomically clean crystalline surfaces, and their interaction with ambient gases; 3) development of tunable ultraviolet lasers; 4) theoretical studies of collision processes involving electrons, ions, atoms and molecules in gases, plasmas and near surfaces.

TEXAS A\&M UNIVERSITY

College Station, Texas 77843

298. X-RAY EMISSION IN HEAVY-ION . $\quad \$ 45,000 \quad 01-3$

R. L. Wat son

Department of Chemistry

Experimental investigations are underway concerning: a) chemical effects on vacancy rearrangement processes in multiple inner-shell ionization by heavy-ion collisions; b) the equilibration of inner-shell vacancy states in fast heavy ions penetrating solid targets; and $c$ ) the polarization of projectile $x$-rays by surface interactions. The studies of chemical effects are aimed at determining the dependence of the L-vacancy transfer probabilities in fluorine compounds on covalency and bond type, and at elucidating the influence of chemical environment on the $K \alpha$ satellite multiplet structure in Mg compounds. Studies of the equilibration of inner-shall vacancy 8 tates concentrate on high resolution measurements of $\mathrm{He}$ - and $\mathrm{H}-1 \mathrm{ike}$ transitions of sulfur ions in an effort to understand the dependence of their relative intensities and widths on target thickness, atomic number, their relative intensities and widths on target thickness, atomic number, and crystal structure. Work on $x-r a y$ polarization involves high resolution angular distribution measurements of metastable $x$-ray transitions produced in tilted-foil experiments. 
Atomic Physics, continued

NATIONAL BUREAU OF STANDARDS

Washingt on, D.C. 20234

299. DETERMINATION OF SELECTED ATOMIC

$\$ 115,000 ; 01-3$

DATA PERTINENT TO THE MAGNETIC

FUSTON ENERGY PROGRAM

W. L. Wiese

Atomic and Plasma

Radiation Division

The objectives of this research project are to provide accurate and reliable atomic data pertinent to the fusion energy program and to evaluate methods for producing these data. At present, this involves the calculation of line strengths and wavelengths of selected $\Delta n=0$ resonance transitions for ionized atoms by superposition-of-configurations techniques including relativistic corrections, theoretical simulations of beam-foil lifetime. experiments in order to better evaluate the reliability of this method, and the application of transition probability data to further develop the branching ratio technique as a radiometric calibration method in the extreme UV. Compilations of critically evaluated f-value data, utilizing systematic trends along isoelectronic sequences, are also carried out for all ions of the iron-group metals, and started on elements in the first row of the periodic table. 
Chemical Energy

YALE UNIVERSITY

New Háven, Connecticut 06520

300. STUDIES OF THE HYDROGENATION OF

SMALL UNSATURATED MOLECULES USING

$\$ 44,000 \quad 02-1$

ORGANOMETALLIC CLUSTER COMPOUNDS

AS CATALYSTS

R. D. Adams

Department of Chemistry

These studies focus on the development of transition metal. cluster compounds as catalysts for the hydrogenation of small unsaturated molecules. This involves: 1)a) determining the conditions under which metal. clusters can activate elemental hydrogen $\left(\mathrm{H}_{2}\right) ;$ b) establishing the nature of the cluster-hydrogen association including bonding and stereochemistry. 2) studying the nature of the interaction of these cluster-hydride complexes with small unsaturated molecules (also known as substrates) such as carbon monoxide, carbon dioxide, carbon disulfide, alkyl- and aryl-isocyanates, and -isothiocyanates, and alkyl- and ary1-isocyanides. The goal of this program is to identify cluster complexes which can readily activate both the hydrogen and the substrates and also smoothly transfer the hydrogen atoms from the metal atoms to the substrates. The conditions and stereochemistry of these hydrogen transfer processes are a principal. concern. Finally, the hydrogenated product should be released by the cluster so additional hydrogenation cycles can occur.

WEBER STATE COLLEGE

Ogden, Utah 84408

301. THE ROLE OF THE HYDROGEN-DONOR

$\$ 30,000 \quad 02-1$ SOLVENT IN COAZ HYDROLIQUEFACTION

R. R. Beishline

Department of Chemistry

The objective of this research is to study the disproportionation of 1,2-dihydronaphthalene (1,2-DHN), 1,2-dihydrophenanth rene $(1,2-D H P)$ and 3,4-dihydrophenanthrene (3,4-DHP) including: a) identification of the principal products, and determination of the identity and extent of formation of side reaction products; b) investigation of the gas and liquid phase kinetics of decomposition of 1,2-DHN, and the liquid phase kinetics of decomposition of 1,2-DHP and 3,4-DHP. The reaction mixtures are separated by preparative gas chromatography (GC) or 1iquid chromatography (LC), and the isolated products identified spectroscopically (MS, NMR, IR). The kinetic experiments include sealed tube reactions conducted through the temperature range $300-420^{\circ} \mathrm{C}$. Quantitative analysis is done with a gas chromatograph coupled to an electronic integrator. These studies are expected to yield rate constants for the reactions, and to help elucidate the mechanisms, i.e., are these free radical reactions, or concerted perieyelic reactiono, or both. 
Chemical Energy, continued

TEXAS A\&M UNIVERSITY

College Station, Texas 77843

302. THE APPLICATION OF FUNCTIONALIZED

POLYMERS IN. CATALYSIS

$\$ 34,000 \quad 02-1$

D. E. Bergbreiter

Department of Chemistry

This program using polymers in catalysis has several objectives; the synthesis and utilization of functionalized polymers to detect soluble intermediates in heterogeneous catalytic reactions; a study of reactions of alkenes catalyzed by polystyrene bound bis(cyclopentadienyl)titanium dichloride reduced by Grignard reagents; and the preparation and use of polymers which activate conventional homogeneous catalysts by absorption of non-volatile ligands from catalytic reactions. Soluble intermediates to be tested using functionalized polymers include monoenes, dienes, and free radicals in hydrogenation-dehydrogenation reactions catalyzed by Group VIII metals. Polymers containing reactive dienes, triazoline-3, 5-dione, and nitroxyl spin labels are being used in attempts to detect these types of soluble intermediates. Polymers to be used to activate homogeneous catalysts contain soft acids to absorb excess phosphine ligands and are designed such that absorption of active transition metal catalysts from solution does not occur.

STANFORD UNIVERSITY

Stanford, California 94305

303. CATALYTIC STEAM GASIFICATION OF CARBON

$\$ 50,000 \quad 02-1$

M. Boudart

Department of Chemical Engineering

As a result of work done elsewhere and in this labora.ury, it is believed that a central problem in coal gasification is the following. Is the catalytic effect of metals on the steam gasification of carbon due to spillover or to reverse spillover? And if either mode of spillover is important, how does it take place? The approach being taken is a kinetic one, supplemented by physical methods of system characterization. The kinetic work is based on an extension of the work described above in the reactor al ready set up to measure both rates and selectivity. Complementary kinetic information is being obtained by means of a vacuum electrobalance for measurements of. the reactivity of solids. Direct kinetic observations are also being made at NASA-Ames under the controlled atmosphere transmission electron microscope (CATEM). 
Chemical Energy, continued

WAYNE STATE UNIVERS ITY

Detroit, Michigan $\mathbf{4 8 2 0 2}$

304. THE SYNTHESIS, CHARACTERIZATION, AND CATALYTIC ACTIVITY OF SUPPORTED

$\$ 50,000 \quad 02-1$ CARBONYL COMPLEXES
A. Brenner
Department of Chemistry

This program deals with the systematic synthesis, characterization, and determination of catalytic activity of novel. heterogeneous catalysts composed of mononuclear, polynuclear, and mixed-metal. carbonyl complexes directly bonded to high surface area, refractory supports. These catalysts lie between the much more studied domains of traditional homogeneous and heterogeneous catalysts and can have chemical and catalytic properties quite distinct from them. Catalysts are being synthesized in which the metal is in unusual oxidation states, has high dispersion, and the catalyst precursor is present as discrete clusters (including mixed-metal species). The catalysts are characterized by the highly efficient and new technique of temperature programmed decomposition (TPDE). Information obtained from TPDE is to be used to predict patterns of catalytic activity and to elucidate the nature of metal-support interactions. Catalytic activities are being studied by another new technique, the "activity spect rum", as well as by standard methods using a state of the art experimental system. This integrated approach to catalysis provides a novel, efficient, and powerful. technique for developing new catalysts as well as adding to our fundamental. knowledge of calialysis. 
Chemical Energy, continued

NORTHWESTERN UNIVERSITY

Evanston, Illinois 60201

305. THE PROPERTIES OF SUPPORTED METAL

$\$ 85,000$

$02-1$

CATALYSTS

J. B. Butt, R. L. Burwe1.1, Jr.,

J. B. Cohen

Departments of Chemical Engineering,

Chemistry, \& Materials Science and Engineering

This program is studying the detailed chatacterizalion of platinum, palladium, and rhodium catalyst particles and their al.joys which are supported on alumina and silica and the subsequent evaluation of their catalytic properties by study of isotope exchange hydrogenolys is and hydrogenation reactions. A series of ten $\mathrm{Pt} / \mathrm{SiO}$, catalysts are being characterized by hydrogen chemisorption and line ${ }^{2}$ profile analysis in $X-r a y$ diffraction. The percentage exposed of Pt varies from 6 to $81 \%$. The hydrogenolyses of cyclopropane and methylcyclopropane, the hydrogenation of propylene, and isotopic exchange between cyclopentane and deuterium are being studied on these catalysts. Extension to $\mathrm{Pt} / \mathrm{A} 1_{2} \mathrm{O}_{3}$ is nearly complete with the exception of $\mathrm{X}-\mathrm{ray}$ characterization. The $\mathrm{Pt} / \mathrm{Al} \mathrm{O}_{3}$ series varied in percentage exposed from about $4 \%$ to $100 \%$. Studies of hydrogen chemisorption, cyclopentane-deuterium exchange and methylcyclop ropane hydrogenolysis on these catalysts have been carried out, similar to the work on $\mathrm{Pt} / \mathrm{SiO}_{2}$.

UNIVERSITY OF WISCONSIN

Madison, Wisconsin 53706

306. MECHANISTIC STUDIES RELATED TO

$\$ 58,800$

02-1.

THE METAL CATALYZED HYDROGENATION

OF CARBON MONOXTIEE TO HYDROCARBONE

C. P. Casey

Department of Chemistry

The stoichiometric reactions of metal complexes which parallel probable steps in the reduction of carbon monoxide to hydrocarbons are being investigated to determine structural factors which influence the reaction. This information is useful in the eventual design of homogeneous catalysts for the reduction of $C O$. The study of the synthesis and stability of metal. formyl compounds is being continued to determine the kinetic and the thermodynamic stability of these compounds which have been proposed as important intermediates in the metal. catalyzed hydrogenation of $\mathrm{C} 0$. The study of hydroxymethyl metal compounds, which have been proposed to be intermediates in the heterogeneously catalyzed reduction of carbon monoxide, is being initiated. The reactions of hydroxymethyl metal. compounds with hydrogen, with carbon monoxide, with acids, and with bases are being studied. 
Chemical Energy, continued

UNIVERSITY OF CHICAGO

Chicago, Illinols 60637

307. SYNTHESIS, CHEMISTRY AND CATALYTIC

ACTIVITY OF COMPLEXES OF LANTHANIDE

$\$ 52,000$

AND ACTINIDE METALS IN UNUSUAL

OXIDATION STATES AND COORDINATION

ENVIRONMENTS

W. J. Evans

Department of Chemistry

The objective of this investigation is the synthesis and chemical and physical characterization of several new classes of lanthanide and actinide complexes which should be instrumental in developing a more comprehensive understanding of the $f$ orbital metals and which should participate in unusual catalytic transformations specific to these metals. Using metal vaporization techniques, $\operatorname{Er}_{2}\left(\mathrm{C}_{6} \mathrm{H}_{10}\right)_{3}$ has been synthesized from $\mathrm{Er}$ and 3-hexyne. This complex functions as a homogeneous catalyst for the hydrogenation of alkynes and alkenes and further investigation is planned of its catalytic activity with respect to hydrogen and other multiply-bonded systems. Investigation of the basic chemistry of this system is underway in search of more novel types of catalytic activity. Studies of the chemistry of the recently synthesized $\mathrm{Ln}\left(\mathrm{t}-\mathrm{C}_{4} \mathrm{H}_{9}\right)$ - complexes are also underway since they may provide a new synthesis of Iow valent lanthanide complexes and since they too exhibit reactivity with hydrogen.

UNIVERSITY OF CALIFORNIA/SANTA BARBARA

Santa Barbara, California 93106

308. DESIGN AND CHARACTERIZATION OF NEW $\$ 99,500 \quad 02-1$ CATALYSTS FOR THE WATER GAS SHIFT REACTION

P. C. Ford

Department of Chemistry

Homogeneous catalysts for the water gas shift reaction are being investigated. The goals in these studies have been the development of new, more active catalysts and the characterization of the fundamental reaction mechanisms governing the behavior of such catalysts. Quantitative reaction mechanism studies have focused largely on the ruthenium carbonyl and mixed metal ruthenium/iron carbonyl clusters first demonstrated to be active catalysts in this laboratory. Longer term goals include the testing of these systems as supported liquid phase catalysts in fixed bed reactors. In this regard; the reaction kinetics of one catalyst (ruthenium carbonyl in acidic solution) in a flow reactor configuration has been examined. Characterizing the reaction dynamics and the key intermediates of such catalysts provides the fundamental information necessary for the logical design of new and more active catalysts. 
Chemical Energy, continued

CORNELL UNIVERS ITY

Ithaca, New York 14853

309. ESR STUDIES OF SURFACE ADSORPTION

AND CATALYSIS UNDER ULTRA-HIGH

VACUUM CONDITIONS

$\$ 90,000$
$(18$ months $)$

$02-1$

J. H. Freed

Department of Chemistry

A new approach for the study of surface adsorption and catalyels on clean metallic and oxide surfaces by.ESR spectroscopy is being planned and exploited. While ESR has previously been extensively used in studies on Insulator (in particular, oxide) surfaccs, such studles usually sutter from the failings of either (1) not having a well-characterized surface and/or (2) not having $u 1$ tra-high vacuum (UHV) conditluus in order to guarantee that it is clean. There have recently been many advances in the field of surface science due to the development of a wide varlety of physical techniques for the study of clean, well-characterized surfaces prepared under UHV conditions. ESR is being developed so that it can rank with the other techniques (e.g. LEED, Auger, Photoel ectron spectroscopy) now employed by surface scientists. In the experimental design, the microwave cavity is itself part of the UHV system so that clean metallic surfaces may be prepared by vacuum evaporation onto the interior of the cavity walls. Various clean gases may then be directly adsorbed onto the surface and in situ ESR spectra may be obtained to study paramagnetic adsorbates and surface reaction kinetics. Then, by studying these clean surfaces with the established techniques, it becomes possible to directly interrelate the findings of the ESR experiments with those from these other methods.

PENNSYLVANIA STATE UNIVERSITY University Park, Pennsylvania 16802

310. MECHANIS TIC STUDIES OF THE METAL $\$ 35,000 \quad 02-1$ CATALYZED REDUCTION OF CARBON MONOXIDE BY. HYDROGEN. TRANSITION METAL CLUSTER COMPLEXES AS MODELS G. L. Geoffroy Department of Chemistry

Transition metal cluster compounds are being used as models to probe the mechanism by which metal surfaces catalyze the reduction of carbon monoxide by hydrogen to methanol and to hydrocarbons. Reasonable mechanistic schemes for surface-catalyzed reactions are being investigated and the feasibility or 1ike11hood of the various intermediates in Individual reaction steps are being tested by examining the reactivity of appropriately selected or designed metal clusters. In addition to yielding a better understanding of the mechanism of carbon monoxide reduction, efforts to prepare potential intermediates should yield new examples of acyl, alkyl and carbene clusters. 
Chemical Energy, continued

UNIVERSITY OF CALIFORNIA

Los Angeles, California 90024

311. STUDY OF CATALYST-BOUND

INTERMEDIATES IN THE CONVERSION

$\$ 78,000$

(18 months)

OF COAL TO ORGANIC MOLECULES

J. A. Gladysz

Department of Chemistry

This research program has as its goal the homogeneous preparation and chemical characterization of ligand types belfeved to be intermediate in the conversion of $\mathrm{CO}-\mathrm{H}_{2}$ gas mixtures (synthesis gas) to methane, methanol, and higher alkanes and ${ }^{2}$ lcohols. Targets include metal-formyl complexes (1), hydrido-hydroxycarbene complexes (2), $\alpha$-hydroxyalkyl complexes ( 3 ), and methylidene (4) complexes. Metal-formyl complexes are being synthesized by trialkylborohydride attack upon a variety of metal carbonyl compounds. It is expected that ligand types 2 and 3 can be prepared by deblocking t-butyl ether precursors. High-pressure carbonylation, protonation, and decarbonylation, are possible routes to ligand types 1,2 , and 3 , respectively. Fundamental chemical reactions (thermal, $\mathrm{H}^{+}, \mathrm{H}^{-}$, organic substrates) of 1-4 are being investigated. Reaction of each 1igand type with $C O$ is being studied to determine the feasibility of chain extension at each reduction state. Ligand types $1-4$ may show enhanced reactivity toward $\mathrm{H}_{2}$ relative to previously prepared alkyl homologs, and methane or methanol ${ }^{2}$ production may be observed under extremely mild conditions. Ultimately, this study may aid the development of milder, homogeneous, and more selective FischerTropsch type catalysts. 
Chemical Energy, continued

UNIVERSITY OF UTAH

Salt Lake City, Utah 84112

-

312. CARBON-13 NUCLEAR MAGNETIC

RESONANCE AS A TOOL FOR THE

ANALYS IS OF HYDROCARBON MIXTURES

$\$ 107,000$
$(18$ months $)$

D. M. Grant \& R J. Pugmire

Department of Chemistry

The overall objective of this research is the application of carbon-13 NMR techniques to the study of hydrocarbon chemical shift parameters, molecular cunfurmation, and spin lattice processes. To this end studies are being carried out to identify additivity relationships existing in a wide variety of hydrocarbons. Relaxation processes for a wide range of aromatic and hydroaromatic species, in order to elucidate basic relaxation mechan'isms, are also being investigated. The research program is divided into two general parts. The first is aimed at broadening the scope of one's ability to predict chemical shifts in hydrocarbons. The additivity relationships of simple hydrocarbons are being extended to more complex species including important hydroaromatic compounds. The existing data base of chemical shift substitutent parameters is being expanded in order to attempt to derive refined additivity effects that will allow predictions of the chemical shifts of this important class of compounds. Using model compounds synthesized in this laboratory and data from the literature, an archival file of compounds and compound types believed to be present in fossil derived liquids is being established. The intent is to be able to predict chemical shifts of compounds for which spectra have not been recurded. In the long term, the potential for pattern recognition techniques in the identification of unknown chemical species will be assessed. The second major part of the effort is associated with relaxation parameters and their associated mechanisms. This factor is critical in the use of carbon-13 NMR in the arsenal of analytical tools employed to study hydrocarbons or hydrocarbon mixtures. The use of 25 and $75 \mathrm{MHz}$ field strengths in the study of model compounds will permit the debineation of dipolar and chemical shift anisotropy contributions to relaxation processes. 
Chemical Energy, continued

CALIFORNIA INSTITUTE OF TECHNOLOGY

Pasadena, California 91125

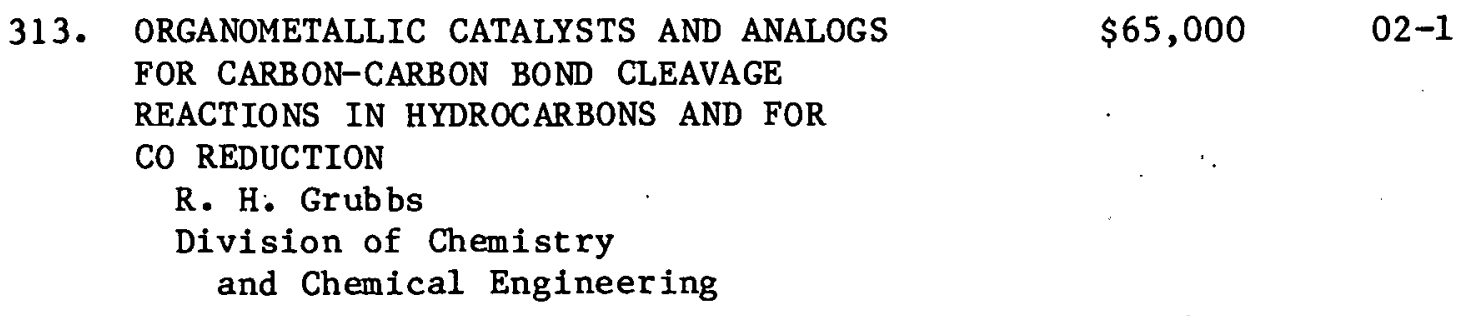

The objectives of this research are to develop homogeneous catalysts and organometallic analogs which define the basic steps in these processes. Two major processes which require the use of catalysts are hydrocarbon cracking or isomerization, and carbon monoxide reduction. New homogeneous and bifunctional catalysts should result from these studies. In addition to their practical value these catalysts may provide fundamental knowledge about reactions occurring on "classical" heterogeneous catalysts. Particular objectives are to (a) optimize for practical use and define the structure of a new soluble, low temperature, hydrocarbon cracking system developed in this laboratory; (b) examine the energetics of model reactions for hydrocarbon cracking processes, and (c) develop co reduction catalysts of a new bifunctional type.

RUTGERS UNIVERSITY

Newark, New Jersey, 07102

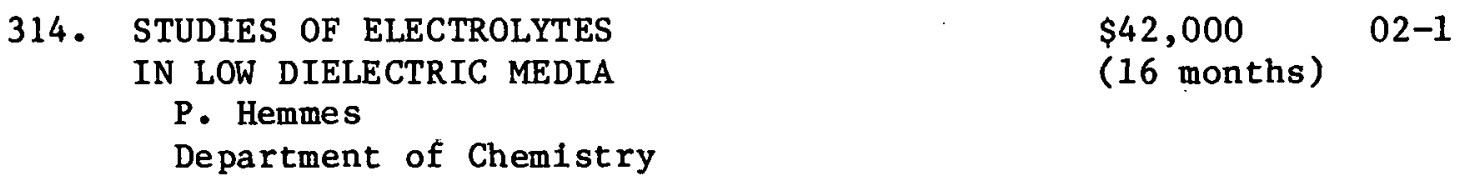

Studies of the formation of ion pair dimers in solvents of low dielectric constant are underway. A high field modulation instrument is being constructed which will permit determination of the quadrupole formation constants of various salts. Extension of these measurements is planned to determine $\Delta \mathrm{H}^{\mathrm{O}}$ and $\Delta \mathrm{S}^{\mathrm{O}}$ for quadrupole formation. With the recent suggestion that certain types of quadrupole formation may enhance conductance, ways are being sought to produce or destroy quadrupoles. Thereby It is hoped to increase conductance of electrolytes used in, for example, lithium anode batteries. It has been found recently that the conductance of certain solutions in low dielectric media can be enhanced by the addition of certain carbohydrate derivatives which selectively find anions. This is very significant since the cation electrochemistry is not influenced adversely, as may happen with cation complexing agents. It is believed that the large complexes cannot form quadrupoles. The spectroscopic properties of these systems are being examined for evidence of this. 
Chemical Energy, continued

UNIVERSITY OF PITTSBURGH

Pittsburgh, Pennsylvania 15260

315. STUDIES OF METAL-SUPPORT INTER-

ACTIONS IN HYDRO-DESULFURIZATION

AND HYDROGENATION CATALYSTS

D. M. Hercules

Department of Chemistry

The object of this research is to elucidate the binding of metals to supports, with emphasis on hydrodesul furization and hydrogenation catalyst8. Primary focus is on binding of $\mathrm{Co}, \mathrm{Ni}$, Mo, and $\mathrm{W}$. to alumina and silica. Spectroscopic techniques used are X-ray Photoelectron Spectroscopy (ESCA), Secondary Ion Mass Spectrometry (SIMS), and Ion Scattering Spectrometry (ISS). The binding of Mo and $W$ to alumina and silica is being studied as a function of metal concentration. Variables are: catalyst composition, method of preparation, and calcination. ISS and ESCA are being compared to determine the nature of binding sites. SIMS is being used to study the nature of the Mo surface species. The binding of $\mathrm{Ni}$ and $\mathrm{Co}$ to supports is being studied with and without Mo or W. Variables include composition of catalyst, method of preparation, calcining, and reduction with hydrogen. Particular emphasis is placed on the distribution of metal species on the catalyst surface. ESCA and ISS studies are being used and correlated with metal dispersion measured by chemisorption. Reduction of catalysts in hydrogen is being studied and distribution of oxidation states is being measured. Changes in surface composition on reduction are being studied.

SRI INTERNATIONAL

Meñlo Park, California 94025

316. HIGH TEMPERATURE CHEMISTRY OF
HYDROGEN PRODUCTION CYCLES
D. L. Hildenbrand
Physical Sciences Department

The objective of this program is to obtain fundamental thermodynamic and $k i n e t i c$ data for a variety of decomposition/vaporization processes pertinent to energy rechnologies such as thermochemical hydrogen generation, stack gas cleanup, and MHD. These decomposition processes are being studied by the torsion-effusion method and by high temperature mass spect rometry, so that both absolute pressure and vapor composition are determined; since the effusion method is dynamic in nature, information about kinetic barriers is obtained from the variation of pressure with effusion orifice area. Thus far, the effort has focused on studies of metal sulfate decomposition processes, many of which exhibit significant kinetic barriers, particularly with regard to attainment of $\mathrm{SO}_{3}-\mathrm{SO}_{2}$ gas phase equilibrium. Effective catalysts have been found in some instances, and catalyzed decomposition processes are also being studied. Results yield the type of accurate thermochemical and kinetic data required for optimum process design as wel.]. as for elucidation of basic mechanistic features. 
Chemical Energy, continued

UNIVERSITY OF DELAWARE

Newark, Delaware 19711

317. AUGER AND REACTION STUDIES OF POISONING

$\$ 99,400$

$02-1$

BY SULFUR AND REGENERATION OF METAL

SYNTHESIS GAS CATALYSTS

J. R. Katzer

Department of Chemical Engineering

The objective of this work is to determine the rate and mechanism of sulfur poisoning and of regeneration of metal catalysts for synthesis gas $\left(\mathrm{CO}+\mathrm{H}_{2}\right)$ conversion to hydrocarbons. The high sensitivity (low tolerance) of metaf catalysts to sulfur in the feed gas necessitates the development of catalysts that are either sulfur tolerant or are easily regenerated, preferably in situ. Advances along these directions would represent major developments. Such studies require catalyst characterization employing multiple complementary techniques. Auger electron spectroscopy and in situ reaction studies of sulfur deactivation and regeneration are being used to. define the mechanism of sulfur poisoning and regeneration, and the results are being used to develop sulfur tolerant catalysts and regeneration procedures. 
Chemical Energy, continued

UNIVERSITY OF GEORGIA

Athens, Georgia 30602

318.

TRANSITION METAL CHEMISTRY

UNDER HIGH CARBON MONOXIDE

PRESSURE

R. B. King, A. D. King

Department of Chemistry
$\$ 70,000$

$02-1$

This work involves investigating the catalytic properties of various rransition metal. carbonyl cumpuuds in chemical reactions that are impnrtant steps in the producrion of clean fuels from coal. Three types of homogeneous chemical reactions are being studied: (1) hydroformylation of ethylene, and related compounds; (2) the hydrogenation of carbon monoxide to form alcohols, and ( 3 ) the production of hydrogen and carbon dioxide from liquid water and carbon monoxide. High pressure infrared spectroscopy is being used to monitor the metal carbonyl species present during hydroformylation reactions involving the most simple olefin, ethylene. Here I.R. spectra of the catalyst solutions have shown new bands which appear during the course of the reaction. These have been assigned to an hitherto unknown unstable alkyl rhodium intermediate which plays an essential role in the series of discrete steps in the cycle of reactions constituting the hydroformylation reaction. High pressure $I . R$. spectroscopy is also being used to elucidate various other aspects of potential hydroformylation catalysts. This technique is being used to study the carbonylation of metal-metal triple bonds under elevated carbon monoxide pressures. Gas chromatography coupled with high pressure sampling terhniques hao becn used lu ublitin kineric data for the water gas shitt reaction operating at $10 \mathrm{w}$ temperature $\left(120 \mathrm{C}-200^{\circ} \mathrm{C}\right)$ through the use of homogeneous catalysts. Various promising catalyst systems have been identified in this work. This technique has also been used to examine the kinetics of hydrogenation reactions that convert carbon monoxide to methanol and higher alcohol.8. 
Chemical Energy, continued

NORTHWESTERN UNIVERS ITY

Evanston, Illinois 60201

319. SOLID STATE, SURFACE AND CATALYTIC STUDIES OF OXIDES

H. H. Kung, P. C. Stair

$\$ 89,300$

(18 months)

Chemistry Department

The selective oxidative dehydrogenation of butene to butadiene on catalysts containing iron oxide is being studied in order to understand the role of crystal structure and surface composition in the activity and selectivity of the oxide. The oxides studied include mixed metal oxides of iron of different cyrstal structures, and those in which iron is substituted by other metal ions, such as chromium. Experiments on these oxides include:

(1) the determination of surface composition by Auger electron spectroscopy, (2) ultraviolet photoemission spectroscopic study of butene adsorption, (3) adsorption and thermal desorption of ammonia, carbon dioxide, butene and butadiene, and (4) isotope labelling and measurement of activity and selectivity in a pulse reactor. Correlations among the results from these measurements are being made to understand the interdependence of the interaction of the surface with reaction molecules and the surface composition and structure. 
Chemical Energy, continued

TEXAS A\&M UNIVERSITY

College Station, Texas 77843

320. A STUDY OF SURFACE COMPLEXES AND

$\$ 104,200 \quad 02-1$

INTERMEDIATES RESPONS IBLE FOR

METHANATION OF EITHER CO OR $\mathrm{CO}_{2}$

(2 years)

AND MECHANISMS OF SUBSEQUENT

REACTIONS

J. H. Lunsford

Department of Chemistry

Th1s research program is devoted to two aspests of eynthcois involving carbon monoxide and efther hydrogen or water. One objective is to determine the catalytic properties of small metal rilusters within seolites, and the other is to explore the importance of gas phase radicals which are formed on catalytic surfaces. The study of small metal clusters within zeolites Includes not only kinetic measurements, but also extensive characterization of the catalysts in order to determine metal particle size, location of the particle with respect to the zeolite structure, and metal-support interactions. The other major theme of this research has been the formation and identification of radicals which enter the gas phase after being formed on catalytic surfaces. In these experiments reactants are passed over a heated catalyst bed and the resulting gases are trapped in an argon matrix at vlok. These studies have confirmed that $\pi$-allyl radicals are. Indeed formed when propylene reacts with a bismuth-molybdate catalyst. Results have shown that although Ru clusters remain in the large cavities of a zeolite, the turnover frequencies. in the reaction of $\mathrm{CO}$ with $\mathrm{H}_{2}$ for several samples were in agreement with those observed for ruthentum supported on alumina. Thus, the zeollte had no significant effect on the rate of reaction per surface ruthenium atom.

DREXEL UNIVERSITY

Philadel phia, Pennsylvania 19104

321. PHYSICAL AND CHEMICAL STUDIES OF

$\$ 36,000 \quad 02-1$

CHLOROPHYLL IN MICROEMULSIONS

R. Mackay

Department of Chemistry

The overall objective of this work is to investigate the utility of microemulsions as solvent media for solar energy absorbers which can act as photosensitizers of redox reactions. To this end, the chlorophyll mediated photoreduction of dyes, principally methyl red, by ascorbate in oll micellar emulsions in water has been employed as the model system. The reaction quantum yield is being measured as a function of chlorophyll concentration and microemulsion type. Based on the model system results, the work will be extended to include mechanistic studies and the use of other pigments. These Investigations provide fundamental information on the nature of interactions and (photo)reactions at microscopic oil-water interfaces, as well as a basis for photochemical energy conversion methods. 
Chemical Energy, continued

STANFORD UNIVERSITY

Stanford, California 94305

322. MOLECULAR BEAM REACTIVE SCATTERING

R. J. Madix

Department of Chemlcal Engineering
$\$ 80,000 \quad 02-1$
(16 months)

Molecular beam studies of activated adsorption and reactive scattering of small molecules from single-crystal metal surfaces are being conducted. The dissociative reaction probabilities of molecules such as $\mathrm{H}_{2} \mathrm{O}$, $\mathrm{CO}_{2}, \mathrm{~N}_{2} \mathrm{O}$, etc. and saturated hydrocarbons are being studied using seeded nozzle beams. The translational dependence of the sticking probabilities of these spectes is being determined in order to elucidate the dynamical character of the reactive collision at the surface. The experiments are being performed in an ultra-high vacuum apparatus which is constructed to allow maximum surface definition and high sensitivity for detecting reaction events. Both angular dependencies of adsorption and desorption and surface residence times are being observed to characterize the adsorptive interaction with the surface. Additional studies of the reactive scattering of $\mathrm{CO}$, NO, $\mathrm{N}_{2}, \mathrm{H}_{2}$ and $\mathrm{O}_{2}$ are being made to better understand the fundamental nature of the chemical kinetics of heterogeneous reactivity. For this purpose, modulated molecular beams are being. employed which afford the direct measurement of surface reaction times subsequent to adsorption. A clearer understanding of the molecular dynamics of surface reactivity is expected to result from this work. 
Chemical Energy, continued

STANFORD UNIVERSITY

Stanford, California 94305

323. ELECTROCATALYTIC OXIDATION OF

$\$ 50,200 \quad 02-1$

GASEOUS HYDROCARBONS ON SOLID-

OXIDE IONIC ELECTROL YTES

D. M. Mason

Department of Chemical Engineering

The main objective of this research program is to perform laboratory-scale experiments to obtain electrocatalytic rate data for gaseous organic compounds reacting on oxygen-ion type electrolytes being considered for practical fuel cells. Such an investigation should lead to a better understanding of the electrocatalytic and diffusion mechanisms occurring. Emphasis is being placed on the mechanism of anodic oxidation of such gaseous fuel species as: $\mathrm{H}_{2}, \mathrm{CO}, \mathrm{CH}_{1}$, and $\mathrm{CH}_{3} \mathrm{OH}$ derivable from coal, wood and other sources. Though focus is on the electrocatalytic oxidation of fuels, the kinetics at the air cathode are also being analyzed. Because of the necessary trend to operate at more moderate temperatures than $10000 \mathrm{C}$, for the sake of increasing the lifetime of materials, the rate processes of chemical kinetics and diffusion become of importance. Thus the present study should provide the necessary physical insight to enable one to operate at lower temperatures, more hospitable to materials. Specifically being studied are the steady-state D.C. current-voltage characteristics of electrochemical systems comprising fuel-air with (i) reactant composition being varied; ( $i$ i) disc-shaped electrolytes about 2.5 $\mathrm{cm}$ in diameter and 1-2mm thick composed of scandia and yttria-stabilized zirconia, and gadolinia-stabilized ceria being employed; (iii) various metal. electrodes being used such as $P t$ and $A u$ as we 11 as conducting compounds like lanthanum chromite; (iv) surface morphology being carefully studied by scanning electron- and photomicroscopy and Auger spectroscopy; ( $v$ ) the ratio of electrolyte to electrode surface area being varied by photodeposition techniques employing various size grids of electrode material; (vi) temperature being varied between 1000 to $700^{\circ} \mathrm{C}$ at 1 atm.; (vii) gas-phase diffusion being controlled by varying flow-rates of gas in stagnation flows normal. to the disc electrodes; (viii) the possible role of color centers forming catalytic sites being investigated by exposing the electrode under reacting conditions to laser radiation. 
Chemical Energy, continued

SRI INTERNATIONAL

Menlo Park, California 94025

324. MEAS UREMENT OF THE RATES OF CRITICAL

$\$ 60,000 \quad 02-1$

BOND CLEAVAGE PROCESSES AND RADICAL

STABILITIES IN COAL STRUCTURES

D. F. McMillen

Chemical. Kinetics Department

The objective of this work is to measure the rates of thermal bond scission (and thus the stability of the radicals formed) for certain key structures representative of the alkyl-aromatic systems present in coal, and to incorporate the results into an empirical-theoretical framework. This wil1. eliminate the need to actually measure the rates for each individual. structure important in coal, and will thus form a concise basis for understanding the rates at which coal structures undergo thermal degradation. The principal technique used is Very Low-Pressure Pyrolysis, which allows measurement of initial. bond cleavage reactions without complications from rapid secondary reactions involving the radical. intermediates. The other technique used is Laser-Powered Homogeneous Pyrolysis, which totally eliminates the surface catalyzed reactions, which can be a complicating factor with surface-sensitive substrates. The results consist of thermodynamic data (heats of formation) for the radicals selected, the rates of formation of these radicals by bond scission, and a test of the validity and accuracy of the previously published theoretical-empirical estimation technique.

UNIVERS ITY OF CALIFORNIA/BERKELEY

Berkeley, California 94720

325. SURFACE CHEMISTRY AND CATALYTIC
CHEMISTRY OF METALLIC SURFACES
E. L. Muetterties
Department of Chemistry

A complete ultrahigh vacuum system equipped with peripheral accessories including the necessary instruments for Auger spectroscopy, low energy electron diffraction and mass spectrometric studies was purchased for this program and has been fully assembled, tested and modified as required for the planned research. This system is being used to initiate preliminary studies of the chemisorption of small molecules like benzene, ethylene, acetonitrile, and methyl. isocyanide on low index platinum surfaces. It has been demonstrated that the chemisorption of all of these molecules on the Pt(11.1) surface is largely thermally reversible. The ligand field strength series for this set of molecules is acetonitrile > carbon monoxide > benzene > methyl is ocyanide. 
Chemical Energy, continued

UNIVERSITY OF CALIFORNIA/SAN DIEGO

La Jolla, California 92093

326. HYDRIDE FORMATION

$\$ 40,000 \quad \cdot 02-1$

H. Oesterreicher

Chemistry Department

A study of hydride formation of intermetallic compounds is underway. Parameters of interest include equilibrium pressures, heats of formation, amount of hydrogen uptake, and kinetic as we 11 as cryotallographic and phase diagram data: Materials are chosen such that hydrogen uptake wi11 Lake place under conditions close to ambient. For this purpose model calculations on the stability of hydrides are employed. Materials are further chosen so that a systematic understanding of factors involved in hydride formation such as the influence of the nature of the metal hydrogen bond (ionic-covalent) will result. A typical model system is $\mathrm{LaNi}_{2}-\mathrm{MgNi}_{2}$. In the later parts of this study, emphasis is placed on relatively ${ }^{2}$ light weight and economically appealing materials. It is expected that a fundamental understanding will evolve which will help in the design of materials for practical applications connected with hydrogen storage.

UNIVERSITY OF SOUTHERN CALIFORNIA

Los Angeles, California 90007

327.

SUYEKACID CATALYZ̃ED DEPOLYMERIZATION

AND CONVERSION OF COALS

G. A. Olah

Department of Chemistry
$\$ 58,600 \quad .02-1$

(1)

Superacids possess acidities up to a billion times stronger than conventional strong mineral acids, such as sulfuric acid. Novel, superacid catalyzed conversions of bituminous cosls and lignites are being studied in order to increase the H/C ratio of coals. Reactions being studicd inelude depolymers ization reactions, alkylation and transalkylation reactions, acylation, nitration and reductive coupling reactions. Reactions with both liquid and solid superacidic catalyst systems are being investigsţed. Liquid superacidic systems are being used for structural studies (using ${ }^{2}$ C NMR spectroscopy) of the solubilized carbocationic components of coals. In order lo obtain better understanding of the basic chemistry of the superacid catalyzed conversion reactions, model systems, such as diphenylmethane, dinaphthylmethane and dianthracylmethane are also being studied under comparable reaction conditions. 
Chemical Energy, continued

UNIVERSITY OF CALIFORNIA/SANTA BARBARA

Santa Barbara, California 93106

328. REACTIONS OF METAL ATOMS AND CLUSTERS

IN LOW TEMPERATURE MATRICES

$\$ 75,000$

$02-1$

R. G. Pearson, P. H. Barrett

(18 months)

Department of Chemistry

Mössbauer and infrared spectroscopy are being used to study a variety. of isolated metal atoms and small clusters in low temperature matrices containing possible reactant molecules. The object of this program is to rate both the metals and the substrates in terms of relative reactivity. Also, the effect of degree of aggregation of the metal upon reactivity will be $s$ tudied. It has already been found that $\mathrm{Fe}_{2}$, but not $\mathrm{Fe}$, reacts with $\mathrm{N}_{2}$ and $\mathrm{CH}_{4}$. Both $\mathrm{Fe}$ and $\mathrm{Fe}_{2}$ react with $\mathrm{NH}_{3}, \mathrm{C}_{6} \mathrm{H}_{6}$ and $\mathrm{i}-\mathrm{C}_{4} \mathrm{H}_{10}$. These reactions of aliphatic hydrocarbons with isolated metal atoms and dimers are unprecedented. The reaction is believed to be cleavage of the $\mathrm{C}-\mathrm{H}$ bond, a reaction of great importance in catalysis. These studies should be of value in understanding both heterogeneous and homogeneous catalysis by transition metals.

UNIVERSITY OF TEXAS

Austin, Texas 78712

329. DEVELOPMENT OF HOMOGENEOUS CATALYSTS

FOR THE UTILIZATION OF CARBON MONOXIDE

$\$ 50,000 \quad 02-1$

R. Pettit

Department of Chemistry

The objective of this research is the development of homogeneous catalysts for two aspects of the utilization of carbon monoxide; specifically, the conversion of carbon monoxide and water into hydrogen (the water gas shift reaction) and the conversion of carbon monoxide into electrical energy (a co fuel cell). The two problems are related in that the chemistry involved in the catalytic cycle of each process is, up to a certain point in the cycle, similar. In each process a homogeneous metal complex reacts with carbon monoxide to form a metal carbonyl derivative which is then converted by the action of water and base to a metal hydride anion. In the production of hydrogen the metal hydride anion is protonated to form a neutral metal dihydride which yields molecular hydrogen and regenerates the original catalytic species. In the generation of electricity the metal hydride anion donates electrons to an electrode with regeneration of the original catalyst. 
Chemical Energy, continued

INDIANA-PURDUE UNIVERSITY

Indianapolis, Indiana 46205

330: THE METAL-AMMONIA REDUCTION AND

REDUCTIVE ALKYLATIQN OF COAL TAR

$\$ 32,200$

$02-1$

HYDROCARBONS AND ${ }^{3} \mathrm{C}$ NMR

CHARACTERIZATION AND CONFORMATIONAL

ANALYSIS OF THE REDUCED PRODUCTS

P. W. Rabideau

Department of Chemistry

Loal tar hydrocarbons (e.g., anthracene) readily accept electrons from alkali metals in anhydrous ammonia. The anionic intermediates may be protonated with varying degrees of alkyl substitution. There has been considerable interest in the mechanistic details of these reactions, the structural nature of the anionic intermediates as well as the regioselectivity of reduction and the stereoselectivity of reductive alkylation. Considerable attention has been given to the nature of the 1,4-cyclohexadiene "inner ring," and the effect of the substituents on conformational processes. This research encompasses two major areas, (1) the nature of the anionic intermediates in reduction and reductive alkylation, apd (2) the $\mathrm{H}$ and ${ }_{C} \mathrm{NMR}$ conformational analysis and characterization $\left({ }^{13} \mathrm{C}\right)$ of reduced aromatic hydrocarbons. This is being accomplished through the investigation of several common coal-tar hydrocarbons together with model compounds.

MARQUETTE UNIVERSITY

Milwaukee, Wisconsin 53233

331. SOLID PHASE CATALYSTS AND

$\$ 40,000$

$02-1$

REAGENTS

S. L. Regen

Department of Chemistry

This research is aimed at obtaining an understanding of how polymer structure affects catalyst activity. Systematic variation in cross-1ink density and the percent ring substitution in macroreticular and microporous polystyrene copolymers are being examined. In addition, the importance of the orientation of catalytic sites relative to the polymer backbone and how surface, internal, and homogeneously functionalized polymers compare in activity are being assessed. Studies aimed at elucidating the mechanism and role of ion exchange in phosphonium-based polymers are also planned. Finally, the synthesis of a series of crown ether-based triphase catalysts is being carried out, and the synthetic scope as well as mechanistic details are being examined. 
Chemical Energy, continued

TEXAS A\&M UNIVERSITY

College Station, Texas 77843

332. THE INFLUENCE OF F-ELECTRON

$\$ 50,000$

$02-1$

CONFIGURATION ON CATALYTIC

PROPERTIES OF LANTHANIDE OXIDES

M. P. Rosynek

Department of Chemistry

Periodic trends in the catalytic behaviors of selected rare earth oxides for the dehydration/dehydrogenation of alcohols are being investigated. Following initial determinations of the overall activity/selectivity characteristics of the dual-path process over each oxide, the kinetics and energetics of the two principal reaction pathways are to be established, and a combination of experimental techniques is being applied to elucidate the nature of the active sites involved. Primary emphasis throughout the project is being placed on identifying and characterizing correlations that exist between catalytic parameters of the various oxides, such as apparent activation energies and the nature and surface densities of active sites, and periodically-varying electronic, magnetic, and structural properties that are a direct result of cationic f-electron configurations or solid-state phase transformations. The dual-path nature of the test reaction allows the effects of such features on catalytic properties to be distinguished from those caused by trends in surface basicity and lattice oxygen mobility across the sesquioxide series. In a broader sense, the results of this research provide a better understanding of the influence of partlally-filled f-uivitals on the oolid-ctato and surfar.e. properties of metal oxides. 
Chemical Energy, continued

WASHINGTON STATE UNIVERSITY

Pullman, Washington 99164

333. USE OF TRANSITION METAL CARBONYLS

AS CATALYSTS FOR OXIDATION

REACTIONS WITH MOLECULAR OXYGEN

$\$ 83,000$
$(18$ months $)$

02-1

D. M. Roundhill

This project involves the use of transition metal carbonyl complexes as homogeneous catalysts for the oxidation of carbon monoxide and other organic compounds such as alcohols and ketones with molecular oxygen. The reaction is carried out in the 85-120 $\mathrm{c}^{\circ}$ temperature range under high pressure conditions. The product yield using $\mathrm{Rh}_{6}(\mathrm{CO})_{16}$ as a catalyst increases in proportion to the carbon monoxide pressure, and it is likely that a lower homologue transition metal carbonyl is responsible for the catalytic activity. The reactions are being approached from a mechanistic viewpoint and possible pathways are being tested. A reaction of the complex $\operatorname{IrCl}(\mathrm{CO})\left(\mathrm{o}-\mathrm{Me}{ }_{2} \mathrm{NC}_{6} \mathrm{H}_{4} \mathrm{PPh}_{2}\right)$ with molecular oxygen is being investigated. The product involves carbonyl loss under mild conditions, and the compound is being isolated and characterized. This is an unusual reaction in iridium(I) chemistry, and it is anticipated that oxidation of the coordinated $\mathrm{CO}$ has occurred. The goal of the project is to devel op useful low temperature oxidation reactions, and to form a basis of rational understanding of oxygen atom transfer chemistry with homogeneously catalyzed reactions.

UNIVERSITY OF KENTUCKY

Lexington, Kentucky 40506

334. A FUNDAMENTAL STUDY OF CATALYSTS USING $\$ 60,000 \quad 02-1$ LASER RAMAN, INFRARED, AUGER ELECTRON SPECTROSCOPY AND LOW ENERGY ELECTRON DIFFRACTION

G. A. Sargent - Department of Metallurgical Engineering and Materials Science

E. B. Bradley - Department of Electrical Engineering

A research program is underway to study the surface structures and bonding of gas molecules, such as $\mathrm{CO}, \mathrm{CH}_{4}, \mathrm{H}_{2}, \mathrm{D}_{2}$ and $\mathrm{O}_{2}$ and $\mathrm{H}_{2} \mathrm{~S}$ on single crystal surfaces of the catalytically active material, ${ }^{2} \mathrm{Ni}$. The techniques employed for this study are laser-Raman spectroscopy, which has only recently been developed for the study of adsorbed gases on solid surfaces, infrared reflection spectroscopy, low energy electron diffraction (LEED), and Auger electron spectroscopy (AES). The above techniques are used to obtain data about surface structures, surface dipole moments, chemical species, intermediate molecular structures and segregation of elements at the surface of catalysts. The data are obtalned as functions of temperature and gas pressure. The ultimate objective of the research is to develop a better understanding of the mechanisms of catalysis. 
Chemical Energy, continued

MASSACHUSETTS INSTITUTE OF TECHNOLOGY

Cambridge, Massachusetts 02139

335. REDUCTION OF CARBON MONOXIDE WITH

HYDROGEN GAS

$\$ 65,000 \quad 02-1$

R. R. Schrock

Department of Chemistry

The immediate goal of this research project is to discover how to reductively couple two molecules of carbon monoxide in niobium or tantalum complexes stoichlometrically. The longer range goal is to discover how to do this catalytically with molecular hydrogen as the reductant. The approach is to make new carbon monoxide or hydride complexes of niobium, tantalum, molybdenum or tungsten which are likely to react easily with molecular hydrogen or carbon monoxide, respectively, to give reduced and/or coupled CO contalning ligands. Synthetic studies are being backed up by mechanistic studies, and if any catalytic process is discovered, by detailed catalytic studies. Mixed metal complexes involving early and late transition elements and polymer supported early transition metal hydrides will also be studied.

COLORADO STATE UNIVERSTTY

Fort Collins, Colorado $\mathbf{8 0 5 2 3}$

336. PALLADIUM CATALYZED COUPLING REACTIONS: $\$ 60,000$ 02-1 MECHANISM OF REDUCTIVE ELIMINATION

J. K. St 11le

Department of Chemistry

The coupling reaction of hydrocarbons or other organic reagents catalyzed by transition metals is one of the most important methods of generating carbon-carbon bonds, yet it is a reaction about which little mechanistic information is available. The vinylation of aromatics and the coupling of aromatics catalyzed by palladium are two such reactions of industrial importance. The final step in these coupling reactions is the elimination of the organic portion from the transition metal by reductive elimination. The elucidation of the mechanism of reductive elimination, which is a key. step in palladium catalyzed coupling reactions, is to be accomplished by a variety of approaches. The synthesis of isomeric dialkyl, diaryl and mixed alkylaryl palladium complexes containing different geometries and ligand ! 1 s outlined. The effect of 1 igands, complex geometry, electronic structure of the organic molety, and added electron acceptors on the rates of decomposition is being studled in order to afford mechanistic information and define the optimum conditions for this step in the catalytic cycle. The stereochemistry attending the elimination and the detection of reactive intermediates provides additional mechanistic information. In addition, these mechanistic probes are brought to bear on the reductive elimination reaction taking place from palladium (IV) complexes and binuclear palladium complexes. 
Chemical Energy, continued

PURDUE UNIVERSITY

West Lafayette, Indiana $\$ 7907$

337. MECHANISM AND KINETICS OF CELLULOSE HYDROLYSIS BY ACIDS AND ENZYMES

G. T. Tsao

Laboratory of Renewable

Resources Engineering

The major empliasis of chis project has been on the biosynthesis, purification, and kinetics of cellulnse pnryme complcico. Convenleul procedures tor isolating pure endoglucanase, cellobiohydrolase and collobiaoc in high ylelds are studied. This project is concerned with the pretreatment of cellulosic materials with cellulose solvents which leave cellulose in a structural form which can be easily hydrolyzed by either acid or enzyme to give $100 \%$ yield of glucose. This research deals with the structural changes caused by the solvents. Under certain conditions the crystalline structure of cellulose can be changed to readily dissolvable forms.

PENNSYLVANIA STATE UNIVERSITY

University Park, Pennsylvania 16802

338. METAL CRYSTALLITE SIZE AND SUPPORT

EFFECTS ON CO HYDROGENATION

$\$ 90,000$
$(18$ months $)$

$02-1$

M. A. Vannice

Department of Chemical Engineering

This program is concerned with the influence of metal-support interactions and metal crystallite size effects on catalytic behavior. In particular, the extent to which these effects exist in supported $\mathrm{Pt}, \mathrm{Pd}$, and $\mathrm{Ni}$ catalysts is being determined, and the influence of these effects on the Co hydrogenation reaction is being studied, since improvements in activity and selectivity are highly desirable in this reaction. A unique, combined IR reactor cell has been designed which operates as a single-pass, plug-flow differential reactor and also allows in situ IR spectra to be obrained under well-defined reaction conditions. Changes in the adsorbed state of CO which can be correlated with measured differences in catalytic properties are being sought. Simultaneous IR/kinetic results have been obtained for $\mathrm{Pt}$ and $\mathrm{Pd}$ catalysts which agree well with kinetic parameters determined in separate differential reactor systemo, and variatiuns in turnover frequencles between Pd catalysts have been observed. Adsorbed $C O$ is detected as the predominant surface species under reaction conditions on $\mathrm{Pt}$ and $\mathrm{Pd}$, as others have reported for Ru catalysts, with one exception. Perhaps the most intriguing results to date show that no IR-active $C O$ is visible on $\mathrm{Pd} / \mathrm{TiO}_{2}$, a system recently shown to exhibit a strong metal-support interaction (SMSI), yet the specific activity is comparable to that over $\mathrm{Pd} / \mathrm{Al}_{2} \mathrm{O}_{3}$. Presently, TiO - supported systems are being examined in greater ${ }^{3}$ detail, including ${ }^{2} \mathrm{Ni} / \mathrm{TiO}_{2}$ catalysts. 
Chemical Energy, continued

PENNSYLVANIA STATE UNIVERSITY

University Park, Pennsylvania 16802

339. GASIFICATION OF DISORDERED

CARBONS (CHARS)

P. L. Walker, Jr.

Department of Materials science

\& Engineering
$\$ 80,200 \quad 02-1$

(15 months)

Rates of gasification of chars derived from coals vary widely with the rank of coal and the gasification medium used. However, most of the carbon burn-off versus time plots have a similar shape, given by a cubic equation, having only one adjustable constant, that is, the time to reach $50 \%$ burn-off. It thus appears that the differential rate of char gasification at any char burn-off is related in a fundamental way to the active site area of the char at that particular char burn-off. The main objective of this program is to confirm this possible relationship. Gasification of a high purity char in $\mathrm{O}_{2}$ is being measured as a function of time, temperature, and $0_{2}$ pressure. Changes in physical structure of the char, such as active surface area, total surface area, particle density, total open pore volume, and pore volume distribution are being followed as a function of carbon burn-off. Rate constants for char gasification rates and active surface burn-off levels from a knowledge of differential gasification are being calculated at selected burn-off levels from a knowledge of differential gasification rates and active surface areas at these burn-off levels. The study is to be repeated for the char to which platinum has been added as a gasification catalyst. In this case, rate constants for gasification are calculated based on the active areas of both the char and platinum.

YALE UNIVERSITY

New Haven, Connecticut 06520

340. A STUDY OF ENERGIES OF ORGANIC

$\$ 65,000 \quad 02-1$ COMPOUNDS

K. B. Wiberg

Department of Chemistry

The energies of organic compounds are being determined by calorimetric methods. The reactions being studied include: 1, the enthalpies of hydrolysis of ketals, acetals and orthoesters; 2 ; the enthalpies of hydration alkenes; 3 , the enthalpies of cleavage of small rings; and 4 , the enthalpies of rearrangement of strained hydrocarbons. The data which are derived from this investigation will be useful in defining steric effects and bond angle deformation effects on the energies of organic compounds. They also will be of help in defining the parameters for molecular mechanics-type estimates of the energies of these compounds. In addition, automated calorimeters are being developed which will facilitate the measurement of heats of reaction. 
Chemical Energy, cont inued

SRI INTERNATIONAL

Menlo Park, California 94025

341. THERMODYNAMICS OF SULFUR AND

CHLORINE ADSORBATES ON METAL

$\$ 94,000$

$02-1$

CATALYST SURFACES

(20 months)

H. Wise

Solid State Catalysis Laboratory

Coal-derived synthesis gas ( $\mathrm{CO}$ and $\mathrm{H}_{2}$ ) is the feedstock for substitute natural gas (methane) production using group VIII transition metal catalysts. Howevèer, thésé catalysts are susceptible to deactivation by trace contaminants of sulfur compounds in the feedstocks. Reduction of the concentrations of such catalyst poisons to levels necessary to ensure reasonably long catalyst lifetimes requires considerable capital investment and operating expense. The thermodynamic aspects of sulfur poisoning on nicke1, ruthenium and other metals have not been determined with sufficient accuracy to establish the threshold levels of contaminants above which the catalyst surface deactivates. The purpose of this research is to provide such basic thermodynamic information. In the research program, the thermodynamics of sulfur and halogen chemisorption are being examined using two complementary techniques: (a) a recirculating gas system to study reversible sulfur and halogen chemisorption on supported nickel, copper, iron, cobalt, platinum and ruthenium catalyst surfaces, and (b) an ultrahigh vacuum system to study sulfur chemisorption on well-defined surfaces of these same metals, such as single crystals.

NATIONAL BUREAU OF STANDARDS

Washington, D.C. 20234

342. STUDY OF HETEROGENEOUS CATALYTIC

$\$ 115,400$

$02-1$

CHEMISTRY ON TRANSITION METALS

J. T. Yates ; Jr.

Surface Science Division

The detailed reaction mechanism for several heterogeneous processes is being studied using various modern surface science methods. Among the processes under investigation are: (1) the catalytic methanation reaction over nickel and ruthenium single crystals; (2) the water synthesis from $\mathrm{H}_{2}$ and $\mathrm{O}_{2}$ over rhodium single crystals; (3) the vibrational spectrum of molecules and molecular fragments stabilized on single crystal surfaces; (4) the confirmation of species in (3) using electron impact methods. These experiments provide a deeper insight into the molecular processes governing surface chemistry. 
Chemical Energy, continued

ROCKWELL DIVISION

Atomics International

Canoga Park, California 91304

343. MOLTEN SALT INTERACTIONS IN

COAL PROCESSING

$\$ 140,000 \quad 02-1$

S. J. Yosim

This research project is directed toward the definition of the fundamental processes which occur in sparged sodium-carbonate sodium-sulfate melts during the oxidation of spectroscoplc grade graphite. The dependence of the rate of graphite oxidation on reaction parameters such as melt temperature, oxygen concentration of the sparge gas, nature of the graphite surface, and concentration of sodium sulfate in the molten sodium carbonate is being investigated. The present concern is with the in situ determination of the identity and concentration of the species present in the melt during the oxidation of graphite and, hence, the mechanism of the process. An understanding of the mechanism of the oxidation of pure graphite in molten sodium carbonate will provide a theoretical basis for the application of the molten sodium carbonate system to the production of fuel gas from more complex carbonaceous materials. 
Separations

UNIVERSITY OF MINNESOTA

Minneapolis, Minnesota 55455

344. CONTINUOUS CHEMICAL REACTION

$\$ 32,800$

$02-2$ CHROMATOGRAPHY

R. Aris \& R. W. Carr

Department of Chcmical

Engineering \& Materials Science

Reaction chromatography is being done on a continuous basis in a rotating, packed cylindrical annulus. In addition to advantages in throughput over conventional pulsed mode reaction chromatography, reactions of the type $A^{*}$ $B+C$ can be forced to greater than equilibrium conversions by chromatographic separation of the products, suppressing the reverse reaction. A fixed, cylindrical annular charcoal packed bed with rotating inlet is being used for investigations of continuous reaction chromatography of the acid hydrolysis of aqueous methyl formate. A second apparatus is being used for investigations of continuous reaction chromatography of gas-solid catalytic reactions. It features a rotating cylindrical annulus and a fixed inlet.

BEND RESEARCH, INC.

Bend, Oregon 97701

345. COUPLED TRANSPORT LIQUID MEMBRANES $\$ 56,300 \quad 02-2$ FOR URANIUM SEPARATIONS

W. C. Babcock

The objective of this program is to perform fundamental studies with a new class of liquid membranes called "coupled transport membranes." These membranes consist of a water immiscible complexing agent, held by capillary forces in the pores of a microporous polymeric sheet. The complexing agent acts as a carrier of ions, picking them up from an aqueous solution on one side of the membrane, carrying them across the membrane as a complex, and depositing them in an aqueous solution on the opposite side of the membrane. To preserve electrical neutrality, the carrier must transport another ion of like charge in the opposite direction or an ion of opposite charge in the same direction. This coupling of ions permits the transport of a desired ion up its aqueous concentration gradient as long as the coupled ion flows down its concentration gradient, i.e. the carrier is a "chemical pump." In these studies, uranium ions are transported in one direction, while typical coupled ions are hydrogen ion, bisulfate, and carbonate. The principal goal is to determine how aqueous compositions ( $\mathrm{pH}$, ionic strength, etc.) and membrane composition (concentration and type of agent, type of organic diluent, etc.) affect transmembrane uranium flux. 
Separations, continued

AMHERST COLLEGE

Amherst, Massachusetts 01002

346. SOLVENT AND SOLUTE ISOTOPE EFFECTS

$\$ 35,000 \quad 02-2$

IN THE AQUEOUS SOLUTION OF GASES

B. B. Benson

Department of Physics

Relatively little has been known about isotope effects in the physical solution of chemically non-reactive gases. Neither the effect of changing the isotopic constitution of the solvent, nor the isotopic fractionation of the solute gas, has received much attention. Because these isotopic effects are small, very precise measurements are required. A new method for measuring the Henry solubility coefficient with an accuracy of approximately $0.02 \%$ has been developed. This accuracy is an order of magnitude better than previous work. For the determination of differences in the solubilities of the isotopes of a given gas mass, spectrometric null techniques are employed to compare an isotope ratio in the dissolved gas with the ratio in the gas above solution. Measurements on oxygen and four noble gases with a precision of 10 to $20 \mathrm{ppm}$ have revealed how the isotopic fractionation of. the solute varies with temperature and gas. These techniques are being applied to the solubility and isotopic fractionation of hydrogen, nitrogen, oxygen, and five noble gases in heavy water, $D_{2} O$. Beyond their practical applications, the results of these very accurate measurements provide a unique opportunity for exploring molecular interactions in water through the effects of isotopic substitution in the solvent.

STATE UNIVERSITY OF NEW YORK/STONY BROOK

Stony Brook, New York 11794

347. FUNDAMENTAL STUDIES IN ISOTOPE

$\$ 113,100 \quad 02 \div 2$

CHEMISTRY

J. Bigeleisen

Department of Chemistry

A program of experimental and theoretical investigations of isotope effects in physical and chemical processes is underway. Fundamental understanding of isotope effects has broadened the knowledge of the behavior of matter and provides the basic science from which new isotope separation processes are developed. The experimental investigations are being principally directed at the behavior of condensed media, a relatively unexplored and fruitful area of investigation for which a unique experimental facility has been established. The theoretical program is concerned with the correlation of isotope effects with molecular and intermolecular forces. 
Separations, continued

BRIGHAM YOUNG UNIVERSITY

Provo, Utah 84602

348. SEPARATION OF SELECTED CATIONS

$\$ 52,500$

$02-2$ BY LIQUID MEMBRANES

J. J. Christensen

The Theoretical Institute

The overall objective of this research is to determine the factors which influence cation transport across liquid membranes by macrocyclic carriers so that systems for separating cations can be devised. The species being studied include the alkali, alkaline earth and lanthanide (III) cationo. It is planned to meet this broad objective by identifying the 1 igand and solvent parameters which determine the extent of binding of trivalent lanthanide cations to macrocyclic ligands in water-methanol solvents, determining the alkali, alkaline earth and lanthanide cation transfer rates and selectivity patterns in liquid membranes of several macrocyclic ligands, and relating these two sets of data to determine the relationship of cation selectivity demonstrated by macrocycles in a single phase to that demonstrated in the liquid membrane multi-phase system. This knowledge should make it possible to choose macrocycles from the many for which single phase data are available for use as carriers in liquid membranes to accomplish specific cation separations. 
Separations, continued

UNIVERS ITY OF CALIFORNIA/LOS ANGELES

Los Angeles, California 90024

349. MULTIHETEROMACROCYCLES THAT COMPLEX

$\$ 76,000 \quad 02-2$

METAL IONS

D. J. Cram

Department of Chemistry

The objective of this program is to design, synthesize, and evaluate cyclic host organic compounds for their abilities to complex and 1ipophilize guest metal lons selectively and impart special properties to them. Crowns and cryptands are cyclic and bicyclic collections of oxygen and nitrogen binding sites whose cavities, when not filled with guest cations or solvent, are filled intramolecularly by conformational reorganization of parts of the host. Thus complexation involves the guest reorienting binding sites of the host. Hosts, termed spherands, possess rigid support structures, which, when noncomplexed, contain enforced cavities lined with electron pairs. Much of the driving force for complexation of spherands is derived from the release of electron-electron repulsion and the filling of an empty cavity. Gulded by scale molecular models and past experience, spherands are being designed, synthesized, and tested for their abilities to bind selectively inorganic ions and to solubilize them in organic solvents. The spherands and hemispherands (combinations of rigid and nonrigid support structures) are being tested for their abilities to selectively complex and 11pophilize the various cations of the periodic table. Selectivity based on kinetics and equilibria is being examined. Mass, NMR, UV, and IR spectra, elemental analyses and $X$-ray structure are used to identify ligand systems and; sometimes, the complexes. Association and rate constants in both extraction and mixing experiments are being determined. 
Separations, continued

UNIVERSITY OF SOUTH CAROLINA

Columbia, South Carolina 29208

350. THE USE OF POLYETHERS IN THE

$\$ 40,000$

$02-2$

TREATMENT OF ACIDIC HIGH

ACTIVITY NUCLEAR WASTES

M. W. Davis, Jr.

Department of Chemical Engineering

The purpose of this work is to develop a solvent extraction process capable of removing $99.9 \%$ of the strontium and cesium from acidic high activity nuclear waste. Compatibility with the Purex processes is desirable. Macrocyclic polyethers or "crown" compounds were chosen as the organic complexing agents to be investigated because of their ability to complex alkali metals and alkaline earths. The work has involved measurement of distribution coefficients using a variety of crown compounds in conjunction with both organic and inorganic anions. The removal of $99.9 \%$ of both $\mathrm{Sr}^{+2}$ and $\mathrm{Cs}^{+\mathrm{P}}$ will reduce the relative toxicity (the ratio of the concentration in the waste to the maximum permissible). of 10 year old high activity waste by a factor of $10^{3}$, thus alleviating the ultimate disposal problem of the bulk of the waste. It is befleved that industrial uses will be developed for the recovered $\mathrm{Sr}^{+2}$ and $\mathrm{Cs}^{+1}$.

UNIVERSITY OF ARIZONA

Tucson, Arizona 05721

351. EHELA'IING EXTRACTANTS OF

$\$ 60,100$

$02-2$

IMPROVED SELECTIVITY

H. Freiser

Department of Chemistry

New chelating extractants of improved selectivity for lanthanides and actinides are being synthesized using principles of reagent design derived from pattern recognicion studies of the existing chelate extractant data base. Laboratory evaluation of kinetic and equilibrium characteristics of selected extractants with $\mathrm{La}(\mathrm{III}), \mathrm{Th}(\mathrm{IV})$, and $\mathrm{U}(\mathrm{VI})$ is being conducted by both extraction and liquid chromatographic techniques. The high susceptibility of lanthanide chelate stability to steric hind rance has been confirmed. The increase in coordination number of lanthanides from lanthanum to ytterbium as evidenced from extraction equilibria serves to increase their separability. 8-Quinolinol immobilized on silica can separate lanthanide ions. 
Separations, continued

HARVARD UNIVERS ITY

Cambridge, Massachusetts 02138

352. ELECTRONIC STRUCTURE OF HELIUM AND HYDR IDE COMPLEXES IN LIQUID TRITIUM

$\$ 25,000$

$02-2$

D. R. Herschbach

Department of Chemistry

The objective of this project is to achieve a theoretical understanding of intriguing evidence for some kind of bound complex of helium in liquid tritium. The evidence indicates that most of the helium formed by radioactive decay does not escape as gas; more than a hundred times as much helium is held in solution than can be accounted for by the known solubility. Our theoretical approach makes use of approximate electronic structure calculations to examine the stability and interactions of helium complexes which might account for the observations. The final results expected from the project include electfonic energies and molecular geometries for clusters of the form $\left(\mathrm{HeH}^{+}\right)\left(\mathrm{H}_{2}\right), \mathrm{n}=0$ to 6 and $\left(\mathrm{H}^{-}\right)\left(\mathrm{H}_{2}\right), \mathrm{m}=0$ to 6 ; insight into the general phenomena of solvation enhancea by ionic interactions; and ideas for new experimental approaches to test and elucidate the mechanism for this phe nomenon of "supersolubility" of helium in liquid tritium.

BROOKLYN COLLEGE OF THE CITY

UNIVERSITY OF NEW YORK

Brooklyn, New York 11210

353. STABLE ISOTOPE STUDIES

$\$ 83,000 \quad 02-2$

T. Tshida

Department of Chemistry

The objective of this program is to obtain basic data on the fractionation of stable isotopes such as ${ }^{13} \mathrm{C}$ and ${ }^{15} \mathrm{~N}$ and to gain understanding of effects of isotopic substitutions on the properties of the liquid, the cryogenic vapor pressure of isotopic fluoromethanes and countercurrent column operations for the $\mathrm{NO} / \mathrm{N}_{2} \mathrm{O}_{3}$ system. Electrodics of electrochemical reflux processes for the $\mathrm{NO} / \mathrm{N}_{2} \mathrm{O}_{3}$ and $\mathrm{NO} / \mathrm{HNO}_{3}$ systems are being studied by potentiostatic and chronopotentiometric methods. To improve fundamental theories of isotope effects, theoretical studies are being carried out on the differential effects of molecular forces on isotope effects, the correlation of sulfur' isotope effects with vibrational forces in sulfur compounds, the evaluation of a new concept of atomic force parameter for possible use in isotope effect studies, and the quantum mechanical calculations of individual vibrational frequency shifts upon condensation. 
Separations, continued

UNIVERSITY OF GEORGIA

Athens, Georgia 30602

354. A STUDY OF MECHANISMS OF HYDROGEN

$\$ 58,400$

$02-2$

DIFFUSION IN SEPARATION DEVICES

M. H. Lee

Department of Physics

The diffusion of light gases (e.g. H isotopes) in Pd and other metals is selective. Hence, these metals, if used in the form of a membrane, can be useful as a separation device applicable in nuclear fusion reactors and other technical uses. To explore these possible applications, the mechanismo of hydrogen diffusion in Pd are being studied by developing a statistical mechanical model for the PdH system. This model is first given a mean-field analysis to provide a qualitative picture of the dynamics of hydrogen diffusion. The diffusion does not follow the known classical pattern, but seems to be more consistent with a certain quantum idea which is being developed. The present work centers on obtaining a complete dynamical solution by the method of Mori and that further developed by. Lee and Dekeyser recently.

TEXAS SOUTHERN UNIVERSITY

Houston, Texas 77004

355. SOLVENT EXTRACTION STUDIES OF

$\$ 35,000 \quad 02-2$

METALS USING HIGH MOLECULAR

WEIGH'I AMINE'S

C. W. McDonald

Department of Chemistry

The primary objective of this research project is to provide the basic data needed to develop highly efficient extraction met '.ds for removing a number of toxic metal ions from aqueous solutions us ang high-molecularweight amines and-quaternary ammonium salts. There is also concern for determining reaction stoichiometry, mechanisms and efficiencies of the new extraction systems. In order to accomplish these objectives, a number of high-molecular-weight amines and quaternary ammonium salts are being purchased for use in the extraction studies. Xylene and other non-polar solvents are being used as solvents for the amines. The extraction efficiencies are being determined by use of an atomic absorption spectrophotometer. The goal of the project is to demonstrate on the bench scale the feasibility of developing commercial scale processes for the simple, inexpensive removal of toxic metal ions from polluted industrial wastewater. 
Separations, continued

UNIVERS ITY OF MINNE SOTA

Minneapolis, Minnesota 55455

356. PHOTO-INDUCED CATAPHORETIC

$\$ 73,300$

$02-2$

ISOTOPE SEPARATION

H. J. Oskam, J. A. Carruthers,

(18 $1 / 2$ months)

L. M. Chanin

Department of Elecțrical Engineering

The objective of these studies is to test the feasibility of radiationinduced cataphoretic isotope separatigh in a gaseous discharge. A He-Ne discharge containing both $\mathrm{Ne}^{20}$ and $\mathrm{Ne}^{22}$ is subjected to radiation either from a $0.63 \mu \mathrm{m}$ laser or from monoisotope neon radiation lamps. Observations on the isotope ratio are undertaken by means of specialized Fabry-Perot. scanning spectrometers. Isotope separation has not been observed with either the $0.63 \mu \mathrm{m}$ laser radiation or the neon radiation lamps. Experiments are now planned to combine the two sources.

UNIVERSITY OF GEORGIA

Athens, Georgia 30602

357. FUNDAMENTAL STUDIES OF

$\$ 64,000 \quad 02-2$ SEPARATION PROCESSES

L. B. Rogers

Department of Chemistry

This research is concerned with basic aspects of optimization in chromatography and with ways of expressing the overall result in terms of information theory. Optimization, per se, is being examined in two different types of chromatography: recycle gas chromatography and supercritical fluid chromatography. Indirectly; optimization is also being exanined with respect to the chromatographic packing and the composition of the eluting liquid using both the oligomers of polystyrene and the vanadium porphyrins found in Venezuelan crude oil. Finally, chromatographic fractionations of the carbon and oxygen isotopes in carbon monoxide are being studied with the goal of comparing them with results obtained using carbon dioxide. 
Separations, continued

SYRACUSE UNIVERSITY

Syracuse, New York 13210

358.

MECHANISM OF FLUID PERMEATION
THROUGH POLYMER MEMBRANES.
TESTS OF A "FREE VOLUME" MODEL
OF PERMEATION
S. A. Stern
Department of Chemical Engineering
and Materials Science

$\$ 49,700$

$.02-2$

A recent model of fluid permeation through nonporous polymeric memhranes, based on "free-volume" concepts offers a comprehensive theoretical descrip$t$ ion of the permeation behavior of pure gases and gas mixtures. The purpose of this study is to subject the model to rigorous tests in order to assess its regimes of validity. The tests consist of the prediction of permeability coefficients for selected penetrant - polymer systems, including both pure gases and their mixtures, by means of specified free-volume parameters and solubility data. The required parameters are determined from high-pressure diffusivity measurements. The predicted permeability coefficients are then compared with experimental values over a wide range of pressures and temperatures. Diffusivity and solubility measurements are being performed simultaneously in a new high-pressure apparatus under isobaric and isothermal conditions. Permeability coefficients are also being determined for several binary gas mixtures in selected polymeric membranes at high pressures, since very few data reported in the literature are suitable for tests of the free-volume model. The free-volume model of permeation, if confirmed, will prove extremely useful for the development of membrane separation processes. Extensions of the model will 180 offer a fresh insight into the nature of interactions between polymers and small penetrant molecules. 
Separations, continued

ILLINOIS INSTITUTE OF TECHNOLOGY

Chicago, Illinots 60616

359. SELECTIVE METAL ION EXTRACTION

FOR MULTIPLE ION LIQUID--L IQUID

$\$ 41,700 \quad 02-2$

EXCHANGE REACTIONS

L. L. Tavlarides

Department of Chemical Engineering

The feasibility of many energy efficient hydrometallurgical solvent extraction processes depends upon the selective separation of metal lons from multiple metal aqueous solutions. The problem of predicting the selectivity of a given metal ion when the rate processes and chemical equilibria do not both favor the desired species has not been addressed. This research is intended to develop a fundamental understanding of the interplay between mass transfer with interfactal chemical reaction and chemical equilibria for multiple metal systems to predict selective extraction. The research program includes the following four tasks: (1) Selection of a binary metal model system from three prospective systems is being made. (2) Equilibrium studies are being conducted to obtain distribution data for thermodynamic models. (3) Experimental chemical reaction studies follow in order to obtain kinetic models for each reactant and the exchange reaction between metal complexes. (4) A comparison of predictions of selectivity with experimental results for a single stage contactor is being made. The analysis is being extended to predict selectivity for multiple staged mixer-settlers. The results of this research indicate methodology to develop data and models which may permit rational design of multiple metal solvent extraction processes from basic principles. 
Separations, continued

SYRACUSE UNIVERSITY

Syracuse, New York 13210

360. PARTICLE DEPOSITION IN GRANULAR

$\$ 66,500$

$02-2$ MEDIA

C. Tien

Department of Chemical

Engineering \& Materials Science

This study is concerned with a fundamental investigation of particle deposition arising from the flow of a gas-solid suspension through a granular medium. The specific problems to be considered include the prediction of the rate of deposition, the morphology of deposits and its evolution, the effect of particle deposition, the cleaning of filters by backwashing and the determination of the conditions leading to the formation of filter cakes. Both experimental and theoretical work is underway. In the experiment both experimental filters composed of sand as filter grains and specially-made two dimensional model filters are being used. In the theoretical analysis filter media are characterized by various porous media models but the principal model is the constricted tube model proposed recently. The study provides the necessary basic information essential to the eventual development of a comprehensive granular filtration theory.

COLUMBIA UNIVERSITY

New York, New York 10027

361 .

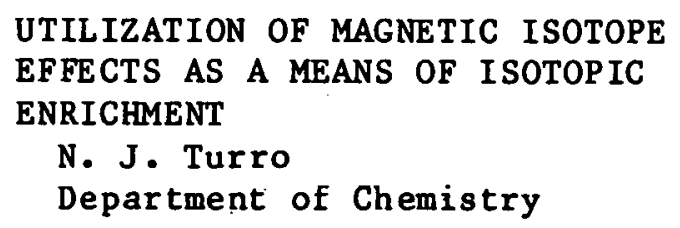

The magnetic isotope effect is being employed as a means of separating magnetic isotopes from non-magnetic isotopes. The method is, in prinriple;

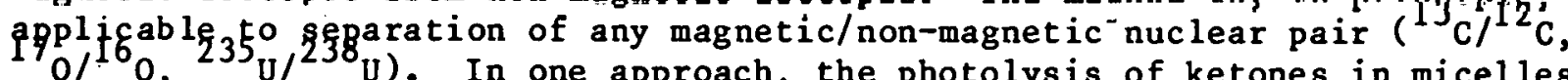
has been employed as the chemical basis for separation of ${ }^{3} \mathrm{C}$ from $12 \mathrm{C}$. In a second system, the thermolysis of endoperoxides has peen utilized as the chemical basis for a separation of ${ }_{0}^{1}$ from ${ }_{0}$ and ${ }^{18}$. 
Separations, continued

UNIVERSITY OF CALIFORNIA/IRVINE

Irvine, California 92717

362.

$$
\begin{aligned}
& \text { STUDIES OF ISOTOPIC MASS } \\
& \text { EFFECTS IN CHEMISTRY } \\
& \text { M. Wolfsberg } \\
& \text { Department of Chemistry }
\end{aligned}
$$

$$
\$ 61,100 \quad 02-2
$$

An understanding of the effect of isotopic mass on the physical and chemical properties of molecules is being sought. It is further desired to predict the numerical values of such isotope effects. These theoretical studies are carried out using the methods of quantum mechanics and statistical mechanics. Included among the effects to be studied are isotope effects on chemical equilibria and on reaction rates. The understanding of isotope effects and the ability to calculate them is important because most processes of separating one isotopic species from another depend on isotope effects. Statistical mechanical perturbation theory is being employed in the elucidation of isotope effects on chemical equilibria. Perturbation theory ${ }_{8}$ has 6 been carried to fourth order and shown to be convergent. Relative ${ }_{0} /{ }_{0}$ isotope effects are being investigated; these effects are of interest from the point of view of cosmochemical problems. Exact vibrational-rotational energies of small molecules are being calculated by variational methods. These energies are needed to calculate isotope effects on chemical equilibria. The Born-Oppenheimer correction has been formulated for polyatomic molecules; such a formulation is needed for very precise calculations of isotope effects. 
Separations, continued

THE AEROSPACE CORPORATION

Los Angeles, California 90009

363. TWO-STEP LASER PHOTODISSOCIATION

$\$ 80,000$

$02-2$

OF MOLECULES WITH APPLICATIONS TO

ISOTOPE ENRICHMENT

P. F. Zittel

Chemical Physics Department

The object of this research is to investigate the important parameters in the proccoo of isotope separation by lwu-slep, isocoplcally selective photodissociation of molecules. The two-step process involves the initial vibrational excitation of a particular isotopic species of a molecule by a pulsed infrared laser, which is followed by photodissociation with a pulsed ultraviolet laser. An experimental apparatus which,utilizes an on-line, sampling mass spectrometer to analyze the products generated by photodissociation and subsequent chenical scavenging has been developed to measure the isotopic enrichment and product yield of the two-step process as a function of various experimental parameters. In conjunction with the experimental work, an extensive computer modeling capability is used to simulate the isotope separation process. The results of experimental and computer modeling studies are compared t ${ }_{8}$ identify enrichment 1 imiting processes. Inttial studies are focused on 81 isotope enrichment by two-step photodissociation of $\mathrm{HBr}$, leading to subsequent studies involving the enrichment of $\mathrm{C}, \mathrm{O}$ and $\mathrm{S}$ isotopes by two-step photodissociation of more complicated polyatomic molecules. Particular emphasis is placed on isotopes not easily enriched by current techniques. 
Analysis

UNIVERS ITY OF MASSACHUSETTS

Amherst, Massachusetts 01003

364. DYNAMICS OF HEAT, MASS AND MOMENTUM

$\$ 44,100 \quad 02-3$

TRANSFER IN AN INDUCTION PLASMA

Ramon M. Barnes

Department of Chemistry

The computer modeling of the flow, temperature, concentration and radiation distributions in an induction discharge operated at atmospheric pressure under conditions popular in commercial configurations employed as spectral excitation sources is the objective of this project. The computation is based upon the solution of steady-state two-dimensional momentum and energy equations in terms of stream function, vorticity and enthalpy simultaneously with one-dimensional electric and magnetic field equations and the phase difference between them. Resul ts to date have been obtained for argon induction discharges in the frequency range of 3 to $27 \mathrm{MHz}$, and the influence of gravity and natural convection as we 11 as sheath gas swirl velocity have been evaluated. Properties of mixed gases (nitrogen-argon) have been evaluated, and computation in mixed argon-nitrogen discharges is underway. Particle trajectory and evaporation calculations are in progress, and spectral radiation results will follow. Experimental verification of temperature and flow distributions are proceeding in parallel.

UNIVERSITY OF UTAH

Salt Lake City, Utah 84112

365. FOUR IER TRANS FORM PHOTOACOUSTIC

KINETIC SPECTROSCOPY OF SOLID SURFACES

$\$ 52,000 \quad 02-3$

Edward M. Eyring

Department of Chemistry

A recently developed rapid scan, Fourier transform photoacoustic spectrometer (FTPAS) can measure changes in the visible absorption spectra of opaque solid surfaces that are undergoing chemical reactions. FTPAS is being used to identify visibly colored, nonstoichiometric copper sulfide minerals appearing in the early stages of mineral leaching and the times at which these copper minerals successively appear and disappear. This information adds significantly to the present understanding of corrosion processes in hydrometallurgy. An infrared Fourier transform photoacoustic spectrometer (IRFTPAS) is being constructed and its signal to noise properties are being compared with other photoacoustic spectrometers and with other infrared spectroscopic instruments. The IRFTPAS is used to investigate chemical reactions occurring un upaque solid surfaces that do not involve visible color changes. The first such study is of the industrially important silver oxide-catalyzed conversion of ethylene to ethylene oxide. 
Analysis, continued

BROOKL YN COLLEGE/CUNY

Brooklyn, New York 11210

366. APPLICATIONS OF NUCLEAR AND

$\$ 50,300$

02-3

RADIOCHEMICAL TECHNIQUES TO

CHEMICAL ANALYS IS

Harmon L. Finston, Evan T. Williams

Department of Chemistry

The program of application of proton-induced $X-r$ ay emission to various problems of interest is being continued and expanded. Varlous types of sample pretreatments, e.g., Schoniger combustion of organic materials, and both different fusion fluxes and fuming with HF are being investigated to develop optimum techniques. Investigations of activation analysis by inelastic neutron scattering are continuing with special emphasis on those elements not amenable to thermal neutron activation. Further studies of the homogeneous 1iquid-1iquid solvent extraction systems are being performed. The extraction into propylene-carbonate of both monodentate ligand and bidentate ligand complexes (other than TTA) are being studied. The properties and extraction behavior of propylene carbonate analogues are also being studied. Possible applications of the homogeneous liquid-liquid solvent extraction to isotopic enrichment are to be investigated.

THE AEROSPACE CORPORATION

Los Angeles, California 90009

367. LASER-EXCITED NONRESONANT

$\$ 48,700 \quad 02-3$

FLUORESCENT SPECTROSCOPY

Jerry A.' Gelbwachs

Analytical Sciences Department

This program is investigating the advantages of the newly developed laserexcited nonresonant fluorescence method of trace elemental analysis for the rejection of spectral interference effects from sample matrix components and analytical reservoirs. The analyte and matrix interferent are placed in flame and/or nonflame atomizers in which they are illuminated by a lase to excite the vaporized analyte. Optical emission at nonresonant fluorescent wavelengths of the analyte is monitored as a function of optical bandpass at the nonresonant wavelength and as a function of the ratio of interferent concentrations to analyte concentraton to assess the spectral interference problem. The rejection of interferents is being studied as a function of excitation wavelength, laser intensity, buffer gas, nonresonant detection wavelength and bandwidth, and detection geometry in order to optimize detection sensitivity and specificity. 
Analysis, continued

UNIVERSITY OF MARYLAND

College Park, Maryland 20742

368. NON-DESTRUCTIVE DETERMINATION OF

TRACE ELEMENT CONCENTRATIONS

Glen E. Gordon, William B. Walters,

William H. Zoller

Department of Chemistry

A new method of non-destructive analysis for a number of elements in coals, minerals, fly ash, waste streams and atmospheric particles is under development: neutron-capture prompt gamma-ray activation analysis, PGAA. Samples are irradiated in a beam of thermal neutrons from a nuclear reactor. Prompt gamma-rays emitted from the various elements during irradiations are observed with high resolution germanium detectors. The intent of this project is that of determining the origins of all gamma rays observed by irradiation of a wide range of sample types in order to find lines that can be used for analysis for as many elements as possible. The final result will be the description of the PGAA method as applied to many materials, especially those of importance in the production of energy. The description will indicate the best design of a facility, the elements observable, the best lines to use for each element and any corrections that must be made for interferences, and a list of concentrations measured in many standard reference materials. 
Analysis, continued

NATIONAL BUREAU OF STANDARDS

Wa shington, D.C. 20234

369. DEVELOPMENT OF NEW METHODS FOR

$\$ 80,800$

$02-3$ QUANTIFICATION OF FOSSIL FUELS

BY MASS SPECTROMETRY

W. Sieck

Chemical Thermodynamics Division

New methods are being developed for the rapid chemical ionization-mass spectrometric screening and quantitation of selected components in petroprodurts. Tho cationic ailalyses involve photolonization. nf, variouo oolvents for luel samples in order to produce specific reagent fuel. Negative ion spectra of aromatic derivatives are obtained by $\mathrm{OH}^{-}$reactions, where $\mathrm{OH}^{-}$is generated by the reactions of $0^{-}$, from $\mathrm{N}_{2} \mathrm{O}$, with aliphatic solvents for liquid fuels. Both methods provide two minute turn-around times between successive samples and batch introduction, and eliminate the necessity for prior separation of fractionation. Quantitation of aromatic components by molecular weight is carried out using deuterium-labelled marker compounds (isotope dilution), and it appears that the type of information provided by the mass spectra are ideally suited to quality control during petroleum refining. A feasibility study concerning the use of photoionization, as opposed to electron impact, in mass spectrometers which are directly interfaced with liquid chromatographs, is also in progress. 
Chemical Engineering Sciences

STATE UNIVERS ITY OF NEW YORK/STONY BROOK

Stony Brook, New York 11794

370. CHEMICAL REACTIONS AND TURBULENCE

R. Chevray

Department of Mechanical Engineering

High quality data are being obtalned for a well-defined turbulent situation - a two-dimensional mixing layer - in which chemical reactions with a known simple kinetic. scheme take place. Additional complexities of finite heat release are ayoided by use of small concentrations for the reaction chosen $\left(\mathrm{NO}+\mathrm{O}_{3} \rightarrow \mathrm{NO}_{2}+\mathrm{O}_{2} \rightarrow \mathrm{NO}_{2}+\mathrm{h} \nu+\mathrm{O}_{2}\right.$ ). Large. Reynolds numbers, small dilution numbers, 1 arge ${ }^{2}$ reaction speed numbers and several concentration ratios are being investigated. On the theoretical side, efforts are directed at predictions using the promising formulations in terms of probability densities and conditioned moment and probability equations. While intermediate results are of much interest by themselves, this program is aimed, in the longer term, at gaining practical insight into the problem of turbulent combustion. The process of mixing from macroscopic to molecular scales, and the subsequent chemical reaction of two chemical species are being investigated systematically and exhaustively.

STANFORD UNIVERSITY

Stanford, California 94305

371. FUNDAMENTAL STUDIES OF FLULD

$\$ 35,000 \quad 02-4$

MECHANICS AND HEAT TRANSPORT

IN POROUS MEDIA

G. M. Homsy

Department of Chemical Engineering

Work is underway on two fundamental problems in fluld flow and heat transport in porous media. The first is a computational study of the probability of occurrence of two- or three-dimensional convection patterns in porous media heated from below. Earlier work has indicated that, for parameters above a certain value, both two and three dimension convection patterns can exist. It is important to assign a probability of occurrence to each of these convection modes, so that their engineering significance can be assessed. Modern computational techniques are being used to calculate this probability. The second problem is a combined theoretical and experimental study of slow flow of complex fluids through porous media. Fluids are being characterlzed in the context of a restricted class of constitutive equations and flow behavior; then their response during flow in packed beds is measured. Finally, theoretical predictions for the case of dilute particle concentrations are being made to generalize Darcy's law and afd in correlation of results in terms of material constants. 
Chemical Engineering Sciences, continued

NATIONAL BUREAU OF STANDARDS

Washing ton, D.C. 20234

372. TRANSPORT AND PHASE EQUILIBRIA

IN MULTICOMPONENT FLUIDS

J. M. Kincald

Thermophysics Division

\author{
$\$ 73,600 \quad 02-4$ \\ (18 months)
}

The purpose of this project is to develop and implement simple, but accurate, techniques to treat the transport and phase transition properties to multicomponent, multiphase systems. There are three basic aspects nf the projecl: (1) the development of new techniques to study multicomponent systems; (2) the "translation" and adaptation of recent theoretical advances in transport and phase transition phenomena to forms usable to the energy technologies, especially reactor safety programs; (3) approximation assessment and implementation. All three of these areas can be expected to advance the understanding of multicomponent flulds at high temperatures on a short term basis, as well as ensuring progress on long term aspects of the problem.

UNIVERS ITY OF CALIFORNIA/DAVIS

Davis, California 95616

373. CÜMYU'LEK MODELIŃG OF TURBULENT JETS WITH CHEMICAL REACTION

\author{
$\$ 53,600$ \\ (17 months) \\ $02-4$
}

B. E. Launder, H. A. Dwyer

Department of Mechanical Engineering

This work intends to improve the reliability with which the flow and combustion characteristics of turbulent flames may be predicted. The work focuses one by one on different characteristics of turbulent jets (the basic flow configuration of a large number of turbulent flames) including large density variations and swirl. The way that these different: factors modify the turbulent mixing processes in the jet is being analysed; thereafter mathematical models of the effects are to be devised. The adequacy of the modeling is assessed using numerical solution of the differential conservation equations incorporating the proposed models for terms representing the various turbulent interactions. 
Chemical Engineering Sciences, continued

UNIVERS ITY OF PENNSYLVANIA

Philadel phia, Pennsylvania 19104

\begin{tabular}{|c|c|c|}
\hline 374. & $\begin{array}{l}\text { THERMOCHEMICAL PROCESSES FOR HYDROGEN } \\
\text { PRODUCTION BY WATER DECOMPOSITION } \\
\text { D. D. Perlmutter } \\
\text { Department of Chemical Engineering }\end{array}$ & $\begin{array}{l}\$ 110,000 \\
(2 \text { years })\end{array}$ \\
\hline
\end{tabular}

The objectives of this research are to derive and test models for simulating the heat and mass transfer processes inside rotary solid-gas reactors; to establish the effects of surface renewal of solids on the mass transfer phenomena; and to compare the results with static packed bed reactors. This work relates to gas-solid reactor design which is important to a number of thermochemical cycles for producing hydrogen as well as other technologles concerned with reactions of solids where heat and mass transport occur.

UNIVERS ITY OF CALIFORNIA/SANTA BARBARA

Santa Barbara, California 93106

375. TRANSPORT AND REACTION IN POROUS

$\$ 35,400$

$02-4$ MEDIA SUPPORTING CATALYT IC AND NON-CATALYTIC LIQUIDS

R. G. Rinker

Chemical and Nuclear Engineering Department

The main objective of this program is to obtain a basic understanding of the behavior of supported liquid phase catalysts (SLPC), which have significant potential for use in chemical energy development. To meet this objective, efforts have been directed along three coupled 1ines of attack, namely, (1) developing and experimentally testing a general model for predicting transport of gaseous species in general porous media having varying amounts of liquids in the pores; (2) developing and experimentally testing a dispersion model for wetting liquids in general porous media having unimodal and multimodal pore structures; and (3) Investigating the fundamental mechanistic and kinetic behavior of certain homogeneous catalysts consisting of mononuclear and/or cluster organometallic complexes dissolved in nonvolatile, stable liquids for potential use in SLPC. With sufficient understanding in these areas, it will then be possible to predict with reasonable confidence the effectiveness of SLPC systems, and this capability in turn will permit design of reactors fur chemical processes uoing SLPC or modification thereof. 
Chemical Englneering Sclences, continued

UNIVERSITY OF MINNE SOTA

Minneapolis, Minnesota 554.55

376. FUNDAMENTAL HEAT TRANSFER PROCESSES

$\$ 50,000$

$02-4$

RELATED TO PHASE CHANGE THERMAL

STORAGE MEDIA

E. M. Sparrow, J. W. Ramsey

Department of Mechanical Engineering

A program is being performed that is directed at identifying the dominant heat transfer coefficlents for phase change thermal storage. The focus of the research includes studies of melting in bulk storage configurations, melting in encapsulated storage media, and solidification problems associated with heat extraction. Special consideration is being given to the role of natural convection in the freezing and melting process and to its effect either in augmenting or deteriorating storage and extraction. In the main, the research is experimental. Numerical solutions are being undertaken for one of the bulk storage problems in order to develop this capability.

STATE UNIVERSITY OF NEW YORK/STONY BROOK

Stony Brook, New York 11974

377. TRANSPORT PROPERTIES OF MULTIPHASE SYSTEMS

G. R. Srell

Department of Mechanical Engineering

\author{
$\$ 75,000$ \\ (18 months) \\ $02-4$
}

Development of a comprehensive microscopic theory of transport in multicomponent systems is underway with special emphasis on the transport properties of (1) multicomponent fluid mixtures that phase-separate under changes of temperature and concentration, (11) two-phase materials in which one of the phases is fluid and the other a porous medium or suspension of particles (fluidized bed). 
Chemical Engineering Sciences, continued

CORNELL UNIVERSITY

Ithaca, New York 14853

378. EXPERIMENTAL AND THEORETICAL

STUDIES OF DENSE FLUID MIXTURES

$\$ 50,000 \quad 02-4$

W. B. Streett, K. E. Gubbins

School of Chemical Engineering

The work performed in this program consists of two parts: (a) experimental studies of the equation of state of selected mixtures (PVT measurements), at temperatures between 70 and $500 \mathrm{~K}$, and pressures to 4,000 atmospheres; and (b) theoretical studies of dense fluid mixtures by means of perturbation methods. Mixtures being studied include $\mathrm{H}_{2}, \mathrm{CO}, \mathrm{CO}_{2}, \mathrm{C}_{2} \mathrm{H}_{2}, \mathrm{SO}_{2}, \mathrm{CH}_{3} \mathrm{OH}, \mathrm{HCl}$, and other fluids. This work is coordinated with computer ${ }^{2}$ simulation studies and high-pressure phase equilibrium experiments on similar systems. The long term goal is the development of reliable methods, based on statistical mechanics and intermolecular potential theory, for correlating, extrapolating and predicting the physical and thermodynamic properties of dense fluids. 
BES outlay funds are divided among operating, equipment and construction funds. Equipment funds are provided primarily to DOE laboratories. (Operating funds provided to other contractors are used for all costs, including purchase of necessary. equipment.) Chemical Sciences FY 1979 Equi pment Funds were assigned as follows.

Equi pment Funds

(KS)

Ames Laboratory

Argonne National Laboratory

Atomics International, Inc.

Bartlesville Energy Technology Center

Brookhaven National Laboratory

Lawrence Berkeley Laboratory

Lawrence Livermore Laboratory

Los Alamos Sclentific Laboratory

Morgantown Energy Technology Center 15

Mound Facility

50

Notre Dame Radiation Laboratory

145

Oak Ridge National Laboratory

625

Pactfic Northwest Laboratory

Pittsburgh Energy Technology Center

100

Sandia Laboratories/Al buque rque

Sandia Laboratories/Livermore 
INDEX

\section{Atmospheric Chemistry}

$6,20,23,31,46,163,185,195,217,219,366$

\section{Combustion}

$6,16,17,39,42,43,46,52,57,58,6071,72,73,74,180,238,239$, $241,243,244,245,248,250,251,252,253,255,256,257,258,259,261$, $266,268,269,271,273,275,276,370,373$

Fossil Chemistry and Physics, including MHD

$6,17,48,70,71,92,95,100,102,107,110,123,128,129,131,133,135$, $139,143,148,151,162,289,292,301,312,317,324,327,330,339,342$, $343,360,371$

Fluid and Particle Dynamics

$143,146,180,182,371$

Fusion

$38,76,79,82,83,85,86,88,89,90,91,142,156,183,277,281,284,285$, $287,291,292,293,295,296,298,299,352$

Heterogeneous Catalysis

$24,29,41,46,49,52,59,65,66,67,87,95,108,113,117,123,125,136$, $194,220,249,302,303,304,305,309,315,317,319,320,322,328,331,332$, $334,338,341,342,375$

Homogeneous Catalysis

$93,94,101,103,105,108,114,117,131,300,302,306,307,308,310,311$, $313,318,329,331,333,335,336,375$

Hydrogen and Hydrides

$50,99,104,109,119,120,121,124,126,132,141,142,156,316,326,352$

Isotope Effects and Separation

$77,140,141,142,144,146,346,347,352,353,354,356,361,362,363$

Nuclear Fuei and Waste Processing

$3,98,138,139,141,145,147,148,149,150,151,152,154,155,350,358,359$

Resource Recovery

$137,147,153,345,348,349,351,355$ 
Solar Photo- and Bioconversion

$2,5,7,8,9,10,13,14,18,20,21,22,24,25,29,31,35,40,55$, $56,105,111,132,186,187,188,192,196,197,198,205,206,207,210$, $211,214,221,222,223,226,227,228,229,230,231,232,233,234$, $235,236,237,242,321,337$

Thermodynamics

$52,64,96,102,106,121,127,181,270,314,316,340,341,372,377$, 378 


\section{Index of offsite Institutions}

\section{Universitles}

University of Alabama.

L. D. Kispert, 201

Amherst College

B. B. Benson, 346

University of Arizona

G. Tollin, 222

H. Freiser, 351

Arizona State University

T. A. Moore, D. Gust, 236

Boston University

R. H. Clarke, 187

G. Jones II, 196

N. N. Lichtin; M. Z. Hoffman, 205

Brown University

E. F. Greene; 249

Brigham Young University

J. J. Christensen, 348

California Institute of Technology

A. Kuppermann, 203

R. H. Grubbs, 313

K. C. Janda, 255

University of California/Davis

B. E. Launder, H. A. Dwyer, 373

J. W. Root, 216

University of California/Irvine

E. K. C. Lee, 260

F. S. Rowl and, 217

M. Wolf sberg, 362

University of California/Los Angeles

D. J. Cram, 349

M. A. ElSayed, 242

J. A. Gladysz, 311
University of California/Santa Barbara

P. C. Ford, 308

J. H. Kennedy, 198

R. M. Martin, 265

R. G. Pearson, P. H. Barrett, 328

R. G. Rinker, 375

M. Steinberg, D. 0. Harris, 273

R. J. Watts, 223

University of California/San Diego

H. Oesterreicher, 326

California State University/Fullerton J. A. Olmstead, 237

Carnegie-Mellon University

R. M. Richman, 214

University of Chicago

W. J. Evans, 307

U. Fano, 283

J. C. Light, 263

University of Colorado

S. R. Leone, 261

S. J. Cristol, 188

Colorado State University

J. K. Stille, 336

T. G. Lènz, 234

Culumbla University

G. W. Flynn, 191

N. J. Turro, 361

Cornell University

J. H. Freed, 309

W. J. McLean, 266

W. B. Street, K. E. Gubbins, 378

University of Delaware

J. E. Bulkowski, 229

J. R. Katzer, 317 
Universities (continued)

Drexel University

R. Mackay, 321

University of F1orida

R. J. Hanrahan, 194

R. H. Johnsen, 195

University of Georgia

R. R. Hautala, 232

M. H. Lee, 354

L. B. Rogers, 357

Georgia Institule of Teclinulogy

F. P. 'lully, A. R. Ravishankara, 276

Harvard University

D. R. Herschbach, 352

K. S. Peters, 212

Harvard College Observatory

A. Dalgarno, G. Victor, 282

Howard University

W. M. Jackson, 254

University of Illinois/Urbana

K. J. Kaufmann, 197

University of Illinois/Chicago Circle

R. J. Gordon, 247

J. H. Kiefer, $25 \overline{7}$

Illinols Institute of Technology

D. Gutman, 251

L. L. Tavlarides, 359

Indiana University/Purdue

P. W. Rabideau, 330

Johns Hopkins University

W. S. Koski, 202

D. W. Robinson, 215

University of Kansas

R. E. Christoffersen, 186

Kansas State University

C. -D. Lin, 290

J. R. MacDonald, P. Richard, 293
University of Kentucky

G. A. Sargent, E. B. Bradley, 334

Louisiana State University

J. Callaway, R. J. W. Henry, 287

N. R. Kestner, 199

Marquette University

S. L. Regan, 331

University of Maryland

G. E. Gordon, W. B. Walters, W. H. Zoller, 368

University of Massachusetts

R. M. Barnes, 364

Massachusetts Institute of Technology

J. Ross, 270

R. R. Schrock, 335

M. S. Wrighton, 227

University of Minnesota

R. Aris, R. W. Carr, Jr., 344

R. W. Carr, Jr., 185

W. R. Gentry, 246

E. M. Sparrow, J. W. Ramsey, 376

D. G. Truhlar, 274

Untiversity of Missourt/St. Inuis

J. J. Leventhal, 262

University of Nebraska

J. Macek, G. Gallup, 291

G. G. Meisels, 209

E. P. Rack, 213

J. A. R. Samson, A. F. Starace 294

University of New Mexico

H. C. Bryant, 279

University of New Or leans

R. D. Kern, Jr., 256

New York University

B. Bederson, 278

City University of New York/

Brooklyn College

H. L. Finst on, 366 
Universities (continued)

State Untversity of New York/ Stony Brook

J. Bigeleisen, 347

R. Chevray, 370

T. Is hida, 353

G. R. Stell, 377

Northwestern University

J. B. Butt, R. L. Burwe11, J. B. Cohen, 305

H. H. Kung, P. C. Stair, 319

C. K. Law, 259

University of North Carolina

T. J. Meyer, 210

S. M. Shafroth, 295

Ohio State University

L. M. Dorfman, 189

R. F. Firestone, 190

E. L. Gross, 231

University of Oklahoma

D. E. Golden, M. A. Morrison, 286

University of Oregon

P. C. Engelking, 243

Oregon State University

C. A. Kocher, 289

University of Pennsylvania

D. D. Perlmutter, 374

Pennsylvania State University

C. F. Fischer, 284

G. L. Geoffroy, 310

F. W. Lampe, 204

M. A. Vannice, 338

P. L. Walker, Jr., 339

University of Pittsburgh

J. E. Bayfield, 277

D. M. Hercules, 315

D. W. Pratt, 267

Princeton University

H. A. Rabitz, 268

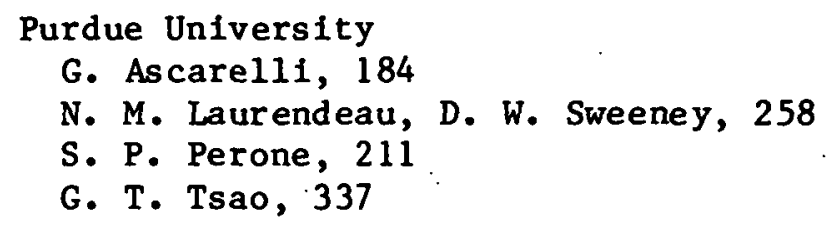

Rice University

R. F. Cur1, 241

R. E. Smalley, 272

G. K. Walters, N. F. Lane 297

University of Rochester

J. M. Farrar, 244

Rockefeller University

D. C. Mauzera11, 235

Rutgers University

P. Hemmes, 314

University of South Carolina

M. W. Davis, Jr., 350

University of Southern California

G. A. $01 \mathrm{ah}, 327$

University of Southern Mississippi

D. Creed, N. C. Fawcett, 230

Stanford University

M. Boudart, 303

R. K. Hanson, 252

R. K. Hanson, C. T. Bowman, 253.

G. M. Homsy, 371

R. J. Madix, 322

C. Mason, 323

Syracuse University

S. A. Stern, 358

C. Tlen, 360

University of Tennessee

I. A. Sellin, R. S. Thoe, 296

T. F. Williams, 225

University of Texas

M. A. Fox, 192

R. Pettit, 329 
Universities (continued)

Texas A\&M University

D. E. Bergbreiter, 302

Wright State University

D. A. Church, 281

J. H. Lunsford, 320

M. P. Rosynek, 332

G. B. Skinner, 271

R. L. Watson, 298

Y. N. Tang, 220

Yale University

R. D. Adams, 300

K. B. Wiberg, 340

Texas Southern University

C. W. Mc Donald, 355

University of Utah

E. M. Eyring, 365

D. M. Grant, R. J. Pugmire, 312

W. A. Guillory, 250

L. D. Spicer, 219

Virginia Polytechnic Institute and State University

H. J. Ache, 183

Washngton University

P. P. Gaspar, 193

Washington State University

D. M. Roundh111, 333

Wayne State University

A. Brenner, 304

L. Kevan, 200

E. C. Lim, 264

R. L. Lintvedt, J. F. Endicott, 206

Weber State College

R. R. Beishline, 301

Western Connecticut State College

A, $n, \operatorname{Adler}, 238$

The College of William and Mary

L. D. Doverspike, R. T. Champion, 280

University of Wisconsin

C. P. Casey, 306

R. W. Conn, 240

J. E. Wi1l1ard, 224

Worcester Polytechnic Institute

A. A. Scala, 218 
Industrial and 0ther Laboratories

Aerochem Research Laboratories

A. Fontijn, 245

The Aerospace Corporation

J. A. Gelbwachs, 367

P. F. Zittel, 363

Bend Research Corporation

W. C. Babcock, 345

Calspan Corporation

J. W. Rich, 269

General Electric Corporation

R. H. Wilson, 226

SRI International

J. R. Barker, 238

T. F. Gallagher, 285

D. L. Hildenbrand, 316

D. F. McMillen, 324

H. Wise, 341 
INVESTIGATOR INDEX

Abell, G. C.

Ache, H. J.

Adams, R. D.

Adler, A. D.

Agron, P. A.

Alire, R.

And rews, $M$.

Angelici, R. J.

Annis, B. K.

Appelman, E. H.

Aris, R.

Arnold, W. D.

Ascare111, G.

Babcock, W. C.

Baes, C. F., Jr.

Bamberger, C. E.

Barke $r$, J. R.

Barnes, R. $M$.

Barnett, C. F.

Barrett, P, H.

Bartlett, N.

Basile, L. J.

Bautista, R. G.

Bayfield, J. E.

Becker, R. L.

Bederson, $B$.

Beishline, R. R. 301

Bel1, A. T.

Be11, J. T.

Benjamin, B. $M$

Benson, B. B.

Bergbreiter, D. E. $\quad 302$

Bergman, R. G. $\quad 114$

Berkowitz, J.

Bernstein, H. J. 50

Berry, H. G. $\quad 76$

Berry, W. B. 28

Beuhler, R. J. 53

Blelski, B. H. J. II

Bigelef gen, J. $\quad 317$

Blanch, H. W.

Bottcher, C.

Boudart, $M$.

Bowman, C. T.

Buwman, M. G.

Bowman, M. K.

Bowman, R. C., Jr. 124

Bradley, E. B. $\quad 334$

Brauer, F. P.
Brenner, A. $\quad 304$

Brenner, D. M. 12

Brink, G. $0 . \quad 239$

Brown, F. R. 136

Brown, L. L. 128

Brown, N. 58

Bryant, H. C. 279

Buchanan, A. C. III. 131

Bulkows k1, J. E. 229

Burwel1, R. L., Jr. 305

Busey, R: H. 127

Butt, J. B. 305

Callaway, J. 281

Calvin, M. . 21

Canada; D. C. 172

Canon, R. M. 153

Carlson, T. A. 87

Carr, R. W., Jr. 185, 344

Carruthers, J. A. 356

Casey, C. P. 306

Champion, R. L. 280

Chanin, L. M. 356

Chevray, R. $\quad 370$

Childs; W. J. 77

Christensen, J. J. 348

Christie, W. H. $\quad 170$

Christof fersen, R. E. 186

Church, D. A. 281

Clarke, R. H. 187

Cleiin, K. 169

Clinton, S. D. $\quad 152$

Closs, G.

Cohen, J. B. 305

Coleman, C. F. $\quad 151$

Collins, C. J. 128

Conn, R. W. 240

Connick, R. E. 115

Connolly, J. S. $\quad 40$

Conzemius, R. 159

Cúliss, L. M. $\quad 50,51$

Cram, D. J. $\quad 349$

Crandall, D. H. $\quad 88$

Crawford, O. H. 69

Creed, D. 230

Crespi, H. L. 10

Creutz, C. 13

Cristol, S. J. $\quad 188$

Crosswhite, H. M. 45

Curl, R. F. 241

Dale, J. M. 171 


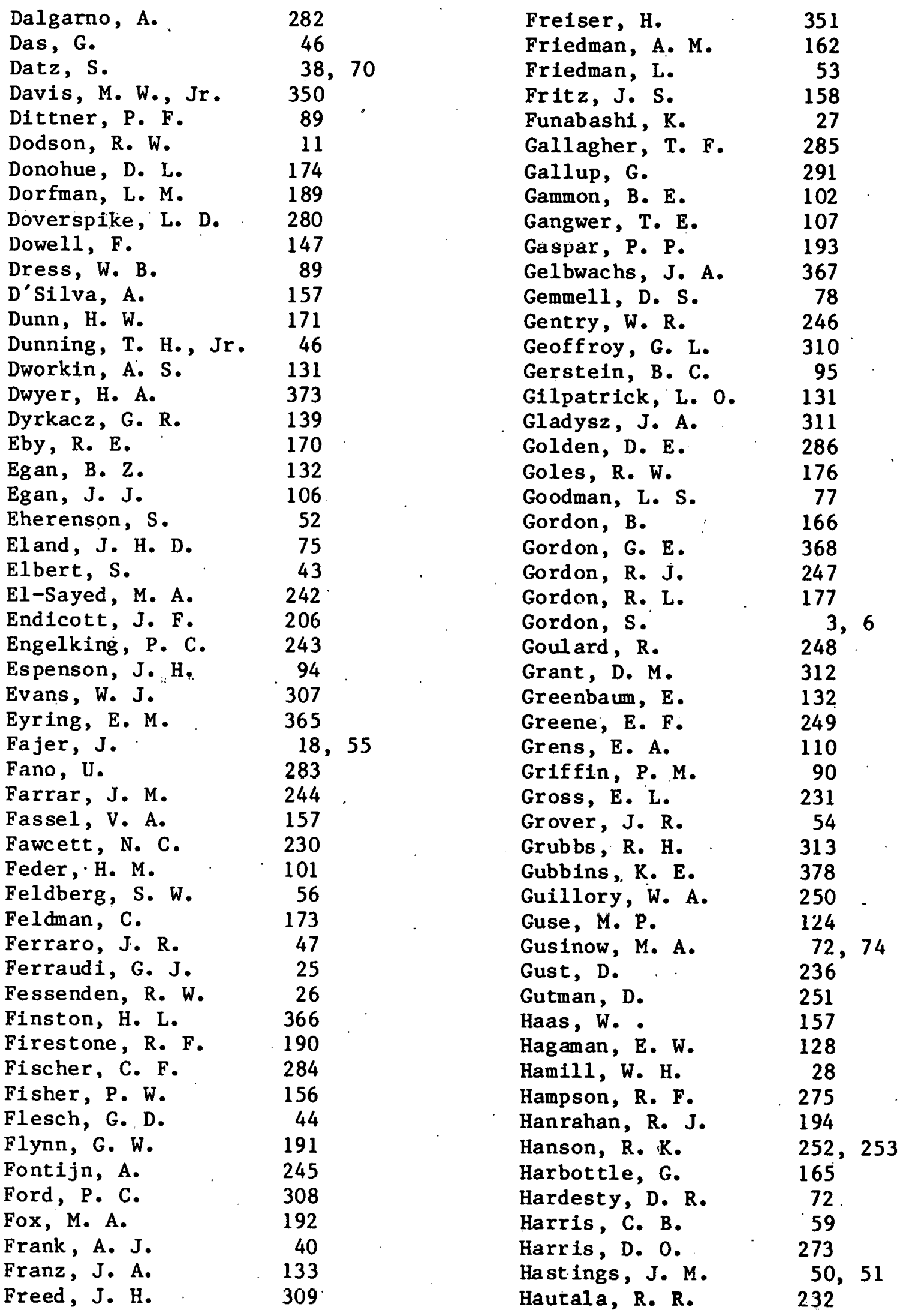




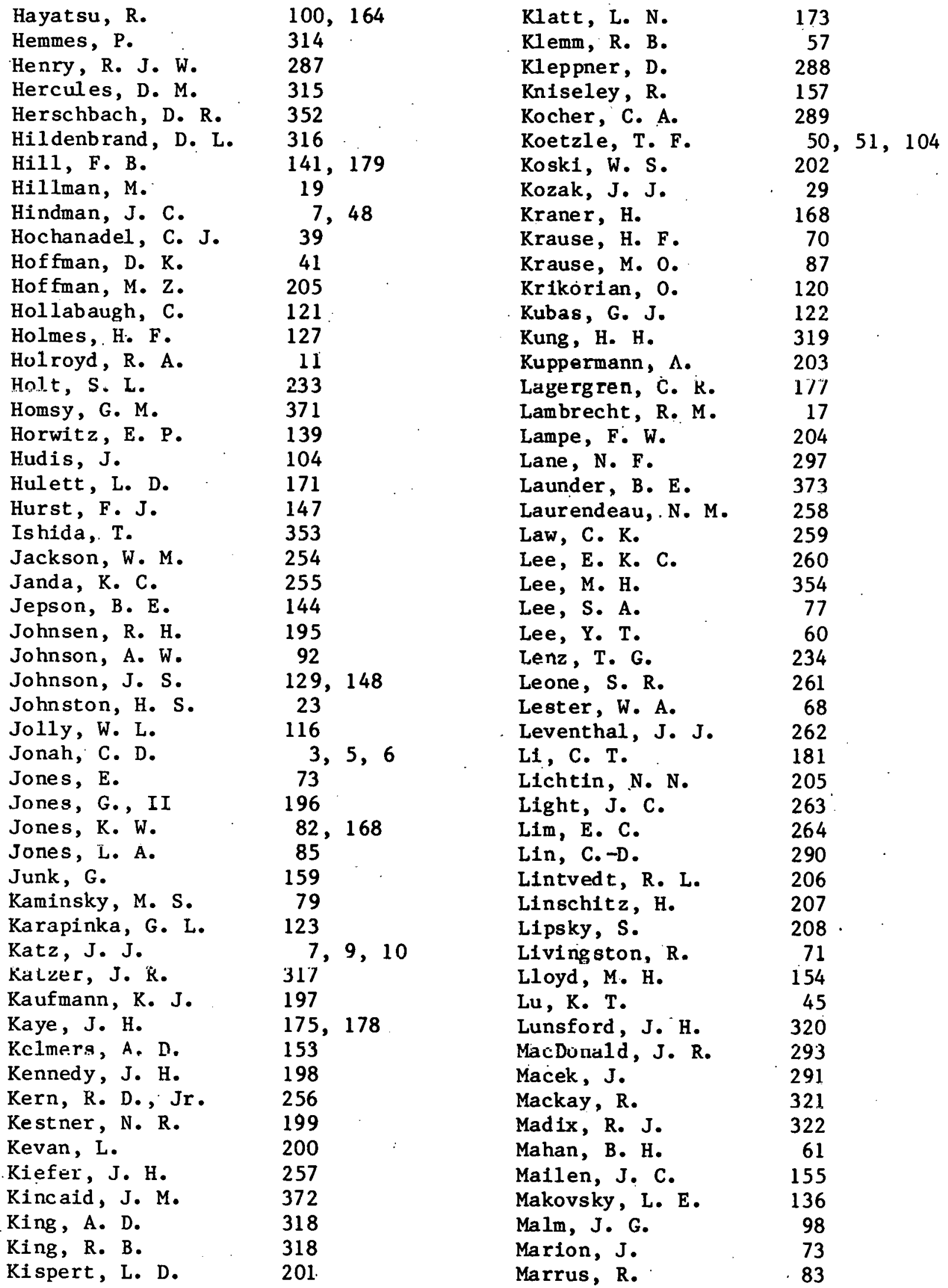




\begin{tabular}{|c|c|c|c|}
\hline Marshal1, W. L. & 127 & Perlman, M. L. & 104 \\
\hline Martin, R. M. & 265 & Perlmutter, D. D. & 374 \\
\hline Mason, C. & 121 & Perlow, G. J. & 80 \\
\hline Mason, D. M. & 323 & Perone, S. P. & 211 \\
\hline Mason, G. W. & 139 & Peters, K. S. & 212 \\
\hline Mattern, P. & 74 & Pettit, R. & 329 \\
\hline Mauzera11, D. C. & 235 & Pitzer, K. S。 & 64 \\
\hline Mc Bay, E. H. & 172 & Powe11, J. E。 & 138 \\
\hline Mc Donald, C. W. & 355 & Pratt, D. W. & 267 \\
\hline Mc Dówe11, W. J. & 151 & Prausnitz, J. M. & 181 \\
\hline McLean, W. J. & 266 & Pritchard, C. A. & 172 \\
\hline McMillen, D. F. & 324 & Pugmire, R. J. & 312 \\
\hline McMullen, R. K. & 50 & Rabideau, P. W. & 330 \\
\hline Meisel, D. & 5 & Rabitz, H. A. & 268 \\
\hline Meisels, G. G. & 209 & Rack, E. P. & 213 \\
\hline Mesmer, R. E. & 130 & Rainey, W. T. & 172 \\
\hline Meyer, T. J. & 210 & Ramsey, J. M. & 173 \\
\hline Michaels, E. D. & 144 & Ramsey, J. W. & 376 \\
\hline Miller, J. R. & $3,4,6$ & Rathke, J. & 101 \\
\hline Miller, P. D. & 90 & Ravishankara, A. R. & 276 \\
\hline Miller, W. H. & 62 & Regan, S. L. & 331 \\
\hline Moak, C. D. & 90 & Reilly, J. J. & 109 \\
\hline Molton, P. M. & 134 & Ricci, E. & 171 \\
\hline Monahan, J. E. & 80 & Rich, J. W. & 269 \\
\hline Moore, C. B. & 63 & Richard, P. & 293 \\
\hline Moore, T. A. & 236 & Richman, R. M. & 214 \\
\hline Morrey, J. R. & 135 & Rinker, R. G. & 375 \\
\hline Morrison, M. A. & 286 & Robben, F. & 180 \\
\hline Mozumder, A. & 27 & Robinson, D. W. & 215 \\
\hline Muckerman, J, & 52 & Robinson, P. R. & 126 \\
\hline Mueller, T. R. & 174 & Rodgers, B. R. & 152 \\
\hline Muetterties, E. L. & 117,325 & Ro $c_{5}$ ers, L. B. & 357 \\
\hline Mulac, W. & 5 & Root, J. W. & 216 \\
\hline Neta, $\mathbf{P}$. & 30 & Ross, A. B. & 31 \\
\hline Netzel, $T$. & 14 & Ross, H. H. & 173 \\
\hline Newman, J. & 118 & Ross, J. & 270 \\
\hline Newton, M. D. & 15,52 & Rosynek, M. P. & 332 \\
\hline $\mathrm{Ng}, \mathrm{C} .-\mathrm{Y}$ & 42 & Roundhill, D. M. & 333 \\
\hline Noid, D. W. & 69 & Rowl and, F. S. & 217 \\
\hline Norcross, D. W. & 292 & Ruby, S. L. & 81 \\
\hline Norris, J. R. & 8,10 & Ruedenberg, $\mathrm{K}$. & 43 \\
\hline Oesterreicher, $\mathrm{H}$. & 326 & Russe 11 , D. H. & 172 \\
\hline Olah, G. A. & 327 & Rutherford, W. M. & 144 \\
\hline Olmstead, J. A. & 237 & Samson, J. A. R. & 294 \\
\hline Onstott, E. I. & 121 & Sapienza, $\mathbf{R}$. & 108 \\
\hline Oskam, H. J. & 356 & Sargent, G. A. & 334 \\
\hline Otvos, J. & 21 & Sauer, M. C. & 3,6 \\
\hline $\begin{array}{l}\text { Overbury, S. H. } \\
\text { Packer, L. }\end{array}$ & $\begin{array}{l}38,125 \\
22\end{array}$ & $\begin{array}{l}\text { Sayer, E. V. } \\
\text { Scaiano, J. C. }\end{array}$ & $\begin{array}{r}165 \\
32\end{array}$ \\
\hline Parks, E. K. & 49 & Scala, A. A. & 218 \\
\hline Patterson, L. K. & 30 & Schmidt, K. H. & 3,6 \\
\hline Pearson, R. G. & 328 & Schreiner, F. & 99 \\
\hline
\end{tabular}


Schrock, R. R.

Schuler, R. H.

Schwartz, M.

Schwarz, H. A.

Scott, D. W.

Sellin, I. A.

Seltzer, S.

Shaefer, H. F., III

Shafroth, S. M.

Shaw, R. W.

Sheng, S. J.

Shiao, S. - Y.

Shipman, L. L.

Shirley, D. A.

Shugart, H. A.

Sieck, W.

Silver, G. L.

Skiens, W. E.

Skinner, G. B.

Smal1, G. J.

Smalley, R. E.

Smart, J. C.

Smith, D. H.

Smith, F. J.

Smith, G. P.

Smith, N. K.

Somor jai, G. A.

Sparrow, E. M.

Spedding, F. H.

Spicer, L. C.

Stair, P. C.

Starace, A. F.

Stein, L

Steinberg, M.

Stell, G. R.

Stelzner, R. W.

Stern, S. A.

Stevens, C. M.

Steward, S.

Stille, J. K.

Stoenner, R. W.

Streett, W. B.

Struve, W. S.

Studier, M. H.

Sytris, D. L.

Sutherland, G. W.

Sutin, N.

Svec, $H$.

Sweeney, D. W.

Sweeton, F. H.

Sworski, T. J.

Talbot, J. B.

Tang, Y. N.
11

102

296

105

65

295

173

33

148

8,46

66

84

369

145

135

271

1

272

40

174

149

131

102

24,113

376,113

96

219

319 .

294

98

273

377

170

358

163

119

3.36

165

378

2

100,164

178

20

13

44, 159

258

127

39

156

220
Tanner, R. 167

Tavlarides, L. L. 359

Taylor, R. D. 142

Taylor, W. L., $\quad 146$

Thoe, R. S. ' 296

Thomas, R. 50

Thomson, D. B. 85

Thurnauer, M. C. 8

Tien, C. $\quad 360$

Tingey, G. L. 135

Tolbert, L. M. 221

Tollin, G. 222

Tomkins, F. S. $\quad 45$

Toth, L. M. 150

Treat, R. P. 143

Trifunac, A. D. 3

Triolo, R. 129

Trozzolo, A. M. 36

Truhlar, D. G. 274

Tsang, W. 275

Tsao, G. T. 337

Tu11y, F. P. 276

Turro, N. G. $\quad 361$

Ulrichs on, D. L. 97

Uphaus, R. A. 139

Vandergrift, G. F. 139

Vannice, M. A. 338

Vermeulen, T. 110

Victor, G. 282

Voigt, A. F. 160

Waggener, W. C. 125

Wagner, A. F, 46

Walker, P. L., Jr. 339

Walker, R. L. 174

Waltero, C. K. 297

Walters, W. B. 368

Warmack, R. J. 170, 174

Wasielewski, M. R. $\quad 9,10$

Watson, R. L. 298

Watio, R. J. 223

Wells, G. F. 91

Weston, R. E., Jr. 16,140

Wexler, S. 49

Whitten, W. B. $\quad 173$

Wiberg, K. B. $\quad 340$

Wiese, W. L. 299

Wilke, C. R. 111

Wi1lard, J. E. 224

Williams, E. T. 366

Williams, T. F. 225

Wilson, R. H. 226

Winans, R. E. $\quad 100,164$

Wintcur, D. H. 37 
Winn, J. S. 67

Wise, H. 341

Wiswall, R. H. 109

Wolf, A. P. 17

Wolfsberg, $M \quad 362$

Wong, Y. W. 141

Wrighton, M. S. 227

Yates, J. T., Jr. 342

Yeung, E. S. 161

Yosim, S. J. 343

Young, C. E. 49

Young, J. P. 173

Zeldes, $\mathrm{H}$. 71

Zittel, P. F. 363

Zoller, W. H. . 368

\&U.S. GOVERNMENT PRINTING OFFICE: 1980- 310.912:1014 